\title{
Una reconstrucción de la lógica de la investigación de John Dewey: antecedentes y derivaciones
}

\author{
Federico E. López \\ Tesis para optar por el grado de Doctor en Filosofía \\ Directora, María Cristina Di Gregori, UNLP
}

Ensenada, 29 de diciembre de 2014 


\section{Agradecimientos}

Esta tesis ha sido posible gracias al apoyo que significó la beca de CONICET, que me permitió desarrollar mis actividades en el Instituto de Investigación en Humanidades y Ciencias Sociales (FaHCE-UNLP/CONICET). A dichas instituciones, sus autoridades y sus colaboradores, va mi agradecimiento. Asimismo, quiero agradecer a la Red de Macro Universidades Públicas de América Latina y el Caribe, que me permitió realizar una estancia académica en la UNAM, donde gracias a la generosidad de León Olivé y de Ana Rosa Pérez Ransanz pude aproximarme a una serie de discusiones que enriquecieron mi trabajo. Quiero agradecer también a Cecilia Duran, directora del Departamento de Filosofía durante la mayor parte del tiempo en que llevé adelante mis actividades de investigación, por su apoyo constante y por haberme guiado en mis primeros pasos en la enseñanza universitaria.

Quiero agradecer también a mis amigos y compañeros de equipo de investigación, Andrés Hebrard, Victoria Sánchez, Livio Mattarollo y Chantal Rosengurt: en reuniones de equipo, en pasillos o realizando trabajos en colaboración he podido discutir con ellos muchas de las cuestiones abordadas en esta tesis. Agradezco también a Evelyn Vargas, de cuyo profundo conocimiento de la obra de Peirce he aprendido yo también.

Agradezco también, especialmente, a Cristina Di Gregori, quien me acompañó como directora, de una manera siempre generosa, desde que inicié mis actividades de investigación. Mi deuda con ella es mucho mayor de lo que la lectura de la tesis permite inferir: las ideas interesantes que pudiera contener han surgido de y gracias a discusiones con ella. Sus observaciones críticas, su disposición al diálogo, su apoyo constante y su impulso han hecho posible esta tesis.

Agradezco, por último, a Tatiana, quien no sólo ha sabido apoyarme $\mathrm{y}$ acompañarme durante el tránsito no siempre sencillo que significa la redacción de una tesis, sino que se ha tomado también el trabajo de revisar y corregir atentamente estas páginas. Gracias a su trabajo, el mío ha sido más liviano. 


\section{Índice}

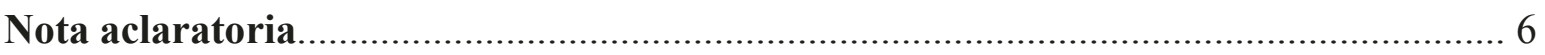

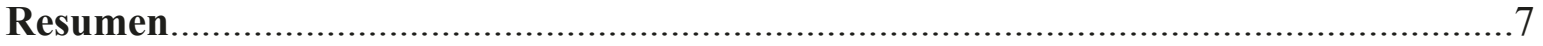

Introducción: La pregunta por el legado filosófico de John Dewey..................................... 9

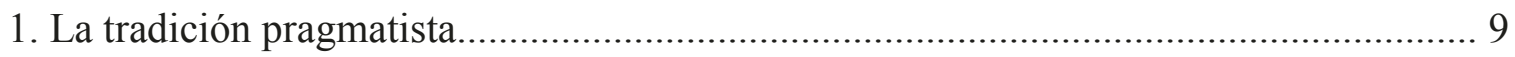

2. La recepción crítica del pragmatismo y su resurgimiento ........................................... 12

3. La pregunta por el legado filosófico de Dewey......................................................... 16

4. La sociología del conocimiento y el giro hacia las prácticas ......................................... 21

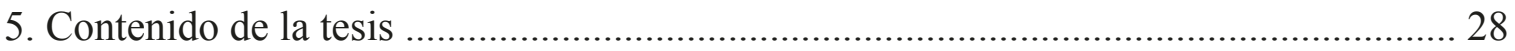

I. Primera Parte: El programa pragmatista de investigación en sus orígenes: los aportes de

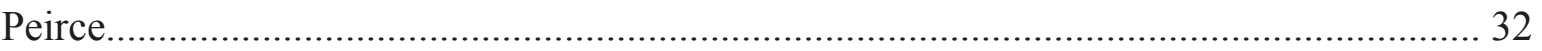

1. La crítica peirceana a la tradición filosófica.......................................................... 33

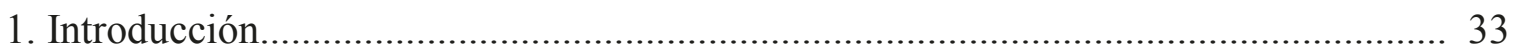

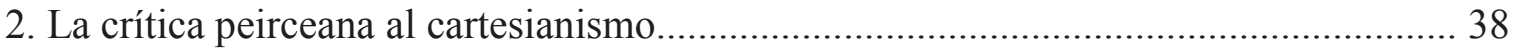

2.1. Contra el principio metodológico de la duda universal............................................ 40

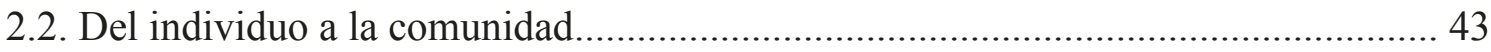

2.3. La forma de la argumentación y el supuesto de lo inexplicable................................ 46

2.4. El rechazo de la intuición y la crítica al fundacionalismo........................................ 48

3. Conclusiones: hacia una nueva forma de hacer filosofía............................................. 58

\section{Hacia una nueva concepción del conocimiento: la lógica pragmatista de la}

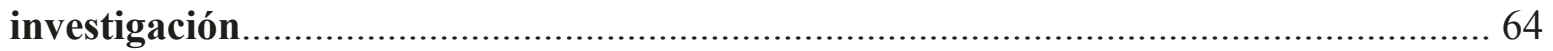

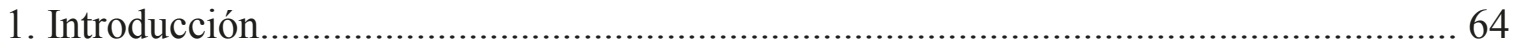

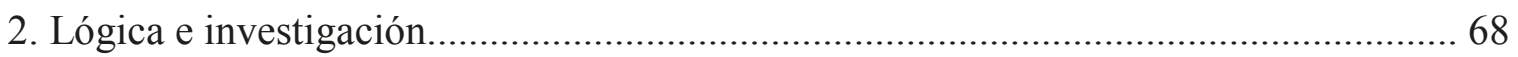

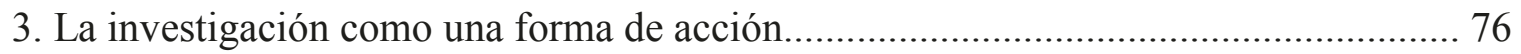

4. Conocimiento, realidad y verdad en la nueva concepción del conocimiento................. 80

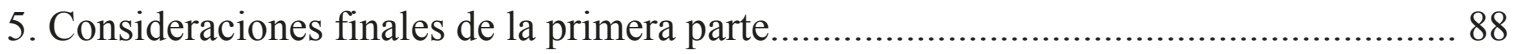

II. Segunda Parte: La teoría deweyana de la investigación................................................. 93

3. El punto de partida: la teoría de la experiencia....................................................... 94

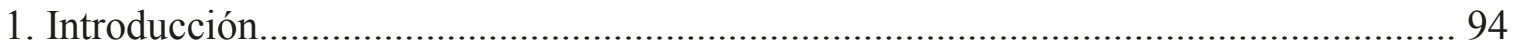

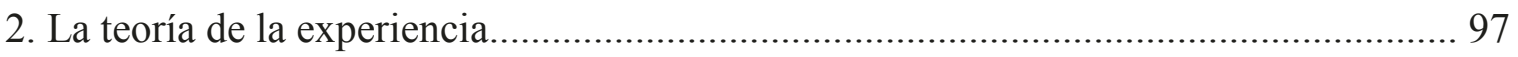

2.1. La experiencia como transacción: la crítica al concepto tradicional de experiencia 98

2.2. Inmediatez cualitativa: el carácter estético y emocional de la experiencia............ 107

2.3. Experiencia primaria y experiencia reflexiva: el conocimiento como experiencia 113 


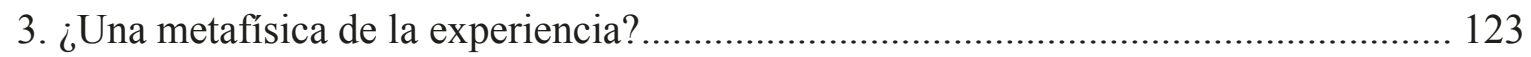

3.1. La filosofía lingüística y la experiencia............................................................. 124

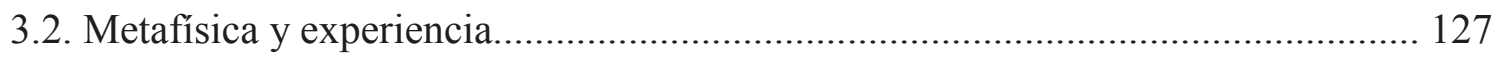

4. Conclusiones: la teoría de la experiencia como punto de partida................................ 133

4. El conocimiento como práctica: la teoría deweyana de la investigación................ 137

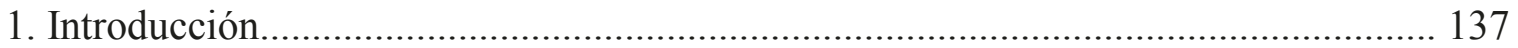

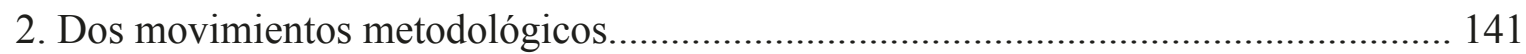

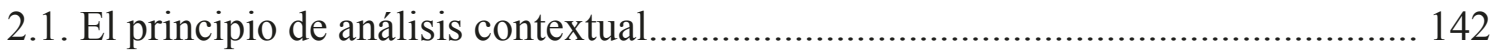

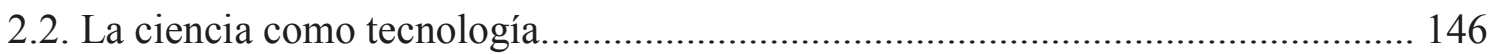

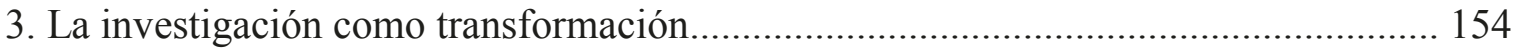

3.1. La continuidad: el seno biológico y cultural de la investigación............................. 156

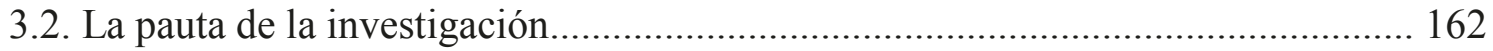

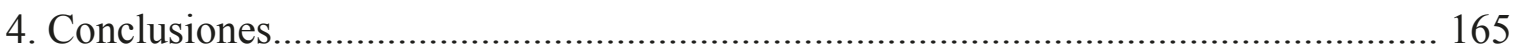

5. La concepción deweyana de la lógica............................................................. 169

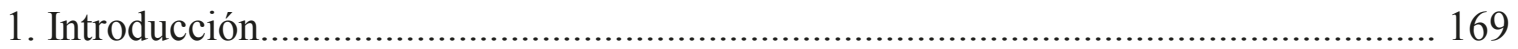

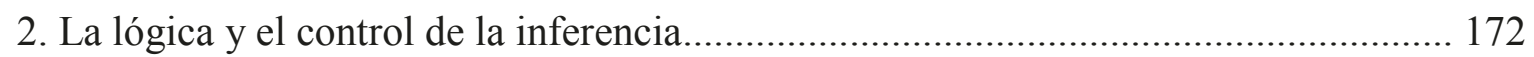

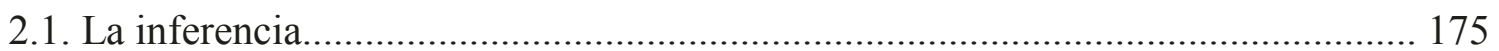

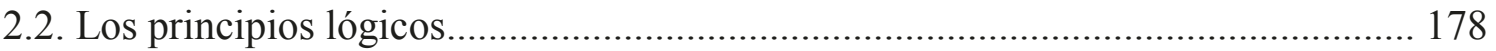

3. ¿Es la lógica de Dewey una verdadera lógica?........................................................... 184

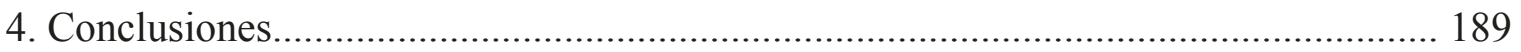

6. Investigación científica y valoración..................................................................... 192

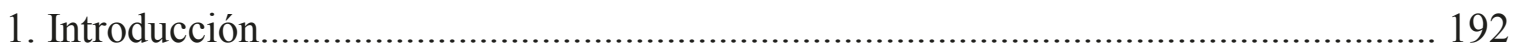

2. Investigación científica, juicios prácticos y valoración............................................... 198

2.1. La investigación como producción y validación de juicios prácticos..................... 201

2.2. Valoración en sentido distintivo: evaluación y apreciación.................................... 209

2.3. Las proposiciones evaluativas y la relación medios / fines.................................... 217

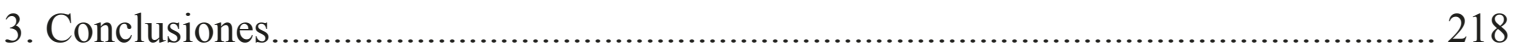

7. Los medios y los fines en el continuo de la valoración/investigación........................ 221

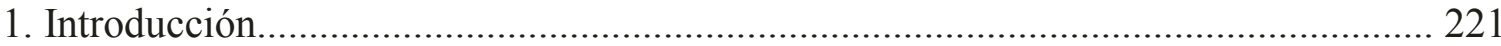

2. La evaluación de los fines y el continuo de la valoración............................................ 223

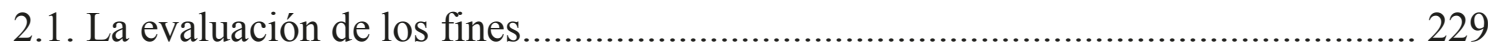

2.2. El continuo de la valoración y el contexto del pensamiento.................................. 232

3. El pragmatismo y la teoría crítica: racionalidad y valores........................................... 240

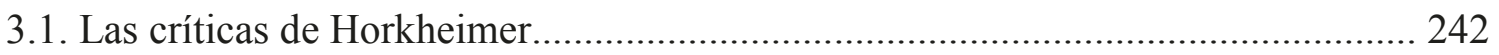

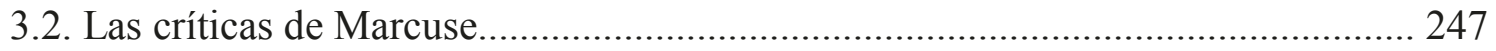

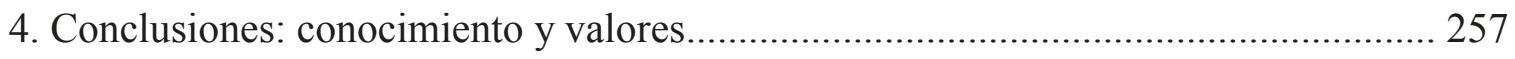


III. Tercera Parte: La teoría de la investigación de Dewey a la Luz de algunos desarrollos recientes.

Recapitulación de los resultados de la segunda parte y presentación de la tercera... 266

8. La lógica de Dewey y la teoría de la argumentación contemporánea.................... 270

1. Introducción: Dewey, Toulmin y el giro práctico de la lógica.................................. 270

2. Toulmin y Dewey, entre pragmática y pragmatismo.............................................. 276

3. Toulmin y Dewey, una comparación programática............................................... 282

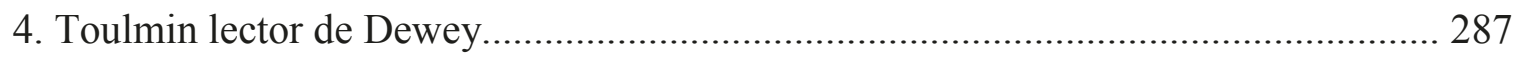

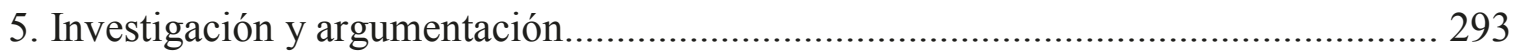

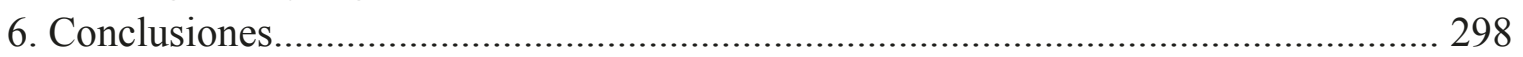

9. La teoría de la investigación de Dewey y los estudios del laboratorio.................... 302

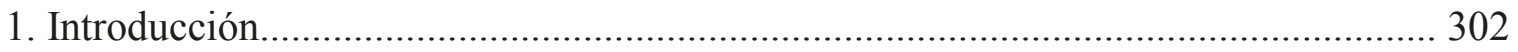

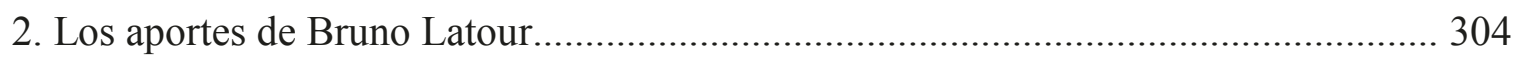

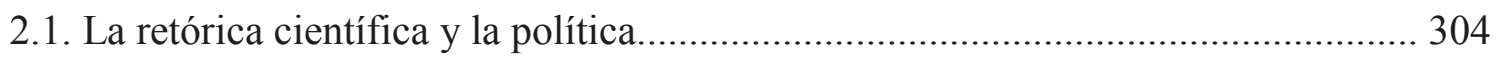

2.2. La ciencia y la sociedad: dentro y fuera del laboratorio.................................... 307

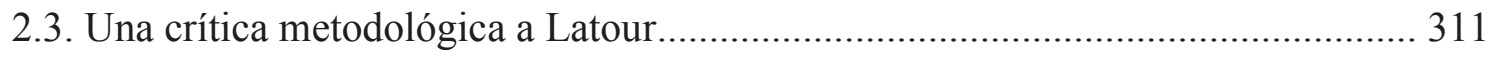

3. Las arenas transepistémicas de investigación.......................................................... 314

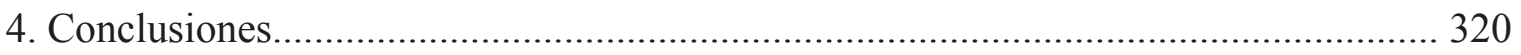

10. El problema de la reflexividad de los estudios de la ciencia............................. 324

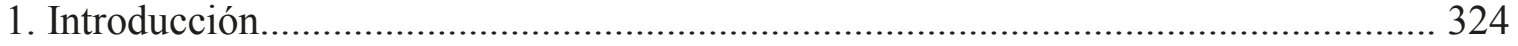

2. Dos miradas sobre el problema de la reflexividad: Bloor y Bourdieu........................ 327

3. Algunas dificultades en torno a la propuesta de Bourdieu...................................... 332

4. Conclusiones............................................................................................ 341

Conclusiones generales: recapitulación de los resultados alcanzados...................... 344

1. De Peirce a Dewey.................................................................................................... 344

2. La teoría de la investigación de Dewey.................................................................... 346

3. Dewey y el giro práctico de la lógica y de los estudios de la ciencia.......................... 353

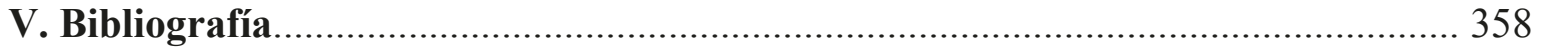




\section{Nota aclaratoria}

Como es usual en la literatura sobre el pragmatismo, los textos de Peirce y Dewey serán citados siguiendo la edición canónica de sus obras. Así, en el caso de Peirce, las citas corresponden a la versión electrónica de los Collected Papers, cuya referencia puede encontrarse en la bibliografía. Las obras de Dewey son citadas según la versión electrónica de las obras completas de Dewey (Boydston, Jo Ann (ed.) (1969). The Collected Works of John Dewey, 1882-1953 (37 Volumes). Southern Illinois Up.) Así, se indicará ew (Early Works), mw (Midle Works) o lw (Later Works) según corresponda, y seguido con la indicación del volumen y el número de página. Se ha optado por ofrecer una traducción de todas las citas y en los casos de las obras que han sido publicadas en castellano, se ha ofrecido la referencia a la edición consultada siempre que se haya utilizado la traducción publicada. 


\section{Resumen}

El objetivo de esta tesis es ofrecer una reconstrucción de la teoría de la investigación de John Dewey, prestando atención a sus antecedentes en los escritos del padre del pragmatismo, Charles Sanders Peirce, y a algunas derivaciones de tal teoría en la teoría de la argumentación contemporánea y en los estudios sociales de la ciencia. La misma está dividida en tres partes dedicadas a (I) explorar algunos antecedentes de la teoría de la investigación de Dewey, (II) desarrollar y analizar críticamente los aspectos centrales de tal teoría y, por último, (III) seguir la pista de algunas de sus derivaciones.

El punto de partida es el análisis de la concepción de la lógica de la investigación de Peirce, tal como éste la fuera construyendo a partir de su crítica a la filosofía moderna. Ofrecemos una reconstrucción de las ideas de Peirce que permite dar cuenta de que, pese a las importantes diferencias entre las ideas de Peirce y Dewey, los desarrollos de este último pueden ser considerados como una prosecución, en nuevas y profundas direcciones, de algunas de las ideas más destacadas del primero y que constituyen, por ello, una lectura posible de algunos de los escritos más destacados de Peirce.

En la segunda parte, la central de esta tesis, se aborda la teoría de la investigación de Dewey. En este marco, se reconstruye la teoría de la experiencia de Dewey, que constituye, como se argumenta, un verdadero punto de partida para la teoría de la investigación. Se argumenta que la teoría de la experiencia de Dewey puede ser considerada como un análisis de las consecuencias para la filosofía de algunos de los resultados más influyentes en el campo de la biología, la psicología y la antropología social en relación con la comprensión de los seres humanos. Se reconstruye también la teoría de la investigación que, al ser comprendida como una forma de la experiencia, permite dar cuenta del carácter mediador y transformacional del conocimiento. Se analizan, asimismo, las consecuencias que para la comprensión de la lógica se siguen de dicha concepción y se argumenta que, pese a lo que Peirce y algunos intérpretes contemporáneos sostienen, la lógica de Dewey puede ser considerada una verdadera lógica. Además, en esta segunda parte se analiza la concepción deweyana de la valoración y se reconstruye una perspectiva acerca de la interdependencia del conocimiento y los valores. Asimismo, se argumenta que, y contra lo que las críticas de 
Horkheimer y Marcuse sugieren, la teoría de la valoración de Dewey tiene un potencial crítico que permite plantear y abordar el problema de los fines de la acción y, en especial, los de esa acción cognitiva a la que llamamos ciencia.

En la tercera y última parte de esta tesis se abordan algunas de las derivaciones de la teoría de la investigación de Dewey. En primer lugar, se exploran las relaciones entre la propuesta de Dewey y la de uno de los más destacados representantes de la teoría de la argumentación contemporánea, a saber, Stephen Toulmin. Se muestra que en la obra de este último puede identificarse una dimensión pragmatista y deweyana. En segundo lugar, se aborda la cuestión de la relación entre la teoría de la investigación de Dewey y el giro hacia las prácticas de los estudios sociales de la ciencia. En particular, se analizan algunos aspectos de la obra de Bruno Latour y de la de Karin Knorr Cetina, mostrando las profundas e interesantes continuidades que suponen con el trabajo de Dewey. Además, se aborda un problema fuertemente discutido en el ámbito de la sociología del conocimiento, a saber, el problema de la reflexividad de los estudios de la ciencia, con el objetivo de ofrecer una mirada deweyana sobre tal cuestión, lo que permitirá sostener una interpretación de la filosofía del conocimiento de Dewey como filosofía política de la ciencia.

Palabras clave: Investigación; Experiencia; Valores; John Dewey; Ch. S. Peirce; Teoría de argumentación; Estudios sociales de la ciencia 


\section{Introducción}

\section{La pregunta por el legado filosófico de John Dewey}

\section{La tradición pragmatista}

Este estudio toma como punto de partida la obra de uno de los así llamados pragmatistas clásicos norteamericanos, a saber, John Dewey. Constituye, principalmente, una reconstrucción, una discusión y una hipótesis acerca de su legado filosófico. Como es sabido, Dewey es uno de los miembros más destacados de la tradición pragmatista, tradición que cuenta ya con una larga historia y tiene su origen en Norteamérica en las últimas décadas del siglo XIX. Si bien es cierto que Hegel ha sido una influencia importante en el pensamiento de Dewey (cfr. Bernstein 2010, cap. 4) y que él mismo ha evitado muchas veces etiquetar su filosofía como "pragmatista", sus ideas y su nombre han quedado definitivamente asociados a tal tradición. En efecto, debe comprenderse el rechazo a tal identificación más bien como una forma de librarse de las distorsiones y malas 
interpretaciones del pragmatismo que de desligarse de las ideas que legítimamente constituyen al mismo.

Aunque debemos a William James la primera aparición pública del término pragmatismo, éste atribuye a Charles S. Peirce, en unas conferencias impartidas en 1898, (1898, p. 290), el haber señalado con su practicalismo o pragmatismo ${ }^{1}$ la dirección que la filosofía debía seguir. De este modo reconoce a Peirce como el padre del pragmatismo y ubica en la década de 1870, en las reuniones del Metaphysical Club al que Peirce y James asistían $^{2}$, el nacimiento de esa corriente de pensamiento que fue vista, así, como la primera escuela filosófica propiamente norteamericana. De este modo, los actualmente muy conocidos artículos publicados por Peirce entre 1877 y 1878, "La fijación de la creencia" (CP 5.358-387) y “Cómo hacer nuestras ideas claras” (CP 5.388-410), constituirían las verdaderas actas de nacimiento del pragmatismo. Sin embargo, y como señalan Bernstein (2010, p. 17) y Apel (1997, p. 36) puede señalarse la más temprana fecha de 1868 como el comienzo del pragmatismo con la publicación por parte de Peirce de algunos artículos en el Journal of Speculative Philosophy. En particular en los artículos "Cuestiones acerca de ciertas facultades atribuidas al hombre" (CP 5.213-63) y "Algunas consecuencias de cuatro incapacidades" (CP 5.264-317) Peirce anticipa, como tendremos oportunidad de apreciar (cap. 1), algunas de las ideas de los trabajos que son tenidos como la inauguración del pragmatismo, ideas que, en nuestra opinión y como trataremos de mostrar, Dewey habría de llevar hasta sus últimas consecuencias.

\footnotetext{
${ }^{1}$ La elección por parte de Peirce del término pragmatismo y su preferencia respecto de practicalismo, explicitada en un escrito llamado "What Pragmatism Is?"(CP 5.411-37), se debe al respeto por parte de Peirce a la distinción kantiana entre práctico y pragmático.

${ }^{2}$ Para una estudio histórico del surgimiento del pragmatismo véase Menand (2002)
} 
De este modo, entonces, nos hemos propuesto investigar ciertas cuestiones en torno al conocimiento tomando como punto de partida una tradición, la del pragmatismo, que tiene ya más de 140 años de historia. Sin embargo, esta historia ha estado marcada por momentos de auge, de apogeo y de declinaciones. Luego de un comienzo más bien silencioso en el Club Metafísico y del gran impulso y expansión que experimentó en las primeras décadas del siglo XX, el interés por el pragmatismo en general y por la filosofía de Dewey en particular se hallaba, en la década de 1950, como recuerda Bernstein (2010, p. 25), en su punto más bajo. Este descenso tan pronunciado en el interés por el pragmatismo ha sido generalmente explicado por el influjo de los filósofos europeos emigrados a Estados Unidos a raíz de la Segunda Guerra y por la rápida y contundente expansión de la filosofía analítica en las universidades de los Estados Unidos. Durante cierto tiempo, la mirada oficial de la historia de la filosofía en Norteamérica relataba que la declinación del pragmatismo americano se debía a que su aporte se limitaba a la anticipación de algunas tesis del positivismo lógico e inclusive de la filosofía analítica, anticipación que, por lo demás, carecía del rigor y la sutileza que el estudio de la moderna lógica formal habría aportado a las nuevas generaciones de filósofos.

A la luz de tal posición, el estudio de las obras de los pragmatistas clásicos, tal vez con la excepción de Peirce cuya obra fue más fácilmente asimilada por la tradición filosófica dominante, resultaba carente de interés para el filósofo, quedando reservado, a lo sumo, para el historiador de las ideas y en el caso específico de Dewey para aquellos interesados en la pedagogía, puesto que en tal campo su importancia e influencia fue siempre ampliamente reconocida, incluso también en Argentina y Latinoamérica (cfr. Ali Jafella, 2006). 


\section{La recepción crítica del pragmatismo y su resurgimiento}

Recordemos que en el contexto de la filosofía europea, la recepción filosófica del pragmatismo, previa a la emigración antes aludida, había sido marcadamente crítica. Como comenta Hans Joas (1995, p. 111) el pragmatismo fue el tema sobresaliente del Congreso Mundial de Filosofía de 1907 celebrado en Alemania. En tal contexto se generó una serie de publicaciones y controversias sobre el pragmatismo, mayoritariamente con un fuerte tono crítico pero que desconocía, incluso, los argumentos de los pragmatistas en respuesta a esas mismas críticas que se volvían a formular. La identificación del pragmatismo con algunos de los peores rasgos de la sociedad norteamericana era ciertamente, -e incluso en algunos contextos lo seguirá siendo por algunas décadas más- una idea ampliamente difundida.

Una de las críticas más fuertes contra el pragmatismo ya en el ámbito de la filosofía continental ha sido la formulada por algunos representantes de la Escuela de Frankfurt. Como señala Joas "uno de los objetivos principales de las críticas de Horkheimer era precisamente ese pragmatismo" (1998, p. 95). Horkheimer es así, el portavoz de una interpretación del pragmatismo en Alemania, que se hacía eco además de una lectura anterior de Max Scheler, en Conocimiento y Trabajo de 1926. Horkheimer asume una identificación entre el pragmatismo y el positivismo y condena fuertemente la concepción instrumental de la razón que renunciaría, en su opinión, a todo intento de fundamentación de los fines y que atribuye explícitamente a Dewey. Cabe recordar, además, que Herbert Marcuse publicó dos reseñas que tendremos oportunidad de discutir más adelante, de dos de las obras más destacadas de Dewey, a saber Theory of Valuation publicada originalmente en 1939 y Logic: the theory of inquiry de 1938. Estas reseñas, publicadas 
entre 1939 y 1941 en el Zeitschrift für Sozialforschung, exhibían una interpretación más amigable del pragmatismo en comparación con la de Horkheimer y concedían, por ejemplo, algunas de las importantes diferencias entre el pragmatismo y el positivismo. Sin embargo ofrecían también una mirada crítica de la propuesta de Dewey. A los ojos de Marcuse, el pragmatista postulaba una mirada cientificista de la razón incapaz de fundamentar una filosofía que fuera crítica respecto de las sociedades contemporáneas y del rol ocupado en ellas por el desarrollo científico-tecnológico. Este rechazo del pragmatismo por parte de los pensadores ligados a la teoría crítica podría explicarse, ciertamente, por las valoraciones disímiles de la democracia de unos y otros. Sin embargo, en nuestra opinión, la controversia sobre la razón es un punto que merece ser aclarado, puesto que las críticas contra la concepción pragmatista de la racionalidad, o de la inteligencia como hubiera preferido decir Dewey, amenazan ciertamente con socavar las posibilidades críticas del pragmatismo, posibilidades que queremos tener presentes en esta tesis, de cara a ciertos debates actuales sobre la ciencia. En este punto coincidiremos con Joas para quien el pragmatismo "no era una forma ingenua de cientificismo, y no implicaba una confianza ciegamente optimista en la propagación de la democracia. Sólo piensan así quienes excluyen la posibilidad de justificar la democracia y la ciencia una vez pasada la metafísica” (Joas, 1998, p. 2).

Este rechazo en el contexto de la así llamada filosofía continental europea ha encontrado su contrapartida, aunque acaso de modo menos visceral, en la filosofía anglosajona. En efecto, una de las figuras que más fuertemente ha criticado al pragmatismo en el mundo anglosajón, para mencionar un ejemplo destacado, ha sido Bertrand Russell. Resulta curioso que mientras filósofos continentales como Horkheimer y Marcuse ubicaban 
a Dewey en la tradición del positivismo más próxima a lo que luego se denominaría filosofía analítica, uno de los héroes de la tradición analítica hace precisamente lo contrario. En un texto acerca de la lógica de Dewey, Russell traza una distinción entre la filosofía británica, más próxima al análisis, y la continental, más próxima a la síntesis, y ubica a Dewey del lado de esta última (Russell, 1989, p. 138). Esta expulsión, por así decirlo, de Dewey del ámbito de la filosofía analítica, filosofía que, recordemos, se volvería dominante en los Estados Unidos, sólo comenzará a ser revertida algunas décadas más tarde.

Ahora bien, esta valoración de la importancia y los aportes del pragmatismo clásico comenzó a ser cuestionada a partir de la década de 1970. Tal cuestionamiento encuentra su punto de partida en la obra de algunos filósofos, tanto norteamericanos como europeos, que resultaron fuertemente influyentes en el último tercio del siglo XX y que comenzaron a llamar la atención sobre los aportes de los pragmatistas clásicos. Podemos mencionar, entre otros, a Richard Rorty y Hilary Putnam, quienes suelen ser considerados como neopragmatistas y a Jürgen Habermas y Karl-Otto Apel quienes, tomando una distancia mayor respecto de los pragmatistas clásicos, han recuperado algunas de sus ideas, reubicándolos en la Historia, con mayúsculas, de la filosofía contemporánea, por así decirlo. Como señala David Hildebrand (2003, p. 2) en referencia a Rorty y Putnam comentario que por nuestra parte extendemos a Habermas y en menor medida a Apel ${ }^{3}$ aunque estos filósofos no hayan sido especialistas en el estudio de los pragmatistas clásicos, han jugado un rol determinante en la difusión del pragmatismo clásico tanto en el

\footnotetext{
${ }^{3}$ En menor medida a Apel porque ha publicado un estudio erudito sobre la obra de Peirce (Apel, 1997), que si bien ofrece una interpretación de Peirce atravesada por su propio idea de una transformación semiótica y pragmática de la filosofía kantiana que ha sido cuestionada, exhibe un conocimiento amplio de los escritos de Peirce.
} 
contexto de la filosofía continental como en el de la filosofía analítica. De este modo, el interés que despertaron las ideas de estos filósofos trajo consigo un resurgimiento del interés en las obras de los pragmatistas clásicos. Ello se vio reforzado, además, por la insistencia de Rorty, de Putnam e incluso de Toulmin en que Dewey debía ser considerado como uno de los filósofos más importantes del siglo XX, a la par de pensadores ampliamente reconocidos como Heidegger y Wittgenstein. Inclusive, han sido publicados numerosos escritos en los que se señalan las profundas coincidencias entre estos últimos y los pragmatistas clásicos (Toulmin, 1984; Honneth, 2007). Esta revalidación posterior del pragmatismo implicó, además, un cuestionamiento de esa mirada historiográfica acerca de la virtual desaparición del pragmatismo de las universidades norteamericanas. En opinión de Joas, por ejemplo, el hecho de que muchos de los más destacados filósofos americanos contemporáneos -entre los que menciona no sólo a Rorty, Putnam y Toulmin sino también a Quine, Davidson, Bernstein, Goodman e incluso a Kuhn- se hayan situado en la tradición pragmatista o fueran situados en ella por otros, "muestra bien a las claras el punto hasta el cual el pragmatismo se ha mantenido como medio discursivo de las universidades americanas, a pesar de la represión que sufriera en ese mismo contexto durante décadas" (Joas, 1998, p. 2).

Sin embargo, este resurgimiento del interés en las obras de los pragmatistas no se ha limitado a una discusión sobre historia de la filosofía; es decir, no se trata sólo de que el pragmatismo clásico haya sido recuperado como un hito importante en la historia de la filosofía norteamericana e incluso mundial. Antes bien, el interés en sus ideas se debe, en nuestra opinión, fundamentalmente a que pueden encontrarse en ellas sugerencias, respuestas y soluciones a diversos problemas y preguntas en el campo de la filosofía, e 
incluso a algunos que sólo se hicieron patente algunas décadas después de la muerte de los pragmatistas. Richard Bernstein (2010, cap. 6) ha sostenido, por ejemplo, que el concepto de experiencia tal como es comprendido por Peirce, James o Dewey ofrece algunas soluciones a las aporías generadas por el giro lingüístico de la filosofía del siglo XX. Asimismo, Habermas y Apel han recurrido a Peirce y a su noción de comunidad ilimitada de interpretación para formular una concepción de la racionalidad que permitiera superar las consecuencias devastadoras de la crítica de la razón de los frankfurtianos y los posmodernos. Por citar un ejemplo más, como sostendremos más adelante, puede interpretarse el resurgimiento de la teoría de la argumentación contemporánea como una crítica a la lógica formal, en una dirección próxima a la crítica de Dewey a la lógica de su tiempo. Aún más, como veremos, los dos pilares sobre los que se asentó el resurgimiento de la teoría de la argumentación contemporánea, a saber, la obra de Toulmin Los usos de la argumentación (2007) y la de Perelman y Olbrechts-Tyteca Tratado de la argumentación: la nueva retórica (2006), delatan influencias pragmatistas.

\section{La pregunta por el legado filosófico de Dewey}

En este contexto cabe la pregunta acerca de si los aportes del pragmatismo, y en particular los de Dewey que nos ocupan en esta tesis, han sido suficientemente incorporados en la filosofía actual. Esta pregunta apunta, en primer lugar, a la cuestión de si los autores antes mencionados como responsables del resurgimiento del pragmatismo clásico han desarrollado efectivamente o continuado de una manera adecuada el programa de investigación propuesto por Dewey. En nuestra opinión y como han argumentado autores como Joas (1998), Bernstein (2010), Sleeper (2001) y Hildebrand (2003), entre otros, 
pueden señalarse fallos en la interpretación de la obra de Dewey por parte de autores como Habermas, Apel, Rorty y Putnam, y pueden señalarse, además, divergencias importantes entre el programa de investigación propuesto por Dewey y los desarrollados por dichos autores.

En relación con Habermas y Apel cabe recordar, con Joas, que pese al rol destacado que ocuparon en la rehabilitación del pragmatismo como una filosofía interesante en el ámbito de la filosofía alemana y europea, "hasta Apel y Habermas mencionan a Dewey sólo de pasada" (1998, p. 133). En efecto, las referencias a Dewey en sus obras son escasas y en general el análisis de sus ideas tiende a ser algo superficial, lo que no ocurre con otros pragmatistas. En efecto, la semiótica peirceana y la idea de una comunidad ilimitada de investigación fueron ampliamente analizadas por Apel y Habermas por cuanto servían a su programa de transformación del concepto kantiano de racionalidad. Incluso, el sociólogo pragmatista George Herbert Mead fue una importante fuente de inspiración para la elaboración de la teoría de la acción comunicativa de Habermas. Sin embargo, ambos autores, aunque de modo más marcado Apel, tendieron a ver a Dewey como un pensador menor, bienintencionado pero algo ingenuo, relativista a pesar suyo, e incluso un poco cientificista y tecnocrático. $^{4}$

En lo que respecta a Rorty $\mathrm{y}$, en menor medida, a Putnam, generalmente reconocidos como neopragmatistas, puede decirse que una de las primeras cuestiones que se debatieron en relación con su rehabilitación del pragmatismo fue la de la fidelidad de sus reapropiaciones e interpretaciones del mismo. En nuestra opinión, David Hildebrand (2003) ha mostrado de un modo adecuado tanto los problemas en las interpretaciones que Rorty y

\footnotetext{
${ }^{4}$ En verdad, Habermas (2002) reconoce que la cientifización de la política que Dewey promovía suponía una previa politización de la ciencia. En ese sentido, en opinión de Habermas, el de Dewey no era un modelo político tecnocrático, aunque considera que su programa es sencillamente irrealizable.
} 
Putnam han ofrecido de Dewey, como la diferencia entre el proyecto de Dewey y los de aquellos neopragmatistas, mostrando así hasta qué punto el legado de Dewey no ha sido suficientemente recogido por ellos. Las sospechas de Hildebrand acerca de que hay un problema respecto de esa reapropiación se fundamentan en la opinión de que, mientras que la obra de Dewey proponía una vía para superar el debate entre realistas e idealistas, Rorty y Putnam habrían revitalizado tal debate, pero esta vez bajo la forma de realismo/antirrealismo (Hildebrand, 2003, p. 2). Así, en su opinión, las propuestas de Rorty y Putnam, al menos en lo que respecta a tales debates, constituyen una vuelta atrás más que una verdadera prosecución de la propuesta de Dewey. En efecto, en opinión de Hildebrand, no se trata solamente de que Rorty y Putnam hayan interpretado mal la posición de Dewey, sino de que han construido filosofías que, en algunos puntos centrales, marchan en un sentido contrario a la de Dewey. En sus palabras, "ninguno de estos enfoques neopragmatistas son derivaciones legítimas del pragmatismo clásico” (2003, p. 4). Aún más, en opinión de Hildebrand, "la posición de Dewey es más original y, de hecho, más defendible que las posiciones neopragmatistas derivadas de ella" (p. 5). En esta misma línea, el sociólogo francés Bruno Latour ha afirmado que "los pragmatistas han sido destrozados por Rorty, Putnam y los otros, vaciados de sus pragmatas y convertidos en simpáticos idealistas” (Entrevista con Fossier, 2006, pp. 118-119).

Aunque tendremos oportunidad de volver sobre algunos aspectos de la interpretación rortyana de Dewey cabe mencionar que, como argumenta Hildebrand (2000), su insistencia en la distinción entre un Dewey "bueno" y un Dewey "malo" es lo que lo lleva a malinterpretar algunas de sus posiciones y a no proseguir lo que, en nuestra opinión, resultan las líneas de investigación más interesantes abiertas por Dewey. El "Dewey bueno" parece ser, a los ojos de Rorty, el Dewey crítico de la tradición filosófica y en especial de la 
epistemología y la metafísica modernas. Se trata del Dewey que intenta desarmar algunas dicotomías y disolver ciertos problemas filosóficos, recordando básicamente que el conocimiento, lo mismo que el lenguaje, no pueden ser ya vistos como meramente representativos, sino que constituyen verdaderas herramientas para la acción transformadora del mundo. El "Dewey malo", en opinión de Rorty, parece ser ese Dewey más constructivo que, sobre la base del concepto de experiencia, pretende fundar una nueva concepción del conocimiento y la inteligencia que dé cuenta no sólo del modo en que de hecho se construye conocimiento en el ámbito de las ciencias naturales, sino también de la posibilidad, legitimidad e imperiosa necesidad de que la inteligencia acometa de una vez por todas la tarea de proponer fines y valores para modificar nuestras prácticas, y en especial nuestras prácticas cognitivas. Las críticas de Rorty van dirigidas, fundamentalmente, contra el intento deweyano de reelaborar una teoría de la experiencia y contra el intento de reelaborar una teoría de la investigación. En efecto, en su introducción al volumen 8 de las obras tardías de John Dewey (lw.8.ix-xviii), lo mismo que en su muy discutido artículo "Dewey's metaphysics" (1982), Rorty dirige sus críticas hacia la legitimidad y la utilidad de realizar, por un lado, una investigación de la investigación, es decir, lo que Dewey entendía como una lógica, y por otro, una recuperación del concepto de experiencia. Como tendremos oportunidad de apreciar, se trata de dos cuestiones centrales en todo el programa de Dewey. Su intento de rehabilitación del concepto de experiencia es el punto de apoyo de su programa de transformación de la filosofía, y su concepción de la investigación como una forma de experiencia constituye su intento más acabado por ofrecer una nueva concepción del conocimiento. Tal concepción, a su turno, permitiría una reelaboración no sólo de la teoría del conocimiento sino también de la lógica 
y la teoría de los valores. Ahora bien, todo esto, que es precisamente lo que Rorty rechaza de Dewey, es el resultado directo de su crítica a la tradición filosófica, crítica que por otro lado sólo adquiría sentido y utilidad, a los ojos de Dewey, en función de la necesaria reconstrucción y recuperación de la filosofía. Lo que, de acuerdo con Rorty, constituye una tensión en Dewey, es decir, la diferencia entre la crítica a la filosofía y su reconstrucción sobre la base de un nuevo concepto de experiencia y de investigación constituye una distinción entre dos fases igualmente necesarias e inseparables del programa de Dewey. En nuestra opinión, Rorty sigue al Dewey crítico de la tradición, pero sin notar que la crítica a la tradición tiene para Dewey un sentido de reforma: liberarnos de viejas ideas porque impiden hacernos con unas nuevas que nos llevarían a acercarnos a nuestras metas y objetivos mejor fundados.

En relación con Putnam las cosas son diferentes. En primer lugar cabe destacar que, tal como lo reconocen los especialistas, sus interpretaciones del pragmatismo son, en líneas generales, mucho más adecuadas que las de Rorty. Sin embargo, Putnam dirige algunas críticas a Dewey que, en opinión de Hildebrand, suponen un análisis poco profundo del concepto de experiencia tal como Dewey lo desarrolla en obras como Experience and Nature o Logic: the Theory of Inquiry. En palabras de Hildebrand, las críticas de Putnam “están sujetas al hecho de que Putnam no ha comprendido adecuadamente - o no ha intentado comprender- la noción de experiencia de Dewey con ningún detalle” (2006, p. 151). Por nuestra parte, asumiremos una lectura de Dewey, apartándonos con ello de Rorty y Putnam, que reconoce el lugar central del concepto de experiencia en su filosofía y que muestra cómo esa nueva concepción de la experiencia es la que permite elaborar una nueva concepción del conocimiento. 


\section{La sociología del conocimiento y el giro hacia las prácticas}

Como mencionamos anteriormente, la desconfianza respecto de la recuperación neopragmatista de la filosofía de Dewey es compartida por Bruno Latour. En su opinión, el programa de investigación epistemológico que Dewey había propuesto no ha sido llevado a cabo suficientemente por ninguno de los filósofos que suelen relacionarse con el neopragmatismo. De acuerdo con Latour, incluso, mientras Dewey mismo se había encargado de desarrollar su programa pedagógico, no habría hecho lo mismo con su propio programa de investigación epistemológico, quedándose tan sólo en la formulación del mismo. Esta última afirmación se apoya en la idea de que el programa epistemológico de Dewey era fundamentalmente un programa empírico, esto es, un programa que se proponía investigar el modo en que de hecho se produce el conocimiento en la sociedad concreta en que se desarrolla. Este tipo de estudio empírico es pensado en la actualidad no ya como epistemología o como filosofía del conocimiento sino fundamentalmente como sociología del conocimiento científico o como estudios sociales de la ciencia. Si ello es así, entonces, habría que buscar a los verdaderos realizadores del programa de Dewey entre los participantes en tales campos.

Resulta significativo, en este sentido, que ya en la temprana fecha de 1940 el sociólogo Charles Wright Mills viera este vínculo entre la propuesta de Dewey y el pragmatismo en general con la sociología del conocimiento. En efecto, en un breve artículo titulado "Methodological consequences of the sociology of knowledge" (1940) Wright Mills recurre al pragmatismo de Peirce y James, pero fundamentalmente al de Dewey, para despejar algunos cuestionamientos sobre la pertinencia epistemológica de una sociología 
del conocimiento. Afirma, siguiendo a Dewey, que hay diferentes aspectos relacionados con el conocimiento científico que deben ser historizados y relativizados y que resultan, por tanto, abiertos a la indagación sociológica. Así, tomando el análisis de Dewey acerca de la lógica griega y los métodos de fijación de creencias expuestos por Peirce, argumenta que los criterios que permiten decidir si algo será aceptado como verdadero u objetivo no son invariables sino que han cambiado a lo largo de la historia, lo que habilita la indagación acerca de por qué en una época dada se han aceptado y usado tales o cuales criterios. De este modo, en opinión de Wright Mills, los criterios de verdad y objetividad y la manera en que se eligen y aplican, las categorías mismas del lenguaje científico, los problemas que se investigan e incluso los esquemas perceptuales que determinan lo que vemos, todos estos elementos que afectan la dirección de la investigación y su validación misma, serían aspectos abiertos a la investigación sociológica (1940, p. 325). Para defender esta tesis Wright Mills se apoya en la concepción de los principios lógicos como algo que surge en el seno mismo de la investigación, desarrollada por Dewey desde 1906 y publicada de una manera sistematizada en su obra Logic: the Theory of Inquiry de 1938, apenas dos años antes del artículo que mencionamos. Como resulta evidente, este texto de Wright Mills anticipa, en más de dos décadas, algunos de los puntos centrales de la visión kuhniana de la ciencia, que serán a su turno discutidos y estudiados empíricamente en el contexto de la sociología de la ciencia y del así llamado programa fuerte. De este modo queda planteada una de las cuestiones que abordaremos en esta tesis, a saber, la valoración de la concepción deweyana de la investigación a la luz de algunos de los desarrollos en el campo de los estudios de la ciencia de las últimas décadas.

Como es sabido, y en gran parte como consecuencia del enorme impacto de la obra de Thomas Kuhn, a partir de la década de 1960 la sociología del conocimiento cobra un 
impulso renovador y se produce un giro muy significativo en su seno. Como señalaron los representantes más destacados del programa fuerte de la escuela de Edimburgo, la importancia que Kuhn otorgó a la historia de cara a la construcción de una imagen más adecuada de la ciencia abrió las puertas hacia una nueva sociología, no meramente de la ciencia entendida como institución ni del mero error, sino del conocimiento científico mismo. Como recuerda Andrew Pickering (1995, p. 5) esta concepción cognitivista de la sociología se propuso establecer vínculos (causales) entre esa red conceptual en que consiste el conocimiento científico y las variables sociológicas clásicas como el interés, la clase, la religión, etc. Si la validación del conocimiento científico y el cambio conceptual mismo suponen, como había mostrado Kuhn, la producción de consensos en el interior de las comunidades científicas, y si, por otro lado, la filosofía de la ciencia había llegado a la conclusión de que la producción de ese consenso no puede explicarse apelando sólo a la lógica y la observación, por cuanto no hay en ciencia observación neutral respecto de la teoría y no hay algo así como un método que nos asegure un procedimiento inequívoco aceptado por todos los científicos y que garantice un resultado único, entonces se hace necesario explicar la producción de consenso de otro modo. Así, quedaba sugerida la idea de que si no es la observación y el método lo que permite alcanzar el consenso en las comunidades científicas, debe explorarse la posibilidad de que los así llamados "factores sociales", tales como la clase, la nacionalidad o el interés, jueguen algún rol en el proceso de producción/validación del conocimiento científico.

Si comparamos estos desarrollos con el libro de Dewey Logic: The Theory of Inquiry, por mencionar una de sus obras de madurez más importantes, las diferencias resultan significativas. En efecto, aunque en tal libro Dewey insista en el carácter social de 
toda investigación e incluso en la presencia de juicios valorativos en ella, el libro consiste en una exposición de la estructura de la investigación y del rol jugado en ella por el lenguaje y los principios lógicos, analizando por ejemplo el rol de los datos, las hipótesis, los enunciados universales, el razonamiento y otros elementos en el proceso de la investigación. Este enfoque, visto desde la óptica del programa fuerte, puede aparecer como un nuevo programa de epistemología tradicional. En efecto, no encontramos en Dewey algo parecido al intento de explicar el proceso de validación del conocimiento como un proceso determinado por elementos sociales entendidos como extra-epistémicos. Para Dewey el conocimiento es el producto de la investigación y debe su carácter de validado o garantizado al hecho mismo de ser el producto de una investigación controlada o dirigida. Ello no implica de ningún modo que el conocimiento no sea visto por Dewey como un hecho social. La investigación misma ocurre en un seno que es siempre, a la vez, natural y cultural, e incluso, como veremos, en ella se halla siempre involucrado un verdadero proceso de valoración, de modo que los valores, y a través de ellos también los deseos y emociones, juegan un rol en el proceso de investigación. Pero aún así, la validación del conocimiento científico, la producción de aserciones garantizadas, depende de su capacidad para resolver el problema que se investiga y no de valores o intereses provenientes de algún sitio ubicado más allá de la investigación misma.

Ahora bien, el programa de investigación de la escuela de Edimburgo ha encontrado en el contexto mismo de la sociología del conocimiento sus propias limitaciones. En particular, hay dos de ellas que nos parecen especialmente relevantes en el contexto de la presente investigación. En primer lugar, como ha señalado Pickering (1995), la sociología del conocimiento ha estado demasiado atada a una visión representativista del conocimiento. Tal visión asume la idea de que el conocimiento es básica y esencialmente 
un intento de descripción del mundo, descripción entendida como una suerte de representación lingüística del mismo. El proceso de validación de tales representaciones podía estar determinado, en las versiones más tradicionales, por el método y la observación, quedando abiertas a la investigación sociológica tan sólo las "desviaciones" metodológicas y observacionales, desviaciones que, por otra parte, se consideraban como socialmente inducidas (sociología del error). Por otro lado, en las versiones más próximas al programa fuerte, todas las representaciones científicas, y no sólo aquellas consideradas erróneas, resultan pasibles de investigación sociológica, destacando que toda representación, incluso la considerada científicamente validada, resulta influida y, al menos en parte, determinada por factores sociales. Así, ambas posiciones coinciden en su comprensión del conocimiento como una forma de representación, considerando, en todo caso, a la práctica científica como la actividad de producción, ampliación o extensión de esa representación lingüística, entendida generalmente como una red conceptual. Frente a esta visión representativista Pickering ha propuesto elaborar un lenguaje performativo para dar cuenta del conocimiento científico, es decir, un lenguaje que permita abordar el conocimiento entendiéndolo como una forma de la acción. Esta visión performativa del conocimiento expone definitivamente el sitio en donde ocurre la investigación, el "laboratorio" en muchos casos, a la mirada del investigador social: si el conocimiento es una práctica, una forma de acción, entonces si queremos comprender cómo se conoce, debemos observar los procesos mismos de producción de conocimiento científico, es decir, las prácticas científicas.

Esta importancia metodológica otorgada a la práctica científica no es exclusiva de Pickering. Hacia fines de la década de 1970, como han reconocido diversos autores (Schatzki, 2001; Pickering, 1992; Turner, 1994), se produjo en la sociología del 
conocimiento un giro hacia las prácticas. Autores como Bruno Latour y Steve Woolgar, Karin Knorr-Cetina e incluso Andrew Pickering se propusieron abordar, como señala Kreimer, "ya no los problemas derivados de la producción de conocimiento científico, o meramente los contenidos de la investigación, sino que su objetivo está dirigido a dar cuenta de las prácticas científicas propiamente dichas" (1999, pp. 146-147). Ahora bien, este giro hacia las prácticas, y la primacía teórica otorgada a ellas, como resulta claramente reconocido en la compilación de Schatzki, Knorr Cetina y von Savigny (2001), no es tampoco algo exclusivo de la sociología del conocimiento científico, sino que abarca a la filosofía, a la sociología y a las humanidades en general. En este sentido, incluso el pragmatismo americano clásico puede ser visto como un antecedente importante en dicho giro hacia las prácticas. Como veremos, la atribución a la práctica de un carácter central es reconocida por muchos intérpretes como una de las marcas distintivas del pragmatismo. Ahora bien, como mencionamos, no fue sino hasta finales de la década de 1970 que los estudios de la ciencia comenzaron a indagar de manera empírica las prácticas científicas mismas. Tales estudios, que adoptaron muchas veces métodos etnográficos y antropológicos, han arrojado resultados diferentes que permitieron a su vez poner en cuestión la imagen tradicional del conocimiento, incluso en algunos aspectos que sobrevivieron aún en la imagen poskuhniana de la ciencia.

Es en relación con este giro hacia las prácticas de los estudios de la ciencia que, en esta tesis, intentaremos contrastar la posición de Dewey reflexionando a su vez acerca de los aportes que su mirada, en tanto que mirada filosófica, tiene para ofrecer. Así, uno de los propósitos centrales de esta tesis será analizar la actualidad de la propuesta de Dewey, y en especial de su teoría de la investigación, a la luz de algunos desarrollos más o menos recientes en el ámbito de la sociología del conocimiento. Dewey había ofrecido una mirada 
filosófica sobre el conocimiento que insistía en la idea de que para explicar qué es el conocimiento hay que analizar cómo de hecho se produce conocimiento. Esta marca empírica de la filosofía explícitamente pretendida por Dewey no fue sin embargo, como sugiere atinadamente Latour, desarrollada completamente por él. Aún así, como intentaremos mostrar en esta tesis, el programa de Dewey comparte importantes aspectos con este giro hacia las prácticas de la sociología de la ciencia. En efecto, como veremos, si el pragmatismo confiere a la práctica un lugar destacado en la filosofía, ello se traduce en una nueva concepción del conocimiento como forma de la práctica. Esta idea, anticipada por Peirce en su artículo "La fijación de la creencia" (CP 5.358-387), que era resultado a su vez de su crítica a la concepción cartesiana del conocimiento, será desarrollada por Dewey de un modo sistemático y consecuente. Tal como la entenderemos aquí la Logic: The Theory of Inquiry de Dewey constituye su intento más elaborado, complejo y sistemático por construir una visión del conocimiento, y de los principios lógicos que lo regulan, que tenga en cuenta que conocer no es meramente describir el mundo sino transformarlo. En dicha obra, Dewey ofrece una interpretación de algunos conceptos epistemológicos tradicionales (datos, hipótesis, razonamiento, enunciados universales, inferencia, etc.) que resulta consistente con la idea de que el conocimiento es una transformación controlada o dirigida de una situación problemática. Al ofrecer tal concepción del conocimiento, Dewey propuso una verdadera transformación del modo en que se comprende a la lógica y a los principios lógicos que, como habremos de ver, halla en algunos desarrollos de la lógica informal y la teoría de la investigación una interesante línea de continuidad. Esta concepción del conocimiento como forma de la práctica supone, además, que el conocimiento es siempre algo situado, puesto que es un modo de respuesta a una situación 
problemática que es siempre singular. En este contexto, la actividad del científico consiste, básicamente, en la elaboración de lo que Dewey mismo llama “juicios prácticos.”

Esta teoría de la investigación formulada por Dewey resulta, como argumentaremos, confirmada en buena medida por ciertos resultados de los estudios de laboratorio. En particular, nos detendremos en algunos aportes de Bruno Latour y de Karim Knorr Cetina que parecen profundizar y confirmar algunas de las ideas de Dewey. Sin embargo, en tanto que mirada filosófica sobre el conocimiento, creemos, tal como intentaremos mostrar, que la teoría de la investigación deweyana complementada con su teoría de la valoración y de la democracia permiten superar lo que a los ojos de Steve Fuller constituye una de las limitaciones más importantes de los estudios empíricos de la ciencia, a saber, la pérdida de una dimensión normativa o crítica. De este modo, argumentaremos que la filosofía del conocimiento de Dewey permite articular algunos de los resultados de los estudios de la ciencia, pero sentando las bases para una verdadera filosofía política del conocimiento y la ciencia.

\section{Contenido de la tesis}

De acuerdo con lo planteado hasta aquí, esta tesis estará dividida en tres partes. La primera de ellas (capítulos 1 y 2) estará referida fundamentalmente a reconstruir el programa de investigación pragmatista tal como ha sido bosquejado por Peirce, el padre del pragmatismo. En esta primera parte, en el capítulo uno, reconstruiremos la crítica peirceana a la tradición filosófica para mostrar de qué modo tal crítica permite a Peirce delinear una nueva concepción del conocimiento. El capítulo dos, estará destinado a exponer el 
programa de investigación del pragmatismo tal como éste aparece delineado en los artículos de Peirce que han sido considerados las verdaderas actas de nacimiento del pragmatismo.

La segunda parte (capítulos 3 a 7) estará destinada a analizar la concepción deweyana de la investigación y su propia versión del programa pragmatista. Para ello, en el capítulo 3, reconstruiremos la concepción deweyana de la experiencia, concepción ésta sobre la que se apoya su teoría de la investigación. Abordaremos una de las críticas más destacadas en relación con la recuperación del concepto de experiencia, volviendo así sobre la relación entre el giro lingüístico y la apelación al concepto de experiencia y retomando de un modo crítico la visión de Richrad Rorty acerca de esta cuestión. En el capítulo 4, reconstruiremos la teoría deweyana de la investigación destacando su carácter de transformación de la situación, derivado en buena parte del carácter transaccional de la experiencia. En el capítulo 5 analizaremos los cambios en la concepción de la lógica y de los principios lógicos introducidos por Dewey al comprender a la lógica como una teoría de la investigación. En particular, sostendremos contra algunas interpretaciones usuales, que la lógica de Dewey sí puede y debe ser considerada como una verdadera lógica.

Los capítulos 6 y 7 estarán destinados a reconstruir la concepción de la valoración de Dewey lo que, en consonancia con algunos desarrollos recientes, nos permitirá sostener el carácter cargado de valores de la investigación, señalando a su vez, la fuerza crítica de la tesis de Dewey según la cuál, los valores mismos, incluso los valores éticos y políticos, resultan cargados de investigación. Así, en el capítulo 6 comenzaremos nuestro análisis de la valoración destacando, en primer lugar que, puesto que toda investigación es para Dewey una forma de la práctica, en la que se formulan juicios prácticos como verdaderos instrumentos de transformación, toda investigación supone juicios valorativos. En el 
capítulo 7, nos detendremos en el análisis de lo que Dewey llama juicios valorativos en sentido distintivo y mostraremos que la posibilidad de su validación depende, para Dewey de la posibilidad de fundar fines y valores desde la relación de medios y fines, teniendo en cuenta además lo que Dewey llamará el continuo de la valoración. Asimismo, en este capítulo analizaremos las críticas de la Horkheimer y Marcuse a Dewey, toda vez que tales críticas amenazan con socavar el potencial crítico de la teoría de la investigación de Dewey, potencial que nos interesa tener presente en este estudio.

La tercera parte de la tesis estará dedicada a explicitar una valoración de la teoría de la investigación de Dewey a la luz de algunos desarrollos teóricos posteriores. En primer lugar, en el capítulo octavo, analizaremos los vínculos entre la concepción de la lógica de Dewey y la de uno de los más destacados representantes de la teoría de la argumentación contemporánea, a saber, Stephen Toulmin. Trataremos de mostrar, que la perspectiva de Toulmin incorpora una verdadera dimensión pragmatista, pese a que ello no ha sido reconocido por los estudiosos del campo. Si bien, en nuestra opinión, la teoría de la investigación de Dewey ofrece algo más que lo que en la actualidad suele entenderse como una lógica, su concepción de la lógica resulta, como argumentaremos y pese a las interpretaciones más usuales, de una actualidad notable.

Los capítulos 9 y 10 están dirigidos a analizar algunos aportes y discusiones en el ámbito de los estudios sociales de la ciencia. Argumentaremos que algunos resultados de los estudios empíricos de las prácticas científicas confirman y profundizan en algunos puntos centrales la comprensión deweyana del conocimiento. En particular nos detendremos, en el capítulo 9, en algunos aspectos de la obra de Burno Latour y en el concepto de arenas transepistémicas de investigación propuesto por Knorr Cetina. En el capítulo 10 analizaremos uno de los problemas que han sido más fuertemente discutidos en 
el ámbito de la sociología del conocimiento, a saber el problema de la reflexividad de los estudios de la ciencia, con el objetivo de ofrecer una mirada deweyana sobre tal cuestión. Para finalizar, en las consideraciones finales y luego de recapitular las conclusiones a las que hemos arribado en esta tesis, nos detendremos en la concepción de la filosofía de Dewey, a efectos de explicitar, contra Rorty, los profundos vínculos entre crítica y transformación que la misma supone. 


\section{Primera Parte}

El programa pragmatista de investigación en sus orígenes:

los aportes de Peirce 


\section{La crítica peirceana a la tradición filosófica}

\section{Introducción}

En este capítulo y el que sigue presentaremos una serie de tesis e ideas expuestas por Charles Sanders Peirce en algunos de sus escritos más destacados. Tales escritos contienen, en nuestra opinión y como trataremos de evidenciar en los capítulos que siguen, un esbozo del programa de investigación que Dewey habría de desarrollar años más tarde llegando incluso a consecuencias que Peirce habría de cuestionar. Las ideas que contienen dichos escritos son, además, las que constituyen y caracterizan lo que podemos denominar el programa de investigación pragmatista.

El intento de caracterizar tal programa no carece de dificultades. Sin embargo, en un clásico texto en el que Hilary Putnam discute la herencia del pragmatismo, menciona las siguientes cuatro tesis que, en su opinión, constituirían la base de las filosofías de Peirce, 
James y Dewey. Se trata, en primer lugar, del anti-escepticismo contenido en la tesis de que la duda requiere justificación lo mismo que la creencia ${ }^{1}$; en segundo lugar, del falibilismo contenido en la tesis de que no hay garantías últimas de que tal o cual creencia no necesitará nunca ser revisada; en tercer lugar, de la tesis acerca de que no hay una dicotomía fundamental entre hechos y valores; y, por último, "la tesis de que, en un cierto sentido, la práctica es primaria en filosofía” (1997, p. 145). Desde nuestro punto de vista, y como suele reconocerse, esta última tesis es, por así decirlo, más básica que las anteriores. En efecto, es este compromiso con la centralidad de la práctica en filosofía lo que permite, por ejemplo a Dewey, elaborar una visión anti-escéptica y falibilista del conocimiento que lo considera además como valorativamente cargado. Es esta misma centralidad otorgada a la práctica lo que llevó a Stephen Toulmin a señalar que en su opinión Dewey había señalado correctamente la dirección en la que debían moverse la lógica y la epistemología, a saber, hacia la búsqueda de "la materia primera para la teoría del conocimiento en las prácticas reales de razonamiento de los pensadores humanos" (1984, p. 8). Además, la concepción del conocimiento como una forma de la práctica ha llevado a sociólogos de la ciencia como Latour y Pickering a reconocer en el pragmatismo, y específicamente en Dewey, a un precursor del giro hacia las prácticas dado por los estudios sociales de la ciencia desde la década de 1970. Pero incluso más importante resulta el hecho de que es esta relevancia conferida a la práctica lo que da a la tradición pragmatista su nombre. En efecto, es ese "método" para esclarecer nuestras ideas propuesto por Peirce en 1878, conocido desde entonces como máxima pragmática, lo que parece constituir el núcleo duro

\footnotetext{
${ }^{1}$ Esteban Cloquell (2006, p. 70) recuerda que, a diferencia de esta categorización del pragmatismo como antiescéptico, Rescher (1977) ha afirmado que los escépticos, o al menos Carnéades, son protopragmatistas. Asimismo, Toulmin (1984) ha sostenido, como señalamos en el capítulo 8, la existencia en Dewey de una dimensión escéptica. En nuestra opinión dichas caracterizaciones son en realidad compatibles por cuanto apuntan a aspectos distintos del escepticismo (cfr. cap. 8 n12 de esta tesis).
} 
de la filosofía pragmatista. No resulta demasiado arriesgado afirmar que en el contexto del pragmatismo la práctica resulta central sin más, y no sólo en filosofía. Ello es así por cuanto la concepción pragmatista del significado sugerida por o contenida en la máxima pragmática confiere a los factores prácticos un lugar central en la determinación del significado en cualquier contexto. No obstante ello, la idea de que tal forma de esclarecer el significado de las ideas debía ser incorporado también en filosofía condujo a la idea de que el componente propiamente pragmatista de las filosofías de Peirce, James y Dewey es más bien un estilo o forma de hacer filosofía que un conjunto de tesis sustantivas. En este sentido, parece ser un componente metafilosófico lo que caracteriza y distingue al pragmatismo. Sin embargo, no debe olvidarse que el pragmatismo ha impulsado también una forma de transformar y reconfigurar, tomando como punto de partida la crítica a la tradición filosófica, una serie de conceptos y tesis. En opinión de Bernstein (2010, p. 35) la importancia de la máxima pragmática en la comprensión del pragmatismo ha sido exagerada ya que el pragmatismo se caracteriza también por una serie de ideas acerca del conocimiento, el hombre y la realidad. En nuestra opinión, sin embargo, debe destacarse la importancia que este nivel metafilosófico ha tenido en el pragmatismo, puesto que es esta transformación de la filosofía lo que permite al pragmatismo ofrecer una serie de aportes sustantivos en relación con nuestra concepción del conocimiento y del hombre.

Antes de comenzar con nuestra exposición de las ideas de Peirce, es importante señalar, y pese a la caracterización propuesta por Putnam, que la tarea de definir de una manera a la vez unitaria, fiel y precisa en qué consiste esa filosofía a la que suele calificarse como pragmatista, parece ser una tarea condenada al fracaso. Ello es así tanto más cuanto que, según el propio James, el pragmatismo no sería más que un nuevo nombre para una 
vieja forma de pensar. Tal forma de pensar encontraría antecedentes en filósofos tan diversos como Kant ${ }^{2}$, Hume y Bacon. Las cosas se complican aún más si tenemos presente que muchos filósofos contemporáneos, que han defendido posiciones no sólo distantes entre sí sino también diferentes de las del "triunvirato clásico" de los pragmatistas americanos, se han reivindicado como pragmatistas o han sido reivindicados como tales por otros. Ello ha llevado a algunos intérpretes a hablar de un pragmatismo viejo y uno nuevo (Haack, 2001) y a otros a afirmar que acaso el pragmatismo sea, en la actualidad, tan sólo un viejo nombre para nuevas formas de pensar (Kloppenberg, 1996). Por otro lado, las diferencias entre los miembros del triunvirato no son pocas y han sido objeto de debate no sólo entre los intérpretes sino también entre los propios pragmatistas (Di Berardino, 2010, Haack, 2006; Houser, 2006; Margolis, 2002; Philstrom, 2004). Puesto que estamos más interesados en la recuperación de algunas ideas de cuño pragmatista que en el estudio de su desarrollo histórico, dejaremos de lado, en gran medida, tales discusiones.

Como es sabido, Peirce ha sido un pensador difícil. Acaso la dificultad mayor se deba a que, pese a haber sido un pensador sistemático, es decir, un pensador que ha intentado desarrollar un verdadero sistema filosófico, fue a la vez un escritor fragmentario que ha dejado un sinnúmero de escritos mayoritariamente breves. Más aún, en varios de sus escritos ha vuelto una y otra vez sobre las mismas ideas realizando, muchas veces, cambios

\footnotetext{
${ }^{2}$ Es el propio Peirce quien ve en Kant un protopragmatista. En su opinión "Kant (por quien siento algo más que admiración) no es sino un pragmatista algo confundido (...)". (CP 5.525, 1905). La relación de la filosofía de Kant con los pragmatistas clásicos es una cuestión muy debatida por los comentadores e intérpretes del pragmatismo. Así, por ejemplo, Apel $(1985,1997)$ ha presentado, con buenas razones, a la filosofía de Peirce como un intento de transformación semiótica de la filosofía trascendental kantiana, intento que a su vez es utilizado por Apel en la formulación de su propia línea de argumentación pragmáticotrascendental. Por su parte, tanto Brandom (2011) como Putnam (2006, p. 64) parecen ver en Kant un protopragmatista, mientras que Rorty (2000), aproximando las filosofías de James y Dewey a la de Nietzsche, ha resaltado el carácter anti-kantiano del pragmatismo. Sin pretender zanjar esta cuestión trataremos de explicitar algunos sentidos en que esta forma de argumentar de los pragmatistas, centrada en lo práctico, apunta contra los argumentos trascendentales. Sobre la relación entre la propuesta de Putnam cfr. Posada Kubissa (2012). Sobre la relación entre Dewey y Nietzsche, véase Allen (2010) y Fairfield (2010).
} 
en la manera y en el énfasis de su presentación cuando no en las ideas mismas. La presencia de estos cambios ha llevado a los intérpretes a señalar distintos momentos o etapas en el desarrollo de su pensamiento, sin que haya una clara unanimidad en la forma de dividirlos. Así, por ejemplo, Nathan Houser, en su introducción al tomo I de la Obra filosófica reunida de Peirce (2012, p. 21), menciona tres modos en que el desarrollo intelectual de Peirce ha sido dividido (Fisch, 1986; Deledalle 1996; Murphey, 1961). Por su parte, K. O. Apel (1997) ofrece una forma propia de periodización del pensamiento de Peirce que no se ajusta exactamente a ninguna de las anteriores.

En este capítulo y el que sigue estudiaremos un conjunto pequeño de artículos de Peirce que contienen, en nuestra opinión, el programa de investigación del pragmatismo. En primer lugar, analizaremos una serie de artículos relativamente tempranos que contienen su crítica a la concepción cartesiana y moderna del conocimiento y que anticipan algunas de las ideas del período de formulación del pragmatismo. Así, en este capítulo, nos centraremos en la crítica de Peirce a la tradición, lo que nos permitirá delinear los aspectos centrales de la concepción del conocimiento que desarrollará tomando como punto de partida tal crítica. Además, como trataremos de evidenciar, estos artículos contienen una primera formulación y una ejemplificación de ese componente metafilosófico del pragmatismo al que nos hemos referido.

En segundo lugar, en el capítulo que sigue, estudiaremos los artículos de Peirce que han sido considerados verdaderas actas de nacimiento del pragmatismo, publicados entre 1877 y 1878 en el Popular Science Monthly y que son, probablemente, sus escritos más ampliamente conocidos y discutidos. Reconstruiremos, entonces, la concepción de la investigación del período propiamente pragmatista de Peirce destacando los cambios 
profundos que introduce en el modo tradicional de comprender las relaciones entre conocimiento y acción.

\section{La crítica peirceana al cartesianismo}

La concepción del conocimiento y, en general, la filosofía de Peirce, se construye, de modo similar a lo que ocurre con Dewey, a partir de un diálogo sistemático y profundo con la concepción del conocimiento y del hombre heredada de la modernidad, o al menos de sus posiciones hegemónicas. Es a partir de la crítica de ciertos supuestos comunes de la filosofía moderna acerca del conocimiento, la realidad, la mente y el hombre, que los pragmatistas construirán una nueva concepción filosófica acerca de tales asuntos. En el caso de Peirce, como recuerda Apel, su filosofía "pone en cuestión presupuestos esenciales que no son propios sólo de Hume y Kant, sino de toda la filosofía moderna” (1997, p. 42). Para comprender el cambio que los pragmatistas intentan producir en nuestra concepción del conocimiento resultará, por tanto, de especial interés tener en cuenta esa verdadera deconstrucción de la concepción tradicional del conocimiento operada por los pragmatistas. Si bien en el caso de Dewey la crítica se remonta una y otra vez al pensamiento de la Grecia clásica, Peirce se limita, en los dos artículos de 1868 y en uno de 1871 que consideraremos a continuación, a una crítica a la concepción moderna del conocimiento aunque retoma, como es sabido, algunas discusiones centrales de la filosofía medieval en torno a la disputa entre nominalismo y realismo.

Los escritos de Peirce aludidos, a saber, "Cuestiones acerca de ciertas facultades atribuidas al hombre" (CP 5.213-263) y “Algunas consecuencias de cuatro incapacidades" 
(CP 5.264-317) ${ }^{3}$, contienen una crítica profunda tanto a las posiciones que suelen catalogarse como racionalistas como a aquellas otras próximas al empirismo e incluso algunas críticas a la filosofía de Kant. En ellos se bosqueja una nueva manera de comprender el conocimiento, así como también una nueva forma de entender la actividad filosófica. Nos encontramos así, y ya en estos escritos tempranos, con el componente metafilosófico del pragmatismo antes mencionado, en el que nos detendremos en primer lugar.

El blanco de las críticas en dichos escritos es lo que Peirce entiende como el espíritu del cartesianismo. Tal espíritu, que caracteriza mediante cuatro principios, no es exclusivo de Descartes y sus seguidores próximos sino que, en su opinión, "la mayoría de los filósofos modernos han sido cartesianos en alguno de estos aspectos o en todos" (2012, p. 72). Los aspectos a los que se refiere Peirce, cuya revisión era en su opinión exigida por el desarrollo de la ciencia y la lógica, son los siguientes: (1) la filosofía debe comenzar con la duda universal; (2) la prueba última de certeza debe buscarse en la conciencia individual; (3) la argumentación (filosófica) debe seguir un único hilo de inferencia; (4) hay ciertas cosas que resultan inexplicables. En el cuestionamiento de estos principios atribuidos al cartesianismo, Peirce sugiere algunas de las ideas que formarán parte esencial de la concepción pragmatista del conocimiento. Para decirlo brevemente, se trata de una concepción anti-fundacionalista, anti-escéptica y falibilista del conocimiento. Veamos, entonces, cómo desarrolla Peirce su argumentación.

\footnotetext{
${ }^{3}$ Puesto que transcribiremos las citas siguiendo la traducción de Darin McNabb, revisada por Sara Barrena y Fausto José Trejo en Peirce (2012) señalaremos la paginación de la edición castellana utilizada indicando la ubicación del artículo en los CP.
} 
2.1. Contra el principio metodológico de la duda universal

Como es sabido, la máxima metodológica de la duda universal está ligada al ideal cartesiano de certeza y su identificación con la ausencia absoluta de duda. En efecto, el imperativo de comenzar con la duda universal tiene para Descartes la función de eliminar toda creencia respecto de la cual encontremos el más mínimo motivo de duda. Esto, a su turno, se fundamenta en el rechazo cartesiano de la idea misma de conocimiento probable. En la explicación de la segunda de sus Reglas para la dirección del espíritu (2011, p. 5), Descartes afirma que "rechazamos todos los conocimientos tan sólo probables y establecemos que no se debe dar asentimiento sino a los perfectamente conocidos y respecto de los cuales no cabe dudar". Si bien la crítica peirceana no se dirige directamente a este punto, veremos cómo su crítica metafilosófica a la máxima metodológica de la duda universal supone, en efecto, una revisión profunda de aquel rechazo al conocimiento probable a favor de una concepción falibilista del conocimiento.

La objeción que presenta Peirce es que la exigencia de que en filosofía deba comenzarse con la duda universal es inútil y, en el mejor de los casos, un mero autoengaño. Esta objeción encuentra su apoyo en un análisis del concepto de duda que lo liga indisolublemente al concepto de razón, anticipando, como ha sido señalado muchas veces (p. ej. Apel, 1975, ) algunas reflexiones de Wittgenstein en torno a la certeza. En opinión de Peirce sólo tiene sentido dudar de algo si hay razones positivas para hacerlo. Como señala Bernstein, la duda no es para Peirce, como no lo será para ninguno de los pragmatistas clásicos, un mero estado psicológico filosóficamente irrelevante sino más bien un concepto normativo que supone el cumplimiento de ciertos requisitos (Bernstein, 2010, p. 33). Aunque Peirce no explica esta idea de razones positivas, de duda real, como también la 
llama, contrapone la duda específica y concreta, basada en razones, a la duda producida por la máxima cartesiana. Como veremos más adelante, el concepto de duda jugará un rol fundamental en la concepción pragmatista del conocimiento y, transformado en la idea de situación problemática, llevará a Dewey a otorgarle el rol central de ejercer el control de la investigación.

Ahora bien, ¿por qué es esa duda cartesiana un autoengaño inútil? En opinión de Peirce, pretender dudar mediante una máxima general (p. ej. los sentidos engañan a veces) de algo respecto de lo cual no tenemos ninguna razón positiva para dudar (p. ej. de que estoy aquí, sentado frente a la computadora), es decir, dudar de lo que no dudamos es, en el mejor de los casos, un (auto) engaño, no una duda real sino una simulada. Así, puesto que la duda universal produce una duda ficticia o de papel, el cartesiano sólo queda satisfecho cuando recupera "formalmente todas aquellas creencias que se ha abandonado en el plano formal" (2012 p. 73). Precisamente porque el principio de la duda universal propone dudar de aquello de lo que en verdad no se duda, quien sigue tal principio sólo estará satisfecho al recuperar, no realmente porque nunca lo ha perdido sino "formalmente", aquello que (no) ha perdido. En otros términos, parece afirmar Peirce, desde un punto de vista metodológico la duda universal cartesiana, esa suerte de "escepticismo inicial” (2012 p. 72) es inútil: es sólo un rodeo para recuperar luego, y sobre bases pretendidamente más sólidas, todas las creencias puestas en tela de juicio. Podríamos objetar, sin embargo, que este rodeo es un mero rodeo, es decir, es efectivamente inútil, únicamente si las nuevas bases son sólo pretendidamente más sólidas. En efecto, si el rodeo sirviera, por ejemplo, para robustecer lo que es débil, no necesariamente resultaría inútil. Sin embargo, para Peirce, las bases o fundamentos sobre los que el cartesianismo y la filosofía moderna en general pretenden 
apoyar el conocimiento son efectivamente débiles. Ese rodeo propuesto por Descartes, que permitiría fundamentar el conocimiento sobre la base de la intuición del cogito, supone para Peirce, como veremos más adelante, en la sección 2.4 de este capítulo, una serie de tesis inadmisibles. El artículo "Cuestiones acerca de ciertas facultades atribuidas al hombre" (2012, pp. 55-71), anterior a este que comentamos, va dirigido precisamente a mostrar la debilidad de los fundamentos y los supuestos en los que se apoyan el cartesianismo y gran parte de la filosofía moderna.

Así, desde el punto de vista metafilosófico antes mencionado, tenemos entonces que la filosofía no debe dudar de cualquier cosa, sino de aquello respecto de lo cual encuentra razones positivas para dudar. En ese sentido nos exhorta Peirce: "no pretendamos dudar en filosofía de lo que no dudamos en nuestros corazones" (2012, p. 73). Pero hay otra cuestión que Peirce menciona en relación a la temática de la duda que resulta interesante. En su opinión, la filosofía debe "empezar con todos los prejuicios que realmente tenemos cuando iniciamos [su] estudio" (2012, p. 72). El punto de partida que reclama Peirce recuerda, parar usa una expresión de Heidegger, que el filósofo es también un ser-en-el-mundo: su punto de inicio no es un vacío abstracto que debe irse llenando de conceptos y tesis sin supuestos, sino las creencias y las dudas que lo constituyen; debe empezar con sus creencias, sus dudas $\mathrm{y}$ sus preocupaciones reales: son tales creencias, dudas $\mathrm{y}$ preocupaciones las que ofrecen apoyo y orientación a nuestras investigaciones. De otro modo, la duda, la pregunta filosófica, resulta vacía.

Esta problemática en torno de la duda sugiere también la adopción por parte de Peirce de una concepción antifundacionalista y falibilista del conocimiento. Al comentar el principio de la duda universal, Peirce afirma que, a diferencia del cartesianismo, el escolasticismo "nunca había cuestionado los fundamentos" (2012, p.72). Para tomar 
distancia también de ese escolasticismo y para que no se entienda que propone un dogmatismo que no permite dudar de los fundamentos, Peirce afirma lo siguiente: "es verdad que, a lo largo de sus estudios, una persona puede encontrar razones para dudar de lo que al principio creía; pero en ese caso duda porque tiene una razón positiva para ello" (p. 73). La duda, entonces, no queda descartada pero exige razones. Ahora bien, puesto que la duda no queda descartada sino que una persona (cualquiera) puede encontrar más tarde razones para dudar de lo que cree, queda sugerido el rechazo al principio cartesiano de la certeza y, con ello, a la posición cartesiana en torno al conocimiento probable. Puesto que (siempre) pueden aparecer razones para dudar, el objetivo del conocimiento no puede ser ya la ausencia absoluta de duda sino, en todo caso, la ausencia de razones positivas, de peso, para cuestionar una creencia. Si para Descartes la idea de conocimiento probable era algo así como una contradicción en los términos, la idea de ciencia infalible es, para los pragmatistas, lisa y llanamente, un sinsentido. El conocimiento es producto de la investigación y nada podría asegurar de antemano que la investigación futura no nos obligará a abandonar incluso las creencias que hoy consideramos mejor establecidas. Queda así sugerida la posición falibilista que Peirce y el resto de los pragmatistas defenderán en múltiples ocasiones y que se volverá, en el siglo $\mathrm{XX}$, un lugar común ampliamente compartido por los filósofos de la ciencia.

\subsection{Del individuo a la comunidad}

El segundo de los principios del cartesianismo presentados por Peirce es el que afirma, en oposición al principio medieval de autoridad, que la prueba de la certeza debe hallarse en la 
conciencia individual. Frente a ello, Peirce introduce en el ámbito de la epistemología dos conceptos que cobrarán una relevancia cada vez mayor con el paso de las décadas durante el siglo XX. Se trata de los conceptos, íntimamente conectados entre sí, de consenso o acuerdo y comunidad. El juicio individual, la certeza individual, nunca puede ser tenido por criterio de verdad, y tampoco como signo de la verdad. En las ciencias, dice Peirce, toda teoría está a prueba hasta que se alcance un acuerdo entre los hombres que la llevan a cabo. El conocimiento es, así, validado colectivamente y, una vez logrado ese acuerdo, dice Peirce, no importa si resulta absolutamente cierto, pues ya nadie duda de él. Por supuesto no quiere decir esto que el acuerdo no pueda cuestionarse: como dijimos antes, a lo largo de las investigaciones, pueden surgir dudas acerca de cualquier creencia. De este modo, si el conocimiento depende de la validación colectiva, entonces un hombre no puede, individualmente, esperar alcanzar ningún conocimiento, y por tanto ningún conocimiento filosófico, sino que todo lo que puede hacer es buscarlo comunitariamente. En palabras de Peirce: "como individuos, no podemos esperar razonablemente alcanzar la filosofía última que perseguimos; por tanto, sólo la podemos buscar por la comunidad de filósofos” (2012, p.73). Resulta interesante llamar la atención acerca de los verbos utilizados por Peirce en este pasaje por cuanto parecen sugerir, otra vez, una posición falibilista. En efecto, afirma que el individuo no puede esperar alcanzar (hope to attain) el conocimiento filosófico de modo individual sino que sólo puede buscarlo (seek) colectivamente. El individuo aislado no puede alcanzar el conocimiento puesto que el conocimiento requiere validación colectiva. Por esa razón no puede tener esperanza de lograrlo: no se puede tener esperanza en lograr algo que, por definición, no puede lograrse. Al afirmar que "sólo se puede buscarlo" colectivamente queda sugerida la idea de que tal vez nunca pueda alcanzarse, o al menos, de que nunca podremos estar seguros de haberlo alcanzado. Esta sugerencia no 
debe entenderse en la línea de un escepticismo que niega la posibilidad del conocimiento, sino más bien de un falibilismo que afirma que nunca podremos estar absolutamente seguros de que no tengamos de descartar, completar o modificar algunas de nuestras creencias.

Conviene señalar, con Bernstein, que en el texto que comentamos Peirce sienta las bases para el desarrollo de una "concepción intersubjetiva (social) de la investigación, el conocimiento, la comunicación y la lógica” (2012, p. 36). Así, en opinión de Bernstein, tenemos en este escrito temprano de Peirce una de las fuentes primarias del giro de la filosofía contemporánea hacia un modelo comunicativo, intersubjetivo y social en la concepción de la acción humana y la racionalidad; concepción que, por ejemplo Habermas (1999) y Apel (1985), entre otros, habrían de desarrollar. Cabe agregar que esta relevancia epistemológica del consenso y la comunidad de investigadores, en contraposición a aquella epistemología sin sujeto de finales del siglo XIX y comienzos del XX (Broncano y Pérez Ransanz, 2009), será ampliamente reconocida con el correr de las décadas en el siglo XX, volviéndose objeto de reflexión para filósofos, sociólogos e historiadores ${ }^{4}$. En efecto, casi cien años antes de que Thomas Kuhn publicara La estructura de las revoluciones cientificas, Peirce había introducido ya el consenso y la comunidad como elementos relevantes desde un punto de vista epistemológico sentando así las bases para el abandono del proyecto (positivista) de explicar la justificación del conocimiento apelando pura y exclusivamente a una observación considerada neutral y a un método entendido algorítmicamente.

\footnotetext{
${ }^{4}$ En el volumen de Broncano y Pérez Ransanz, Eds. 2009, puede encontrarse una amplia discusión sobre la cuestión del sujeto o los sujetos de la ciencia. La cuestión ha sido debatida también en el ámbito de la epistemología social analítica. (Schmitt, 1994).
} 
2. 3. La forma de la argumentación y el supuesto de lo inexplicable

El cuestionamiento de los últimos dos principios que Peirce atribuye al cartesianismo, a saber, que (3) la argumentación (filosófica) debe seguir un único hilo de inferencia y que (4) hay ciertas cosas que resultan inexplicables, apunta también a proponer una nueva forma de hacer filosofía. Por un lado, propone abandonar el carácter uniforme del estilo de argumentación moderno, que pretendía proceder de premisas supuestamente evidentes, mediante un encadenamiento de deducciones, hasta las consecuencias remotas. Por otro lado, apunta, en clara alusión a Kant, contra la pretensión de poner un límite a priori al conocimiento, asumiendo la inexplicabilidad de ciertas cosas.

Para explicar su rechazo al estilo uniforme de argumentación propone Peirce, contra la metáfora cartesiana del encadenamiento de deducciones, la metáfora de un cable compuesto por muchas fibras. Afirma, en efecto, que el razonamiento en filosofía "no debe formar una cadena” (2012, p. 73), puesto que no sería más fuerte que su eslabón más débil, sino "un cable cuyas fibras pueden ser muy delgadas, siempre y cuando sean suficientemente numerosas y están íntimamente conectadas” (ibídem). Esa metáfora de la cadena, omnipresente en las Reglas para la dirección del espíritu de Descartes, está ligada al ideal del conocimiento axiomático y junto con los conceptos de intuición y deducción forma la base del fundacionalismo cartesiano. La tercera de las Reglas propuestas por Descartes afirma que:

Acerca de los objetos propuestos se debe investigar, no lo que otros hayan pensado o lo que nosotros mismos sospechemos, sino lo que podamos intuir con claridad y evidencia o deducir con certeza, pues no se adquiere la ciencia de otro modo (2011, p. 7). 
Así, de acuerdo con Descartes, las únicas dos facultades u operaciones mediante las cuales obtenemos conocimiento son la intuición y la deducción. Por intuición entiende Descartes "una concepción no dudosa de la mente pura y atenta que nace de la sola luz de la razón" (2011, p. 9). Se trata de una aprehensión directa de algo que es simple y evidente y que por cuanto es claro y distinto no puede sino ser verdadero. La deducción es, en cambio, el paso necesario desde una verdad evidente a sus consecuencias, distinguiéndose de la intuición en que implica sucesión o movimiento (2011, p. 10) Así, el conocimiento, o bien es una intuición directa que no depende sino de la luz de la razón, o bien se sigue deductivamente de aquella, formando una cadena, cuyas uniones pueden intuirse de modo claro y distinto mediante "un movimiento continuo y no interrumpido del pensamiento que tiene una intuición clara de cada cosa. No de otro modo conocemos que el último eslabón de una cadena está en conexión con el primero" (2011, p. 9).

Este modelo axiomático, en el que cada paso de la deducción o bien es un axioma autoevidente o bien se sigue deductivamente de un paso anterior, es reemplazo por un modelo que se representa mediante la imagen de un cable compuesto por múltiples fibras que, aunque no resulten indestructibles en sí mismas, dan solidez al argumento. Peirce no exigirá ya para la filosofía premisas evidentes conocidas por intuición ni argumentos estrictamente deductivos, sino que pedirá "imitar los métodos de las ciencias exitosas, en el sentido de proceder sólo a partir de premisas tangibles que puedan someterse a escrutinio cuidadoso" (2012, p. 73). El punto de partida no es, entonces, la certeza sino lo "tangible", aquello que está, por así decirlo, al alcance de la mano y que por ello puede escudriñarse y resulta, así, bien establecido. El filósofo, como el detective, debe confiar más bien en la multiplicidad de indicios tangibles que en el carácter concluyente de cada uno de ellos. De 
este modo, queda superado ese ideal uniforme de certeza axiomática para abrazar un modelo de racionalidad más amplio que confía más en razones positivas que en certezas absolutas. Como veremos más adelante, este rechazo se fundamenta en la negación por parte de Peirce de esa capacidad de intuición directa que a Descartes le parecía tan intuitivamente cierta.

El último de los principios atribuidos por Peirce al cartesianismo, en el sentido amplio en que usa tal término, es el que afirma que hay cosas que no pueden explicarse "a menos que decir que 'Dios lo hace así' se considere como una explicación” (2012, p. 72). Mediante el rechazo de este principio, en nuestra opinión, Peirce está oponiéndose a cualquier intento de poner un límite a priori al conocimiento. Esto es, Peirce rechaza la idea de que hay algo que por definición no está abierto a la investigación. Esta cuestión está vinculada a su vez con su rechazo al supuesto de que existen cosas en sí incognoscibles y con su propia versión del realismo, que analizaremos en el capítulo siguiente. Lo importante aquí es reconocer que, desde un punto de vista metafilosófico, la afirmación de que algo es inexplicable o incognoscible no es para Peirce un supuesto admisible, puesto que afirmar que algo es inexplicable no es más que dejarlo sin explicación, y, en este sentido, abandonar la tarea antes de empezarla.

2.4. El rechazo de la intuición y la crítica al fundacionalismo

El artículo en el que Peirce desarrolla esta crítica al cartesianismo se llama, como mencionamos, "Algunas consecuencias de cuatro incapacidades" (CP 5.264-317). Las incapacidades a las que refiere el título son las siguientes: la incapacidad de introspección, la de intuición, la de pensar sin signos y la de concebir algo absolutamente incognoscible. 
La afirmación de tales incapacidades es, en realidad, el resultado de un artículo anterior cuyo título es "Cuestiones acerca de ciertas facultades atribuidas al hombre" (CP 5.213263). Como mencionamos antes, el rechazo de esta plataforma cartesiana encuentra su sustento, en última instancia, en el rechazo de la existencia de ciertas facultades que se atribuían al hombre. En esta sección reconstruiremos el rechazo peirceano a la capacidad de intuición e intentaremos extraer algunas consecuencias en relación a la concepción peirceana del conocimiento. Como veremos, en su argumentación Peirce va delineando una concepción del conocimiento que habría de completar en sus artículos pragmatistas de 1877.

El artículo que acabamos de mencionar está organizado en torno a siete secciones o “cuestiones". La última de estas cuestiones aborda directamente el problema de la intuición mientras que la negación de la capacidad de introspección, de pensar sin signos y de concebir algo incognoscible son, más bien, pasos de un argumento principal que pretende establecer el rechazo a la capacidad de intuición. La cuestión principal es si existe o no una “cognición no determinada por una cognición previa", fórmula con la que define Peirce, precisamente, el término "intuición” (2012, p. 55). Aclara, además, que tal como usa el término, una intuición es una premisa que no es ella misma una conclusión. Así, una intuición parece ser un punto de inicio absoluto del conocimiento, un comienzo no mediado, directamente aprehendido, y exclusivamente "determinado por algo fuera de la conciencia" (2012, p. 55). Este sentido otorgado al término cuadra así con la intuición tal como es entendida por Descartes, pero también con una intuición "sensible", es decir, con un conocimiento directamente aprehendido por medio de los sentidos sin la intervención de ningún tipo de interpretación e inferencia. 
Este carácter de inmediatez de la intuición, y el hecho de que esté pretendidamente determinada tan sólo por algo enteramente externo a la mente, es decir, por algo totalmente independiente del sujeto individual, confieren a la intuición una nota de infalibilidad: si la intuición es inmediata o directa, si sólo está determinada por la aprehensión de su objeto sin que intervenga nada más, entonces no parece haber allí posibilidad de error y es por tanto infalible. Así, el ataque de Peirce a la intuición constituye un verdadero ataque a un fundacionalismo infalibilista ${ }^{5}$, esto es, a la idea de que hay fundamentos últimos infalibles para nuestras pretensiones de saber. En opinión de Peirce no hay ninguna evidencia, en el sentido de razón de peso, que avale la existencia de tales intuiciones, es decir, de conocimiento inmediato, de primeros principios absolutos del conocimiento. Así, de acuerdo con Peirce todo conocimiento, incluso el llamado "conocimiento sensible", es inferencial: es el resultado de un proceso de razonamiento, que supone también el uso de signos, sin que haya un fundamento último o primero en que descanse todo el edificio. Al rechazar la intuición e insistir en el carácter necesariamente lingüístico del conocimiento, Peirce está realizando un giro en la teoría del conocimiento, quitando a éste del ámbito privado y subjetivo de la mente en el que parecían estar las impresiones y las ideas, para colocarlo en el ámbito intersubjetivo y público del lenguaje.

La argumentación desarrollada por Peirce en el artículo que comentamos es compleja y múltiple. No obstante, podemos señalar un argumento medular o básico que, en nuestra opinión, organiza todo el artículo. Podemos reconstruir tal argumento como sigue:

(1) Si tuviéramos una intuición no podríamos saber que es una intuición. En sus palabras, "no puede ser conocida ninguna cognición no determinada por una

\footnotetext{
5 Tomamos la expresión de Carnicer (2003, p. 97). Aunque la expresión "fundacionalismo infalibilista" pueda parecer redundante cabe recordar que Apel (1991) ha defendido la posición de que el fundacionalismo, al menos en la versión que él mismo propone, es compatible con un falibilismo limitado.
} 
cognición previa" (2012, p. 70). Dicho en otros términos, si algo fuera una intuición sería incognoscible.

(2) El supuesto de algo existente pero incognoscible es inadmisible (autocontradictorio).

Por lo tanto,

(3) No (tenemos ninguna razón para afirmar que) hay intuiciones.

La argumentación mediante la cual Peirce fundamenta la primera premisa es la más extensa e involucra las cuestiones $1,2,3$ y 4, mientras que la segunda premisa se desarrolla en las cuestiones 5 y 6.

La argumentación para defender la primera premisa puede entenderse como una respuesta a la siguiente pregunta: dada una cognición cualquiera ¿cómo podemos saber si es una intuición? La respuesta a esta pregunta supone una disyunción: o bien lo sabemos intuitivamente, de un modo directo o inmediato, o bien lo inferimos a partir de otra cognición. La estrategia de Peirce consiste en rechazar ambas posibilidades para establecer así que no puede conocerse si una cognición es una intuición.

En primer lugar tratará de establecer que no tenemos la capacidad de distinguir intuitivamente si algo es o no es una intuición. Lo primero que señala Peirce en relación con tal capacidad es que no hay ninguna prueba de que tengamos esa facultad, pese a lo cual, generalmente, se la da por supuesta por cuanto "parece que sentimos tenerla" (2012, p. 56). Ahora bien, ese sentimiento de que tenemos la facultad en cuestión no resuelve el asunto sino que incurre en una petición de principio: la apelación a tal parecer supone que podemos saber que ese sentimiento, por ejemplo, no es producto de la educación y de nuestros hábitos de inferencia, sino que es él mismo intuitivo. En otros términos, no podemos apelar a una intuición para demostrar nuestra capacidad intuitiva de reconocer intuiciones, puesto que tal apelación supone el asunto que se discute. 
Esta primera sospecha respecto de nuestra capacidad intuitiva de reconocer intuiciones es reforzada por Peirce apelando a una serie de argumentos de diversa índole. Así, por ejemplo, las interminables disputas entre los filósofos acerca de qué cogniciones son intuitivas sugiere, para Peirce, que no tenemos la capacidad intuitiva de saber si algo es una intuición, puesto que en caso de que la tuviéramos deberíamos reconocer intuiciones de modo infalible. Asimismo, el cambio a lo largo de la historia en aquello que los hombres consideran una premisa última o punto de partida evidente en sí mismo, es decir, una intuición, sugiere que lo que hoy nos parece intuitivo puede mostrarse mañana como determinado por otros supuestos. Todo ello indica, una vez más, que no tenemos una capacidad intuitiva (infalible) de saber si algo es una intuición, sino que más bien lo que se considera intuitivo varía histórica e incluso individualmente. ${ }^{6}$ Nótese además que este desacuerdo se explica mejor si suponemos que efectivamente no tenemos la capacidad intuitiva de detectar intuiciones. Para reforzar su posición, Peirce recurre a otros argumentos que refieren más bien a lo que podemos llamar intuiciones sensibles. Por ejemplo, la dificultad que muchas veces experimentamos en distinguir entre lo que hemos visto y lo que hemos inferido, sugiere que no tenemos una capacidad intuitiva (infalible) de reconocer si algo es una intuición e incluso, tal dificultad se explica mejor, una vez más y de acuerdo con nuestro autor, si suponemos que no la tenemos. Luego de mencionar otros ejemplos similares, Peirce concluye que "tenemos, entonces, una variedad de hechos, todos los cuales se explican muy fácilmente al suponer que no tenemos ninguna facultad intuitiva de distinguir entre cogniciones intuitivas y mediatas" (2012, p. 62).

\footnotetext{
${ }^{6}$ Puede leerse esta argumentación de Peirce como una anticipación de la idea de Lewis de a priori histórico. (Duarn, y Di Gregori, 2012, y Rosenthal, 1976)
} 
Como resulta evidente, esta argumentación no es concluyente. En efecto, está lejos de formar una cadena de deducciones que parta de principios evidentes. Sin embargo, sobre la base de los ejemplos y los argumentos ofrecidos por Peirce parece razonable suponer que efectivamente no tenemos la capacidad en cuestión. En opinión de Peirce, si analizamos la naturaleza de su prueba, veremos que contiene "razones muy fuertes para no creer en la existencia de esa facultad" (2012, p. 62). Desde su punto de vista, ninguno de los ejemplos presentados requiere que supongamos la existencia de esa facultad meta-intuitiva, por así decirlo. Además, si bien es cierto que podrían explicarse mediante otras hipótesis, al adoptar la hipótesis de que no hay una facultad intuitiva de reconocer intuiciones, todos esos hechos se vuelven convergentes y se apoyan unos a otros. Aún más, afirma Peirce, estas razones se volverán más fuertes "cuando las consecuencias de [rechazar la facultad intuitiva de reconocer intuiciones] se desarrollen en forma más completa" (2012, p. 62). Esta reflexión de Peirce acerca de sus propios argumentos es una muestra cabal de lo que hemos llamado el componente metafilosófico del pragmatismo: más que buscar argumentos definitivos e infalibles hemos de buscar buenas razones, razones convincentes, para sostener las hipótesis filosóficas; además, al menos en parte, la corroboración de una hipótesis filosófica, tal como ocurre con cualquier hipótesis, pasa por el análisis de sus consecuencias. También en filosofía, más que buscar fundamentos últimos e indiscutibles para nuestros juicios debemos tratarlos como hipótesis plausibles, basadas en buenas razones, que deben ser evaluadas en función de sus consecuencias. ${ }^{7}$

Una vez rechazada la capacidad de distinguir intuitivamente que algo es una intuición y para allanar el camino hacia su rechazo de la misma, Peirce aborda, en las

\footnotetext{
${ }^{7}$ Como veremos en el capítulo 3, esta posición será asumida por Dewey, por ejemplo y de modo claro, respecto de su tesis naturalista acerca de la continuidad.
} 
cuestiones 2, 3 y 4, el asunto de la autoconciencia y la introspección. La autoconciencia y la capacidad de introspección parecen ser, desde un punto de vista cartesiano, los apoyos fundamentales a la tesis de la existencia de intuiciones. En efecto, la conciencia de que yo existo parece ser la intuición por antonomasia y la capacidad de introspección la que permite conocer de manera inmediata, esto es, intuir, los estados subjetivos.

Hasta ahora, Peirce ha establecido que no tenemos una capacidad intuitiva de reconocer intuiciones. La pregunta que formula ahora es si el fenómeno de la autoconciencia, el hecho de que yo sepa que yo existo (2012, p. 62), es entonces una prueba (no intuitiva) de la existencia de intuiciones. En efecto, si la única manera de explicar la autoconciencia fuera la existencia de una capacidad de intuición, y dado que de hecho hay autoconciencia, sería razonable aceptar la hipótesis de que sí tenemos una capacidad de intuición. Sin embargo, por un lado, argumenta Peirce, otra vez apelando a diferentes fibras argumentativas, que hay fenómenos como la aparición tardía de la autoconciencia en los niños en relación con otros conocimientos que sugieren que no tenemos esa facultad y, por otro lado, ofrece una explicación de la autoconciencia que no necesita suponer una facultad de intuición. En sus palabras:

(...) a la edad en la que sabemos que los niños son autoconscientes, sabemos que se han dado cuenta de la ignorancia y el error; y sabemos que a esa edad poseen poderes de entendimiento suficientes que les permiten inferir su propia existencia a partir de la ignorancia y el error. Así encontramos que facultades conocidas, que actúan bajo condiciones que se sabe que existen, se elevarían a la autoconsciencia (2012, p. 64).

Como Peirce reconoce otra vez, este argumento no es concluyente. Pero resulta, en su opinión, mucho mejor fundado que aquel que postula la existencia de una facultad de 
intuición para explicar un hecho que puede explicarse de otra manera apelando a capacidades que, aunque no sepamos que se han usado de la manera sugerida, tenemos, al menos, evidencia clara de que existen. En otros términos, no sabemos si los niños usan su capacidad de reconocer sus errores y su capacidad de razonamiento para inferir su propia existencia a partir de la ignorancia y el error, pero al menos no estamos postulando ninguna facultad desconocida, sino que, apelando a las facultades que sabemos que los niños tienen, podemos suponer una manera en que pueden hacerse consientes de su propia existencia. En otros términos, y no es más que esto lo que está tratando de establecer Peirce, la postulación de una capacidad de intuición no es exigida por el fenómeno de la autoconciencia.

La argumentación en contra de la capacidad de introspección va en un sentido próximo a la que acabamos de exponer. El argumento de Peirce es que, dada la ausencia de evidencia clara a favor de la existencia de tal capacidad, sólo podemos postular que existe si su postulación resulta necesaria para explicar los hechos conocidos. En opinión de Peirce ello no es así tampoco en el caso de la introspección. Consecuentemente, formula explicaciones que pretenden mostrar que el conocimiento de ciertos hechos considerados internos (sensaciones, emociones y actos de voluntad), puede explicarse no como el resultado de una facultad de introspección sino como una inferencia a partir de hechos externos. Como menciona Carnicer (2003, p. 119) siguiendo a Hookway (1985, p. 27), la argumentación de Peirce en este punto es muy débil si se la considera un rechazo absoluto de la capacidad de introspección. Sin embargo, en opinión de Peirce, puede aceptarse la hipótesis de que todo nuestro conocimiento de hechos internos es inferido a partir de nuestro conocimiento de hechos externos. Recordemos una vez más que se trata de una hipótesis que deberá aun ser corroborada analizando sus consecuencias. 
A partir de ésta última hipótesis, es decir, de la negación de la capacidad de introspección, y dando por descontado que todo conocimiento acerca de hechos externos se da en signos, esto es, se formula lingüísticamente, Peirce concluye que todo pensamiento se da en forma de signos. Su argumentación aquí resulta ciertamente un tanto débil y ello tanto más cuanto que una de las premisas de este argumento, la que niega la capacidad de introspección, cargaba ya con una fundamentación insuficiente. Sin embargo esta tesis, de carácter hipotético -recordemos una vez más- constituye un aspecto importante del pensamiento de Peirce, y ha llevado a Apel $(1996,1985)$ a afirmar que el pragmatista ha realizado una transformación semiótica del concepto de conocimiento. En opinión de Apel (1985, p. 149), si se compara la Crítica de la razón pura de Kant, leída como una teoría de la ciencia, con la filosofía de la ciencia del siglo $\mathrm{XX}$, la diferencia más profunda que se aprecia es una sustitución del análisis de la conciencia por un análisis del lenguaje. Esta sustitución, ligada por cierto al así llamado giro lingüístico de la filosofía del siglo $\mathrm{XX}$, es operada, en el caso de Peirce, mediante esta hipótesis acerca del carácter necesariamente lingüístico, formulado en signos, de todo pensamiento y, a fortiori, de todo conocimiento.

Esta hipótesis de que todo conocimiento se da en signos, junto con la hipótesis de que todo conocimiento es inferido a partir de hechos externos, permitirá a su vez deducir el carácter a-significativo del concepto de lo incognoscible. Si todo nuestro conocimiento se obtiene a partir de juicios acerca de hechos externos, es decir, de juicios de la experiencia, y dado que en la experiencia no se da, por definición, nada incognoscible, no puede concebirse nada absolutamente incognoscible. Por otro lado, dado que el significado de un signo, argumenta Peirce, es la concepción que transmite (2012, p. 68), un signo que refiera a lo absolutamente incognoscible carece de significado. Afirma Peirce: 
Más allá de cualquier cognición, existe una realidad desconocida pero cognoscible; pero más allá de toda cognición posible sólo existe lo autocontradictorio. En resumen, la cognoscibilidad (en su sentido más amplio) y el ser no son meramente iguales metafísicamente, sino que son términos sinónimos (2012, p. 69).

Este pasaje contiene lo que Apel (1996, p. 41 y ss.) ha caracterizado como un realismo crítico del sentido, esto es, la afirmación de que el único significado que puede tener el término real debe remitir a algo cognoscible, tal vez conocido o quizás desconocido, pero siempre cognoscible. Esta posición realista defendida por Peirce será analizada con mayor detalle en el capítulo siguiente.

Pero volvamos ahora al problema de la intuición. Hasta ahora, Peirce ha establecido que aún cuando fuera cierto que tenemos intuiciones, no podemos afirmar que tengamos una capacidad intuitiva que nos permita saber si algo es una intuición. Si ello es así, la única forma de saber que algo es una cognición sería infiriéndolo a partir de hechos externos, puesto que todo conocimiento parte de hechos externos. Ello implicaría, para Peirce, ofrecer una explicación de esa supuesta intuición. Implicaría decir qué es lo que la determina, lo que supone entonces que no es una intuición, es decir, un conocimiento directo, no mediado por otro conocimiento. Por otro lado, podríamos pensar que una intuición no resulta de, o no está determinada por, otra cognición, sino por algo absolutamente externo, por un objeto trascendental. Pero ese objeto externo o bien es presentado en una cognición, en cuyo caso no hacemos más que ofrecer la cognición que determina mi cognición, o bien lo tratamos como algo absolutamente incognoscible, lo que ha sido ya vedado. Así, la conclusión es que si algo fuera una intuición sería incognoscible, 
pero dado que el supuesto de algo incognoscible no es aceptable, se sigue que no podemos afirmar que tengamos intuiciones.

Nuevamente, como han señalado algunos intérpretes y como Peirce mismo reconoce, su argumentación no es concluyente. En efecto, en el artículo en el que desarrolla las consecuencias de las incapacidades sugeridas afirma que "no puede considerarse que estas proposiciones hayan quedado establecidas con toda seguridad; y, para someterlas a una prueba más, se propone ahora desarrollar sus consecuencias” (2012, p. 74). Puesto que las consecuencias que analiza Peirce son consecuencias respecto de discusiones más específicas no las abordaremos aquí.

\section{Conclusiones: hacia una nueva forma de hacer filosofía}

En la introducción de este capítulo hemos presentado la caracterización del programa pragmatista propuesta por Putnam. Según tal caracterización el pragmatismo se propuso desarrollar un falibilismo antiescéptico, que otorga un carácter central a la práctica y que propone superar la dicotomía entre hechos y valores. Como hemos visto, Peirce desarrolló ya en estos artículos tempranos una concepción del conocimiento falibilista y antiescéptica en el sentido señalado por Putnam, por cuanto rechaza la pretensión de certeza absoluta pero sin renunciar a la posibilidad de un conocimiento legítimo. Hemos visto, también, que Peirce realiza una crítica a lo que entiende como la concepción moderna del conocimiento en general y del conocimiento filosófico en particular. Esta crítica supone, como hemos mostrado, un cambio hacia una concepción del conocimiento que podemos caracterizar, además, como antifundacionalista e intersubjetiva o social. Por otro lado, a partir de su crítica al concepto de cosa en sí (incognoscible), Peirce formula lo que, siguiendo a Apel, 
hemos llamado un realismo crítico del sentido, que en conexión con la tesis de la convergencia ha generado una importante controversia. Esta concepción del conocimiento tomará, en los artículos de 1878 que estudiaremos en el capítulo siguiente, una forma más explícita y mejor articulada. En efecto, todos estos componentes de la concepción pragmatista del conocimiento pueden ser integrados y comprendidos en toda su anchura si tenemos en cuenta el profundo cambio en la concepción de la relación entre conocimiento y acción que Peirce comenzará a delinear en dichos artículos, tomando como punto de partida una nueva definición de la creencia.

Para finalizar, sin embargo, queremos llamar la atención nuevamente acerca de los cambios que Peirce realiza o al menos sugiere en relación con la filosofía misma y que resultarán característicos de la filosofía tal como será entendida por Dewey y también por James. Podemos afirmar que tales cambios afectan tanto al estilo que adoptará la argumentación filosófica como al tipo de problemas que se investigará. En efecto, frente a lo que entiende como el espíritu del cartesianismo, Peirce propone que la filosofía tome como ejemplo a la ciencia y comprenda sus afirmaciones como hipótesis que, tal como ocurre en la ciencia, nunca pierden su carácter hipotético. Los artículos que hemos analizado contienen, tomados en conjunto, una clara ejemplificación de lo que significa considerar a las tesis filosóficas como verdaderas hipótesis. Esta concepción rompe con el ideal que, desde Platón, ha dominado gran parte de la tradición filosófica, a saber, el ideal de la filosofía como saber sin supuestos. Este ideal está ligado, a su vez, al modelo axiomático del conocimiento y al intento de encontrar un fundamento (auto) evidente que sirva de apoyo a la filosofía y en última instancia a todo el conocimiento. Este 
fundacionalismo ${ }^{8}$ ha implicado, muchas veces, la comprensión de la actividad filosófica como una búsqueda de condiciones antecedentes de posibilidad de ciertos hechos o creencias, cuya caracterización como necesarias y/o a priori las convertían en fundamentos evidentes. Así, comprender a la filosofía como una empresa hipotética implica que, en última instancia, una tesis filosófica se valida, no apelando a los primeros principios de los que se supone que se sigue ni reconociendo su carácter necesario, sino en función del análisis de sus consecuencias. Este es uno de los aspectos del componente metafilosófico del pragmatismo que ha sido para los propios pragmatistas la nota fundamental de su filosofía. Así, por ejemplo, en opinión de James, el pragmatismo era un cierto talante intelectual que podía definirse como "la actitud de apartar la vista de las cosas primeras, los principios, las 'categorías', las pretendidas necesidades y mirar hacia las últimas cosas, los frutos, las consecuencias, los hechos" (citado por Dewey en mw.4.98). Esta manera de presentar al pragmatismo como un giro desde las condiciones antecedentes hacia las últimas, hacia las consecuencias efectivas, lo mismo que la utilización entre comillas de la expresión 'categorías' por parte de James en la cita anterior, sugiere que la forma pragmatista de investigar se presenta como una forma explícitamente opuesta, también, al tipo de argumentación trascendental propuesto por Kant. En efecto, como señala Isabel Cabrera (1999), la argumentación trascendental, usualmente utilizada contra escépticos y pragmáticos, "busca concluir condiciones trascendentales, es decir, condiciones a priori de la posibilidad de un cierto tipo de experiencia, de conocimiento o de lenguaje” (p. 7). Como ha sido reconocido, los argumentos trascendentales plantean una serie de cuestiones difíciles que no abordaremos aquí. ${ }^{9}$

\footnotetext{
${ }^{8}$ Sobre el concepto de fundacionalismo cfr. Di Gregori (1995) y Bengoa Ruiz de Azúa (1997)

${ }^{9}$ Para una presentación de tales críticas véase Cabrera (1999) y Crelier (2010)
} 
Ahora bien, cabe recordar que esas consecuencias de las cuales dependería la validación de una hipótesis filosófica, son entendidas como consecuencias prácticas, lo que explica aquella centralidad que, como señalaba Putnam, concedieron los pragmatistas a la práctica. Como tendremos oportunidad de analizar con mayor detalle, la "práctica" remite aquí a la interacción del organismo humano en su medio. Esta interacción, aun cuando pueda estar mediada por abstracciones tales como teorías e incluso resultados matemáticos, es decir por el conocimiento, es una interacción siempre local y situada, atravesada por “el conflicto, la necesidad, la carencia, el deseo, el esfuerzo, la pérdida, la satisfacción" (Dewey, mw.4.125). Todas estas cosas serán asociadas con la actividad de resolución de problemas, entendida precisamente como la supresión del conflicto y la carencia implicados en la duda- por la estabilidad -implicada por la creencia- mediante la investigación. Acaso uno de los aportes más importantes del pragmatismo, que reconfigura la relación entre conocimiento y acción, sea vincular la función del conocimiento (en el contexto de la experiencia humana) y su estructura lógica (juicios, proposiciones, inferencias y razonamiento) con la práctica en el sentido antes mencionado; vínculo que será sellado, como veremos, mediante la máxima pragmática.

Ahora bien, esta relevancia otorgada a la práctica produce un giro en el tipo de problemas que se espera que la filosofía aborde. Si el conocimiento es el intento de resolver un problema su legitimidad se establece por el éxito en tal resolución, su alcance se reduce estrictamente al problema resuelto y no es ni universal ni necesario. ${ }^{10}$ Como consecuencia

\footnotetext{
10 Por supuesto que los logros de una investigación, y entre ellos la formulación de ciertos hábitos de inferencia, pueden extrapolarse a otros problemas y otras áreas. Pero tal extrapolación no debe olvidar que los resultados de la investigación no pierden nunca su carácter hipotético, y tanto más cuanto pretendemos usarlos en el contexto de nuevos problemas.
} 
de ello, esa nueva lógica de argumentación promovida por el pragmatismo, en palabras de Dewey,

proscribe, orilla, ignora -como quieran decirlo- un cierto tipo de problemas y lo sustituye por otro. La filosofía renuncia a inquirir por los orígenes absolutos y las finalidades absolutas para así poder explorar valores específicos y las condiciones específicas que los generan (2000 p. 56 / mw.4.10).

Nos encontramos aquí, tal vez, con una de esas consecuencias sacadas por Dewey del programa de investigación pragmatista que acaso incomodaron a Peirce.

Así, desde este punto de vista hay ciertos problemas, casualmente muchos de los que la argumentación trascendental aborda, que son, más bien, pseudo-problemas. En efecto, los argumentos trascendentales son muchas veces utilizados para demostrar o justificar afirmaciones que, desde el punto de vista del pragmatismo, no tiene sentido pretender justificar o fundamentar. Cuestiones como mi propia existencia o la existencia del mundo no parecen representar verdaderos problemas: de acuerdo con el carácter antiescéptico del pragmatismo se requieren razones para dudar y no resulta claro que las tengamos respecto de la propia existencia o la del mundo exterior. Esto no implica que no haya efectivamente inconvenientes en el contexto de la filosofía, o mejor de ciertas filosofías, para dar cuenta de mi propia existencia o de la existencia del mundo exterior. Pero ello no se soluciona con un argumento cuya conclusión sea que existo o que existe el mundo exterior, sino que debería llevarnos a revisar los supuestos filosóficos que me han llevado a dudar de algo sobre lo que parece que no tenemos ninguna razón para dudar. En este sentido, la forma pragmatista de argumentar en filosofía apunta a cuestionar, como señalaba Dewey, sobre la base de su contrastación con la práctica, "ese cuerpo de 
aversiones y preferencias intelectuales, mitad conscientes, mitad instintivas, que a fin de cuenta determinan nuestras empresas intelectuales más deliberadas” (p. 54). Podemos resumir esta cuestión señalando que si la argumentación trascendental va dirigida contra el escéptico, y si por su parte el pragmatista es anti-escéptico, lejos de ser útil también contra el pragmatista como afirma Cabrera (1999), la argumentación trascendental parece condenada a correr la misma suerte que el escepticismo mismo, por cuanto parecen suscribir a ciertos supuestos comunes, por ejemplo, el supuesto de que nuestra incapacidad para explicar la existencia de un fenómeno pone en duda su existencia misma.

Para finalizar, recordemos que este cambio que el pragmatismo proponía frente a la tradición filosófica tenía, al menos en opinión de Dewey, un aspecto ético y político insoslayable. En virtud de esa nueva filosofía que promovía,

El interés pasa de (...) la meta de un bien último, a los incrementos directos en justicia y felicidad que se podrían lograr con una administración inteligente de las condiciones existentes, y que la falta de cuidado o la estupidez presente quizá destruyan o dejen escapar (2000 pp. 57-58, / mw.4.11). 
2

\section{Hacia una nueva concepción del conocimiento: la lógica pragmatista de la investigación.}

\section{Introducción}

En la introducción de su libro Truth, Rationality and Pragmatism. Themes from Peirce (2002), el estudioso de la obra de Peirce, Christopher Hookway, comienza llamando la atención acerca de la multiplicidad de temas y problemas abordados por Peirce a lo largo de su obra. Frente a la pregunta acerca de la unidad en tal diversidad, Hookway afirma que "la mejor manera de encontrar unidad en este amplio rango de actividades filosóficas es respetar la auto-descripción preferida de Peirce: él era un 'lógico"” (p. 1). Como Hookway señala rápidamente, el término "lógica" tiene, en este contexto, un significado bastante más amplio que aquel que le ha sido conferido en el contexto de la así llamada lógica formal. En sus palabras, 
Sus contribuciones a la lógica formal fueron extensas y seminales, siendo su importancia sólo ahora apreciada completamente (...) Sin embargo, en el uso de Peirce, "lógica" también abarca mucho de lo que los filósofos contemporáneos incluirían en epistemología y filosofía del lenguaje. Él tuvo un profundo interés en los estándares normativos, reglas y métodos que nos guían cuando llevamos a cabo investigaciones, cuando tratamos de resolver problemas y arribamos a creencias establecidas (p. 1).

Aunque tendremos oportunidad para reflexionar acerca de la implícita cesión a los lógicos formales de la autoridad para determinar el verdadero alcance de la lógica, la caracterización de Hookway del interés profundo de Peirce parece describir de modo fiel el contenido de los artículos que analizaremos en este capítulo y que han sido considerados, por otro lado, como verdaderas actas de nacimiento del pragmatismo. En efecto esta caracterización, que confiere a las preocupaciones lógicas un lugar destacado en la obra de Peirce, se condice con el hecho de que los dos artículos de Peirce más leídos y discutidos toman como punto de partida una cuestión lógica. Dichos artículos, a saber, "La fijación de la creencia" y "Cómo esclarecer nuestras ideas", contienen, efectivamente, reflexiones acerca de lo que podríamos llamar una lógica de la investigación ${ }^{1}$. Ambos comienzan con reflexiones acerca del estado y el valor de los estudios lógicos y tienen un carácter metodológico: contienen, en palabras del propio Peirce, "la formulación más temprana de un método de análisis lógico al que había tenido el hábito de aludir como [mi] pragmatismo" (citado por Houser y Kloesel en Peirce, 2012, p. 157). Este capítulo está destinado a reconstruir la concepción del conocimiento y la investigación delineada por Peirce en dichos artículos. Como consecuencia de ello quedará delineado el programa de

\footnotetext{
${ }^{1}$ Estamos en este punto de acuerdo con Colapietro (2002, p. 50) quien señala contra Sleeper (2001, p. 49), que Peirce, al igual que Dewey, entendió a la lógica como una lógica de la investigación.
} 
investigación que Peirce había bosquejado en los artículos que analizamos en el capítulo anterior y que, en nuestra opinión, Dewey habría de desarrollar en su propia dirección.

Antes de comenzar con tal análisis conviene anticipar una posible objeción a la empresa que nos proponemos. En efecto, mientras pretendemos que la lógica de la investigación de Peirce anticipa algunos aspectos centrales de la lógica de la investigación de Dewey, es bien conocida la dureza con que Peirce criticó lo que en su opinión fue el intento deweyano de sustituir esa ciencia normativa que debía ser la lógica por una "historia natural del pensamiento" (cfr. Peirce, CP. 8. 188-191 y CP. 8.239-245) ${ }^{2}$. Larry Hickman, en un artículo titulado “Why Peirce Didn’t Like Dewey’s Logic” (1986), explica la dureza de la crítica resaltando las importantes diferencias entre Peirce y Dewey y señalando que, a diferencia de este último, el padre del pragmatismo fue un pensador marcadamente apriorista y teoricista e incluso que la antipatía de Peirce hacia la lógica de Dewey mostraría el carácter vacilante del compromiso de Peirce mismo con el pragmatismo. En un sentido similar, aunque acaso menos duro con Peirce, Esteban Cloquell (2008, p. 186 n15) sostiene que la crítica se debe a que el naturalismo normativo sostenido por Dewey no era en absoluto compartido por Peirce.

Por su parte, Colapietro (2002) sostiene que las diferencias entre Dewey y Peirce no son tan grandes como pretende Hickman e incluso ofrece algunas explicaciones de índole psicológica para explicar el rechazo, que cree desmedido, de Peirce a Dewey en este respecto. En este sentido, sugiere que debería escribirse un artículo, complementario al de Hickman, que se titule "Por qué a Peirce le debería haber gustado la lógica de Dewey más

\footnotetext{
${ }^{2}$ Los términos de la crítica son en verdad duros en las cartas de Peirce a Dewey publicadas en CP. 8. $239-245$. No hay una respuesta conocida a estas cartas y, como recuerda Colapietro (2002), no hay evidencia de que tales cartas hayan sido enviadas a Dewey. En la reseña de los Studies in logical Theory de Dewey (1903) publicados en CP.8. 188-191, los términos son más amigables, si bien Peirce formula sus dudas respecto de que la historia natural del pensamiento que a sus ojos proponía Dewey pudiera llamarse lógica.
} 
de lo que le gustó" (p. 48). Como Colapietro señala, la discusión aquí es marcadamente meta-lógica, y en particular se trata de una discusión acerca de cómo debe entenderse la lógica en el contexto de una posición naturalista que rechaza cualquier dicotomía absoluta entre la naturaleza y un mundo de conceptos e ideas. En otros términos, se trata de dilucidar si puede darse cuenta del carácter normativo de los principios lógicos en el contexto de una filosofía decididamente naturalizada. No nos detendremos a analizar de manera exhaustiva la concepción peircena de la lógica a efectos de establecer su relación con la de Dewey. Más bien adoptaremos una posición que resultará próxima a la de Colapietro e intentaremos mostrar que en los artículos seminales de Peirce sobre el pragmatismo pueden encontrarse algunas de las tesis lógicas que Dewey desarrollará a lo largo de su obra. La cuestión de si Peirce traicionó luego esas ideas, de si su adhesión al pragmatismo fue vacilante como pretendió Hickman, o si más bien se mantuvo en la misma línea, no será analizada aquí. Nos bastará en cambio con mostrar, siguiendo en ello al propio Dewey, que la concepción de la lógica de este último puede de hecho entenderse al menos como un desarrollo posible a partir de algunas ideas formuladas por Peirce en los artículos que analizaremos a continuación.

Esta concepción de la lógica como una lógica de la investigación, que desarrollaremos en la sección siguiente (2), se complementa con una concepción de la investigación como una forma de acción cuya finalidad es el establecimiento de la creencia entendida como una regla o hábito para la acción y que será desarrollada en la sección (3) Las tesis supuestas en esta concepción permiten, a su turno, delinear una concepción del conocimiento falibilista, realista y meliorista que abordaremos en la cuarta sección (4) de este capítulo. Todo este programa filosófico, unido a la concepción peirceana de la filosofía 
reconstruida en el capítulo anterior, constituyen la plataforma de la concepción pragmatista del conocimiento que Dewey desarrollará a lo largo de su obra, reconstruyendo, ampliando y extrayendo nuevas consecuencias a partir de estas ideas del padre del pragmatismo.

\section{Lógica e investigación}

El primero de los artículos se titula, como dijimos, "La fijación de la creencia". Su punto de partida es el establecimiento de una relación directa entre la lógica, como estudio de la forma en que se extraen inferencias, y la historia de la ciencia. En opinión de Peirce, esta última podría pensarse como una historia acerca de la práctica del "poder de hacer inferencias" (cfr. 2012, p. 157) y más aún "cada paso principal de la ciencia ha sido una lección de lógica” (2012, p. 158). Esta manera de comprender la lógica supone ya una distancia respecto de la concepción formalista de la lógica. En efecto, esta ha sido comprendida desde finales del siglo XIX como una disciplina análoga a la matemática, encargada del estudio de una entidad abstracta, a saber, "la relación de consecuencia que se da entre las premisas y la conclusión de un argumento correcto" (Mates, 1979, p. 16). Si la lógica se entiende como el estudio de ciertas relaciones lógicas (p. ej. implicación, equivalencia, contradicción, etc.) concebidas como algo perteneciente a un cierto universo de entidades abstractas, entonces, la idea de una historia de la lógica debe restringirse. En ese marco el razonamiento es comprendido como un producto, como una realidad ya hecha, que puede y debe ser estudiado por el lógico sin tener en cuenta en absoluto el contexto en el que ocurre ni el proceso del que resulta. Así, la historia de la lógica podría ser, tan sólo, la historia del descubrimiento progresivo de las propiedades o relaciones lógicas de las proposiciones. Pero la idea de que la historia misma de la ciencia deba correr paralela a la 
historia de la lógica sólo tiene sentido si se piensa un vínculo más estrecho entre los principios lógicos y el modo en que los hombreas razonan cuando investigan. Como ha señalado S. Toulmin, (2007, p. 23) una concepción matemática de la lógica parece conllevar como consecuencia una desvinculación con la práctica real del razonamiento en la mayoría de los campos de argumentación, quedando la cuestión de su uso en procesos reales de razonamiento reservado, en el mejor de los casos, a algo así como una "lógica aplicada" epistemológicamente devaluada.

Sin embargo, la concepción peirceana de la lógica, al menos la contenida en los artículos que discutimos, toma un sendero diferente. En efecto, Peirce afirma que El objeto del razonamiento es el de descubrir, a partir de la consideración de lo que ya sabemos, algo más que no sabemos. Consecuentemente, el razonamiento es bueno si da una conclusión verdadera a partir de premisas verdaderas, y no de otra manera. Por lo tanto, la cuestión de su validez es puramente una cuestión de hecho, y no de pensamiento. Siendo A las premisas y B la conclusión, la pregunta es si estos hechos están realmente relacionados de modo que si A, entonces B. (2012, p. 159)

Así, el razonamiento es entendido por Peirce como el establecimiento de una conclusión que llega a conocerse a partir de premisas ya conocidas. Cabe destacar que esta definición de razonamiento es similar a la definición de razonamiento (syllogismós) de Aristóteles. En efecto, según el estagirita un razonamiento es "un discurso (lógos) en el que, sentadas ciertas cosas, necesariamente se da a la vez, algo distinto de lo establecido" (Top I, 1, 100a 28, y de manera muy similar, $A n P r$ I, 1, 24b19). No obstante, resulta evidente que el elemento de necesidad presente en la definición aristotélica se pierde en la definición peirceana, lo que abre las puertas a un tratamiento unificado de formas de razonamiento 
que no se ajustan a la necesidad deductiva y que la lógica formal mantuvo apartadas por mucho tiempo. ${ }^{3}$

En esa misma dirección, el "paso" de las premisas a la conclusión, en la concepción peirceana, no debe entenderse como una cuestión meramente formal o de pensamiento, sino que su legitimidad depende de una "cuestión de hecho.” Así, para saber si el razonamiento es correcto, debemos saber si es cierto que las premisas permiten, de hecho, afirmar la conclusión. Esto es, debe determinarse si el enunciado condicional que afirma que si lo que enuncian las premisas es cierto, entonces, también es cierto aquello que enuncia la conclusión, es verdadero o no lo es. Como puede verse, la caracterización del razonamiento que ofrece Peirce guarda algunos puntos de coincidencia con la caracterización propuesta por Toulmin en su conocido libro Los usos de la Argumentación (2007). Según Toulmin, un razonamiento o argumento es el paso de unas premisas, a las que llama "datos" o "fundamentos", a una conclusión o "pretensión" (claim). Dicho paso debe estar convalidado por lo que Toulmin llama "garantía" (warrant), lo que ha sido entendido como un principio material de inferencia (Pinto, 2006), y cuyo vínculo con los topoi de Aristóteles ha sido también señalado (Bird, 1961). En esta línea, entonces, se inscribe la concepción del razonamiento de Peirce, quien entiende a tales principios de inferencia como hábitos. Así, afirma que "una inferencia se considera válida o no (...) en la medida en que el hábito que la determina sea tal que en general produzca conclusiones verdaderas o

\footnotetext{
${ }^{3}$ Cabe recordar que el estudio del razonamiento en Aristóteles no se reduce al estudio del tipo de razonamiento deductivo o demostrativo estudiado en Analíticos, esto es, al así llamado silogismo categórico. Antes bien su dialéctica y su retórica, marcadamente relegadas por la tradición lógica, han abordado otros tipos de argumentos con una perspectiva mucho menos formal. Sin embargo, lo cierto es que el estudio del razonamiento deductivo ha sido el objetivo central de la lógica formal, al menos hasta mediados del siglo XX. A partir de entonces, como lo muestra el caso del estudio del razonamiento no monótono, la lógica formal misma comenzó a abordar otras formas de razonamiento.
} 
no.” (2012, p. 160). Estos hábitos de inferencia pueden formularse en proposiciones dando lugar a lo que Peirce llama principio directriz de la inferencia. ${ }^{4}$

Nótese que, como señala Toulmin (2007), estos principios directrices, las garantías, han sido tratados por la tradición como una premisa más, quedando su contenido, es decir la relación que establece entre los fundamentos y las conclusiones, fuera del alcance de la lógica entendida como una disciplina meramente formal. En cambio, si estos principios materiales de la inferencia son asunto propio de la lógica, la relación entre el estudio de los contextos en donde esos principios son utilizados y la lógica misma se vuelve más estrecha. Así, queda formulada una tesis que Dewey habría de desarrollar, a saber, la que afirma que hay una estrecha vinculación entre la lógica, entendida como investigación acerca de los principios de inferencia, y el estudio de la investigación científica y su historia. Si la lógica es el estudio de los hábitos de inferencia, y si dichos hábitos son los que se ponen en juego en la producción de conocimiento, la lógica no puede simplemente desentenderse del estudio de ésta última. Como mencionamos en la introducción de éste capítulo, Peirce problematizará más tarde, como se evidencia en sus cartas de 1904 a Dewey, este vínculo entre lógica e historia de la investigación o historia natural del pensamiento. Su objeción es que una tal historia no puede sustituir a la lógica, que debe ser una ciencia normativa encargada en tanto que tal del estudio de posibilidades y no de la descripción de realidades. En palabras de Peirce, la historia del pensamiento que ofrecía Dewey no abordaba el

\footnotetext{
${ }^{4}$ El ejemplo que da Peirce de principio directriz de la inferencia da muestra clara de su carácter de principio material de inferencia: "Supongamos, por ejemplo, que observamos que un disco rotatorio de cobre se detiene rápidamente cuando lo ubicamos entre los polos de un imán, e inferimos que esto sucederá con todo disco de cobre. El principio directriz es que lo que es verdadero de un trozo de cobre lo es de otro. Tal principio directriz sería mucho más seguro respecto del cobre que respecto de muchas otras sustancias -el latón, por ejemplo-" (2012, p. 160). Esta concepción de los principios de inferencia atenta contra la separación tajante entre materia y contenido y entre principio de inferencia entendido como algo meramente formal, como una forma sin contenido, y los principios sustantivos que conducen la investigación. Y por lo tanto atenta contra la separación tajante entre lógica y epistemología o metodología.
} 
“pensamiento meramente posible que la Ciencia normativa estudia, sino el pensamiento tal como se presenta en una experiencia aparentemente inexplicable e irracional" (CP: 8.239). Sin embargo, este rechazo de la identificación de la lógica con una historia natural del pensamiento no debe interpretarse como un rechazo total por parte de Peirce a toda conexión entre la lógica como disciplina y la práctica y la historia real de la investigación. En efecto, en otra carta a Dewey que se estima posterior a aquella, Peirce rechaza la concepción deweyana de la lógica como una ciencia genética que rechaza la dicotomía absoluta entre génesis y validez ${ }^{5}$, pero afirma lo siguiente:

[T] odos mis estudios son conducidos en vista de memorias científicas reales y otros registros de investigación científica, en los cuales [mis estudios] llevaron a negar conclusiones a las que la mala lógica había llevado a sus autores; y algunos de mis estudios no-genéticos han llevado directamente a descubrimientos en matemáticas $\mathrm{y}$ otros a instituir investigaciones experimentales sobre cuya realidad, por no decir solidez, no puede haber ninguna duda; y en pocas palabras querría yo saber qué lógico genético alguna vez estuvo tan cerca de la ciencia real como yo he estado (CP. 8.243).

Y un poco más adelante, afirma, también refiriéndose a Dewey, que

Lo que tenías derecho a decir era que para ciertos problemas lógicos el progreso entero del conocimiento y junto con él el de su objeto resulta pertinente, y por lo tanto debería ser tenido en cuenta. Lo que dices es que ninguna investigación para la cual ese progreso no sea pertinente debería permitirse (CP. 8.244).

\footnotetext{
${ }^{5}$ Esta era la posición más firmemente defendida por Dewey. En el libro de Dewey cuya reseña ocasionara las críticas de Peirce, Dewey afirma que "Resulta sorprendente que, en vista del avance del método evolucionista en ciencias naturales, los lógicos aún insistan en establecer una rígida diferencia entre el problema del origen y el problema de la naturaleza, entre génesis y análisis, entre historia y validez" (MW 2.309). Este rechazo resulta paralelo al cuestionamiento de la distinción entre contexto de descubrimiento y validez, cuestionamiento que, como sugiere Alfredo Marcos (2000) permitió ampliar las fronteras de la filosofía de la ciencia.
} 
Así resulta claro, en nuestra opinión, que aún cuando Peirce rechazara la identificación de la lógica con algo así como una historia natural del pensamiento, con todo, creía que la lógica no podía dar la espalda de modo absoluto a la práctica real de la investigación ni a su historia. La diferencia con Dewey radicaba más bien en la cuestión de la explicación del carácter normativo de los principios lógicos. En efecto, no es que Dewey negara tal carácter, sino que pretendía que podía darse cuenta del mismo desde una perspectiva genética o histórica, e incluso, podríamos decir, contextual. En efecto, Dewey sostuvo lo que con Esteban (2008, p. 184) podemos llamar un naturalismo normativo con el que Peirce no parecía estar de acuerdo. Cabe señalar que las críticas de Peirce van dirigidas contra los Studies in Logical Theory de 1903, y que no llegó a conocer la Lógica: teoría de la investigación de 1938, en la que Dewey intentó dar cuenta de un modo más desarrollado que en los escritos de 1903 del carácter normativo de los principios lógicos, y ello desde una perspectiva completamente naturalizada. Más aún, en el libro de 1938 Dewey niega explícitamente lo que Peirce parece atribuirle en la cita anterior, a saber, que la lógica debe desarrollarse teniendo todo el tiempo a la vista la práctica real del razonamiento. En efecto, allí afirma Dewey que su posición no prohíbe el desarrollo de modelos formales, aunque llama la atención sobre ciertos problemas filosóficos, subyacentes a tales desarrollos, que los lógicos parecen desconocer con la esperanza de que su propia concepción de la lógica permita el desarrollo de más y mejores sistemas formales.

Por último, cabe señalar que en la concepción de la lógica esbozada por Peirce en los trabajos que analizamos la perspectiva naturalista a la que acabamos de aludir se encuentra también esbozada. Como veremos más adelante, en el caso de la lógica, la perspectiva naturalizada para Dewey significaba que había una continuidad entre las 
funciones más desarrolladas de los organismos más complejos, por ejemplo la actividad inteligente con sus leyes lógicas, y las funciones orgánicas más básicas. Tal continuidad, cabe recordar, excluye tanto la mera repetición de lo mismo como la existencia de saltos absolutos. Es decir, las leyes lógicas ni se reducen a meros mecanismos orgánicos (por ejemplo a conexiones neuronales) ni constituyen realidades totalmente ajenas a la naturaleza. Más bien, son instrumentos forjados por el ser humano en el proceso de su interacción con el medio, es decir, en y por la experiencia. Pues bien, algunas especulaciones de Peirce acerca del carácter lógico del animal humano pueden leerse como el puntapié inicial para los desarrollos de Dewey. En efecto, leemos en "La fijación de la creencia" que "la logicidad en cuestiones prácticas es la cualidad más útil que un animal puede poseer y podría, por tanto, resultar de la acción de la selección natural" (2012, p. 160, CP. CP 5.366). Esta visión naturalista se halla asimismo presente en la concepción de la creencia y el conocimiento esbozada por Peirce en este artículo y que analizaremos en la sección siguiente.

Sin embargo, y antes de emprender tal análisis, cabe señalar otro aspecto de la concepción de la lógica de Peirce que resulta relevante. Es bien sabido que Peirce identificó tres formas de razonamiento, a saber, el razonamiento deductivo, la inducción y la hipótesis que luego llamará abducción. ${ }^{6}$ Estas dos últimas formas de inferencia, es decir, las inferencias que son probables, son las que permiten de hecho el avance del conocimiento. En efecto, constituyen, según Peirce, “el único modo de inferencia que puede enseñarnos algo, o llevarnos de alguna manera más allá de lo que estaba implícito en las premisas” (CP 5.354 / 2012, p. 126). Ahora bien, como vimos, la validez de una inferencia depende, de acuerdo con Peirce, de la verdad de la afirmación de que si lo que enuncian las premisas es

\footnotetext{
${ }^{6}$ Para una discusión del concepto de abducción en Peirce cfr. Aliseda (2003)
} 
cierto, entonces también lo será lo que enuncia la conclusión. Sin embargo, esto es algo que, de acuerdo con Peirce, nunca puede saberse en el caso de una inferencia probable. En efecto, en su opinión "[no] puede decirse que una conclusión inductiva es verdadera (...); sólo sabemos que al aceptar conclusiones inductivas, a largo plazo nuestros errores se equilibran entre sí" 7 (CP 5.350 / 2012, p. 124); es decir, la validez de las inferencias no deductivas descansa, no en que aseguren cada vez conclusiones verdaderas, sino en que "sólo a largo plazo se aproximan a la verdad" (ibídem). Resulta interesante señalar que, en este contexto, la validez de las inferencias no reside en un principio formal y abstracto separado de la práctica de la inferencia, sino en la continuidad del proceso de investigación. Esto es, tenemos una teoría acerca del carácter normativo de los principios lógicos, de su carácter de norma de la inferencia válida, según la cuál, solo en el largo plazo, en el continuo de la investigación, podemos tener garantías de su validez. Es decir, la validez de los principios de inferencia no deductivos depende de la función que juegan en el contexto de un desarrollo continuo de la investigación.

La consecuencia que Peirce extrae de esta tesis resulta sumamente interesante, fundamentalmente si la contrastamos con la tradición dominante de la lógica, que ha pretendido reducir la lógica a una ciencia puramente formal. De acuerdo con nuestro autor, esta tesis implica que ninguna inferencia individual es en sí misma lógica. Su logicidad, por cuanto descansa en la continuidad de la investigación, supone su testeo por parte de la comunidad de investigación, agente de esa continuidad indefinida de la investigación. Esto es, la afirmación de que una inferencia probable concreta realizada por un individuo o grupo de individuos concretos es válida es tan sólo una afirmación hipotética cuya

\footnotetext{
${ }^{7}$ Esta afirmación se aplica a toda inferencia probable tal como explícitamente lo afirma Peirce un poco más adelante "Todo lo dicho hasta aquí, particularmente sobre la inducción, se aplica a toda inferencia probable" (CP 5.352 / 2012, p.125)
} 
confirmación definitiva quedará indefinidamente supeditada a su supervivencia en el continuo de la investigación. Por esta razón, el individuo que investiga debe subordinar sus intereses a los intereses de la comunidad, ya que en caso contrario, "según la teoría de la validez de la inferencia que se acaba de desarrollar, está desprovisto de toda seguridad y no puede hacer ninguna inferencia válida (...) Así, el principio social está arraigado intrínsecamente en la lógica” (CP 5.354 / 2012, p. 126). En otros términos, la pretensión de extraer una conclusión de modo correcto supone que el individuo que realiza la inferencia adopte el punto de vista de la intersubjetividad de la comunidad de investigadores. De este modo vemos que la concepción de la lógica de Peirce queda indisolublemente unida a su concepción de la investigación que, al ser comprendida como una forma de acción, permitirá elaborar una concepción del conocimiento francamente opuesta a la de la tradición filosófica.

\section{La investigación como una forma de acción}

En opinión de Peirce la lógica entendida de esta forma, es decir, como una disciplina de algún modo conectada con la investigación y por tanto con la historia de la ciencia y no como una disciplina puramente formalista ${ }^{8}$, toma ciertos supuestos como su punto de partida. Tales supuestos refieren al concepto de creencia y a su relación con la duda, y a la

\footnotetext{
${ }^{8}$ Como recuerda Putnam (1999, p. 94), este rechazo de la comprensión formal de la lógica ha llevado a Morton White (1949) a hablar del pragmatismo como una revolución contra el formalismo. Asimismo, cabe destacar que el propio Dewey comprendió de este modo la lógica peirceana, esto es, como una superación de la concepción de la lógica como algo puramente formal y desligado de la práctica real de la inferencia. En este sentido, en opinión de Dewey "El Sr. C. S. Peirce (si lo interpreto correctamente) cree que una de las mayores ventajas de las proposiciones matemáticas o simbólicas es que la lógica puede trascender de ese modo las limitaciones del mero formalismo y convertirse en una instrumentalidad potente al desarrollar un sistema que tiene una referencia inherente a la búsqueda de la verdad y la validación de la creencia" (mw.3.66).
} 
posibilidad del paso de una a otra. En otros términos, el estudio de la lógica supone una cierta concepción de lo que Peirce denominará investigación. La investigación será definida como una lucha por alcanzar un estado de creencia provocada por la irritación que supone la duda (CP. 5.374). En este esquema la duda es entendida, no como una mera pregunta, sino como un estado del organismo que investiga, el humano, que conlleva una cierta irritación. Tal irritación es el "motivo inmediato para la lucha por alcanzar la creencia" (CP. 5.374 / 2012, p. 162). La duda es, así, un estado de inquietud e insatisfacción que impulsa a la acción, a esa acción que tomará la forma de una lucha por alcanzar la creencia. Por su parte, la creencia no tiene este carácter de impulsor de la acción, pero no por ello carece de todo vínculo con ella. Antes bien, la creencia es una suerte de disposición a la acción. En palabras de Peirce, la creencia "nos pone en una condición tal que, dada cierta ocasión, actuaremos de cierta forma" (CP. 5.374, 2012, p. 162). Así, la creencia es comprendida como un hábito, como una disposición a actuar de determinada manera en determinadas condiciones. En este contexto, el fin o la meta de la investigación es el establecimiento de la opinión o creencia, esto es, de un hábito, de una forma estandarizada de respuesta activa.

De este modo queda configurada una nueva relación entre el conocimiento y la acción, lo que tendrá a su turno como consecuencia un cambio en el modo de comprender otros conceptos centrales ligados al concepto de conocimiento como el de realidad y verdad. En primer lugar, cabe señalar que el fin, el objeto del conocimiento no es alcanzar una descripción del mundo, sino una opinión o creencia, que es "de la naturaleza de un hábito". Además, el proceso mismo por el cual se establece la opinión, la investigación, es una acción que exhibe un cierto patrón, que comienza con la duda en virtud de la irritación que conlleva y finaliza cuando se establece la creencia y se cancela la duda. Es importante 
remarcar que este patrón tiene un anclaje biológico, o al menos resulta análogo a ciertos procesos orgánicos, lo que implica, así, una mirada naturalista sobre el conocimiento que, como se dijo, entenderá a éste último como continuo con los procesos orgánicos. Esta concepción de la investigación conlleva una re-ubicación del conocimiento en el contexto vital de la actividad humana; por así decirlo, el conocimiento no es ya algo separado de la acción ni de la vida concreta de los seres humanos, sino una respuesta a un fenómeno que puede surgir y de hecho surge en el transcurso de la vida, esto es, a la duda entendida no como una mera pregunta, sino como una cierta irritación, una cierta inquietud que impulsa a la acción.

Utilizando una expresión de Andrew Pickering (1995), nos encontramos en este artículo de Peirce, con un primer paso en lo que podemos caracterizar como el cambio de un lenguaje representativo a uno performativo para dar cuenta del conocimiento. Así, el término conocimiento, como producto, pierde relativa relevancia frente al término investigación o cognición (congition) que refieren más bien al proceso mediante el cual se obtiene conocimiento. Aún así, no se trata tan sólo de un cambio de énfasis del producto hacia el proceso que dejara intacta la concepción del producto (el conocimiento). En efecto, como señala Peirce, la meta de la investigación no es alcanzar una mera descripción del mundo sino el establecimiento de un hábito, que en tanto que tal guarda una relación inherente con la acción. Esto no implica, en absoluto, que no tenga lugar la representación en la actividad cognitiva ni que el producto del conocimiento sea una mera acción. El resultado de la investigación es formulable como una proposición, pero tal proposición no es una mera descripción de algo en el mundo, sino la formulación de un hábito, que tiene, por su parte, un vínculo insoslayable con la acción. 
Este vínculo con la acción, contenido en la definición misma de creencia y por tanto insertado en el corazón mismo de la teoría del conocimiento, resulta reforzado por la comprensión misma del significado contenida en la bien conocida máxima pragmática, que no parece ser sino una consecuencia de la definición de creencia anteriormente explicitada. Así, de acuerdo con Peirce, "la esencia de la creencia es el establecimiento de un hábito, y las diferentes creencias se distinguen por los diferentes modos de acción a los que dan lugar" (CP 5.398 / 2012, p. 177). De este modo, si queremos analizar el significado de una creencia, y su diferencia con otras, "simplemente tenemos que determinar qué hábitos produce, pues lo que una cosa significa es simplemente los hábitos que implica" (CP 5.400 /2012 p. 179). A su vez, un hábito queda caracterizado por las situaciones y los modos en que nos lleva a actuar, y de acuerdo con Peirce el propósito de toda acción es "producir algún resultado sensible" (ibídem). De este modo, se llega a la idea de "lo tangible y práctico como raíz de toda distinción real del pensamiento" (ibídem). Así, entonces, si una creencia es una regla para la acción, y si toda acción pretende producir un efecto práctico tangible o sensible, resulta que el significado de una creencia radica en los efectos prácticos de la misma. Ahora bien, recordemos que la creencia no es una acción sino una regla para la acción y que por tanto en su carácter de regla resulta general: nos dice cómo actuar en cualquier situación en la que nos encontremos con el objeto de la creencia. En esa medida, el significado de la creencia no se identifica con sus efectos prácticos ya obtenidos y constatados sino con sus efectos prácticos concebibles. Es decir, el significado de la creencia radica en los modos de acción que impondría en toda situación en la que resulte pertinente, y que deben ser anticipados al momento de analizar el significado. 
Así, hemos llegado a lo que ha sido considerado el corazón del pragmatismo, es decir, a la máxima pragmática que Peirce presenta por primera vez en el escrito que analizamos (CP. 5.388-410), de la siguiente manera: “considérese qué efectos, que pudieran concebiblemente tener repercusiones prácticas, concebimos que tiene el objeto de nuestra concepción. Entonces nuestra concepción de esos efectos constituye la totalidad de nuestra concepción del objeto" (CP. 5.402). Tenemos así el punto de partida del pragmatismo, como una filosofía que, tal como lo dijera Putnam, confiere a la práctica una cierta centralidad y que llevó a Dewey a reapropiarse del pragmatismo como una filosofía que, oponiéndose a la estrategia de la filosofía trascendental, dirige su mirada, no a condiciones antecedentes de algún modo supuestas en nuestra acción cognitiva, sino a las consecuencias reales, efectivas, de las ideas en el mundo, por así decirlo.

\section{Conocimiento, realidad y verdad en la nueva concepción del conocimiento}

La concepción de la filosofía, de la lógica y de la investigación que hemos bosquejado en este capítulo y en el anterior se complementa con una concepción falibilista y realista del conocimiento, en la que nos detendremos para finalizar este capítulo. La defensa conjunta de estas posiciones es, en nuestra opinión, uno de los mayores aportes de la concepción pragmatista del conocimiento. En relación al falibilismo lo primero que cabe mencionar es que dicha tesis no es defendida en el contexto de una mirada "escéptica" del conocimiento, es decir, en el contexto de una posición que asuma de algún modo la imposibilidad del mismo o que no se comprometa con la afirmación de que sí lo hay. En el contexto de la filosofía de Peirce, puede afirmarse que sí hay conocimiento, a la vez que se niega que pueda alcanzarse certeza. De este modo vemos, otra vez, una redefinición del conocimiento 
que queda definitivamente divorciado de la certeza absoluta sin que pierda por ello ningún atributo relevante. La falibilidad propia del conocimiento no debe entenderse como una falla o una falta, sino que es más bien una consecuencia de su propia naturaleza. En efecto, de acuerdo con Peirce y como ya hemos señalado, el conocimiento es resultado de un proceso de inferencia sintético o no deductivo que, en tanto que tal, no puede otorgar certeza a su conclusión. En sus palabras,

Todo razonamiento positivo es de la naturaleza del juzgar la proporción de algo en una colección completa por la proporción encontrada en una muestra. De acuerdo con ello, hay tres cosas que nunca podemos esperar alcanzar por razonamiento, a saber, certeza absoluta, exactitud absoluta y universalidad absoluta (CP. 1.141).

Así, puesto que sólo el razonamiento no deductivo proporciona conocimiento fáctico, y puesto que de acuerdo con Peirce no existe ninguna forma de conocimiento intuitivo ni a priori (cfr. CP 1.144), se sigue que el conocimiento sin más, por cuanto es inferencial y depende de inferencias "sintéticas", es falible. Es decir, el conocimiento no puede alcanzar certeza, exactitud ni universalidad absoluta.

Esta concepción falibilista del conocimiento resulta lejana a cualquier pretensión de afirmar la imposibilidad del conocimiento y se conjuga además con una concepción evolucionista o meliorista del mismo. Hemos visto que ya en los tempranos artículos de 1868 Peirce afirmaba que no se puede tener la esperanza de alcanzar individualmente la verdad, sino que sólo cabe buscarla colectivamente. Esta tesis se apoyaba en la comprensión de la inferencia no deductiva analizada en la sección anterior, según la cual si bien es cierto que nunca podremos estar seguros de que la conclusión de tal inferencia es verdadera, en el largo plazo cabe esperar que tales inferencias nos acerquen a la verdad. La 
justificación de esta última afirmación resulta ciertamente compleja e implica otras posiciones de Peirce que no serán abordadas aquí ${ }^{9}$. Lo que resulta significativo es que este hecho descansa en última instancia en lo que Peirce entendió como el método experimental de fijar la creencia. En sus palabras,

Como todo nuestro conocimiento proviene de la inferencia sintética, hay que inferir igualmente que toda certeza humana consiste meramente en que sabemos que los procesos de los que se ha derivado nuestro conocimiento son tales que han conducido generalmente a conclusiones que son verdaderas (CP. 2.693 / 2012, p. 217).

Este largo plazo supone que la validez de las creencias individuales depende, en última instancia, de su "estabilización” en el continuo de la investigación, investigación ésta que no termina con el individuo sino que será llevada a cabo por otros sujetos, por la comunidad de investigación. Esto no quiere decir que no haya ningún margen de racionalidad en las creencias individuales, sino que las creencias individuales son siempre falibles por cuanto nunca podremos estar seguros de si nuestra creencia individual formará parte del consenso último, es decir, si logrará estabilizarse resistiendo al paso del tiempo. Pero, en la medida en que el proceso de investigación continúe, habremos de llegar a buenos resultados. Esto quiere decir, en nuestra opinión, que no podemos sino confiar en nuestros métodos de conocimiento, en la medida en que ellos, como es el caso de la inferencia sintética, toman como punto de partida la experiencia.

Según vimos, el objetivo de la investigación, la cual comienza en virtud de la irritación que conlleva la duda, es el establecimiento de la creencia. Así, podría pensarse que cualquier modo de establecer creencia tiene el mismo valor que cualquier otro.

\footnotetext{
${ }^{9}$ Para una reconstrucción de la justificación de la validez a largo plazo de los procesos de inferencia sintética cfr. Apel, 1997 pp. 74 y ss.
} 
Podríamos, por ejemplo, elegir una creencia al azar, repetírnosla constantemente y hacer caso omiso de toda evidencia en su contra. O podríamos, también, apartar la duda tomando cualquier creencia que cuente con el aval de una autoridad y contentarnos con eliminar sobre esa base todas nuestras dudas. Estas formas de establecer creencias, que Peirce llama respectivamente método de la tenacidad y de la autoridad, tienen sus ventajas pero también sus limitaciones. Tales limitaciones son fundamentalmente de orden práctico: el método de la tenacidad, es decir la auto-imposición individual de cualquier creencia, se encontrará con las opiniones de los otros sin ofrecer ninguna manera de resolver las diferencias de opinión. Ello implica, dada la necesidad de concertar planes de acción con los otros, es decir, dado el impulso social del hombre, un insalvable obstáculo práctico. Por su parte, el método de la autoridad se encuentra también con obstáculos prácticos dada la dificultad de que una autoridad regule todas las opiniones y el consecuente surgimiento de opiniones contrarias, que haría resurgir la duda sobre cualquier creencia que se apoye sólo sobre la fuente de la autoridad. Es decir, en la medida en que quede un resquicio para la individualidad y la comparación con creencias distintas, el método de la autoridad se encuentra con un obstáculo insalvable, que hará resurgir las dudas por doquier. Otro tanto ocurre con otra estrategia para establecer una creencia que Peirce denomina el método a priori. Este método supone tomar como una creencia aceptable aquello que "agrada a la razón" y es identificado con la especulación metafísica. De acuerdo con Peirce, este método hace de la investigación algo semejante al gusto que resulta siempre más o menos sujeto a la moda, y, dadas las diferencias en cuanto a lo que cada uno puede pensar que agrada a la razón, no asegura arribar a acuerdos. 
Todos estos métodos tienen en común el hecho de guiarse, en el establecimiento de creencias, por algo meramente humano, a saber, el capricho individual, la autoridad social o lo que agrada a la razón. Frente a ellos, el método experimental es el único que propone, de acuerdo con Peirce, guiarse por "una permanencia externa" (p. 167), por algo que no dependa del pensamiento humano. Esta independencia no debe ser entendida como una independencia absoluta, sino como una independencia de cualquier sujeto individual o grupo finito de sujetos. Así, este método experimental, que consiste en dejarse guiar por la experiencia para fijar creencia, supone, de acuerdo con Peirce, ciertas hipótesis acerca de la realidad y de la posibilidad de su conocimiento.

Llegamos así a la tesis realista defendida por Peirce. Tal tesis, defendida en "Cómo esclarecer nuestras ideas", había sido en realidad anticipada algunos años antes. Ya en "Algunas consecuencias de cuatro incapacidades" Peirce afirmaba que una creencia verdadera es aquella cuyo objeto es real en tanto que opuesto a aquellos objetos irreales, o ilusiones, que son el objeto de las creencias falsas o erróneas. Ahora bien, esta distinción entre lo real y lo ilusorio o erróneo es, de acuerdo con nuestro autor, una distinción entre aquello que sería sostenido en el largo plazo y aquello que depende solamente de los caprichos de cualquier número finito de hombres. Es decir, la distinción entre real e ilusorio no es una distinción entre objetivo y subjetivo, entendiendo la objetividad como teniendo una independencia absoluta respecto del sujeto, sino más bien una distinción entre intersubjetivo e idiosincrásico, donde la intersubjetividad resulta indefinidamente proyectada hacia el futuro y lo idiosincrásico es identificado con un estado presente de creencias sin más fundamento que su pertenecer a un individuo o a un grupo limitado. En palabras de Peirce, lo real "es aquello en lo que tarde o temprano, la información y el conocimiento resultarán finalmente, y que es por tanto independiente de los caprichos 
suyos y míos” (2012, p. 96). Es decir, el carácter de independencia de lo real no se traduce en independencia del pensamiento, de la mente o del conocimiento, sino en independencia de las creencias de cualquier número finito de hombres. En otros términos, lo verdadero es aquello que seguirá siendo afirmado en el desarrollo indefinido de la investigación, y lo real aquello a lo que refiere. Así lo expresaba Peirce en una reseña titulada "The Works of George Berkeley, de Fraser" escrita en 1871:

Así que esta opinión final es independiente, no, de hecho, del pensamiento en general, sino de todo aquello que es arbitrario e individual en el pensamiento; es completamente independiente de cómo usted o yo o cualquier número de hombres pensemos. Por tanto, todo aquello que se piensa que existe en la opinión final es real, y nada más (2012, p. 134).

Este realismo tiene un estrecho vínculo tanto con la doctrina del falibilismo como con la doctrina del rechazo a la cosa en sí incognoscible. Puesto que la idea de una cosa en sí absolutamente incognoscible resulta contradictoria, cualquier cosa que se signifique mediante el término real debe ser, por definición, cognoscible y no puede ser caracterizada como absolutamente independiente del pensamiento en general. Cualquier cosa que sea lo real, será por definición cognoscible. Sin embargo, la doctrina del falibilismo estipula que nuestro conocimiento es siempre incompleto, de modo que hay siempre una distancia entre lo conocido y lo cognoscible. Puesto que, además, no tenemos certeza absoluta respecto de nuestras creencias actuales, es siempre posible que la investigación futura nos lleve a modificarlas. En resumidas cuentas, y para usar las palabras de Peirce, "no hay nada, entonces, que impida que conozcamos las cosas exteriores tal y como realmente son, y es altamente probable que en efecto las conozcamos en innumerables casos, aunque nunca podamos estar absolutamente seguros de hacerlo en algún caso especial” (2012, p. 96). La 
realidad, en tanto que sustantivo abstracto, queda definida entonces como algo cognoscible de manera indefinida por una comunidad de investigadores (doctrina de la inexistencia de cosas en sí incognoscibles) que no puede reducirse nunca a lo conocido efectivamente por una comunidad efectiva de investigadores (doctrina del falibilismo). Así lo expresó Peirce en una artículo de 1869 titulado "Fundamentos de la validez de las leyes de la lógica: otras consecuencias de cuatro incapacidades", con una claridad inmejorable, razón por la cual nos permitiremos citarlo in extenso:

Por mucho que sepamos, es posible que llegue a descubrirse más. Por tanto, nunca puede conocerse todo. Esto parece contradecir el hecho de que nada es absolutamente incognoscible; y realmente sería así si nuestro conocimiento fuera algo absolutamente limitado. Pues decir que nunca puede conocerse todo quiere decir que la información puede incrementarse más allá de cualquier punto asignable; es decir, que una terminación absoluta de todo incremento de conocimiento es absolutamente incognoscible y, por tanto, no existe. En otras palabras, la proposición meramente quiere decir que la suma de todo lo que será conocido en cualquier momento futuro, por lejano que sea, tiene una razón menor que cualquier razón asignable a todo lo que puede conocerse en un momento aún más lejano. Sin embargo, esto no contradice el hecho de que todo es cognoscible; sólo contradice una proposición, que nadie puede mantener: la de que en algún momento del futuro, dentro de algún número de años, todo será conocido (2012, p. 107).

Esta tesis acerca de la cognoscibilidad de la realidad, es decir, el rechazo de la idea de una cosa en sí incognoscible, lleva también al realismo escolástico defendido por Peirce, en el que no nos detendremos, y que parece ser, por otra parte, una de las diferencias profundas entre las posiciones de Dewey y Peirce. Cabe señalar que, sin embargo y a pesar de tales diferencias, Dewey vio en esta concepción peirceana de la realidad una idea que la 
filosofía, y su filosofía, debía adoptar. Así, al finalizar un artículo de 1919 titulado "The Pragmatism of Peirce" (mw. 10.71-78) Dewey afirma que

(...) no puedo terminar sin preguntar si el recurso a Peirce no tendría una influencia muy beneficiosa en la discusión contemporánea. ¿Una gran parte de nuestras dificultades epistemológicas no surge del intento de definir lo real como algo dado con anterioridad a la investigación reflexiva en vez de como aquello que la investigación reflexiva está obligada a alcanzar y a lo cual, una vez alcanzado, la creencia puede sujetarse establemente? (mw. 10.78)

Así, la idea de que lo real es aquello que la investigación postulará indefinidamente como verdadero llevó a Dewey a aproximar la concepción de Peirce con la suya propia, según la cuál la realidad no es algo dado de manera previa a la investigación sino algo que sólo puede ser caracterizado como su resultado. Se trata de una concepción que toma como punto de partida, justamente, estas ideas de Peirce. En efecto, lo real es ubicado por Peirce en una suerte de futuro y definido, más bien, como un resultado de la investigación. Reconociendo el vínculo de este realismo con Kant, Peirce afirmó que la esencia de su posición consistía, en efecto, en "considerar la realidad como el producto normal de la acción mental, y no como su causa incognoscible” (2012, p. 135). La realidad, lo mismo que la verdad, sólo puede comprenderse como resultados "estabilizados" de la investigación. Esta tesis, que tendrá claros ecos en las posiciones de antropólogos de la ciencia como Bruno Latour y Karin Knorr Cetina, ha sido así, al menos a los ojos de Dewey, anticipada por Peirce. Luego de citar un pasaje de "La fijación de la creencia" en la que Peirce reitera esta concepción de la verdad y la realidad, Dewey afirma, en efecto, que la concepción de la realidad y la verdad de Peirce "hace depender todo del carácter de los métodos de investigación e inferencia mediante los cuales las conclusiones son alcanzadas" 
(mw. 10.76). Como tendremos oportunidad de analizar, este será el camino tomado por Dewey, quien intentará ofrecer una concepción del conocimiento, y de los términos tradicionalmente asociados a él, tomando como punto de partida el estudio de la investigación.

\section{Consideraciones finales de la primera parte}

En este capítulo y el anterior hemos reconstruido, a partir de los escritos de Peirce, algo así como la plataforma pragmatista que habría de servir a Dewey como punto de partida en su propia reconstrucción de la filosofía. La lectura que hemos ofrecido es tan sólo una lectura posible y es, en todo caso, la lectura del propio Dewey: se trata de las ideas que este último creyó encontrar en los escritos de Peirce.

Acaso el punto más controversial sea el referido a la concepción de la lógica. En efecto, como hemos visto, la crítica de Peirce a Dewey parece desautorizar cualquier intento de establecer cierta continuidad entre las posiciones de nuestros pragmatistas. Sin embargo, como hemos intentado mostrar, hay aspectos de la concepción peirceana de la lógica que resultan próximos a la concepción deweyana. En todo caso, resulta evidente que así fue a los ojos del propio Dewey. Así, por ejemplo, en el comienzo de su Lógica: teoría de la investigación, este último afirma lo siguiente:

En cuanto a lo que a tratados lógicos refiere, tengo la esperanza de que la obra misma ofrezca suficiente indicación de mis líneas de deuda mayores. Debería, sin embargo, decir explícitamente que con la destacada excepción de Peirce, yo he aprendido más de escritores con cuyas posiciones he estado finalmente en completo descuerdo (lw.12.5). 
Como hemos visto, la importancia de tener en cuenta el proceso de la investigación en el estudio de la lógica ha sido sugerida por el propio Peirce y es algo que Dewey creía haber aprendido de su maestro. En sus palabras,

Los lectores que estén familiarizados con los escritos lógicos de Peirce notarán mi gran deuda con él en la posición general asumida. Hasta donde sé, él fue el primer escritor de lógica en hacer de la investigación y sus métodos la fuente primera y última de la materia de la lógica (lw.12.19 n).

Así, resulta evidente que, en opinión de Dewey, su concepción de la lógica no difería completamente de la de Peirce, sino que la seguía al menos en su "posición general”. Acaso la exigencia de tomar como punto de partida el estudio de la investigación real para la formulación de la lógica haya hecho pensar a Peirce que Dewey negaba la posibilidad del desarrollo de sistemas que no hicieran una referencia directa a la investigación real. Así parece sugerirlo la insistencia de Peirce en que mientras la lógica, en tanto ciencia normativa, debía ocuparse del pensamiento posible, Dewey sólo proponía una descripción del pensamiento real. Sin embargo, Dewey no negaba ni la existencia ni el carácter normativo de los principios lógicos, con lo que resulta claro que no negaba el carácter normativo de la lógica misma. Es llamativo, en este sentido, que la posición de Dewey al respecto, no era, en su opinión, más que una continuación de la posición de Peirce:

Ni la existencia ni la indispensabilidad de principios lógicos primarios, es entonces, negada. La cuestión concierne a su origen y a su uso. En lo que se dijo sobre este asunto sigo en lo fundamental el enfoque dado por Peirce de los principios "guías” o que "dirigen” (lw12.19).

Por otra parte, y dada la insistencia de Dewey en el carácter normativo u “obligatorio" de los principios lógicos, en nuestra opinión su lógica tiene más bien un 
carácter reconstructivo que descriptivo: no se trata meramente de describir los principios lógicos que rigen de hecho la práctica de la inferencia y el razonamiento, sino más bien de reconstruir, tomando como punto de partida tal práctica, los principios a los que la investigación debe ajustarse. Como afirma Dewey, su tesis se dirige al origen y uso de los mismos. Como tendremos oportunidad de apreciar, tales principios surgen en el curso de la investigación, se explicitan y, en la medida en que cumplen de modo adecuado su rol de guiar o dirigir la investigación, su uso resulta obligatorio. Tal obligatoriedad no resulta, sin embargo, definitiva, sino que está sujeta a revisión en la medida en que el avance de la investigación así lo requiera.

Independientemente de esa discusión, tal vez el aspecto más destacable de la reapropiación deweyana de las ideas de Peirce sea la asimilación, en cierto sentido, de la filosofía con las ciencias experimentales. Si la filosofía es una forma de conocimiento, entonces debe exhibir las características que resultan inherentes a todo conocimiento: no puede basarse en intuiciones últimas (anti-fundacionalismo), ni arribar a certezas incuestionables (falibilismo) y sus afirmaciones, en tanto que hipótesis, al igual que cualquier hipótesis científica, reciben su confirmación a partir del análisis de sus consecuencias (anti-escepticismo). Así, la filosofía misma no es más que una forma de investigación. Como vimos, el agente de esa investigación no puede ser pensado como el individuo, sino como una comunidad: sólo la comunidad de filósofos puede buscar la verdad. Ahora bien, si esto es así es fundamentalmente porque la investigación es un proceso continuo. En tal proceso es posible identificar una investigación como un ciclo que comienza con una duda y termina con la fijación de una creencia. En este esquema, hay dos aspectos que resultan centrales. En primer lugar, la creencia a la que se llega no es un mero contenido mental, sino un hábito, una disposición a la acción. Veremos en los siguientes 
capítulos cómo esta posición será radicalizada por Dewey. Si el fin de la investigación, tanto en el sentido de su terminación como en el de su meta, es la fijación de una creencia, es decir, el establecimiento de una regla de acción, y si tal regla se traduce en una acción concreta, en un hacer práctico que modifica las condiciones con las que se encuentra, entonces los resultados de esa acción, sus consecuencias, resultan relevantes, en última instancia, en la validación o el rechazo de la creencia. La acción dictada por la regla nos permitirá obtener los resultados previstos, confirmando así la adecuación de la regla de acción, o bien no lo permitirá, en cuyo caso la regla deberá ser modificada. Si esto es así, la afirmación de que la fijación de la creencia es el fin de la investigación debe ser complementada: la investigación no termina cuando se ha fijado la creencia sino cuando se han operado una serie de transformaciones prácticas, en virtud de la regla establecida, consistentes con los fines previstos. El fin de la investigación será así, para Dewey, la transformación de una situación en relación con la cual la fijación de la creencia resulta instrumental: la creencia es un medio para la transformación de la situación problemática que dio origen a la investigación.

El otro aspecto destacable en esta pauta de fijación de creencias es que la duda con la que comienza la investigación es una que se apoya en razones: la investigación no comienza con la ignorancia absoluta sino que toma como punto de partida creencias que, a los efectos de esa investigación, pueden darse como descontadas. La filosofía debe comenzar, necesariamente, con todos los prejuicios reales que constituyen la base a partir de la cual podemos formular las razones de nuestras dudas. Como veremos en el capítulo que sigue, este prejuicio, en el sentido más positivo del término, este punto de partida, lo constituirá para Dewey el “darwinismo". Así, la filosofía de Dewey no pretenderá 
2. Hacia una nueva concepción del conocimiento

comenzar desde cero. Antes bien, elaborará un concepto de experiencia, tomando como punto de partida el darwinismo, que le permitirá, a la vez, operar una suerte de deconstrucción de la tradición filosófica y reelaborar, profundizándola, la plataforma peirceana que hemos presentado. 


\title{
II. Segunda parte
}

\author{
La teoría deweyana de la investigación
}




\section{3}

\section{El punto de partida: la teoría de la experiencia}

\section{Introducción}

El concepto de experiencia ha sido un concepto central en la filosofía de Dewey. En efecto, a lo largo de toda su obra y especialmente en sus obras de madurez, tal concepto ocupó un lugar destacado. Sin embargo, la teorización deweyana sobre la experiencia no carece de dificultades, e incluso el lugar y la función del concepto de experiencia dentro del conjunto de su filosofía han sido objeto de discusión. Así, por ejemplo, en su clásico libro sobre la filosofía de Dewey, R. W. Sleeper (2000) comprende a la teoría de la experiencia de Dewey como una lógica de la experiencia, mientras que Richard Rorty ha sostenido que el libro de Dewey Experience and Nature debe ser comprendido como un intento de elaborar una metafisica de la experiencia. Ahora bien, como señalan Rorty $(1998,1982)$ y Philip W. Jackson (2004), entre otros, los problemas en torno al concepto de experiencia, su 
importancia para la filosofía y su lugar en ella han sido reconocidos por el propio Dewey. De tal reconocimiento darían muestras sus intentos, unas veces fallidos y otras no, de escribir una nueva introducción para Experience and Nature ${ }^{1}$, sin dudas su obra central sobre la cuestión que nos ocupa. Más aún, una tardía sugerencia por parte de Dewey de sustituir el término experiencia por cultura en el título del libro $^{2}$, daría testimonio de la conciencia del pragmatista acerca del carácter problemático del concepto de experiencia.

En este capítulo nos proponemos reconstruir la teoría de la experiencia de Dewey que constituye, en nuestra opinión, el verdadero punto de partida de su reconstrucción de la filosofía. Ello no debe ser entendido en un sentido cronológico, aunque ciertamente el concepto de experiencia deweyano, inspirado en Hegel y transformado teniendo en cuenta los aportes del darwinismo a la comprensión del ser humano, ha sido una preocupación temprana para Dewey. Se trata, más bien, de un punto de partida en un sentido lógico o conceptual. En efecto, gran parte de los aportes de Dewey a la comprensión del ser humano y sus actividades pueden explicarse como una readecuación o reconstrucción de algunos conceptos centrales de la filosofía que toma como punto de partida, como premisa principal, la idea de que todo lo que hay, cuando del animal humano se trata, es experiencia, y que esa experiencia puede y debe describirse en términos compatibles con una posición completamente naturalista.

\footnotetext{
${ }^{1}$ El libro fue publicado originalmente en 1925. En 1929 Dewey se propuso realizar una edición corregida de la obra, subsanando algunas de las dificultades que se le habían señalado. Ello supuso la redacción de un nuevo prefacio y la reescritura completa del primer capítulo "La experiencia y el método filosófico". Luego, en 1948, Dewey se propuso escribir una nueva introducción a Experience and Nature, introducción extensa pero inconclusa que sólo fue publicada de modo póstumo. En 1951 retomó el proyecto de escribir una nueva introducción, pero en vez de retomar el manuscrito de 1948, empezó de cero una nueva introducción que su muerte dejó inconclusa.

${ }^{2}$ En la última de esas introducciones Dewey comienza afirmando que si volviera a escribir el libro, lo llamaría Culture and Nature, cambiando también, con ello, los temas acerca de los que trataba el libro.
} 
Al ocuparnos del concepto de experiencia en la obra de Dewey resultará relevante tener presente el bien conocido rechazo rortyano a la apelación deweyana al concepto de experiencia. Como lo ha afirmado en varias oportunidades $(1998,1994)$ el pretender ofrecer una teoría de la experiencia la parecía a Rorty una recaída por parte de Dewey en las viajes trampas de la tradición filosófica. Así, la concepción de la experiencia de Dewey, que constituiría una metafísica de la experiencia, resultaba, para Rorty, un proyecto inviable, del que Dewey mismo se habría retractado sobre el final de su vida. Como veremos más adelante en este capítulo, esta interpretación de Rorty resulta inadecuada. Como han señalado muchos autores, Bernstein (2010) y Sleeper (2000) entre otros, y como tendremos oportunidad de apreciar, el abandono tardío por parte de Dewey tanto del término experiencia como del término metafísica respondía no tanto a un cambio en la posición de Dewey cuanto a una decisión terminológica, habida cuenta de la imposibilidad de sus críticos de asociar tales términos con los significados propuestos por Dewey.

Frente a tal lectura, reafirmamos nuestra pretensión de referirnos a la concepción de la experiencia de Dewey como una teoría que ocupa el lugar de un punto de partida conceptual de su programa filosófico. Así, sostendremos que no cabe referirse a la teoría de la experiencia de Dewey como una metafísica. Más bien, en nuestra opinión, tal teoría constituyó para Dewey uno de esos "prejuicios reales" con los que debía comenzar la investigación filosófica a los que, como vimos en el capítulo 1, se refería Peirce. Más específicamente, el concepto de experiencia de Dewey resultaba, fundamentalmente, de una reconstrucción de la comprensión del ser humano que surgía de disciplinas tales como la biología, la psicología y la antropología social. Así, el filósofo, frente a los avances recientes y siempre parciales de la ciencia en lo que respecta a la comprensión del hombre, 
lejos de dejar en suspenso sus resultados o de pretender fundamentarlos, debía tomarlos como punto de partida, como el punto de partida más sólido al que se pudiera recurrir para comprender un concepto tan central para la filosofía y su tradición como lo es el de experiencia. En la sección siguiente (2) reconstruiremos la concepción deweyana de la experiencia para analizar luego, en la sección 3, la interpretación de la concepción de la experiencia como una metafísica. Finalmente, explicitaremos algunas conclusiones.

\section{La teoría de la experiencia}

Como hemos mencionado, el concepto de experiencia es un concepto clave en la filosofía deweyana y ciertamente complejo. Diferentes aspectos de la experiencia serán tenidos en cuenta por Dewey a la hora de desarrollar, por ejemplo, su teoría del conocimiento como experiencia reflexiva o investigación, su concepción de la lógica como investigación de la investigación y su concepción de la valoración como proceso de formación, elección y justificación de valores. Incluso, el concepto de experiencia será central en el desarrollo de su concepción del arte y de la experiencia estética. En esta sección reconstruiremos la concepción deweyana de la experiencia. Veremos cómo la comprensión de la misma como interacción orgánica o transacción permite a nuestro autor apartarse de la comprensión moderna de la experiencia, y especialmente de la empirista (2.1). Asimismo, nos detendremos en lo que Dewey entiende como el carácter cualitativo de la experiencia, lo que nos conducirá a su vez a la distinción entre el mero tener experiencia, y el tener una experiencia (2.2). Una vez establecido ello reconstruiremos la distinción deweyana entre experiencia primaria y experiencia secundaria o reflexiva, lo que nos brindará la 
oportunidad para descartar la posibilidad de comprender la teoría de la experiencia de Dewey como una suerte de reduccionismo biologicista, al destacar la importancia del lenguaje y de la dimensión cultural en la experiencia humana, sin renunciar sin embargo a una posición naturalista $(2.3)$.

2.1. La experiencia como transacción: la crítica al concepto tradicional de experiencia

En un artículo titulado "The Need for a Recovery of Philosophy" publicado en 1917, Dewey se pregunta por el lugar adecuado desde el cual emprender la crítica a la filosofía de su época. En su opinión, es precisamente el análisis de la noción de experiencia lo que debe constituir el punto de partida, debido a que

es precisamente la visión heredada de la experiencia, común a la escuela empírica y a sus oponentes, la que mantiene vivas muchas discusiones, incluso sobre asuntos que en su superficie son bastante remotos, a la vez que es también esa visión la que resulta sumamente insostenible a la luz de la ciencia existente y de la práctica social (mw. 10.6).

Así, Dewey pretenderá elaborar un nuevo concepto de experiencia que supere lo que en su opinión resultan rasgos problemáticos en la concepción tradicional de la misma. En el artículo que acabamos de mencionar nuestro autor explicita cinco aspectos del concepto tradicional de experiencia que serán rechazados, a saber, (1) su sesgo cognitivo; (2) su sesgo psíquico o subjetivo; (3) su sesgo hacia el pasado; (4) su sesgo particularista o atomista y por último, (5) la oposición experiencia/inferencia

Así, de acuerdo a la noción tradicional de la experiencia, la misma es, básicamente, un asunto de conocimiento. La experiencia sería, en un contexto tal, y al menos en lo que 
hace a su interés filosófico, para unos, aquello en lo que el conocimiento debe apoyarse para tener validez y, para otros, aquello con lo que la razón debe tener cuidado para no extraviarse cuando de conocer se trata. En este contexto la experiencia de un sabor, de un color, o de un objeto cualquiera resulta identificada con el conocimiento de ellos, ya sea que lo consideremos un verdadero conocimiento desde el cual construir la ciencia o una mera creencia que no constituye verdadero saber. Precisamente en la medida en que la experiencia es vista como una forma de conocimiento, y en la medida en que el conocimiento es algo que ocurre en las mentes de los sujetos, la experiencia misma tiene un carácter mental o subjetivo: mi experiencia de un objeto se identifica con las sensaciones o impresiones sensoriales que, en tanto que tales, constituyen entidades mentales y a fortiori subjetivas. En la medida que la experiencia es vista como una suerte de copia mental cognitiva de los objetos que experimentamos, su referencia fundamental es al pasado: la experiencia es una suerte de acervo, de registro de las impresiones y sensaciones que hemos tenido de los objetos en el pasado. En tanto y en cuanto la experiencia es un registro de lo efectivamente sentido o percibido, se diferencia de lo pensado o inferido, y toda relación y toda inferencia no puede ser sino un añadido posterior, ajeno a la experiencia misma, de cuya validez se puede y se debe, por principio, dudar. La experiencia es experiencia de elementos discretos que luego la imaginación, la razón, el intelecto o cualquier otra facultad que supongamos tener deberá relacionar o sintetizar, añadiendo a la experiencia algo que por definición le resulta ajeno.

Como forma de romper con esta concepción de la experiencia Dewey formula la siguiente propuesta:

Supongamos que nos tomamos seriamente la contribución hecha a nuestra idea de experiencia por la biología (...). Todo enfoque sobre la experiencia 
debe ahora ajustarse a la consideración de que experimentar significa vivir; y que la vida avanza en y por un medio ambiente, no en un vacío. Donde hay experiencia hay un ser vivo. Donde hay vida, hay una doble conexión mantenida con el ambiente (mw.10.6-7).

De esta manera, Dewey propone un giro radical en la comprensión de la experiencia que toma como punto de partida la descripción de la misma contenida en la biología, en donde el concepto de experiencia queda vinculado, desde el comienzo, con el concepto de vida. Esta conexión remite, en primer lugar, a la idea de que la experiencia así entendida supone ya siempre un ser vivo, un organismo, y a la vez un medio en el cual y por el cual la vida es posible. Desde este punto de vista, la experiencia es entendida como una especie de interacción entre el organismo y el medio, interacción que supone siempre una conexión doble: el organismo actúa sobre el medio y el medio sobre el organismo. Así, "la interacción del organismo y el ambiente, que resulta en cierta adaptación que asegura la utilización de este último, es el hecho primario, la categoría básica" (mw.12.129). Nótese que, en este contexto, tanto el organismo como el medio resultan agentes: el organismo actúa sobre el medio modificándolo, a la vez que el ambiente actúa sobre el organismo: así, por ejemplo, el hombre modifica el ambiente al arrancar la rama a un árbol o al construir el canal que modifica el curso de las aguas. A su vez, la lluvia inunda bosques y ciudades obligando al hombre a trasladarse, a edificar construcciones más altas, etc. En palabras de Dewey

La vida humana, tanto individual como colectivamente, consiste en transacciones en las cuales los seres humanos toman parte junto a cosas nohumanas del medio y junto a otros seres humanos, de manera que sin esta unión de participantes humanos y no-humanos no podríamos siquiera 
mantenernos vivos, para no decir nada acerca de lograr cualquier cosa. (lw.16.243)

Ahora bien, hasta aquí sólo tenemos dos acciones que, en el mejor de los casos, resultan yuxtapuestas. El organismo A actúa sobre el ambiente B y el ambiente B actúa sobre el organismo A. Sin embargo, lo característico de la experiencia no es tanto eso, cuanto que el organismo actúa sobre el medio a la vez que sufre o padece las consecuencias de su propia acción. El hombre prende fuego en el bosque y el fuego lo quema o incendia el bosque. Así, de acuerdo con Dewey:

El organismo actúa de acuerdo a su propia estructura, simple o compleja, sobre el entorno. Como consecuencia los cambios producidos en el ambiente reaccionan sobre el organismo y sus actividades. La criatura viviente padece, sufre, las consecuencias de su propia conducta. Es esta conexión íntima entre el hacer y el sufrir o padecer las consecuencias de su propia acción lo que llamamos experiencia (mw.12.129).

Esta conexión entre el actuar y el padecer las consecuencias de la propia acción resulta fundamental por cuanto es lo que permite la adaptación y el crecimiento. Por ello, la estructura misma del organismo es un resultado de la experiencia, de su interacción íntima con el medio. Así, un aspecto importante del concepto de experiencia es que, en virtud de la interacción, tanto el organismo como el medio resultan modificados y se constituyen en lo que son. No se trata de que haya un organismo ya formado, ya hecho, que interactúa con un ambiente ya hecho. En otros términos, el punto de partida no es una suerte de dualismo organismo/medio. Antes bien, el organismo y el medio son polos en el contexto de un todo que los incluye a ambos, a saber, la experiencia. Ello es así porque lo que el organismo es, su estructura misma, depende de esa interacción, así como el ambiente es siempre el 
ambiente de un organismo: los aspectos que forman parte del ambiente son aquellos con los que las estructuras orgánicas permiten, de algún modo, lidiar.

Con el objetivo principal de distinguir este tipo de interacción organismo-medio de la que supone dos agentes constituidos de manera independiente que salen luego al encuentro el uno del otro, Dewey propuso en un libro escrito junto a Arthur Bentley y publicado en 1949 el término transacción. Como ha sido señalado (Pronko, N. H y Herman D. T., 1982), el concepto de transacción recogía algunas ideas de Dewey que se remontan, al menos, al año 1896 con la publicación del artículo titulado "The Reflex Arc Concept in Psychology" (ew.5.96-110). En el libro escrito junto a Bentley y titulado Knowing and the Known, el término transacción es utilizado para caracterizar no tanto a la experiencia cuanto a la investigación, dada la temática general del libro que refiere a lo que podríamos caracterizar como experiencia de conocimiento, esto es, a la forma que la experiencia toma cuando estamos ocupados en la actividad de conocer. ${ }^{3}$ Sin embargo, aún en ese texto en el que el concepto de experiencia aparece poco, queda claro que la experiencia misma debe entenderse para los autores de forma transaccional. Ello puede inferirse fácilmente de la siguiente cita: “transaccionalmente empleada, la palabra 'conducta' debería hacer el trabajo que 'experiencia' buscaba hacer en el pasado, y debería hacerlo libre de las aplicaciones vacilantes, vagas y confusas que han hecho finalmente a esta última palabra tan a menudo inservible" (lw.16.260). ${ }^{4}$ En otros términos, puesto que sólo entendido de una forma

\footnotetext{
${ }^{3}$ Esto no debe llevarnos a identificar, como habremos de ver, la experiencia y el conocimiento. Antes bien, en contraposición al sesgo cognitivo del concepto moderno de experiencia, el conocimiento será comprendido por Dewey tan sólo como una forma de experiencia.

${ }^{4}$ Como veremos más adelante en conexión con la crítica a Rorty el abandono del término "experiencia" en estas obras tardías de Dewey no debe interpretarse como una renuncia a su teoría de la experiencia, sino tan sólo como una renuncia al término.
} 
transaccional el término conducta puede reemplazar a experiencia, se sigue entonces que la experiencia misma debe entenderse de esa forma. Es decir, la experiencia es transaccional.

Dewey y Bentley distinguen, en el escrito al que nos referimos, tres enfoques o formas de explicar los fenómenos, de "presentar los objetos" (lw.16.96): el enfoque de la auto-acción, el de la inter-acción y el de la trans-acción. El enfoque de la auto-acción presenta a sus objetos como acabados en sí mismos y caracterizables de forma completamente independiente de las relaciones que mantengan con otros objetos. Este enfoque ve así a las cosas "como actuando bajo sus propios poderes" (lw.16.101). En cambio, el enfoque interaccional analiza las relaciones entre las cosas, por ejemplo, las relaciones causales, pero considerando que cada cosa está ya definida y completa de modo independiente de las interacciones en que participa. Por último, el enfoque transaccional “representa el último nivel en el cual la observación y presentación puede realizarse sin atribuir los aspectos y fases de la acción a auto-actores independientes ni a elementos o relaciones independientemente interactuantes" (1w.16.112). En otros términos, los polos de la transacción sólo son definibles dentro del sistema y por referencia de unos a otros, sin que se pueda asumir una caracterización, descripción o conocimiento de dichos elementos que sea previa a la transacción misma.

Cabe señalar que estos tres enfoques son vistos por Dewey y Bentley como formas sucesivas en que la investigación trató los fenómenos y los hechos. En ese sentido, recogen evidencia de que tanto en física como en psicología se han ido adoptando enfoques transaccionales de los diferentes fenómenos (lw.16.96 y ss.). Por ello, de acuerdo con Dewey, su propio enfoque de la experiencia tiene, por así decirlo, un cierto apoyo independiente, proveniente del enfoque de la actividad del ser humano, en tanto que 
organismo, ofrecido por la biología, la psicología y la antropología social. Frente a ello, el concepto moderno de experiencia es visto por Dewey como no-empírico, en el sentido de que no es derivado a partir de hechos conocidos de la actividad humana, sino que es más bien una consecuencia de ciertos posicionamientos filosóficos tradicionales. En efecto, afirma Dewey, los enfoques tradicionales de la experiencia "no han sido empíricos, sino que han sido deducciones, desde premisas anónimas, de lo que la experiencia debe ser (...) han ofrecido ideas impuestas a la experiencia (...), no tomadas de ella" (mw.10.11).

Volviendo a las críticas de Dewey al concepto tradicional de experiencia, podemos apreciar de qué modo una concepción transaccional de la experiencia amplía, a la vez que corrige, ciertos aspectos de aquel concepto, y fundamentalmente del concepto de experiencia del empirismo moderno. Si la experiencia es transacción organismo/medio, resulta que, en primer lugar (1) el rango de la experiencia es más amplio que la experiencia que tenemos cuando intentamos conocer las cosas. Así, la experiencia no es ni primaria ni exclusivamente una experiencia de conocimiento. Además, (2) si la experiencia es una transacción, no puede reducirse a algo meramente mental o subjetivo sino que supone la acción mutua del organismo y el medio, siendo el aspecto subjetivo de la experiencia sólo una fase de la misma, un aspecto involucrado en la transacción. En palabras de Dewey "lo que la experiencia sugiere acerca de sí misma es un mundo genuinamente objetivo que entra en las acciones y sufrimientos del hombre y padece modificaciones a través de sus respuestas" (mw.10.7). Por otro lado, (3) si la experiencia es transacción, acción orgánica que modifica el ambiente y padecimiento de las consecuencias de la propia acción, no puede pensarse como un registro del pasado, sino siempre como acción hacia el futuro que modifica lo "dado" y no se ajusta meramente a ello. En este sentido, la experiencia misma 
es "experimental": implica "un esfuerzo por cambiar lo dado; se caracteriza por la proyección, por lanzarse hacia lo desconocido" (ibidem).

Los dos últimos aspectos en los que el concepto de experiencia de Dewey se aparta de la tradición resultan intrínsecamente relacionados y apuntan a algunos aspectos acaso más técnicos de su posición. En primer lugar está el hecho de que en la experiencia las cosas no se nos presentan como un agregado de cualidades discretas sino como totalidades en las que podemos distinguir componentes, pero sólo como un resultado posterior obtenido en virtud de un análisis reflexivo. Así, las impresiones simples y aún las complejas de las que hablaba, por ejemplo, el empirismo humeano, no son algo dado que en virtud de su asociación posterior nos permite tener experiencias más complejas, sino que son el resultado de la abstracción y la reflexión. De acuerdo con Dewey, al tomar a las impresiones como elementos dados previamente de los que se compone la experiencia, la filosofía tomó como si fuera algo dado de manera previa algo que en verdad sólo era el resultado de la reflexión. En este sentido, nuevamente, el concepto tradicional de experiencia no es empírico, sino una deducción a partir de ciertos supuestos, de ciertas ideas acerca del conocimiento provenientes fundamentalmente de la concepción griega del mismo. Frente a esto, afirma Dewey, (4) “una experiencia, que es un padecer un ambiente y un esforzarse por controlarlo hacia nuevas direcciones, está cargada de conexiones" (mw.10.7). En este mismo sentido, el pensamiento y la inferencia no son agencias separadas de la experiencia que introducen en ella factores extraños, sino que forman parte de la experiencia misma. Como veremos más adelante, esta posición de Dewey está relacionada con su tesis acerca del carácter natural de la inferencia: el inferir una cosa a partir de otra es un hecho tan natural en la experiencia humana como lo es comer una 
manzana, fijar la atención en un objeto distante o estornudar. En otros términos, el pensamiento y la experiencia no pueden pensarse como términos antitéticos, sino que más bien debe tenerse en cuenta que (5) la inferencia y la reflexión se hallan presentes por doquier en la experiencia del organismo humano.

Si bien es cierto que la caracterización de la experiencia como transacción despeja el camino hacia una nueva concepción de la experiencia humana, su caracterización como mera transacción orgánica resulta aplicable a cualquier organismo y no sólo al animal humano. Si la experiencia es una suerte de transacción que transforma tanto al organismo como al medio, resulta que no sólo el ser humano es capaz de experiencia. Como hemos visto, en este contexto la experiencia extiende su alcance hasta donde se halle vida. Ello no significa, en absoluto, que la forma de la experiencia propiamente humana quede reducida a una transacción puramente física y biológica. Antes bien, la experiencia humana resulta continua con la experiencia de otros organismos. Como tendremos oportunidad de ver, ello significa que los rasgos distintivos de la experiencia humana tienen que poder ser explicados como un resultado de transacciones de un nivel menos complejo, resultado que no es ni una mera reiteración de lo ya dado en los niveles de menor complejidad, ni puede entenderse como un salto explicable por la intromisión de algún factor absolutamente extraño a las transacciones que se conocen como operantes en la naturaleza. En otros términos, los rasgos característicos de la experiencia humana son entendidos por Dewey en un contexto definitivamente naturalista sobre el que volveremos mas delante, al referirnos a su teoría de la investigación. En esta dirección, resulta pertinente detenernos (apartado 2.2) en lo que Dewey denomina el carácter estético de la experiencia, que permite cualificar a las diferentes experiencias, distinguiéndolas las unas de las otras pero mostrando, a su 
vez, sus elementos comunes. Asimismo, en el apartado 2.3 reconstruiremos la distinción de Dewey entre experiencia primaria u ordinaria y experiencia secundaria o distintivamente reflexiva.

\subsection{Inmediatez cualitativa: el carácter estético y emocional de la experiencia}

Como vimos, una de las críticas de Dewey a la tradición es su identificación de la experiencia con la experiencia de conocimiento o cognitiva. Se trata de un punto que tiene, en el contexto del pensamiento de nuestro autor, una relevancia destacada. En efecto, este punto está conectado para Dewey con la posibilidad de un abordaje inteligente, racional o "científico" de la cuestión de los valores, cuestión ésta que acaso constituya su preocupación central. Como veremos en el capítulo 6, la valoración como proceso de formación (elección y justificación) de valores, está estrechamente vinculada con los aspectos cualitativos, emocionales y de uso y goce de la experiencia de donde se extraen los deseos que se convertirán en valores tras la intervención de la inteligencia. Un requisito para que ello sea posible es que los aspectos cualitativos de la experiencia sean tenidos en cuenta como algo más que caracteres ontológicamente degradados de las cosas o como elementos puramente subjetivos o privados, es decir, pertenecientes exclusivamente a la mente. Si los aspectos meramente cualitativos de las cosas son considerados de esa manera, entonces no pueden constituir el material sobre el que se apoye un proceso inteligente o racional de valoración. Si, por otro lado, se identifica a la experiencia con la experiencia cognitiva, y resulta que el conocimiento desecha los aspectos cualitativos de la naturaleza para concentrarse en los aspectos cuantitativos que permiten establecer correlaciones y 
regularidades, se sigue que los aspectos cualitativos quedan expulsados del ámbito de la inteligencia, e incluso de la experiencia misma en la medida en que ésta se comprenda como experiencia cognitiva. Tal sería, por ejemplo, el caso con los empiristas que identifican la experiencia con la suma de "datos" para el conocimiento. Al hacerlo privan a la valoración de toda base racional, o en todo caso reducen el tratamiento de los valores a un mero cálculo de intereses, toda vez que, de ese modo, al ser cuantificados los valores se volverían racionalmente abordables. En palabras de Dewey, esta negación de los objetos cualitativos tiene, en cuestiones estéticas, morales y políticas, el efecto de negar que [tales cuestiones] tengan fundamentación o también, de privarlas, a efectos de subsumirlas en las categorías lógicas comunes, de su significado distintivo - un procedimiento que conduce al mito del "hombre económico" y a la reducción de la estética y la moral, en la medida en que pueden recibir algún tipo de tratamiento intelectual, a asuntos cuasi-matemáticos (lw.5.245).

Así, a los efectos de desarticular esa posición, Dewey comienza por afirmar el carácter de inmediatez cualitativa de la experiencia. Cuando experimentamos, las cosas no son conocidas, sino sentidas, sufridas, padecidas, usadas o disfrutadas. Es decir, la relación del ser humano con las cosas no es, al menos no en la experiencia ordinaria, una relación de conocimiento sino de uso, goce o padecimiento y posee siempre un elemento de inmediatez cualitativa que es sentido o "tenido" en una experiencia.

Podemos señalar, con Bernstein (2010, pp. 131-132), tres aspectos destacables de la tesis deweyana acerca de la inmediatez cualitativa de la experiencia. En primer lugar, las cualidades son directamente experimentadas pero no directamente conocidas. Al igual que Peirce, según vimos en el capítulo 1, Dewey negó de forma categórica la posibilidad de conocimiento inmediato o intuitivo. Todo conocimiento supone la mediación de la 
investigación, por más rudimentaria que sea y supone así algún tipo de inferencia y, por lo tanto, de lenguaje. El aspecto cualitativo de la experiencia, esto es, las cualidades de las cosas que experimentamos, pueden ser conocidas pero ello implica, obviamente, que el tipo de experiencia que se tiene es ya una experiencia a la que cabe calificar como cognitiva. Como afirma Bernstein, la experimentación de cualidades es para Dewey una condición necesaria pero no suficiente para el conocimiento. En principio, las cualidades deben ser nombradas para que puedan intervenir en un experiencia cognitiva, lo que supone fijar la atención sobre ellas y hacer con ellas algo más que "sentirlas".

Un segundo aspecto que menciona Bernstein, y que se sigue de la concepción general de la experiencia expuesta en el apartado anterior, es que las cualidades experimentadas no son entidades puramente subjetivas o mentales como parece haber supuesto la tradición filosófica, sino que son propiedades de un cierto estado de la transacción organismo/medio. En palabras de Dewey, las cualidades que experimentamos como colores, sonidos, ruidos, dolores, placeres, olores, etc., no están ““en’ el organismo; siempre son cualidades de interacciones en las cuales participan tanto las cosas extraorgánicas como el organismo" (lw.1.198). Como veremos en el capítulo siguiente, el concepto de situación cobra aquí un rol especial, por cuanto las cualidades al ser sentidas por el organismo en función de su transacción con el medio son una rasgo de una situación, esto es, de un cierto estado de la transacción, en la que ambos polos de la experiencia, el organismo y el medio, se encuentran. Esto resulta importante y tiene, además, una consecuencia ontológica más fuerte. De acuerdo con Dewey, especialmente bajo el influjo de la revolución científica el mundo fue visto como un mecanismo que involucraba cosas, relaciones o eventos carentes en sí mismos de toda cualidad y por tanto de todo valor. El 
valor y las cualidades directamente sufridas o gozadas eran concebidos como una suerte de agregado caprichoso de los hombres, y la naturaleza fue concebida como carente, en sí misma, de todo valor. Pero, si las cualidades son un rasgo de una transacción organismo/medio, entonces no pueden ser ya expulsadas de la naturaleza, por cuanto tales transacciones son fenómenos tan naturales como cualquier otro. En palabras de Dewey “el mundo en que vivimos de modo inmediato, ese en el que nos esforzamos, tenemos éxito y somos derrotados es preeminentemente un mundo cualitativo. Aquello por lo que actuamos, sufrimos y disfrutamos son cosas en sus determinaciones cualitativas" (lw.5.243).

El tercer rasgo que Bernstein destaca de la concepción deweyana de la inmediatez cualitativa de la experiencia es que las cualidades sensoriales, las comúnmente llamadas cualidades primarias y secundarias, no son las únicas cualidades que son sentidas o tenidas sino que también lo son las cualidades que podemos llamar emocionales, como los sentimientos de alegría, tristeza, aburrimiento, excitación, etc. Estas últimas juegan, además, un rol destacado y son las que permiten identificar un determinado estado de la transacción organismo/medio como una experiencia. En el capítulo tercero de su Art as experience (lw.10.42-64), Dewey distingue entre el mero tener experiencia y el tener una experiencia. Como hemos dicho, la experiencia extiende su alcance allí donde llega la vida, es decir, la experiencia es un proceso constante: "la experiencia ocurre continuamente, porque la interacción de la criatura viviente y el ambiente está involucrada en el proceso mismo de la vida" (lw.10.42). Pero hay ciertas situaciones en las que la experiencia resulta un todo unificado y exhibe fases de inicio, de desarrollo y de cierre o consumatorias. En función de ello, esa experiencia puede ser distinguida de otras experiencias. "Tenemos una experiencia cuando el material sigue su curso hacia su consumación. Entonces, y sólo 
entonces, resulta integrada y demarcada, en el fluir de la experiencia, de otras experiencias" (lw.10.42). El aspecto que permite trazar esta distinción reside, para Dewey, en el cariz específico de su inmediatez cualitativa, al que Dewey se refiere como emocional. En sus palabras, "bajo condiciones de resistencia y conflicto, aspectos y elementos del yo y del mundo que están implicados en esta interacción cualifican la experiencia con emociones e ideas (...). Tal experiencia es un todo y lleva consigo su propia cualidad individualizadora (...)" (lw.10.42). Así, esta cualidad emocional mantiene unificada a la experiencia como una experiencia que es, por tanto, necesariamente singular a la vez que permite integrar los diferentes elementos que intervienen en ella formando un todo unificado. En palabras de Dewey,

una experiencia tiene una unidad que le da su nombre, aquella comida, aquella tormenta, aquella ruptura de la amistad. La existencia de esa unidad está constituida por la cualidad singular que impregna la experiencia entera a pesar de la variación de sus partes constituyentes (lw.10.44).

Este elemento cualitativo o emocional de la experiencia es llamado por Dewey estético. Así, toda experiencia tiene un elemento estético. Ello resulta importante, a los ojos de Dewey, por dos razones. En primer lugar, y aunque no nos detendremos en ello por cuanto no resulta pertinente en el contexto de esta investigación, esta tesis permite a Dewey construir una concepción del arte que toma como punto de partida a la experiencia distintivamente estética, experiencia que tiene continuidad con la experiencia ordinaria por cuanto resulta de la exaltación y promoción del carácter estético inherente a esta última ${ }^{5}$. Por otro lado, esto permite a Dewey encontrar algunos puntos de continuidad entre la

${ }^{5}$ Como ha sido señalado, la filosofía del arte de Dewey, al poner como elemento central la cuestión de la experiencia estética, anticipa algunas tesis de la así llamada estética de la recepción. Sobre esta cuestión cfr. Solas (2008). Sobre la concepción del arte y de la relación entre arte y ciencia en Dewey cfr. Di Gregori y Duran (2008). 
experiencia ordinaria, la experiencia artística propiamente dicha, y la experiencia cognitiva. El punto de partida para ello es la afirmación de que también ésta última tiene una cualidad estética: "la más elaborada investigación filosófica o científica y la empresa industrial o política más ambiciosa tienen, cuando sus diferentes elementos constituyen una experiencia integral, cualidad estética" (lw.10.61). Y ello es así por cuanto "ninguna experiencia del tipo que sea es una unidad a menos que tenga cualidad estética" (lw.10.47). Así, ya no puede pensarse la experiencia cualitativa y la experiencia intelectual en términos antitéticos. Una experiencia cognitiva puede ser estéticamente disfrutada e incluso moralmente promovida: los aspectos cualitativos de la experiencia son relevantes en la promoción de la actividad cognitiva. Pero aún independientemente de ello, la experiencia cognitiva en sí misma debe contener ese elemento cualitativo, porque es tal elemento el que permite, por ejemplo, apreciar que un cierto problema ha sido resuelto. Como veremos en el capítulo siguiente, el proceso mismo de la investigación conlleva la formulación de juicios apreciativos, es decir, de juicios que afirman que un cierto fenómeno tiene una cierta cualidad. En efecto, sostiene nuestro autor,

Lo que es incluso más importante es que, no sólo es esa cualidad un motivo significativo para emprender una investigación intelectual y para mantenerla honesta, sino que ninguna actividad intelectual es un evento integral (una experiencia) a menos que sea completada con esa cualidad. Sin ella, el pensamiento es inconclusivo. Brevemente dicho, lo estético no puede ser separado de la experiencia intelectual, puesto que esta última debe cargar con un sello estético para ser en sí misma completa (lw.10.25).

En otros términos y como han señalado Di Gregori y Pérez Ranzans (2009), el componente emocional de la experiencia juega un papel importante incluso en la experiencia 
propiamente cognitiva, es decir, juega un rol epistémico importante. Como lo sostienen las autoras mencionadas, la posición asumida por Dewey permite afirmar que "las emociones inciden directamente en los procesos cognitivos al aportar un nuevo patrón de relevancia o de contenido informativo, alrededor del cual se reestructura el campo de la percepción y por ende, la construcción de representaciones” (Di Gregori y Pérez Ranzans, 2009, p. 294).

\subsection{Experiencia primaria y experiencia reflexiva: el conocimiento como experiencia}

Una de las preocupaciones mayores de Dewey ha sido el poner en relación diferentes modos de experiencia que veía en la sociedad de su tiempo como compartimentados y asilados los unos de los otros: la experiencia artística se encerraba en el museo y tenía cada vez menos que ver con la experiencia de la vida cotidiana de las personas y la ciencia era vista como una actividad meramente técnica sin ninguna relevancia real respecto de los valores estéticos y morales que mueven a las personas en sus vidas. Particularmente, la relación entre la experiencia cotidiana y sus objetos y la experiencia científica y los suyos fue un tema de preocupación para Dewey. Como ya adelantamos, tal preocupación tenía que ver fundamentalmente con la negación del valor e incluso con la degradación ontológica de los objetos y los valores del sentido común. Así, de acuerdo con una filosofía ampliamente extendida, la ciencia venía a mostrarnos lo que las cosas realmente son, arrogándose un acceso a la "verdadera" realidad, vedada, por principio, a los hombres y mujeres de a pié. El concepto de experiencia ofrecerá a Dewey una vía de escape de esta posición que permita dar cuenta del valor de los objetos y materiales del sentido común, pero sin desconocer el valor y los aportes de la actividad científica propiamente dicha. En 
otros términos, no se trata de depreciar los objetos de la ciencia frente a los del sentido común, tratándolos de ilusiones, sino más bien de mostrar el modo en que se relacionan y los valiosos aportes que la actividad científica tiene para ofrecer.

Hasta aquí hemos caracterizado a la experiencia como una transacción organismo/ambiente que exhibe una característica sobresaliente, a saber, un aspecto de inmediatez cualitativa que, cuando se constituye propiamente en un sentimiento o una emoción, funciona como principio de individuación de las experiencias vividas o sentidas por los seres humanos, a la vez que permite unificar sus elementos internos. Este aspecto se halla presente siempre que se tenga una experiencia. Es sentido tanto en experiencias cotindianas, como lo podría ser un paseo con un perro, cuanto en experiencias más reflexivas, como cuando intentamos averiguar cuáles son los papeles que debemos reunir para poder realizar un trámite. Tenemos aquí dos ejemplos de experiencia que, de acuerdo con Dewey, pueden caracterizarse respectivamente como experiencia primaria u ordinaria y experiencia secundaria o reflexiva. Esta distinción, tarazada por nuestro autor en su Experience and Nature (lw.1), resulta central para entender de modo cabal su concepción transaccional, performativa y valorativa del conocimiento, a la vez que su concepción instrumental de los objetos científicos.

En dicho libro, afirma Dewey lo siguiente:

[Hay] un contraste entre los materiales gruesos, macroscópicos de la experiencia primaria y los objetos refinados y derivados de la reflexión. La distinción es entre lo que es experimentado como resultado de un mínimo de reflexión fortuita y lo que es experimentado como consecuencia de una investigación reflexiva continua y regulada (1w.1.15). 
Así, puede trazarse una diferencia entre la experiencia primaria u ordinaria y la experiencia reflexiva o secundaria. Es importante tener en cuenta que la distinción no es una distinción entre una experiencia directa de mera aprehensión cualitativa del mundo frente a una experiencia que involucra lenguaje y reflexión. Como vimos, el aspecto cualitativo resulta insoslayable para cualquier experiencia. Por otro lado, la experiencia distintivamente humana supone, como veremos más adelante, un medio cultural y lingüístico, es decir, está siempre mediada por el lenguaje y el ambiente cultural en el que transcurre la vida humana. Se trata, más bien, de una distinción entre una experiencia en la que el elemento de reflexión resulta predominante y una experiencia ordinaria en la que se usan, se gozan o se padecen, de modo directo, las cosas del mundo, quedando la reflexión reducida a un rol secundario o fortuito.

Resulta evidente que la distinción resulta difícil de trazar en la práctica, por cuanto las experiencias de uso y goce directo se entremezclan siempre con experiencias reflexivas, sumado esto a que los componentes distintivos de las unas se hallan también presentes, de modo subordinado, en las otras. Con todo, resulta claro que hay ciertas experiencias a las que cabe calificar como distintivamente reflexivas, en las que las cosas son tomadas como signos, como indicios, como consecuencias de otras, mientras que hay otras experiencias en las que las cosas son usadas y disfrutadas o sufridas de modo directo. Podemos pensar, por ejemplo, en una situación en la que se disfruta una comida, o incluso en la que se prepara una de un modo rutinario. Este último caso, por supuesto, implica ciertos márgenes de reflexión, pero hay una diferencia entre la preparación de una comida de modo rutinario, por ejemplo una comida que se ha preparado muchas veces y de cuyos ingredientes se dispone, y una situación en la que no se sabe qué se va a cocinar, o se cocina algo que 
nunca se cocinó y se preparan y buscan los ingredientes y los utensilios que serán usados. En este último caso, se trata de una experiencia distintivamente reflexiva que supone lo que podemos denominar una investigación de sentido común. También, por supuesto, las investigaciones científicas constituyen ejemplos de experiencias reflexivas o secundarias.

Cabe, entonces, preguntarse por la relación entre ambos tipos de experiencias. De acuerdo con Dewey puede afirmarse que "el material de la experiencia primaria plantea los problemas y suministra los primeros datos de la reflexión que construye los objetos secundarios" (lw.1.16). Es decir, la experiencia reflexiva encuentra siempre el punto de partida en la experiencia ordinaria: es algún tipo de ruptura, de problema, de desequilibrio en la experiencia ordinaria lo que genera la ocasión para la reflexión y lo que ofrece los materiales que servirán a la reflexión para construir las respuestas adecuadas. Asimismo, estas respuestas deberán ser testeadas nuevamente en su encuentro con los objetos de la experiencia primaria. Los objetos de la reflexión, los conceptos, las ideas y las hipótesis forjadas, recibirán su validación o su rechazo en función de lo que ocurra con los objetos de la experiencia primaria una vez que se han realizado ciertas operaciones. Así, de acuerdo con Dewey, "el testeo y la verificación de los últimos [de los objetos secundarios de la reflexión] se asegura sólo retornando a las cosas de la experiencia cruda o macroscópica el sol, la tierra, las plantas y los animales de la vida común de todos los días” (lw.1.16). De este modo, vemos que la experiencia reflexiva, y hay que recordar que el conocimiento es experiencia reflexiva por antonomasia, juega un rol intermediario entre una experiencia ordinaria que es previa a la experiencia reflexiva, y una experiencia ordinaria que es posterior a ella, y que ha incorporado nuevos elementos y relaciones como consecuencia de la experiencia reflexiva anterior. En palabras de Dewey, "el modo cognitivo [de la 
experiencia] es intermediario entre un primer tipo de material experimentado, menos organizado, más confuso y fragmentario y uno más ordenado, más claro, más libre y bajo un mejor control de su ocurrencia" (lw.14.12). De este modo, vemos que los objetos de la experiencia reflexiva resultan instrumentales, mientras que los objetos de la experiencia primaria, los usos, goces y sufrimientos de los seres humanos, son a la vez, primeros y últimos. En efecto, según Dewey, resultaba importante reconocer "la primacía y ultimacía [ultimacy] de la experiencia bruta - primaria en tanto se da de una forma incontrolada, última en tanto se da de una forma más regulada y significativa - una forma hecha posible por los métodos y resultados de la experiencia reflexiva" (lw.1.24).

Nos encontramos, así, con una de las características centrales de la concepción del conocimiento de Dewey, es decir, su carácter instrumental y mediador en el contexto de la experiencia humana. El conocimiento es experiencia que se ha vuelto reflexiva a los efectos de enriquecer, ensanchar, asegurar o controlar la experiencia no-cognitiva. El conocimiento es así, en tanto que forma de la experiencia, transaccional, en tanto es una forma de modificar el ambiente que modifica a la vez al organismo que lo desarrolla y permite que la experiencia continúe en nuevas y mejores condiciones. Así, afirma Dewey que "el conocimiento, cuando es alcanzado, es el único medio para un enriquecimiento controlado y para un control de las subsiguientes experiencias de tipo cualitativo no-cognitivo" (lw. 14.13). De este modo, podemos apreciar que el concepto de experiencia permite a Dewey ofrecer un concepto de conocimiento que señala e insiste en la capacidad de la reflexión y la razón para la transformación y reconstrucción de mundo en que vivimos: la meta del conocimiento no es describir al mundo sino modificarlo, intervenir en él. ${ }^{6}$

\footnotetext{
${ }^{6}$ Como resulta evidente, y como su propio autor ha reconocido, la posición de Ian Hacking en su Representing and Intervening: Introductory Topics in the Philosophy of Natural Science (1983) es deudora de
} 
Este instrumentalismo sostenido por Dewey ha sido uno de los aspectos más discutidos por sus críticos. La relación entre conocimiento y acción planteada por Dewey, y la insistencia en que conocer el mundo supone modificarlo más que reflejarlo, han llevado a sus críticos a acusarlo de sostener diversas formas de idealismos y relativismos rayanos con el absurdo. Por ejemplo, en el volumen de The Library of Living Philosophers editado por Paul Arthur Schilpp en 1939 en honor a Dewey fue esta una de las cuestiones más ampliamente debatidas. Esta posición instrumentalista sostenida por Dewey parecía descartar una posición realista. En efecto, la afirmación de que hay un mundo que es por principio independiente de lo que se piense acerca de él constituía para nuestro autor una negación, o al menos un oscurecimiento, de los poderes de transformación que la "mente", la reflexión y las ideas tenían en relación con el mundo. Esa tesis, que ha sido identificada como un realismo metafísico, parecía ser solidaria o al menos compatible con la idea de que el rol del conocimiento es describir esa realidad que es independiente y previa a la acción misma del conocimiento. Así, el sujeto cognoscente sería una suerte de espectador que mira desde afuera la realidad y la intenta describir, es decir, la intenta conocer. Se trata de una concepción del conocimiento que Dewey llamó, es su The Quest for Certainty (lw.4), teoría del conocimiento del espectador (lw.4.19). En el contexto de un realismo metafísico y una concepción especular del conocimiento, la idea de que el conocimiento modifica la realidad que conoce era sencillamente un absurdo: o parecía afirmar que la mente tenía algún poder mágico de trasformación instantánea de la realidad o volvía imposible el conocimiento puesto que se modificaba y por tanto falseaba lo que se quería conocer mediante la acción misma de conocerlo.

Dewey. Afirma Hacking: "mi propia opinión, a saber, que el realismo es un asunto de intervenir en el mundo, más que de representarlo en palabras y pensamiento, ciertamente le debe mucho a Dewey” (1997, p. 83). 
De este modo, si el conocimiento, la reflexión y la mente han de tener algún rol en la trasformación del mundo, como de hecho lo tienen en la técnica y la tecnología, por ejemplo, o, en otros términos, si el conocimiento es una forma de la experiencia, es decir, es transaccional, no puede ya sostenerse que el conocimiento busque describir una realidad previa e independiente. Tal como la acabamos de presentar, la posición de Dewey parece llevar a una suerte de idealismo. Sin embargo, Dewey mismo rechazó esta caracterización e incluso en su respuesta a la acusación de Reichenbach ${ }^{7}$ acerca de que afirmaba una concepción no realista de la ciencia, Dewey afirmó que nunca había pretendido “decir nada que pudiera llevar directa o indirectamente a la creencia de que sostengo una “interpretación no realista de los conceptos científicos"” (lw. 14.20). Antes bien, aclara Dewey, algunos pasajes de su obra que pueden interpretarse de esta manera en realidad sólo constituían una negación de que los objetos acerca de los cuales versa la ciencia, a saber, lo objetos de la experiencia ordinaria, sean meras fantasías, meras ilusiones frente a los objetos que surgen como los "reales" luego de la actividad científica. Cabe recordar, en este punto, que, como acabamos de ver, la experiencia reflexiva, el conocimiento, toma su material de la experiencia primaria y a ella vuelve para testear los conceptos e ideas elaborados por la reflexión. En otros términos, Dewey se estaba oponiendo a un realismo científico, pero sólo en la medida en que tal posición implica negar la realidad a los objetos de la experiencia primaria, es decir, en tanto y en cuanto implica la negación de un realismo de sentido común. En esta medida y como Peter Godfrey-Smith $(2002,2013)$ ha afirmado, la posición de Dewey es más próxima a un realismo de lo que puede parecer a primera vista.

\footnotetext{
${ }^{7}$ El artículo que contiene las críticas de Reichenbach así como también la respuesta de Dewey se encuentran en el volumen editado por Schlipp antes mencionado (Dewey, Schilpp, \& Hahn, 1939).
} 
Sin embargo, la posición de Dewey contiene algunos elementos que conviene recordar. Resulta claro que cuando Dewey afirma que el conocimiento modifica la realidad, se refiere, en primer lugar, a un modificación que se opera a través de la acción: es la acción, guiada por las ideas y conceptos descubiertos en la reflexión y el conocimiento, la que nos permite modificar la realidad, logrando así una experiencia más segura, más rica y cargada de reflexión, por así decirlo. Esta idea de que el conocimiento modifica o transforma la realidad implica que efectivamente hay una realidad previa al conocimiento, pero que el producto de ese conocimiento no es su descripción, sino su transformación. Como Godfrey-Smith señala $(2002,2013)$, esta posición acerca a Dewey con algunos realistas, a la vez que lo aleja de algunas formas de constructivismo social sostenidas en el contexto de los estudios sociales de la ciencia. ${ }^{8}$ Un aspecto remarcable de esta posición es que Dewey hace de la acción un elemento central en el conocimiento: el conocimiento entendido como forma de experiencia implica acción, implica una actividad de trasformación material o física, un reordenamiento de ciertos elementos de la naturaleza. En este sentido, el instrumentalismo de Dewey es un resultado de ubicar el conocimiento, entendido como una cierta práctica de los seres humanos, en el contexto más amplio de la experiencia humana: los seres humanos nos embarcamos en prácticas cognitivas a efectos de transformar ciertos aspectos del mundo y de las relaciones en las que nos encontramos.

Sin embargo, hay otro aspecto de acuerdo con el cual el conocimiento modifica la realidad que conoce, aún previamente a la acción misma. En efecto, al conocer una cosa se establecen nuevas relaciones en las que esa cosa interviene, se abren nuevas posibilidades para la acción; es decir, se establecen nuevas relaciones entre las cosas y entre las cosas y la

\footnotetext{
${ }^{8}$ Como tendremos oportunidad de señalar (cap. 10), esta distancia es más bien con formas de la sociología de la ciencia que siguen atadas a una concepción representativista de la ciencia.
} 
mente. Una vez que conocemos algo, eso se convierte en un medio potencial para ciertas cosas o en una consecuencia de ciertas otras. Como afirma Godfrey-Smith (2013, p. 6), “en razón del establecimiento de esas relaciones, se operan cambios en los objetos, incluso antes de que nuevas acciones hayan sido realizadas", y más aún "antes de las actividades del pensador, hay un estado definido en que el mundo está. Después del descubrimiento de una nueva idea, el mundo está en un nuevo estado" (2013 pp. 6-7). El conocimiento nunca deja las cosas como están, puesto que el surgimiento de una idea, en tanto y en cuanto es un hecho tan real como cualquier otro, introduce cambios, introduce novedades: las cosas entran en nuevas relaciones y una cosa se vuelve el medio o la consecuencia de otra, a la vez que el sujeto que conoce entra en nuevas relaciones con ellas. Como señala GodfreySmith (2013) esta posición no carece de dificultades y se apoya en última instancia en la tesis deweyana acerca de la realidad de las relaciones. Las relaciones en las que una cosa interviene son tan reales como la cosa misma y son experimentadas en la experiencia misma.

Cabe señalar, sin embargo, un punto en que no compartimos completamente la argumentación de Godfrey-Smith. En efecto, dicho autor sostiene que el instrumentalismo de Dewey refiere, más que al conocimiento mismo, al objeto del conocimiento: el conocimiento se ocupa de estudiar relaciones causales o de medios y consecuencias y, en este sentido, el objeto de la ciencia es instrumental. En este sentido, y como Dewey mismo afirma por ejemplo en Experience and Nature "los objetos propios de la ciencia son naturalezas en sus caracteres instrumentales" (lw.1.111). Así, de acuerdo con GodfreySmith, Dewey es un instrumentalista en el sentido de que, para él, "la ciencia es el estudio desinteresado de la instrumentalidad en la naturaleza" (2002, p. 8). Así, Godfrey-Smith ve 
a Dewey como un realista científico especial, por cuanto aquello que se conoce son relaciones, instrumentalidades reales. Sin embargo, en nuestra opinión, Godfrey-Smith minimiza el rol mismo del conocimiento en el enriquecimiento en general. Como veremos en el próximo capítulo, la teoría de la investigación de Dewey se esfuerza muy marcadamente por explicar de qué modo deben interpretarse los conceptos y proposiciones mismos de la ciencia, de modo que puedan ser entendidos como instrumentalidades puestas al servicio de la modificación de la realidad. Y si bien es cierto que Dewey insiste en que la actividad científica tiene un aspecto de desinterés y que no debe estar siempre dirigida a cumplir fines inmediatos, lo cierto es que tal desinterés es sólo transitorio, y no es más que una imposición del método, de la investigación, para evitar vernos frustrados en la consecución de nuestros fines. La investigación va siempre dirigida a resolver un problema, lo que se logra, como veremos, sólo cuando se trasforma la situación. Ello resulta importante porque, si el conocimiento es resolución de problemas, los instrumentos que utiliza para ello, incluidos los conceptos, enunciados e hipótesis, serán evaluados como es evaluado cualquier instrumento, a saber, en virtud de su función, positiva u obstructiva, en la resolución del problema. ${ }^{9}$

En nuestra opinión, cuando Godfrey-Smith afirma que la ciencia no está para Dewey estrechamente ligada a tareas prácticas inmediatas o a beneficios y metas prácticas, desconoce que para Dewey la ciencia misma es un asunto de la práctica. La tarea del científico, como veremos en el capítulo siguiente, consiste en realizar juicios acera de lo

\footnotetext{
${ }^{9}$ Como veremos más adelante, Dewey establece una clara diferencia funcional entre los datos y las ideas o hipótesis en el contexto de la investigación. Los primeros, que no constituyen conocimiento, sino que establecen lo que Dewey llama "hechos del caso", deben ser confiables y fidedignos, en el sentido de que deben estipular qué es lo que podemos considerar como un hecho confiable. Tienen, en este sentido y en nuestra opinión, un cierto contenido de verdad, en el sentido tradicional de tal término. Pero las hipótesis e ideas son posibles soluciones y no se evalúan por su "contenido de verdad" sino en función del servicio que prestan en la resolución del problema.
} 
que conviene hacer. Por supuesto, lo que hay que hacer es, en última instancia, resolver el problema. Cuáles son los problemas que se abordan, si se trata de meros fines inmediatos,

de cuestiones pequeñas que sólo redunden en beneficio de la persona que investiga, o si más bien se trata de problemas de un alcance mayor, es otra cuestión. La ciencia es instrumental, no sólo porque se ocupa de instrumentalidades, sino porque además es el instrumento para modificar la experiencia, es decir, el modo y el mundo en que viven los seres humanos. La ciencia es instrumental independientemente de la inmediatez, el valor y el alcance de los problemas que intenta resolver.

\section{3. ¿Una metafísica de la experiencia?}

Para finalizar este capítulo volveremos a la cuestión del lugar que ocupa, en la obra de Dewey, la concepción de la experiencia. Para ello, resulta oportuno abordar algunos aspectos de las críticas de Richard Rorty al uso por parte de Dewey del concepto de experiencia. Si bien es cierto que Rorty ha sido, probablemente, el autor que más contribuyó a impulsar el resurgimiento del interés en la obra de Dewey, no resulta menos cierto que ha sido también muy crítico de algunas de sus posiciones. En efecto, ha cuestionado, como señala Hildebrand (2003), tanto el intento deweyano de reelaborar una teoría de la experiencia, cuanto su intento de reelaborar una teoría de la investigación. En un clásico texto acerca de la concepción deweyana de la metafísica, Rorty resalta la crítica que Dewey dirige a la metafísica tradicional a la vez que impugna la pretensión del pragmatista clásico de construir lo que Rorty mismo entiende como una metafísica de la experiencia. Tal crítica parece apoyarse, por un lado, en una cierta intuición acerca de que 
el así llamado giro lingüístico de la filosofía del siglo XX impugnaría -en la medida en que supone un aporte duradero- toda apelación al concepto de experiencia. Por otro lado, en opinión de Rorty, la idea de Dewey de una metafísica naturalista de la experiencia resulta auto-contradictoria e insostenible si la analizamos desde el punto de vista de la propia crítica deweyana de la metafísica, y no sería más que una recaída en la enfermedad que intentaba curar. Tal vez como forma de reforzar esta crítica, Rorty insiste en que Dewey mismo se habría dado cuenta de estos problemas, razón por la cuál habría renunciado tanto al concepto de experiencia como a la idea de construir una metafísica apoyada en él. Con el objetivo de comprender mejor el lugar ocupado por el concepto de experiencia en el pensamiento de Dewey, analizaremos en esta sección las mencionadas observaciones de Rorty.

\subsection{La filosofía lingüística y la experiencia}

En su clásico texto acerca de las "Dificultades metafilosóficas de la filosofía lingüística” (1998), Rorty caracteriza a la filosofía lingüística como aquella que sostiene que todo problema filosófico puede resolverse o disolverse produciendo cambios en, o comprendiendo mejor, el lenguaje que utilizamos. En este sentido, la tarea principal del filósofo es analizar los significados de las palabras, lo que debería conducir finalmente a la resolución o disolución de cualquier problema filosófico. Así entendida, la filosofía lingüística de la que habla Rorty sería más bien una posición metafilosófica acerca del modo en que debe proceder el filósofo, es decir, una consideración acerca de la metodología de la filosofía. Si entendemos así al giro lingüístico, es decir, como la 
adopción mayoritaria por parte de la filosofía del siglo $\mathrm{XX}$ de tal presupuesto metodológico, no parece haber ningún inconveniente ni prohibición especial en que una filosofía lingüística se ocupe del significado de "experiencia", así como se podría ocupar del significado de "verdadero", "bueno" o "real". Sin embargo, en su artículo "Veinte años después", que acompaña a la versión española de El giro lingüístico (1998), Rorty cambia el modo de comprender ese fenómeno propio de la filosofía del siglo XX. Afirma, en primer lugar, que su principal contribución no es metafilosófica sino que hace una contribución específica a la filosofía. Tal contribución radicaría, en su opinión, en que sustituye "la referencia a la experiencia como medio de representación por la referencia al lenguaje como tal medio" (1998, p. 164). Este cambio, a su vez, habría permitido prescindir del concepto de representación, por cuanto sentó las bases para la crítica de ese concepto. ${ }^{10}$ Los enunciados, afirma Rorty, serían vistos, después de Quine y Davidson, como “marcas y sonidos usados por los seres humanos en el desarrollo y prosecución de las prácticas sociales, que capacitan a la gente para lograr sus fines, entre los que no está incluido 'representar' la realidad como es en sí misma” (pp. 164-165). Este cambio de la experiencia al lenguaje inhabilitaría entonces el proyecto deweyano de algo así como una metafísica de la experiencia. Tanto más cuanto que, de acuerdo con Rorty, la experiencia era para Dewey, al igual que para Kant, algo intermedio entre impresión sensorial y creencia, términos estos que refieren a entidades mentales, lo que implica que la experiencia sería también para Dewey algo así como una entidad mental.

Como resulta evidente a la luz de la reconstrucción ofrecida en la sección anterior, la primera objeción que se le puede formular a la crítica rortyana es que para Dewey la

\footnotetext{
${ }^{10}$ Esta idea de que la tradición analítica permitía cumplir de un modo más eficaz con la crítica a la tradición que Dewey se proponía, presente en Rorty (1996), es dependiente de la versión oficial de la historia de la filosofía norteamericana.
} 
experiencia no era precisamente un medio de representación ni una entidad mental. Como vimos, una de las luchas mayores de Dewey fue la de intentar hacer a un lado todo concepto de la experiencia como algo privado o subjetivo, como algo que ocurre en las "mentes" de los seres humanos. Además, la idea de la experiencia como medio de representación, es decir, como representación de un objeto por parte de un sujeto, reproduce el dualismo sujeto-objeto que el propio Dewey pretendía socavar utilizando para ello el concepto de experiencia entendido de una forma transaccional. Por otro lado, Dewey fue uno de los pioneros en criticar la idea de que el lenguaje y el conocimiento constituyen medios de "representación”. La idea del lenguaje como un subproducto de la cooperación, como dependiente en última instancia de la necesidad de comunicación, a la que nos referiremos más adelante (cap. 9), es decir, la concepción del lenguaje precisamente como marcas y sonidos usados por los hombres en sus prácticas sociales para lograr fines, es una idea que Dewey ha defendido con firmeza tanto en su Experience and Nature cuanto en su Logic: the Theory of Inquiry.

Hasta aquí, entonces, no parece haber razones de peso para pensar que el giro lingüístico suponga un rechazo a una teoría filosófica de la experiencia, no al menos si por experiencia nos referimos a esa transacción entre el organismo y el medio, o entre fuerzas orgánicas y extra-orgánicas. Resulta llamativo este intento rortyano de proponer un pragmatismo sin experiencia. Por nuestra parte coincidimos con Bernstein en que "eliminar la experiencia del pragmatismo (viejo o nuevo) es desmembrar al pragmatismo, dejándonos con una sombra insignificante del pragmatismo" (2010, p. 128). ${ }^{11}$

\footnotetext{
11 Más aún, en opinión de Bernstein, el recurso al concepto de experiencia tal como es entendido en el contexto del pragmatismo clásico permite dar respuestas a algunos de los problemas que se generan al interior del giro lingüístico tal como es entendido por Rorty. Así, por ejemplo, como señala Bernstein, "a contramano del prejuicio predominante de que el giro lingüístico desplaza al discurso pasado de moda sobre la
} 


\subsection{Metafísica y experiencia}

Uno de los presupuestos de la crítica rortyana a la teoría de la experiencia de Dewey, lo mismo que de muchas de las críticas que despertó Experience and Nature, es la idea de que en él, uno de los objetivos centrales de su autor era construir una verdadera metafísica (naturalista) de la experiencia. La idea de una metafísica naturalista fue, ciertamente, mal recibida. Santayana, un interlocutor frecuente de Dewey, cuestionó la idea misma de metafísica naturalista señalando que se trataría de una contradicción en los términos, posición que medio siglo después Rorty haría suya. No nos detendremos en esta cuestión del naturalismo, sino que abordaremos la cuestión de la experiencia y la idea de una metafísica que tenga por asunto primario tal concepto. Si la idea de que Experience and Nature contiene la teoría de la experiencia de Dewey -y de que tal teoría debe entenderse como una metafísica- es correcta como parece sostener Rorty, entonces, la suerte del concepto de experiencia en el contexto de la filosofía de Dewey está atado al destino, exitoso o fallido, de tal metafísica. Tal vez por ello, Rorty comienza su artículo sobre la metafísica de Dewey anunciando que sobre el final de su vida Dewey habría vislumbrado el

experiencia, la concepción de Peirce de la experiencia nos ayuda a escapar de algunos de los callejones sin salida del giro lingüístico" (2010, p. 137). En efecto, Peirce ofrece una mirada falibilista sobre el conocimiento que evita caer en un idealismo lingüístico, es decir, una concepción que da cuenta del carácter siempre provisorio de nuestras creencias y justificaciones, pero que no pierde de vista el límite que supone una realidad que no se deja identificar con nuestros caprichos e idiosincrasias personales. Por su parte, tanto James como Dewey han señalado no sólo que no se puede reducir la experiencia a la experiencia científica, ni siquiera a la cognitiva, sino que hay otras formas de experiencia como la religiosa o la estética que revisten una importancia filosófica central. Más aún, Dewey ha insistido en que el ambiente con que nosotros, los animales humanos, nos relacionamos, nunca es un ambiente meramente físico o biológico, sino también cultural y que por tanto toda investigación, incluso la de la matemática y la de la física, se dan en un medio que es, a la vez, social y natural. Dewey ha reconocido y enfatizado, además, el insoslayable rol que juega el lenguaje, herramienta de herramientas, que crea y transforma los significados en el contexto de la comunicación, dotando a la experiencia misma de nuevas y más ricas dimensiones. Este reconocimiento de la importancia del lenguaje, y con él de los significados para la experiencia humana, sugiere aún que el pragmatismo ha sido de hecho uno de los impulsores del giro lingüístico, al menos si interpretamos de otra manera esa característica de la filosofía del siglo XX. 
carácter fallido de tal empresa y habría renunciado tanto al término experiencia cuánto al término metafísica (cfr. Rorty, 1996, p. 139). Por supuesto, estas renuncias tardías darían fuerza a la posición de Rorty respecto de la consideración de la apelación a la experiencia como un error y una recaída, por parte de Dewey, en posiciones filosóficas que Dewey mismo estaba tratando de desbaratar. Sin embargo, cabe detenerse en estas pretendidas renuncias, fundamentalmente porque ello nos permitirá comprender mejor el lugar de la teoría de la experiencia en la obra de Dewey.

Como justificación de la renuncia al término experiencia, Rorty refiere a la nueva e inconclusa introducción a Experience and Nature que Dewey intentó redactar en 1951. Esa nueva introducción comienza, como señala Rorty, con la siguiente afirmación: "si hoy escribiera (o reescribiera) Experiencia y Naturaleza, titularía el libro Cultura y Naturaleza y el tratamiento de los temas específicos sería correspondientemente modificado" (lw. 1.361). Esta cita parece apoyar contundentemente, a primera vista, la posición de Rorty. Sin embargo, unas líneas más adelante Dewey afirma sobre el concepto de experiencia que "lo sustituiría [por] el término 'cultura' porque con sus significados ahora firmemente establecidos puede soportar completa y libremente mi filosofía de la experiencia" (lw. 1.361). Es decir, Dewey parece estar dispuesto a renunciar al término experiencia pero no así a aquello a lo que llama su filosofía de la experiencia. En efecto, un poco más adelante declara que "no estoy convencido de que la tarea que emprendí esté totalmente equivocada. Aún creo que, sobre fundamentos teóricos, en tanto que distintos de los históricos, hay mucho para decir a favor del uso de "experiencia"” (lw. 1.361). Queda claro, en nuestra opinión, que Dewey no está renunciado a su filosofia de la experiencia, y que, de hecho, está convencido de que tiene razones teóricas para insistir en tal empresa, aunque no así 
razones históricas. Esas razones u obstáculos históricos para su uso del término se han vuelto, según nos dice Dewey, insuperables (lw.1.361). En efecto, parece reconocer que el término experiencia ha quedado reducido a algo privado y subjetivo que ocurre en las mentes de los sujetos, en vez de referir también, y como él mismo pretendía, a "aquello que es experimentado y a las formas de experimentarlo" (lw. 1.362). En su uso, experiencia remite a ese "material inclusivo" que la filosofía moderna ha partido con sus dualismos sujeto-objeto, mente-mundo y psicológico-físico. Es decir, el término experiencia parecía haber sido definitivamente apropiado por aquellos que sostienen tales dualismos resultando ya su rescate imposible. Son estas razones históricas las que lo empujan a sugerir su cambio por el término cultura, teniendo en cuenta además que este último término se había ampliado, a los ojos de Dewey, para alcanzar mucho de aquello a lo que nuestro autor pretendía referir con experiencia. Si bien es cierto que, en la cita que reproduce Rorty, Dewey sugiere no sólo un cambio en el título sino también un cambio correspondiente en los asuntos específicos de los que trata su libro, lo cierto es que los párrafos que siguen a esa cita apuntan a señalar que el cambio se debe a su fracaso en el intento de convencer a los filósofos de que la experiencia no es algo completamente subjetivo, sino que remite a ese material inclusivo dividido en compartimentos estancos por la tradición filosófica. En el artículo en el que, según Rorty, renuncia al término metafisica, Dewey reitera esta idea de que acaso su intento de producir un cambio en la comprensión del término experiencia está condenado al fracaso, lo que podría ser una razón para abandonar el término. Pero, otra vez, esa renuncia es tan sólo una renuncia al término, no a las ideas. En efecto, allí puede leerse lo siguiente: 
Si mis críticos confinaran sus críticas a asuntos de la interpretación específica [del término experiencia] o si señalaran que históricamente se le han dado muchas interpretaciones diferentes a esa palabra de modo que es muy tarde para rescatarla de la ambigüedad, yo bien podría estar inclinado a acordar con ellos -especialmente respecto del último punto, y podría haber cambiado progresivamente en la dirección de usar términos tales como conducta-vital o actividad-vital, entendiendo por supuesto que, en el caso de la filosofía, la conducta y/o las actividades involucradas son aquellas de los seres humanos y por lo tanto se ven culturalmente afectadas de arriba abajo (lw.16.386).

El artículo al que Rorty refiere para justificar su afirmación de que Dewey también había renunciado al término metafísica es "Experiencia y existencia: un comentario" publicado en 1949. Este artículo es una respuesta a otro artículo publicado en 1948 en la misma revista (Philosophy and Phenomenological Research), que contenía las críticas de Sholom Kahn. En dicho artículo, Dewey se promete a sí mismo nunca jamás volver a usar el término metafísica para referirse a absolutamente nada relativo a su propia posición. Ese gesto irritado de Dewey exhibe un cierto agotamiento frente a la obstinación de sus críticos en no tener en cuenta los significados que explícitamente quería asociar con términos tales como experiencia y metafisica. En efecto, respecto del término metafisica la supuesta "renuncia" por parte de Dewey es más bien una entrega del término a sus críticos. Igual que en el caso anterior, la renuncia tiene más bien que ver con lo que Dewey pensaba que generaba malos entendidos, esto es, los términos elegidos y sus significados tradicionales, que con un cambio real en su posición.

En el comienzo del artículo Dewey cita la siguiente pregunta formulada por su crítico: “¿Incluye su metafísica, [la de Dewey], alguna existencia más allá de la experiencia?" (lw.16.383). La respuesta de Dewey es la siguiente "mi posición o teoría 
filosófica de la experiencia no incluye ninguna existencia más allá del alcance de la experiencia" (ibídem). Como Dewey mismo señala, ha introducido dos cambios en la formulación de su respuesta y todo el artículo va dirigido a explicar esos cambios.

En relación con su uso en Experience and Nature del término metafísica, y luego de dejar en claro que no entiende a filosofía y metafísica como términos sinónimos, Dewey refiere que, en unas pocas páginas del capítulo final de su libro, se ha limitado a explicitar el sentido que el término metafisica podría tener en un contexto como el suyo en el que no hay un más allá de la experiencia. En ese sentido, su uso del término difiere del uso de la tradición clásica. Ello es algo que Dewey señala de modo contundente, afirmando además que:

Ahora me doy cuenta de que fue excesivamente ingenuo de mi parte suponer que era posible rescatar la palabra de su profundamente arraigado uso tradicional. Obtengo un consuelo posible al prometerme a mí mismo nunca usar de nuevo las palabras [metafísico y metafísica] en conexión con ningún aspecto de mi propia posición. Sin embargo, el texto de mi libro deja en claro que yo estaba proponiendo un uso de las palabras tan diferente del uso tradicional que sería incompatible con él. Y aunque pienso que las palabras usadas fueron desdichadas aún creo que aquello que pretendían nombrar es genuino e importante. (lw.16.388)

En nuestra opinión este pasaje deja en claro que si bien Dewey estaba renunciando al término metafisica como afirma Rorty, lo cierto es que de ninguna manera estaba renunciando al proyecto que había intentado desarrollar en Experiencia y Naturaleza. Si esta lectura es correcta se sigue que, a los ojos de Dewey, renunciar a la metafísica no equivale a renunciar a la teoría de la experiencia y que por lo tanto tal teoría no debería pensarse, como a menudo lo hacen los intérpretes, y no sólo aquellos que rechazan sus 
posiciones, como una metafisica de la experiencia. De hecho, esta expresión no aparece en Experiencia y Naturaleza y cuando se habla de la metafísica se dice que ella es una descripción de los rasgos genéricos de la existencia. Más aún, tal definición de la metafísica, acaso como una ontología, no es algo que Dewey mismo proponga sino que en su opinión recoge el uso tradicional. En efecto, afirma que: "si seguimos la terminología clásica, la filosofía es amor a la sabiduría mientras que la metafísica es el conocimiento de los rasgos genéricos de la existencia” (p. 52).

No queremos decir con todo esto que el proyecto de Dewey no tenga sus inconvenientes. Por ejemplo, resulta difícil entender qué es aquello a lo que llama método empírico cuando se aplica a la filosofía. Pero no abordaremos esta cuestión aquí. En su lugar, quisiéramos proponer una hipótesis acerca del lugar ocupado por el concepto de experiencia en la filosofía de Dewey. Como recuerda Ángel Faerna en su comentario crítico al artículo de Rorty que discutimos aquí, el tomar el concepto de experiencia como punto de partida es para Dewey casi una exigencia del darwinismo. Si es cierto que el ser humano es un producto de la evolución, entonces todo aquello que el hombre hace, todas sus creaciones, deben pensarse en continuidad con la naturaleza, es decir, no puede introducirse ningún componente extra o sobre-natural para explicar nada. Si, como quería Nietzsche, el conocimiento es una invención, y si el hombre es un animal, un organismo, que se ha desarrollado en virtud de su interacción con el ambiente, entonces el conocimiento mismo debe poder explicarse sobre bases naturalistas, es decir, como un resultado de la interacción orgánica. Ello no significa para nada que Dewey desconozca los aspectos culturales, por así decirlo, del ser humano. Antes bien, señala, por ejemplo, que el surgimiento del lenguaje a partir de la interacción del hombre con su medio ha tenido unas consecuencias tan 
profundas sobre esa misma interacción que el hombre ha podido desarrollar toda una nueva serie de conductas y actividades. Tomar como punto de partida esa interacción del organismo humano con su medio es, para Dewey, casi una obligación de nuestros tiempos, habida cuenta del conocimiento del que disponemos.

\section{Consideraciones finales: la teoría de la experiencia como punto de partida}

En este capítulo hemos reconstruido la concepción deweyana de la experiencia y nos hemos preguntado por el lugar de la misma en su pensamiento. En este marco, hemos explicitado los alcances de su concepción de la experiencia como transacción, lo que ha permitido apreciar en qué sentidos pretende Dewey apartarse de la concepción tradicional de la experiencia. Asimismo, hemos visto que el reconocimiento del carácter de inmediatez cualitativa de toda experiencia constituye un punto de partida importante para vincular distintos tipos de experiencia. En efecto, fue una preocupación constante de Dewey superar la compartimentación de la experiencia que tendía a aislar al arte del conocimiento, a la ciencia de los valores, y al conocimiento y la ciencia del mundo del sentido común en general. Así, la identificación del aspecto cualitativo de toda experiencia y del carácter emocional de la experiencia cuando se constituye en una experiencia permite dar cuenta, entre otras cuestiones, del rol epistemológico de las emociones. Otro aspecto que hemos abordado es la cuestión del carácter mediador del conocimiento o experiencia cognitiva respecto de la experiencia primaria y su doble dependencia respecto de ella. Esto nos ha llevado, a su vez, a explicitar algunos aspectos de la concepción instrumental del objeto de la ciencia y de la actividad científica misma que sostiene Dewey. 
Por otra parte, en este capítulo hemos intentado establecer algunos puntos que nos permitan cuestionar la pretendida tensión afirmada por Rorty entre el giro lingüístico de la filosofía del siglo XX y el recurso al concepto de experiencia. Asimismo, hemos visto que, contra lo que pretende Rorty, la renuncia tardía de Dewey a los términos experiencia y metafisica es más bien una renuncia a las palabras que no modifica, al menos no sustancialmente, el programa que intentó desarrollar en Experience and Nature. Ello nos permitió ver que, más allá de estas cuestiones, Dewey no creía estar desarrollando una metafísica de la experiencia, y que, por otro lado, debía distinguirse entre filosofía y metafísica. La conclusión de todo esto es, creemos, que contrariamente a lo que Rorty creía, el lugar de la experiencia en la filosofía de Dewey no está atado al lugar de la metafísica. En el artículo de 1948 Dewey insiste en su concepto de experiencia y, aunque reconoce que podría dejarlo a un lado si es que es demasiado tarde para rescatarlo de sus ambigüedades, se promete a sí mismo no volver a usar jamás el término metafísica para referir a ninguna de sus posiciones. Como hemos dicho, la utilización como un punto de partida del concepto de experiencia, en casi todas sus obras y no sólo en Experiencia y Naturaleza, era tan sólo una consecuencia insoslayable de tomarse en serio a Darwin.

Pero aún podemos preguntar: las afirmaciones de Dewey acerca de la experiencia, ¿cumplen el rol de un verdadero fundamento de su filosofía, similar en su función al cogito cartesiano? Si el concepto de experiencia parece tomarse de Darwin ¿es de tal modo dependiente la filosofía de la biología? ¿Cuál es el fundamento filosófico de las afirmaciones de Dewey acerca de la experiencia? Estas preguntas pueden responderse recordando que, para Dewey, el conocimiento es solamente el nombre con el que nos referimos al producto de la investigación. Si la filosofía ha de producir conocimiento, debe 
entenderse entonces como una forma de investigación. Y ninguna investigación empieza de la nada: siempre lo primero es establecer cuáles son los "hechos del caso", es decir, las cosas que en la investigación que se desarrolla pueden darse por sentadas: no porque sean verdades evidentes e incuestionables, sino porque han sido bien establecidas en otras investigaciones o porque no tenemos ninguna razón para dudar de ellas. Que hay experiencias, que nos vemos involucrados en experiencias, es algo de lo que no parece que haya razones para dudar. Que esa experiencia pueda pensarse, no como la de un sujeto ya constituido que sale al encuentro de un objeto totalmente ajeno, sino como una interacción orgánica en la que el organismo modifica a la vez que es modificado por su medio, es algo que las investigaciones biológicas parecen habernos mostrado.

Acaso estas afirmaciones resulten un tanto extrañas, pero en nuestra opinión ello sólo es así si se sigue suscribiendo a la vieja idea de la filosofía como saber sin supuestos. En cambio, la extrañeza desaparece si, con Peirce, afirmamos que

No podemos empezar con una duda completa. Tenemos que empezar con todos los prejuicios que de hecho tenemos cuando emprendemos el estudio de la filosofía. Estos prejuicios no pueden disiparse mediante una máxima, ya que son cosas que no se nos ocurre que puedan cuestionarse. (...) No pretendamos dudar en la filosofía de aquello de lo que no dudamos en nuestros corazones (2012, pp. 72-73)

Este imperativo metodológico de la filosofía propuesto por Peirce resulta próximo a la caracterización deweyana de la filosofía como crítica de la cultura:

La filosofía es crítica: crítica de las creencias influyentes que subyacen a la cultura; una crítica que rastrea las creencias hasta las condiciones que las 
generan tanto como se pueda, que las sigue hasta sus resultados, que considera la compatibilidad de los elementos de la estructura total de creencias. Tal examen termina, se quiera o no, en una proyección de ellas en una nueva perspectiva que conduce a nuevas (lw.6.19) 


\section{4}

\section{El conocimiento como práctica: la teoría deweyana de la investigación}

\section{Introducción}

Como vimos en el capítulo anterior, la concepción transaccional de la experiencia, junto con la tesis acerca de la unidad cualitativa de las experiencias y la distinción entre experiencia primaria y experiencia reflexiva, permite a Dewey ofrecer una concepción del conocimiento en la cual este, al ser entendido como experiencia cognitiva, resulta él mismo una forma de transacción. De este modo, Dewey retoma el camino que había iniciado Peirce cuando comprendió a la investigación como una acción dirigida a cancelar la duda mediante el establecimiento de la creencia. El vínculo entre conocimiento y acción, ya en los artículos de Peirce analizados en la primera parte de esta tesis, no se reduce sin embargo a ello. En efecto, según vimos, la creencia misma tiene un cierto vínculo con la acción, en 
la medida en que ella es comprendida como hábito de conducta, concepción ésta que desemboca en la máxima pragmática y por tanto en la concepción del significado como el conjunto de efectos prácticos concebibles. Este vínculo entre conocimiento y acción resulta radicalizado por Dewey, en razón de su concepción del conocimiento como un tipo de experiencia y de la experiencia como transacción: en efecto, si una transacción tiene como resultado la modificación tanto del organismo como del medio, una concepción transaccional de conocimiento no puede detenerse en la creencia, aún cuando ésta sea comprendida como hábito. Una concepción transaccional va más allá y considera los cambios que de hecho el conocimiento introduce en el mundo. En este sentido, Dewey ofrece no sólo una concepción performativa del conocimiento, es decir una concepción del conocimiento como acción, sino además una concepción transformacional. El conocimiento no es una mera descripción de estados de cosas pre-existentes, ni se limita a proponer una regla de acción, sino que es una transformación del mundo que conoce. Esta última tesis depende, como se dijo, de comprender el conocimiento a la luz de su función en el contexto más amplio de la experiencia humana. Es decir, depende de comprender el conocimiento sin hacer abstracción del contexto en el que éste se desarrolla, contexto que supone a la vez determinaciones biológicas y sociales.

Ahora bien, esta caracterización preliminar del conocimiento como transformación necesita ser explicitada con mayor detalle. En efecto, se hace necesario revisar una serie de conceptos, tradicionalmente vinculados con el conocimiento, como datos, hipótesis, juicio o razonamiento, para determinar qué interpretación debe asignárseles en el marco de una concepción transformacional del conocimiento. Esta tarea de readecuación de los conceptos ligados al conocimiento, una vez que éste último ha sido concebido como transacción, ha 
sido ciertamente una tarea permanente llevada a cabo por Dewey durante más de medio siglo. En nuestra opinión, encontramos en la Logic: the Theory of Inquiry de 1938 el esfuerzo más sistemático de Dewey en ese sentido. En efecto, el punto de partida de ese libro es la definición de la investigación como transformación de la situación problemática que la origina.

Ahora bien, tal vez el título del libro pueda resultar llamativo a la luz de lo que acaba de afirmarse. Como es sabido, la lógica como disciplina no ha sido considerada, mayoritariamente al menos y desde el auge del desarrollo de la lógica formal o matemática, como una disciplina que tenga un vínculo especial con la investigación. Así, mientras el título de la obra de Dewey sugiere una definición de la lógica como teoría de la investigación, la lógica ha sido vista como una teoría del razonamiento y de su validez. Más aún, el concepto de razonamiento en la lógica suele ser el de un conjunto de enunciados, es decir, de entidades lingüísticas, en el que hay un enunciado, la conclusión, que se sigue de los otros, llamados premisas. Al definir al razonamiento de esta manera, no sólo se logra pasar por alto los problemas vinculados a posiciones psicologistas en relación a las leyes lógicas, sino que también se hace abstracción de todo contexto en el que el razonamiento ocurre. Así, la lógica puede y debe, para ser ciencia, estudiar estructuras lógicas, que resultan absolutamente independientes del contexto. Asumiendo una concepción tal, que ha sido la concepción dominante en el campo de la lógica formal, el título de la obra de Dewey es, lisa y llanamente, un absurdo. Teniendo en cuenta este problema, muchos intérpretes, incluso aquellos que parecen compartir las posiciones de Dewey, tienden a hacer la aclaración de que aquello que Dewey llama lógica es algo distinto a lo que comúnmente se 
llama lógica, y que en su lugar, es decir, en vez de presentar una lógica, su libro contiene una metodología o una epistemología.

Por nuestra parte, discutiremos esta interpretación teniendo en cuenta, por un lado, que la diferencia apuntada por los intérpretes era algo de lo que el propio Dewey era conciente: sabía que su uso del término era disruptivo en relación al uso dominante, pero ello, en vez de reflejar sólo una cuestión terminológica, es una señal clara de que estaba defendiendo la tesis de que la concepción dominante de la lógica presentaba algunos problemas que su propia concepción pretendía subsanar. De este modo, la reconstrucción de la teoría de la investigación de Dewey, que nos ocupará en este capítulo y el siguiente, será desarrollada bajo la hipótesis de que tal obra debe ser leída como un intento de ofrecer una nueva concepción de la lógica, que no haga abstracción del contexto en el que la inferencia y el razonamiento ocurren y que sea, por tanto, coherente con una concepción performativa y transformacional del conocimiento. Sin embargo, para hacer ello Dewey se verá llevado a presentar una concepción de la investigación que contiene también una serie de observaciones relevantes para una teoría del conocimiento. En este capítulo, nos detendremos en la idea misma de investigación, a los efectos de explicitar los aspectos recién mencionados. Para ello, en primer lugar, llamaremos la atención sobre dos movimientos metodológicos en el abordaje deweyano de la investigación, a saber, la utilización de un principio de análisis contextual del conocimiento y la inversión de la jerarquía entre conocimiento básico y aplicado, a partir de una concepción tecnológica de la práctica cognitiva. Luego, reconstruiremos la estructura de la investigación y nos detendremos en la noción deweyana de juico práctico, y en la afirmación de que el científico se halla involucrado fundamentalmente en la emisión de tales juicios. En el 
capítulo siguiente, abordaremos la concepción de la inferencia y de los principios lógicos que contienen las tesis principales de Dewey en el contexto de una filosofía de la lógica.

\section{Dos movimientos metodológicos}

Para comprender cabalmente la teoría del conocimiento de Dewey conviene detenernos en dos movimientos metodológicos operados por él para circunscribir el modo en que el estudio del conocimiento debe ser abordado. Teniendo presentes dos distinciones comunes podremos dar cuenta del alcance de tal movimiento. Si el objetivo es dar cuenta del poder transformador del conocimiento, podríamos apelar a las siguientes dos distinciones para que la concepción tradicional del conocimiento nos permita cumplir con él. Podríamos decir que, si bien el conocimiento es un producto de la investigación, podemos estudiar el conocimiento como producto independientemente del proceso mediante el cual fue obtenido. Así, el conocimiento como producto consiste no en una acción, sino en un conjunto de leyes y teorías que puede y debe ser estudiado por la filosofía del conocimiento. Una vez que hemos obtenido ese conocimiento, podemos usarlo para transformar la realidad, si bien no directamente, sino por medio de un conocimiento aplicado o tecnológico que puede ser visto como una forma de transformación del mundo. Así, conocimiento en sentido propio serías el conocimiento puro o básico, y el conocimiento aplicado sería conocimiento en un sentido derivado.

De este modo, las distinciones (1) entre conocimiento e investigación, entendiendo al primero como producto y al segundo como proceso y (2) entre conocimiento puro y conocimiento aplicado, permitirían dar cuenta del fenómeno que Dewey pretendía pensar 
pero conservando a la vez alguna versión de la teoría del conocimiento del espectador. Tal teoría conducía, sin embargo, para nuestro autor y como veremos a continuación, a una serie de postulados que originaban a su vez toda la serie de problemas epistemológicos en los que la filosofía parecía quedar atrapada.

\subsection{El principio del análisis contextual}

Supongamos que consideramos al conocimiento como producto y que, valiéndonos de la diferencia entre proceso y producto, excluimos por principio toda consideración acerca del proceso mediante el cual se produce el conocimiento, es decir de la investigación, para forjarnos una concepción acerca de él. Aunque nos encontramos aquí con una versión simplificada de la conocida distinción entre contexto de descubrimiento y contexto de justificación que ha sido superada por la filosofía de la ciencia poskuhniana (cfr. Marcos 2000), conviene detenernos en algunas de sus consecuencias. Si aceptamos alguna forma de tal distinción, el conocimiento es identificado con un conjunto de leyes y teorías, pero se hace necesario poseer algún tipo de criterio que nos permita distinguir el conocimiento genuino del conocimiento espurio, esto es, de la mera opinión. El candidato principal para ello es la verdad. La verdad es, así, una propiedad de los enunciados, de las leyes y teorías que constituyen el conocimiento, que debe ser independiente del proceso de investigación: si sólo podemos considerar al conocimiento como producto, entonces necesitamos algún tipo de garantía de la verdad, y en última instancia de la racionalidad del conocimiento, garantía que no puede residir en la investigación. En un contexto tal se hace necesario caracterizar a la verdad de alguna manera: como correspondencia entre los enunciados y un 
mundo anterior e independiente de ellos ${ }^{1}$ o bien como coherencia entre enunciados. Como es sabido, tales posiciones conllevan múltiples dificultades en las que no hace falta que nos detengamos aquí.

Frente a este tipo de dificultades, nuevamente, Dewey retoma el camino abierto por Peirce. En efecto, en "La fijación de la creencia", Peirce había afirmado que el fin de la investigación era fijar una creencia, y no una creencia verdadera, en el sentido de una verdad que fuera independiente del proceso de investigación mediante el cual se fija la creencia. En su opinión, todo lo que puede afirmarse es, a lo sumo, que como resultado de la investigación alcanzaremos una creencia "que pensaremos que es verdadera" (2012, p. 162, cursiva del autor), pero ello es, en su opinión, una mera tautología. Así, la verdad no puede pensarse como algo fuera de la investigación, sino más bien como el nombre mediante el cual nos referimos al resultado de la investigación. Esta identificación de la verdad con el resultado de la investigación lleva así a la concepción de la verdad, en un sentido idealizado, como la opinión destinada a ser sostenida indefinidamente por la comunidad de investigadores. En este contexto, nuevamente, Dewey radicaliza la posición de Peirce, proponiendo el término asertabilidad garantizada como un sustituto de la idea de conocimiento o creencia verdadera. ${ }^{2}$ Uno de los resultados de la investigación es la

\footnotetext{
${ }^{1}$ Nótese que en este contexto la independencia es también una exigencia de aislar el conocimiento de la investigación: si la verdad es una propiedad que debe asegurarnos que algo es genuino conocimiento, independientemente de su proceso de producción, se requiere algo externo al conocimiento mismo para garantizar la objetividad o la racionalidad del mismo: si no hay una realidad absolutamente independiente contra la cual contrastar nuestras pretensiones de conocimiento, entonces no hay conocimiento genuino, sino la mera invención de un sujeto que contrasta sus creencias entre sí.

${ }^{2}$ En opinión de Miguel Esteban, la postulación por parte de Peirce de la teoría de la verdad como convergencia responde a un intento, por parte de Peirce, de escapar al relativismo que amenazaba con seguirse de su falibilismo. En cambio, dada la concepción transformacional del conocimiento de Dewey, el hecho de que la ciencia transforma la realidad en vez de limitarse a representarla aleja tal posibilidad. Por ello, Dewey puede llevar el falibilismo a sus últimas consecuencias y sustituir el término verdad por el de asertabilidad garantizada. (cfr. Esteban, 1999, p. 152). Así, en nuestros propios términos, tal sustitución resulta un indicativo de la radicalización deweyana de la tesis acerca de la estrecha relación entre conocimiento y acción: en un contexto transformacional, lo que obtenemos no son tanto enunciados
} 
asertabilidad garantizada, es decir, el hecho de que ciertas aserciones puedan afirmarse gracias a la garantía que han recibido en el curso de la investigación. Es precisamente este vínculo entre el conocimiento como producto y la investigación la razón principal para proponer dicho término, por cuanto el mismo "implica una referencia a la investigación como aquello que garantiza la aserción" (lw.12.16).

Por otro lado, cabe señalar que la asertabilidad garantizada es un resultado de la investigación entendida como un proceso completo. En otros términos, y como veremos más adelante con mayor detalle, lo que completa la garantización de la aserción es el hecho de que la situación problemática que inició la investigación sea transformada. En este sentido, podemos decir, la asertabilidad garantizada es un subproducto de la investigación. Se trata, ciertamente, de un subproducto central por cuanto se constituye en un insumo material para nuevas investigaciones. Es por ello que Dewey utiliza el término asertabilidad y no aserción, para señalar que lo que se obtiene como resultado de una investigación especial, además de la resolución del problema particular, es un recurso que puede ser reinvertido en ulteriores investigaciones ${ }^{3}$. Así, en palabras de nuestro autor, "el uso de un término que designa una potencialidad más bien que una realidad implica reconocer que toda conclusión especial de una investigación especial forma parte de una empresa que es continuamente renovada o que es un asunto en marcha" (lw.12.16-17). En un sentido similar, afirma Dewey en referencia a las conclusiones newtonianas que ellas "dominan como ciencia precisamente porque son tomadas (...) como un material dado para ser empleado en investigaciones e interpretaciones subsiguientes" (lw.6.16).

verdaderos que "pintan" al mundo, para usar la conocida expresión wittgensteiniana, sino enunciados que pueden ser re-utilizados en el proceso de transformación del mundo porque han sido garantizados.

${ }^{3}$ El uso de los términos recurso y reinversión no es de Dewey, pero lo utilizamos aquí solo para sugerir una conexión con los estudios de la ciencia que analizaremos en la tercera y última parte de esta tesis. 
De este modo vemos que resulta esencial, de acuerdo con Dewey, elaborar una concepción del conocimiento sin hacer abstracción del proceso mediante el cual se produce el conocimiento, es decir, la investigación. En efecto, el estudio de esta última resulta central para elaborar una concepción adecuada del conocimiento. En palabras de Dewey,

puesto que cada caso especial de conocimiento se constituye como el resultado de alguna investigación especial, la concepción del conocimiento como tal sólo puede ser una generalización de las propiedades descubiertas como pertenecientes a las conclusiones que son resultados de la investigación. El conocimiento, como un término abstracto, es un nombre para el producto de investigaciones competentes (lw.12.16).

Así, el primer movimiento metodológico de Dewey al que nos referimos es la postulación de la necesidad de estudiar la investigación para forjarse una idea adecuada acerca del conocimiento o, en otros términos, no hacer abstracción de la relación procesoproducto para dar cuenta del conocimiento. Este postulado es referido por Ernest Nagel en su introducción de 1986 a Logic: the Theory of Inquiry (en Dewey, lw.12) como un principio de análisis contextual y, como sostiene Nagel (en Dewey, 1w.12.xi), tal principio gobierna toda la filosofía de Dewey. De acuerdo con Nagel tal principio postula que "se requiere que proceso y producto sean tomados como distinciones correlativas, de modo que a ninguno pueda entendérselo o asignársele un estatus de existencia independientemente del otro" (en Dewey, lw.12.xi).

Cabe destacar que la violación de este principio arrastra a los filósofos, de acuerdo con Dewey, a cometer las falacias filosóficas por antonomasia: la falacia del análisis y la falacia de la universalización ilimitada, que consisten respectivamente en (1) postular como 
si fueran completos y autosuficientes elementos que son en realidad producto del análisis (como lo haría, por ejemplo, la psicología asociacionista del empirismo) y (2) extender principios que sólo valen para un contexto bajo condiciones limitantes a todas las cosas (cfr. Dewey lw.6.5-11). Resulta oportuno señalar que, desde el punto de vista de Dewey, la única alternativa a esta forma de abordar el estudio del conocimiento es elaborar una teoría del conocimiento mediante la mera manipulación "dialéctica" del concepto tradicional abstracto de conocimiento, herencia de la Grecia antigua, y sostenido incluso en la modernidad. En otros términos, de acuerdo con Dewey, o bien construimos un concepto de conocimiento estudiando la forma en que el mismo es producido, o bien nos mantenemos atados a un concepto heredado, forjado además en un momento en que la forma de

producción del conocimiento era distinta, imponiendo así al conocimiento y a la experiencia unas descripciones y concepciones que son en verdad las consecuencias lógicas de una serie de ideas heredadas y no revisadas. De este modo, este principio de análisis contextual se relaciona con la pretensión deweyana de adoptar, para el tratamiento de los problemas filosóficos, un enfoque empírico, en el que la observación de lo que de hecho ocurre, y la experiencia primaria que ofrece los problemas a la filosofía y ejerce el control de las soluciones, tal como ocurre en cualquier forma de conocimiento, encuentren su lugar.

\subsection{La ciencia como tecnología}

El segundo de los movimientos metodológicos antes mencionados consiste en producir una inversión de la relación entre conocimiento aplicado y conocimiento básico. No se trata de negar la distinción entre dichos tipos de conocimiento ni de restarle importancia al segundo 
en el contexto del desarrollo de la actividad científica. Antes bien, se trata de invertir la primacía lógica de la distinción. En la versión tradicional, como dijimos, el conocimiento aplicado y la tecnología son conocimiento en un sentido derivado: aplican un conocimiento en sentido propio, producido de forma al menos lógicamente independiente de toda aplicación, y, en general, de toda forma de la práctica. Frente a tal posición, el instrumentalismo de Dewey supone una comprensión de la ciencia misma como tecnología.

En el capítulo anterior vimos dos sentidos en que cabe entender la concepción instrumentalista de la ciencia sostenida por Dewey, a saber, (a) la ciencia es instrumental por cuanto estudia relaciones de medios/consecuencias y (b) porque tiene un efecto trasformador del mundo, esto es, es un medio para resolver problemas que se plantean en el contexto de experiencias que no son primariamente cognitivas. Sin embargo, cabe señalar aún un tercer sentido en que su concepción es instrumental, sentido que puede ser explicitado mediante la idea de que (c) la ciencia misma es una forma de tecnología. En un artículo de 1944 titulado "By Nature and by Art" (lw. 15.84-97) Dewey reserva el término tecnología para referirse a una concepción de la ciencia como arte, esto es, como una “invención deliberada de artefactos por su propia cuenta” (lw.15.89). En efecto, según su opinión, luego de un periodo en que la ciencia tomó prestadas las habilidades de las artes industriales, la ciencia misma se convirtió en tecnología. De este modo, la ciencia se asimila a las artes industriales por el hecho de que en ellas "la producción de consecuencias relevantes y efectivas [que permiten, por ejemplo, validar las hipótesis], depende de utilizar artefactos y aparatos artificialmente diseñados como medios para la ejecución del plan que dirige las operaciones que se emprenden" (lw.15.86). En otros términos, y como Esteban señala, la concepción instrumentalista del conocimiento de Dewey supone una concepción 
de la investigación como modo de producción tecnológica (Esteban, 1999, p. 139). Así, Dewey fue uno de los primeros en señalar la importancia, de alcances filosóficos, de las "máquinas" y los "aparatos" en la producción de conocimiento. Al hacerlo, anticipó muchísimas discusiones en el ámbito de los estudios de las ciencias, algunas de las cuales abordaremos en la tercera parte de esta tesis. El siguiente párrafo, extraído de una reseña publicada por Dewey en 1927, es lo suficientemente rico como para permitirnos citarlo en extenso:

En realidad la historia de la ciencia es la historia de la invención y el uso de máquinas y de una técnica, tan maravillosa como elaborada, para emplear herramientas. La máquina es la realidad de la ciencia; la interpretación teórica puede o no ser verdadera; al final, la respuesta puede ser leída en alguna máquina más delicada, precisa y más habilidosamente usada que aquella que suministraba el material sobre el cual otras teorías se basaban. La verificabilidad de las conclusiones científicas significa que ellas no se sostienen solas. Ellas se hacen posibles por medio de las máquinas, y cualquiera que opere las máquinas de un modo determinado obtendrá resultados similares (lw.3.306).

De este modo, vemos que la comprensión deweyana de la tecnología ${ }^{4}$ ofrece un punto de vista interesante acerca de la importancia de los artefactos tecnológicos. Nótese que esta importancia no es solamente una cuestión en relación con el contexto social del conocimiento. Es decir, no se trata sólo de que la incorporación de máquinas y aparatos modifique la vida de las personas y el mundo en que vivimos, lo que ciertamente ocurre, sino que además, los artefactos, las máquinas, resultan centrales como herramientas para arribar a conclusiones científicas válidas. Es por esto que la expresión de Esteban nos

\footnotetext{
${ }^{4}$ Un análisis detallado de la filosofía de la tecnología de Dewey pueden encontrarse en Hickman 1992, 2001 y
} 2012. 
parece apropiada: la investigación es una práctica de producción tecnológica. Otro aspecto a tener presente es que no sólo se refiere Dewey a los aparatos materiales, a la maquinaria científica, al hablar del carácter tecnológico de la investigación. El lenguaje será también un instrumento, un aparato, una herramienta en la producción de conocimiento. La contrapartida de tal concepción es la visión del científico como un práctico embarcado en la realización de juicios prácticos, esto es, de juicios que tienen como objetivo modificar una situación, que desarrollaremos más adelante en este capítulo.

Como señala Esteban, la consecuencia de esta posición implica no sólo una revisión de la distinción aristotélica entre theoria, praxis y poiesis, sino también una relativización de la distinción entre ciencia pura y ciencia aplicada, al disolver su fundamento ontológico (la distinción entre esferas de realidad) y el epistemológico, es decir, la concepción de la theoria como contemplación. Como resulta evidente, la disolución de tales fundamentos lleva a Dewey a una revisión del pensamiento griego y a la recuperación de algunos elementos del pensamiento de Aristóteles. ${ }^{5}$ Así, si el conocimiento ha de entenderse como teoría, entonces se trata de una teoría que no puede pensarse ya como contemplación sino como una práctica poiética, un práctica tecnológica de producción de artefactos y aparatos, no sólo con vistas a la satisfacción de fines prácticos específicos, sino también con vistas a la producción misma de conocimiento, a la validación de hipótesis y teorías.

Resulta interesante señalar aquí que la posición que reseñamos resulta contemporánea al auge de la filosofía del positivismo lógico y muy próxima a los trabajos de Robert Merton sobre sociología de la ciencia, coherentes éstos últimos con lo que se ha

\footnotetext{
${ }^{5}$ La relación entre el pensamiento de Dewey y el de Aristóteles es una cuestión interesante que no ha sido ampliamente debatida, pero que escapa a los alcances de esta tesis. Al respecto, puede consultarse Sleeper (2000, pp. 78-105), Pagan (2008), Hobbs (2013) y Kirby (2014). El tema ha sido abordado también en Di Gregori y López (2005).
} 
llamado la filosofía estándar de la ciencia. Así, por ejemplo, Merton publica en 1938 Ciencia, tecnología y sociedad en la Inglaterra del siglo XVII, donde reconoce y estudia el vínculo entre la ciencia y el desarrollo tecnológico. Sin embargo, en 1949, y frente a la utilización de la ciencia en la carrera armamentista y frente a la "ciencia Nazi" y la soviética, publica Teoría y estructuras sociales, en el que llama la atención acerca de los “ataques externos" a la ciencia, e insiste en el desinterés como marca característica de la misma. Es decir, ante los intentos de utilización de la ciencia para fines terribles, proponía el desinterés, la desvinculación con todo beneficio práctico, como antídoto. Por su parte, en vez de declarar la neutralidad del medio (la ciencia) para rechazar al fin, Dewey discutirá directamente el fin: el problema con la aplicación de la ciencia no reside en la aplicación misma, que forma parte de su naturaleza, sino en la utilización de la aplicación en provecho de fines ilegítimos. Así, en palabras de Dewey, “la objeción seria a la ciencia 'aplicada' descansa en la limitación de la aplicación al beneficio privado y el privilegio de clase" $\left(\right.$ lw.1.129) ${ }^{6}$. Mientras que Merton promueve el desinterés, Dewey sugiere, como lo hará años después Dominic Pestre (2005, p. 28) que el ideal de la ciencia pura "ha establecido otro interés de clase, el de los especialistas intelectualistas y distantes” (Dewey, lw.1.131), con una consecuente desviación hacia fines privados o de clase de los esfuerzos (y el dinero), que podrían haber dado mejores frutos, al menos en una sociedad democrática, si se destinaran a aplicaciones menos estrechas. ${ }^{7}$

\footnotetext{
${ }^{6}$ No se trata en esta posición de separar los medios de los fines. Antes bien, tal cosa es imposible. Se trata de enfatizar que el problema con ciertas formas de ciencia aplicada no reside en su carácter de aplicada, sino en su naturaleza misma de ciencia hecha con el fin del exterminio. No es que se rechace el fin y se conserve el medio, sino que se rechaza ese medio particular, esa ciencia, precisamente porque de ella forma parte el fin que se juzga ilegítimo. Esta cuestión de la relación medios/fines será abordad en el capítulo t de esta tesis en relación a la teoría de la valoración de nuestro autor.

${ }^{7}$ El fenómeno del conocimiento aplicable no aplicado (Kreimer y Zabala, 2006 y Kreimer y Thomas, 2005) podría reinterpretarse como una forma de desviar esfuerzos y dinero en el sentido apuntado por Dewey,
} 
En este contexto, Dewey rechaza la categoría de ciencia "pura", absolutamente desvinculada de la práctica: puesto que no hay conocimiento que no sea tecnológico, la idea de una ciencia no-aplicada resulta difícil de sostener. Sin embargo, ello no implica que para Dewey la ciencia deba hacerse siempre con la mira puesta en alguna aplicación práctica específica. Si bien muchos avances en la ciencia fueron producidos, en efecto, en vistas de alguna aplicación práctica específica, su valor como conocimiento radica en que pueda ser aplicado no sólo a ese problema particular, sino a una variedad de problemas. Nuevamente, el valor del conocimiento como producto radica en que pueda ser utilizado en la resolución de otros problemas. De este modo, un conocimiento que no se circunscribe a un problema específico no ve limitada su condición de instrumento, sino más bien amplificada: se vuelve un instrumento al que otros instrumentos (otras investigaciones) pueden recurrir.

Este rechazo a la limitación de la aplicación junto con el reconocimiento del carácter aplicado de todo conocimiento, lleva a Dewey afirmar que "así concebido, el conocimiento existe en ingeniería, en medicina y en las artes sociales más adecuadamente que en matemáticas y física" (lw.1.128). En este sentido, vemos entonces que la comprensión deweyana de la investigación supone una inversión de la prioridad conceptual entre ciencia aplicada y ciencia básica: la ingeniería o la medicina son "más adecuadamente" conocimiento que la física y la matemática. En nuestra opinión, y teniendo en cuenta lo que dijimos anteriormente en relación a que el conocimiento no debe aplicarse necesariamente a fines prácticos específicos, esta inversión de la jerarquía tradicional debe entenderse teniendo en cuenta lo siguiente. En primer lugar, y como hemos dicho, la preocupación filosófica central de Dewey en relación al conocimiento era la relación entre

aunque en este caso, utilizando estratégicamente, la posible aplicación para obtener fondos del Estado, pero cumpliendo en realidad los fines más estrechos de una comunidad de especialistas 
éste y las formas de experiencia que no son primariamente cognitivas. Así, reflexionando acerca de la tarea propia de la filosofía en relación con la ciencia, Dewey afirma que trabajar exclusivamente en el contexto provisto por las ciencias mismas es ignorar su contexto vital. El lugar de la ciencia en la vida, el lugar de sus peculiares asuntos en el esquema amplio de los materiales que experimentamos, es una tarea más fundamental que cualquier reflexión autocontenida de la ciencia como tal (1w.6.19-20).

De modo que, visto desde ésta óptica, el conocimiento que sale más a la luz, aquel cuya relación con el contexto vital resulta más evidente, es el conocimiento vinculado a la resolución de problemas específicos. En él, su carácter instrumental es directo y completo. Sin embargo, ello no quiere decir que el conocimiento básico no sea también instrumental. Lo es claramente, al igual que el conocimiento aplicado en el primero y el tercero de los sentidos antes señalados: ambos tratan de instrumentalidades y ambos son tecnológicos, es decir, dependen en su producción de una actividad de manipulación de materiales, herramientas y conceptos. Por ello, preferimos hablar de conocimiento básico y no puro, puesto que la idea de pureza parece asociarse con el no estar contaminado por la práctica, es decir, con la teoría como mera contemplación. La diferencia entre el conocimiento básico y el conocimiento directamente aplicado estaría en el segundo nivel, el nivel que hemos llamado transformacional: mientras el conocimiento directamente aplicado encuentra soluciones a problemas tal como ellos se presentan en la experiencia primaria, el conocimiento básico aborda problemas más distantes y no se realiza con miras a resolver un problema práctico específico. Sus problemas son, en este sentido, más “artificiales”, pero no por ello resulta menos instrumental. Como vimos, su incalculable valor como instrumento radica en la amplitud de su potencial uso. 
Esta es la razón por la cual la matemática es, por ejemplo, para Dewey la más útil de todas las ciencias: su posibilidad de ser usada en diferentes campos es una consecuencia de su nivel de abstracción, de su distancia respecto de la experiencia primaria. En efecto, en la sección destinada a la matemática en Logic: The Theory of Inquiry de 1938, Dewey ofrece una concepción de esta ciencia que se pretende compatible con su concepción instrumental o tecnológica de la investigación. Allí, sostiene que la construcción de sistemas formales sin interpretación tiene precisamente como fin posibilitar operaciones de transformación ilimitadas (lw.12.402-403). En su opinión, “el uso de la aritmética en transacciones comerciales ordinarias y el rol de las matemáticas en la ciencia física, alcanzan para mostrar que la aplicabilidad es una posibilidad y que esa posibilidad es actualizada en una amplia escala" (lw.12.412). Y más aún, "la aplicabilidad es indefinidamente ampliada precisamente por la libertad respecto de la necesidad de aplicación" (ibídem). Esta posición es ilustrada por Dewey apelando al uso de la geometría en la física. Mientras se pensó que la geometría euclidiana tenía una referencia ontológica directa, su uso en la física resultó restringido y obstructivo. En cambio, afirma Dewey, "las geometrías riemannianas y lobanchevskianas no sólo liberaron a la geometría de su pretendida referencia existencial, sino que al hacerlo proveyeron instrumentalidades para la teoría física de la relatividad general" (lw.12.412).

De este modo, Dewey ha introducido un nuevo movimiento metodológico. En vez de tomar a la matemática y a la física como modelos de conocimiento y tratar de construir imágenes de las otras disciplinas que se ajusten a tal caracterización, partirá de una concepción tecnológica del conocimiento, de una concepción instrumental, que deberá dar 
cuenta, casi como si fuera un experimento crucial, de las disciplinas que no tienen una referencia directa a ningún problema práctico específico.

\section{La investigación como transformación}

En esta sección nos detendremos entonces en la caracterización de la investigación tal como es presentada en Logic: The Theory of Inquiry. En ese libro, Dewey define a la investigación como sigue: "la investigación es la transformación controlada o dirigida de una situación indeterminada en otra que sea tan determinada en sus distinciones y relaciones constitutivas como para convertir los elementos de la situación original en un todo unificado" (lw.12.108). Esta definición contiene muchas de las ideas a las que ya nos hemos referido. En primer lugar, al sugerir una concepción transformacional del conocimiento, cuyo punto de partida es la idea de situación problemática, supone una radicalización del esquema duda-creencia de Peirce: la investigación no finaliza cuando se fija la creencia, sino cuando se resuelve el problema. Sin embargo, Dewey no utiliza la expresión "problema” sino "situación problemática", en la que conviene detenerse.

En primer lugar, la situación es un “todo contextual” (lw.12.72), en cuyo seno es posible identificar y experimentar objetos. Así, de acuerdo con Dewey, “en la experiencia real, (...) un objeto o evento es siempre una parte especial, fase o aspecto de un mundo circundante experimentado-de una situación” (1w.12.72). Una situación es, entonces, un determinado estado de la transacción organismo-medio, que se constituye como un todo en función de una cualidad pregnante que permite identificarla como una situación singular. En otros términos, una situación es una experiencia, en el sentido analizado en el capítulo 
anterior. Así, las situaciones son tenidas en el mismo sentido en que se tiene una experiencia. De este modo, hablar de situación problemática significa comprender a los problemas no como una mera duda, entendida como algo mental, ni como una mera pregunta, sino como un cierto estado que involucra tanto al organismo como al medio.

Por otro lado, su carácter problemático radica en su aspecto de indeterminación: una situación problemática es una situación indeterminada. En ella, la cualidad unificadora es la de incertidumbre. Ahora bien, esta incertidumbre no es un mero estado subjetivo, sino una propiedad de la situación: "nosotros estamos dubitativos porque la situación es inherentemente dudosa. Los estados personales de duda que no están provocados y que no son relativos a una situación existencial son patológicos” (lw.12.109). El carácter de indeterminación implica una cierta falta de completitud, y por ello la situación es indeterminada respecto de su resultado. Una situación indeterminada es confusa, oscura o conflictiva. Es confusa, afirma Dewey, cuando no podemos anticipar su resultado; es oscura cuando los resultados de los procesos en marcha no resultan transparentes y es conflictiva cuando dichos procesos sugieren respuestas discordantes. En este sentido, una situación problemática es una situación en la que su propio carácter de unidad resulta cuestionado: no podemos decir de qué tipo de situación se trata, siendo tan sólo la incertidumbre, la confusión, la oscuridad o el conflicto lo que mantiene la unidad y permite identificarla como una situación. ${ }^{8}$

Así, la investigación comienza frente a una situación que es indeterminada en tales sentidos, y finaliza cuando la situación se vuelve un todo unificado, es decir, cuando su

\footnotetext{
${ }^{8}$ El concepto de situación tal como es usado por Dewey ha sido objeto de controversias. De acuerdo con Russell (1939), por ejemplo, el concepto remitiría al universo entero sin que pueda trazarse una clara delimitación de una situación. Para una discusión del concepto de situación véase Brown 2013, y Burke 2000, 2009a y 2009 b.
} 
cualidad se trastoca de modo tal que ya no resulta indeterminada. No se trata, por supuesto, de un mero cambio en el sentimiento, sino de una transformación real, mediante operaciones materiales y conceptuales que remueven las condiciones que generan la incertidumbre. Es este el aspecto transformacional de la investigación. Pero tal como puede leerse en la definición citada, la investigación es transformación controlada o dirigida, siendo este aspecto la característica propiamente cognitiva o reflexiva de ese tipo peculiar de experiencias que son las investigaciones. Este aspecto resulta central puesto que, como veremos en el capítulo siguiente, en él se encuentra el origen de los principios regulativos de la lógica, y en su estudio nos encontraremos con la lógica misma.

\subsection{La continuidad: el seno biológico y cultural de la investigación}

Resulta interesante señalar, en este punto, que la investigación es una suerte de experiencia de segundo orden: es la continuación, por otros medios, esta vez de carácter distintiva y fundamentalmente reflexivos, de la transacción orgánica: la investigación es un "universo de experiencia”, en el que otro universo de experiencia, a saber, la situación problemática, se vuelve objeto de reflexión y discurso. En otros términos, la investigación es también una experiencia, y en tanto que tal debe exhibir los rasgos distintivos que permiten hacer de la experiencia, una experiencia. En este sentido, la conducta orgánica, en tanto y en cuanto se constituye en una experiencia, deberá exhibir algunos de los rasgos centrales de la investigación. Nos encontramos así con uno de los rasgos distintivos de la tesis de la continuidad que Dewey reafirma en su lógica: como buen naturalista, postula una continuidad entre los procesos y funciones inferiores de los organismos y los superiores: 
"las funciones y estructuras biológicas preparan el camino a la investigación controlada" y “anticipan su patrón” (lw.12.30).

Resulta importante señalar que la tesis de la continuidad pretende oponerse a dos contrincantes. El primero es el antinaturalismo (cfr. "Anti-naturalism in extremis" en lw.15.46-63). La crítica que Dewey dirige contra el antinaturalismo consiste principalmente en aportar una genealogía del mismo y en señalar sus consecuencias prácticas negativas. El antinaturalismo no puede negar los avances de las ciencias pero ciertamente ha impedido que los métodos de investigación se extendieran al ámbito de los asuntos humanos: al interponer una diferencia infranqueable entre materia y espíritu, el antinaturalismo decreta un límite a la aplicación de los métodos de la investigación experimental. Según la opinión de Dewey, el antinaturalismo se puede comprender sólo como la herencia de ciertas creencias supernaturalistas que pertenecen a una etapa precientífica de nuestra historia; creencias que además llegaron a constituir el núcleo básico de las doctrinas religiosas de la tradición judeo-cristiana, que condicionan el desarrollo cultural del hombre y sus relaciones sociales. No es necesario, sin embargo, que el antinaturalismo sea manifiestamente del tipo señalado. La autoridad de una deidad puede reemplazarse por una Razón pura o facultad de intuición que, o bien rebasa los límites de la investigación científica, o bien impone condiciones o legisla sobre la misma. A las consecuencias prácticas de los supuestos antinaturalistas, Dewey contrapone las consecuencias prácticas obtenidas por las ciencias. Pero lo más importante, anticipa las consecuencias prácticas de extender la investigación, en el sentido sugerido por el naturalismo, a aquellos dominios trabados por estar bajo la administración antinaturalista. 
El segundo antagonista pertenece a las filas mismas del naturalismo (Dewey, 1w.3.73-82; Dewey, Hook y Nagel, 1945). La crítica de Dewey se dirige, en este caso, contra aquellas formulaciones del naturalismo que no son consistentes con el postulado de la continuidad. Si el antinaturalismo afirmaba la discontinuidad entre materia y espíritu, entre la naturaleza y el hombre, al naturalismo también se lo puede acusar de querer reducir lo segundo a lo primero. Lo que se afirma en este caso es más bien una identidad que una continuidad. La tendencia reductiva de algunas formas de naturalismo lo acercan peligrosamente a un materialismo que no puede dar cuenta de la realidad y los rasgos distintivos de la experiencia humana. Esto constituye en no menor medida una amenaza a la continuidad. Para evitar esto, hacia el interior del naturalismo, Dewey insiste en que se tenga en cuenta el desarrollo efectivo de las ciencias, atento al hecho de que la formulación de un naturalismo filosófico consistente depende en gran medida del propio desarrollo de la investigación científica. Esto se debe a que la capacidad para "naturalizar" los asuntos humanos no es la misma si disponemos, como Hume, de poco más que la psicología atomista que forma el núcleo de su teoría de las ideas, que si disponemos de la posibilidad de fundar nuestra comprensión de los fenómenos humanos en una comprensión científica más adecuada de los fenómenos propios de la vida y el desarrollo en general. Como hemos ya dicho, esta posibilidad de apoyarse en la comprensión científica no debe limitarse a la biología y a la psicología. En este punto, es también central para Dewey la antropología social, por cuanto permite dar cuenta, asumiendo la tesis de la continuidad, es decir, el naturalismo, de los aspectos sociales y culturales de la experiencia humana.

Teniendo en cuenta el rechazo de ambos antagonistas, Dewey formula entonces el principio de la continuidad como sigue: 
El postulado primario de una teoría naturalista de la lógica es la continuidad de las actividades y formas inferiores (menos complejas) y las superiores (más complejas). La idea de la continuidad no es auto-explicativa. Pero su significado excluye rupturas completas, de un lado, y la mera repetición de identidades del otro; excluye la reducción de lo superior a lo inferior tanto como excluye las rupturas y saltos completos (lw.12.30).

En este contexto, los dos primeros capítulos de Logic: The Theory of Inquiry tienen el objetivo de defender, en particular, la continuidad entre los procesos organizados propios de la vida y la pauta de conducta propia de la investigación. De manera más concreta, Dewey pretende ofrecer "una explicación razonable de los modos en que es posible que los rasgos que diferencian la investigación deliberada se desarrollen a partir de actividades biológicas no señaladas por esos rasgos" (lw.12.31). Esto último es una exigencia de su posición naturalista, en tanto que opuesta a un "sobre-naturalismo", por cuanto que, como sostiene Dewey "si uno niega lo contranatural, le incumbe la responsabilidad de indicar en qué forma lo lógico puede estar conectado con lo biológico en un proceso de desarrollo continuo" (lw.12.32).

Por supuesto, la continuidad entre la actividad puramente orgánica y la investigación está dada por la caracterización de ésta última como una forma de experiencia. No obstante, hay algunos puntos más específicos en los que podemos detenernos. En primer lugar, corresponde a la actividad orgánica un medio ambiente con el que interactúa: "un organismo no vive en un medio, vive por virtud de un medio circundante" (lw.12.32). Ahora bien, los procesos orgánicos son automantenedores, en el sentido de que la actividad orgánica no es meramente sucesiva, sino seriada: cada actividad anticipa y prepara el camino para la que sigue de modo que se mantenga un estado de 
equilibrio en la interacción con el medio ambiente. Los desequilibrios de la interacción pueden provenir tanto del organismo como del medio ambiente y los ciclos de desestabilización y reintegración siguen una pauta determinable, siendo el estado de perturbación del equilibrio la necesidad. El movimiento para restaurarlo constituye la búsqueda y la exploración. La recuperación del equilibrio es logro o satisfacción (lw.12.34). El restablecimiento del equilibrio se logra sólo a través de modificaciones que se dan tanto en el medio ambiente como en el organismo: el restablecimiento de una relación integrada no significa la restauración de un estado previo de la interacción. Las modificaciones orgánicas pueden ser de tal índole que condicionen el comportamiento ulterior, en tanto constituyen hábitos (lw.12.38).

Los aspectos previamente expuestos son anticipatorios, según Dewey, de algunos rasgos característicos de la pauta de la investigación. En primer lugar, se sostiene que las condiciones ambientales son inherentes a la investigación en tanto modo especial del comportamiento orgánico. La situación de desequilibrio entre organismo y ambiente es la ocasión en que surge la investigación, en continuidad con las actividades de búsqueda y exploración del organismo, y la creencia o aserción corresponde al logro de la reintegración orgánica. Este logro implica la realización de cambios en las condiciones ambientales. El carácter serial de la actividad orgánica también deja su impronta en la pauta de la investigación. Los procesos mediante los cuales "se da existencia a un cierre consumatorio" -esto es, se alcanza una relación integrada-, son concebidos como intermedios e instrumentales, y prefiguran, en el nivel biológico, la interpretación deweyana de las “operaciones de inferencia y de deducción” (1w.12.42). 
Ahora bien, la transformación del comportamiento orgánico en comportamiento intelectual está ligada al hecho de que los seres humanos viven, actúan e investigan en un medio ambiente que no es puramente físico, sino también cultural. El hombre, entendido como un animal social, se enfrenta a problemas y maneras de resolverlos sin precedente en el nivel biológico:

lo que el hombre hace y el modo como lo hace no está determinado únicamente por la estructura orgánica y por la herencia física sino por la influencia de la herencia cultural incorporada en las tradiciones, instituciones, costumbres, y las finalidades y creencias que ambas acarrean e inspiran (Dewey, 1950, p. 58).

Según Dewey, esta condición fuerza al hombre a adoptar, en su conducta, "el punto de vista de costumbres, creencias, instituciones, 'sentidos' y opiniones que son, por lo menos relativamente, generales y objetivos" (1w.12.50). El lenguaje, en su dimensión comunicativa, es una condición necesaria de la existencia y transmisión de actividades no puramente orgánicas. Se trata, además, de un modo de comportamiento estrictamente biológico que fuerza, sin embargo, a los individuos a adoptar un punto de vista común. La emergencia del lenguaje ha repercutido sobre las formas previas del comportamiento humano asociado de tal manera que "dotó de una nueva dimensión a la experiencia" (lw.12.62). La investigación controlada es una de las facetas que esta nueva dimensión hace posible, al tiempo que se constituye como el objeto de la lógica. Dejaremos para el capítulo siguiente la concepción de los principios lógicos que Dewey extrae de esta concepción de la investigación, y analizaremos a continuación la pauta de la investigación y el lugar de los juicios prácticos en ella. 


\subsection{La pauta de la investigación}

Hasta aquí hemos visto que, de acuerdo con Dewey, la conducta orgánica anticipa la pauta de la investigación, entendida ésta última como transformación de la situación. Ahora bien, resulta evidente que no toda transformación de la situación constituye una investigación, sino que

la interacción orgánica se convierte en investigación cuando se prevén consecuencias existenciales; cuando se examinan las condiciones ambientales por referencia a sus potencialidades; y cuando se seleccionan y ordenan actividades de respuesta por referencia a la actualización de unas potencialidades en vez de otras en una situación existencial final (1950, p. $125)$.

En otros términos, la investigación supone un aspecto de control y dirección. El primer aspecto que cumple una función de control y dirección, y acaso el más importante, es la determinación o identificación del problema propio de la situación en cuestión. Como señala Dewey, la situación indeterminada es en sí misma pre-cognitiva. El primer paso de la actividad cognitiva es la calificación de la situación como problemática. Ello supone un aspecto de control y dirección por cuanto implica distinguir entre los caracteres de la situación que resultan fijos o estables y los que no. Se trata de determinar cuáles son, en los términos de Dewey, los hechos del caso, los datos, en el sentido de aquello que en esa situación particular puede darse por descontado. Asimismo, el modo en que se caracteriza el problema impacta en los datos que se seleccionan como pertinentes y los que se abandonan. Este proceso de selección de datos supone siempre un cierto grado de actividad orgánica. En efecto, supone que el organismo busca los datos, dirige su mirada de un lado a 
otro, aguza su oído, tantea lo que lo rodea. Los datos de la situación, los hechos del caso, son datos en el sentido de que se toman como establecidos, pero no son algo meramente dado, sino más bien algo producido.

Esta determinación de los hechos del caso no puede ser vista como un mero tanteo ciego. En el proceso mismo de la determinación del problema ciertas posibles soluciones se nos ocurren, nos son sugeridas en la situación. Surgen así las ideas en el sentido de posibles soluciones anticipadas, cursos de acción posibles, como medios para la transformación de la situación. En otros términos, tiene lugar la inferencia, en el sentido básico de sugerencia, a partir de lo presente tomado como signo, de algo no presente pero señalado por aquello. Ahora bien, la inferencia en sí misma no garantiza la solución del problema. La idea inferida o sugerida puede resultar inadecuada. Por otro lado, si simplemente aceptamos la primera inferencia que ocurre, la investigación se detiene. Antes bien, las ideas inferidas deberán a su turno ser examinadas y eventualmente aceptadas o rechazadas, y tal examen supone la valoración de la idea en su capacidad funcional, es decir, en su capacidad como medio para resolver el problema planteado. Este examen adopta, en primer lugar, la forma del razonamiento, esto es, del desarrollo de los sentidos que la idea implica, de las relaciones que mantiene con otros sentidos o ideas. La expresión de tales relaciones es llamada por Dewey proposición. El razonamiento permite aclarar la idea, y echa luz sobre las operaciones que habrá que desarrollar a los efectos de probarla, es decir, de establecer su capacidad como medio para resolver el problema. Así, el razonamiento no se identifica con la inferencia sino que es un factor en su control y dirección. Por otro lado, el razonamiento no constituye una demostración de la inferencia sino que tiene un carácter intermediario. En palabras de Dewey, "la idea o sentido desarrollado en el discurso [es 
decir, el razonamiento] dirige las actividades que, una vez realizadas, suministran el necesario material de prueba" (Dewey, 1950, p. $130 /$ lw.12.115). En este sentido el razonamiento es una suerte de cálculo de proposiciones, de libre desarrollo de las ideas o sentidos en su carácter mismo de ideas o sentidos. El razonamiento permitirá, así, el desarrollo de nuevos sentidos o ideas que serán o no, a su turno, probadas y que servirán a su vez como medios para dirigir las observaciones y los experimentos en la búsqueda del establecimiento de nuevos datos. En otros términos, el razonamiento no establece la asertabilidad de su conclusión, su verdad en el sentido clásico: tal prueba dependerá del hecho de que efectivamente funcione, es decir, de que permita solucionar efectivamente el problema que ocasionó la investigación. Es la inferencia la que, al ser sometida a control, establece la aceptabilidad garantizada de una idea o juicio.

Dewey insiste en el carácter operativo de los datos y las ideas. Tal carácter implica, en primer lugar, que la distinción entre ellos es funcional: los datos son medios para la clarificación o determinación del problema implicado y las ideas soluciones sugeridas. Pero ambos son operativos, esto es, forman parte de la investigación, se seleccionan y describen a los efectos de que sirvan como medios para clarificar y resolver el problema. Como afirma Dewey, “no son autosuficientes y completos en sí mismos” (1950, p. 131), es decir, los hechos del caso o datos nos son el reflejo de una realidad estática y previa o independiente de la investigación. Antes bien, los datos, lo mismo que las ideas, se seleccionan, se manipulan, se fabrican, por así decirlo, de modo que resulten funcionales en la investigación. Ello no quiere decir, por supuesto, que sean meras fantasías o invenciones. Los hechos y las ideas deben resultar adecuados pero, en su carácter de datos, son instrumentales, son medios para resolver problemas. Ello implica, entonces, que las 
proposiciones tendrán también un carácter intermedio, operativo o instrumental. Tenemos aquí un aspecto importante en el que Dewey se diferencia de la tradición lógica. En efecto, desde su punto de vista la teoría tradicional sostiene que "todas las proposiciones son meramente declaratorias o enunciadoras de lo que existe o subsiste con anterioridad a ellas y que esta función declaratoria es completa y final en sí misma” (Dewey, 1950, p. 182). Contra esto, sostiene que las proposiciones declarativas, tanto de hechos como de ideas, son medios o instrumentos. Por último, cabe señalar, Dewey llama juicio, como algo distinto de las proposiciones, al resultado establecido de la investigación. El juicio es la conclusión de la investigación en el doble sentido de ser su resultado y su terminación. Una vez establecido el juicio, la investigación ha finalizado y se ha establecido la solución. El juicio, al igual que una sentencia judicial, resulta terminal como medio de establecer una nueva situación existencial. Por supuesto, el establecimiento del juicio supone, la mayor parte de las veces, la realización de juicios intermedios. En ambos casos, el juicio tiene un aspecto práctico, es un instrumento en la producción de una nueva situación. Esta idea acerca del carácter práctico de los juicios que intervienen en la investigación resulta central en el contexto de la obra de Dewey, por cuanto establecerá un nexo entre los procesos de investigación científica y los procesos de evaluación de fines y valores, que analizaremos en los capítulos 6 y 7.

\section{Conclusiones}

En este capítulo hemos analizado algunas de las características centrales de la concepción de la investigación de Dewey. Hemos reconstruido su posición naturalista señalando el 
principio de continuidad que pretende oponerse tanto a las posiciones anti-naturalistas como a los naturalismos reduccionistas, al tener en cuenta tanto el seno biológico como el cultural en el que la investigación ocurre, y hemos presentado la estructura o pauta de la investigación. Hemos visto, también, que la concepción deweyana del conocimiento se forja a través de un análisis que supone dos movimientos metodológicos. En primer lugar, el principio de análisis contextual supone rechazar una distinción metodológica dicotómica entre proceso y producto, como forma de delimitar el espacio de la reflexión filosófica acerca del conocimiento. Así, nuestra concepción del conocimiento debe considerarse como una generalización de las características que se encuentran como pertenecientes a los resultados de un proceso de investigación. Esto lleva, en primer lugar, a sustituir la verdad por la asertabilidad garantizada como uno de los resultados de la investigación. Así, las aserciones garantizadas son los juicios que la investigación arroja como afirmables de modo garantizado, que cumplen una función de transformación de la situación en tanto que juicios prácticos y cuyo carácter de asertabilidad garantizada indica que pueden considerarse como medios, como recursos, en otras investigaciones. En segundo lugar, este principio de análisis contextual, al dirigir la mirada al proceso de investigación, supone una aproximación empírica a la problemática del conocimiento, aproximación que evitaría a la filosofía volver a caer en la vieja trampa de imponer sobre los hechos una pretendida descripción que no es más que una deducción a partir de supuestos filosóficos tradicionales heredados y no sometidos a revisión.

El segundo movimiento consiste en una inversión de la prioridad conceptual del así llamado conocimiento aplicado por sobre el conocimiento básico. El análisis de esta cuestión nos ha llevado a especificar la comprensión instrumental del conocimiento de 
Dewey que habíamos comenzado a analizar en el capítulo anterior. Así, hemos sostenido que el conocimiento y la ciencia son instrumentales, en Dewey, en tres sentidos, cuya confusión, a veces incluso en los propios escritos de Dewey ha generado diversas críticas. Tales sentidos son los siguientes: (a) el conocimiento es instrumental porque su objeto es instrumental: se trata de las relaciones de condiciones-consecuencias, los procesos que acaecen en la naturaleza; (b) el conocimiento es en sí mismo un instrumento porque constituye un verdadero medio, una herramienta para la transformación del mundo; y (c) el conocimiento es instrumental porque su propia producción es una práctica tecnológica de utilización y modificación de los materiales existenciales y conceptuales que intervienen en la investigación. Este último aspecto llevó a Dewey a anticipar algunas discusiones de los estudios de la ciencia contemporáneos acerca de los aparatos y máquinas intervinientes en el proceso de producción de conocimiento (cfr. el concepto de inscriptores en Laboratory Life de Latour y Woolgar, 1986).

Resulta interesante señalar que tal inversión en la relación entre el conocimiento aplicado y el conocimiento básico es un recurso metodológico tomado por Dewey para pensar un problema que, desde su punto de vista, era el problema central de una filosofía del conocimiento, a saber, el de la relación entre el conocimiento, o mejor dicho, entre la experiencia cognitiva y otras formas de experiencia. Esta cuestión, resulta dependiente de su concepción de la filosofía como crítica de críticas o crítica de la cultura, puesto que nuestro autor asigna a la filosofía, precisamente, la misión de restablecer la unidad y la integridad de la experiencia luego de que la tradición se hubiera encargado de separarla en compartimentos estancos. Este motivo del pensamiento de Dewey, vinculado en su opinión con el aspecto de unidad que encontraba en Hegel, se complementa también con un motivo 
marxista: el objetivo no es tanto un mero comprender la experiencia humana, sino más bien ensancharla y enriquecerla, es decir, transformarla.

Ha quedado en este capítulo, sin embargo, una cuestión pendiente. Hemos reconstruido la concepción del conocimiento de Dewey, que se sigue de su teoría de la investigación, pero, como señalamos en la introducción, nuestro autor pretendía extraer de allí una verdadera lógica. En nuestra opinión, y como argumentaremos en el capítulo siguiente, la lógica de Dewey es investigación sobre la investigación, pero no es toda la investigación sobre la investigación. En efecto, el aspecto propiamente lógico de la investigación hace más bien referencia al aspecto de control, y específicamente a las normas que resultan de aplicación válida en el contexto de una investigación. Puesto que la concepción deweyana de la lógica ha sido cuestionada en su pretensión de ser una lógica, nos detendremos en el capítulo siguiente en esta cuestión a efectos de completar nuestro análisis de la teoría de la investigación de Dewey. 


\section{5}

\section{La concepción deweyana de la lógica}

\section{Introducción}

Este capítulo aborda un aspecto de la filosofía de John Dewey que no ha sido, en nuestra opinión, suficientemente analizado, a saber, sus investigaciones en el ámbito de la lógica ${ }^{1}$. Estas investigaciones, como ha señalado Sidney Hook, constituyeron, para Dewey, "su interés prioritario durante más de cuarenta años" (2000, p. 73). En efecto, componen un aspecto central de su producción desde finales del silgo XIX y encuentran, luego de varias presentaciones, su exposición más articulada con la publicación en 1938 de Logic: The Theory of Inquiry, sobre algunas de cuyas tesis nos hemos detenido en el capítulo anterior. El título de la obra señala su tesis principal: la lógica debe ser abordada en conexión con la

\footnotetext{
${ }^{1}$ Una notable excepción a esta afirmación general han sido los estudios de Burke sobre la lógica de Dewey. Cfr. Bruke, 1992, 1994, 2009a, 2009b y Burke et al., 2002.
} 
teoría de la investigación. Esta concepción de la lógica resultaba inspirada, de acuerdo al propio Dewey, en algunas ideas de Peirce.

Como hemos sugerido en el capítulo anterior, el objetivo principal del libro es ofrecer una concepción naturalista de la lógica, esto es, una concepción naturalizada de los principios lógicos que pueda dar cuenta de su carácter normativo sin suponer ningún tipo de ruptura o dicotomía entre naturaleza y razón. Se trata, de acuerdo con Dewey, de dar cuenta de cómo es que hay principios lógicos obligatorios, principios racionales, en un mundo donde todo lo que hay es naturaleza. En otros términos, Dewey pretendía dar cuenta de la continuidad de las funciones y actividades exclusivamente biológicas del ser humano y las funciones y actividades que cabe calificar como distintivamente lógicas. Un vez más, el problema es ofrecer una concepción de la lógica de acuerdo con la cual las propiedades lógicas son también productos de la interacción orgánica y, en última instancia, resultados de la evolución. En un contexto como este, la lógica no puede entenderse como el estudio de relaciones lógicas ubicadas en alguna región del ser inteligible o a priori. Así, Dewey necesita algo que pueda servir de soporte naturalista a los principios lógicos, y tal soporte será la inferencia y el razonamiento, pero no como meros productos analizables de modo independiente del contexto en el que ocurren, sino en el contexto que les es propio, a saber, la investigación. De este modo, el principio del análisis contextual al que nos referimos en el capítulo anterior encuentra, en el ámbito de la lógica, una nueva aplicación. En este contexto, los principios lógicos, en directa analogía con los principios jurídicos, serán comprendidos como reglas que surgen en la investigación, como un subproducto de ella, frente a la necesidad de controlar y dirigir la inferencia, y que tienen, sin embargo, fuerza normativa respecto de la investigación. 
Como hemos ya anticipado cuando presentamos algunos rasgos de la comprensión de la lógica de Peirce, la tesis de Dewey ha sido objeto de controversias. Peirce mismo vio en el proyecto de Dewey no un desarrollo de la lógica sino su sustitución por una "historia natural del pensamiento"2 . También, más recientemente, incluso intérpretes que tienden a recuperar ideas de Dewey en el campo de la teoría del conocimiento, la ética y la política, tienden a considerar tal pretensión como una extra-limitación equivocada, además, a la luz del desarrollo de la lógica contemporánea y posterior a Dewey. Así, por ejemplo, Esteban, pese a proponer recuperar el naturalismo normativo deweyano, afirma que el pragmatista “fracasa cuando intenta probar que todas las formas lógicas de la lógica contemporánea se originan en avances de la investigación empírica. La lógica es hoy una disciplina autónoma de la metodología de la ciencia" (2008, p. 194).

En este capítulo discutiremos principalmente con dichas interpretaciones. En este sentido, sostendremos que la lógica de Dewey puede y debe verse como una verdadera lógica, y que si bien, como afirma Dewey, la lógica es investigación sobre la investigación, hay elementos en su concepción de la investigación que permiten afirmar que no es toda la investigación sobre la investigación. Para defender una lectura tal, será necesario detenernos, en primer lugar, en la caracterización deweyana de la inferencia y del razonamiento, términos que tienen en este contexto significados distintos. En segundo lugar, expondremos la concepción de las formas lógicas de Dewey, expresión algo anticuada mediante la cual refiere nuestro autor a las leyes, principios y propiedades lógicas.

\footnotetext{
${ }^{2}$ Para un rechazo de esta pretensión de Peirce de que lo que Dewey proponía es tal cosa cfr. Burke 2007, pp. xxi-xxiv.
} 


\section{La lógica y el control de la inferencia}

En el comienzo de la obra de Dewey que analizamos, su autor traza una distinción entre el objeto inmediato y el objeto último de la disciplina. En su opinión, había entre los lógicos de su tiempo un consenso extendido respecto de cuál era el objeto inmediato de la lógica, a saber, las relaciones lógicas entre proposiciones y juicios. Sin embargo, el consenso se desvanecía cuando se indagaba acerca de la naturaleza de tales relaciones, esto es, acerca del objeto último de la lógica. En vista de ello, Dewey se propone un abordaje del objeto inmediato de la lógica que no descuide el problema de su naturaleza. En este sentido, el punto de partida es, como dijimos, el de una filosofía de la lógica que busca establecer claramente cuál es su propósito y cuál es la naturaleza de aquello de lo que habla. Así, el estudio comenzará proponiendo una hipótesis acerca del objeto último de la lógica, esto es, una hipótesis acerca de la naturaleza de las relaciones formales entre las proposiciones, hipótesis que se expondrá más adelante en este capítulo.

Uno de los aspectos más llamativos del libro es que, en un momento de pleno auge del desarrollo de la lógica formal o simbólica, y tal como advierte su autor (Dewey, 1950, p. 4), la obra carece de todo intento de formulación simbólica. Tal carencia es justificada por Dewey sobre la base de dos consideraciones. En primer lugar, afirma, se evita todo intento de simbolización porque uno de los objetivos del libro es, precisamente, cuestionar la distinción tradicional entre materia y forma acríticamente aceptada en tales intentos. En segundo lugar, porque abocarse de lleno al desarrollo de sistemas formales, sin una discusión previa acerca de la naturaleza de aquellas cosas que son formalizadas o simbolizadas, contribuye "a perpetuar los errores existentes y reforzarlos por lo mismo que 
parecerá prestarles aparato científico" (Dewey, 1950, p. 4). Ahora bien, es importante señalar que estos reparos expresados por Dewey no implican un rechazo de la simbolización en sí misma. Antes bien, nuestro autor afirma que, como resultado de sus investigaciones sobre lógica, es esperable e incluso deseable que se produzcan más y mejores simbolizaciones. Nótese que con estas afirmaciones Dewey está ubicando su obra en el campo de la lógica y, a la vez, enfrentándola a las principales concepciones de la lógica de su tiempo, lo que supone imponerse un sendero difícil. Así, resulta evidente que el problema de Dewey con el desarrollo de la lógica formal era que perpetuaba y reforzaba errores, y ello en razón de que dejaba sin analizar el objeto último de la lógica, es decir, la naturaleza de los principios y relaciones lógicas.

Como mencionamos en la introducción de este capítulo, esta obra plantea de modo directo la pregunta acerca de la relación entre los principios lógicos y aquello que se supone que tales principios regulan o dirigen. Desde el punto de vista de la lógica tradicional, los principios lógicos son principios que gobiernan el razonamiento. Ahora bien, en la tradición lógica un razonamiento es básicamente un conjunto de proposiciones o enunciados y una relación, la de consecuencia o implicación lógica, en virtud de la cual una de esas proposiciones -la conclusión- se sigue o se desprende de las otras -las premisas. En la lógica actual parece haber un consenso extendido respecto de esta definición y los desacuerdos comienzan cuando se indaga acerca del estatus ontológico y/o epistemológico de estas entidades que pueblan los razonamientos, esto es, las proposiciones y la relación misma de implicación lógica. Sin embargo, podría plantearse, desde un punto de vista deweyano, que esta caracterización de los razonamientos tiene en principio dos falencias. 
En primer lugar resulta una caracterización demasiado abstracta o, más específicamente, descontextualizada. Es decir, no tiene en cuenta el contexto en el cual los razonamientos ocurren. En segundo lugar, y como consecuencia de lo anterior, no se tiene en cuenta que los razonamientos no son entidades separadas de los sujetos que los formulan, sino más bien algo que ellos hacen en determinadas circunstancias y con determinados fines. En otros términos, un razonamiento o inferencia es una forma de acción. Así, desde el punto de vista naturalista de Dewey, aquello que los principios lógicos regulan o modelan es, básicamente, la conducta inteligente, el pensamiento reflexivo, tal como lo llama en How we Think, o la investigación, como será llamada en Logic: The Theory of Inquiry. El razonamiento, en un sentido más o menos próximo al tradicional, como algo más o menos abstracto e incluso en algún sentido independiente de la situación, esto es, el razonamiento como una suerte de cálculo lógico, ocupará, de hecho, un lugar en la lógica de Dewey pero no será su único objeto ni el más importante.

De esto resulta que, si hemos de estudiar los principios lógicos, no de modo aislado sino tal como ellos surgen y son utilizados en un determinado contexto, y si tal contexto lo constituye la investigación, entonces, el estudio de los principios lógicos, la lógica misma, debe entenderse como una indagación sobre la investigación, esto es, como investigación de la investigación. En este sentido, y por estas razones, la lógica debe ser, para Dewey, una teoría de la investigación. Tal denominación expresa, entonces, la hipótesis de que los principios lógicos sólo pueden ser correctamente estudiados como aspectos o componentes de la investigación, esto es, en su relación con ella. Se trata, en resumidas cuentas, y como señala Ángel Faerna (1996, p. 208), de plantear la pregunta por la relación entre los principios lógicos y la práctica que pretenden regular. En los siguientes apartados nos 
detendremos en el análisis de algunos aspectos importantes de la lógica de Dewey, a saber, su concepción de la inferencia y su concepción de los principios lógicos.

\subsection{La inferencia}

El establecimiento del juicio, (la investigación o el pensamiento reflexivo), puede ser descrito como un proceso de control de la inferencia, es decir, un proceso que debe producir asertabilidad garantizada. En efecto, la investigación es ese proceso que permite determinar cuáles de las inferencias que se han sugerido en la situación merecen nuestra confianza. Para lograr ello es necesario preparar y transformar el material que servirá de base a la inferencia de modo tal de asegurar, tanto como sea posible, que arroje como resultado aserciones garantizadas, esto es, como dijimos en el capítulo anterior, conclusiones que han sido establecidas en la marcha de la investigación y que, en virtud de ello, pueden ser utilizadas como recursos para investigaciones ulteriores.

Ahora bien, esta idea de un control de la inferencia supone, en efecto, que es posible trazar una distinción entre inferencias controladas e inferencias no-controladas. Esta distinción no es equivalente a la distinción entre inferencias válidas o correctas e inferencias incorrectas. Antes bien, se trata de una distinción entre inferencias espontáneas e inferencias que han sido sometidas al control de la investigación. En el capítulo anterior, al exponer la pauta de la investigación, se ha afirmado que la inferencia o sugerencia ocurre en la investigación o que en ella surgen ideas. El uso de estos términos pretendía señalar uno de los aspectos de la inferencia, a los ojos de Dewey, más importante, a saber, su carácter natural. En efecto, de acuerdo con Dewey, la inferencia es un hecho natural, algo 
que ocurre naturalmente, algo tan cierto o tan natural como la existencia de los ojos o el crecimiento de las plantas (Dewey, 1916, p. 419).

En este contexto, la calificación de la inferencia como un hecho natural significa que no es un hecho puramente privado o subjetivo. En otros términos, significa que es un hecho accesible a la investigación empírica, algo que puede observarse por cuanto se trata de algo que los hombres hacen, así como caminan, hablan o mastican. Se trata de una posición propia del pensamiento psicológico de Dewey con la que no hemos encontrado ya varias veces en el curso de esta tesis, y que implica que los hechos mentales o psíquicos son formas de respuestas orgánicas a los desafíos del ambiente, y por tanto no son algo que ocurra en una mente privada e inaccesible a los otros sino una facultad de los hombres como seres biológicos y sociales, una forma que adquiere la interacción orgánica. En este sentido, la inferencia, lo mismo que las intenciones y que el pensamiento en general, son hechos naturales observables, o mejor dicho, cuyo conocimiento puede inferirse a partir de hechos observables. $^{3}$

Pero la inferencia ocurre naturalmente también en otro sentido. Desde el punto de vista de Dewey, inferir es algo que en muchas ocasiones los hombres simplemente hacen, no algo que tengan la intención de hacer. Es decir, la mayor parte de las veces la inferencia tiene un carácter espontáneo, ocurre sin intención. Así, la inferencia como sugerencia de una idea (como posible solución) es algo que ocurre de modo espontáneo en el curso de la investigación y el pensamiento reflexivo. Esto puede apreciarse de un modo más adecuado si se presta atención a lo que, según Dewey, constituye la función obvia de la inferencia espontánea: presentar a un agente consideraciones ausentes a las que este podría responder

\footnotetext{
${ }^{3}$ En este punto también, Dewey asume una posición que ya había postulado Peirce: no hay conocimiento inmediato (intuiciones como diría Peirce) sino que todo conocimiento es inferido a partir de la observación.
} 
del modo en que responde a la fuerza estimulativa de una situación dada. El acto de inferir consiste en "adoptar una actitud de respuesta ante una cosa ausente como si estuviera presente" (Dewey, 1916, p. 423). La actitud propia de la inferencia es la de considerar que algunas cosas ausentes están en un continuo real con las cosas presentes, de modo que nuestra actitud frente a estas últimas está atada a nuestra reacción respecto de las primeras, en tanto partes de la misma situación.

Esta idea de la inferencia como una actitud adoptada remite ciertamente al concepto, central en el pragmatismo, de hábito. En efecto, si se entiende al hábito como una disposición a actuar de un modo determinado frente a algo, resulta que la inferencia puede pensarse como un tipo de hábito. Acaso puede objetarse que, mientras la noción de hábito supone una cierta regularidad en la disposición a actuar de una determinada manera, la idea de inferencia espontánea que se está exponiendo parece suponer, en virtud de tal espontaneidad, un carácter único e irrepetible. Sin embargo, otra vez, el carácter de espontáneo hace referencia a la ausencia de intención y no a su carácter de único e irrepetible o no causado. Antes bien, si tenemos en cuenta que la inferencia resulta, de hecho, las más de las veces, influida por la experiencia pasada, esto es, por las inferencias realizadas con anterioridad, resulta que podemos pensar la inferencia como un hábito. Nuevamente ello no implica un factor intencional, y por lo mismo no implica necesariamente ningún tipo de principio de inferencia propiamente lógico. En efecto, la inferencia que es meramente dictada por la experiencia pasada, por la costumbre, sigue siendo algo que ocurre sin intención, del mismo modo que la acción de cerrar con llave una puerta al salir de la casa resulta no intencional cuando es dictada por el automatizado hábito de cerrar la puerta con llave al salir. 
De este modo, vemos que la inferencia supone una relación entre lo que en una situación determinada resulta dado o presente y algo no presente, lo inferido o sugerido. En otros términos la inferencia es un modo de reacción frente a lo presente o lo dado que toma a esto último como signo de algo más. En palabras de Dewey, estamos en presencia de la inferencia cada vez que "las cosas son usadas como signos, indicaciones, o evidencia a partir de los cuales procedemos hacia otra cosa aun no directamente dada" (Dewey, 1916, p. 420). De acuerdo con lo dicho, esta idea de uso de "las cosas" como signo no implica que tal uso deba ser entendido como una acción intencional. Sin embargo, de acuerdo con Dewey, la existencia de este tipo de inferencias espontáneas, que en tanto que tales carecen de toda propiedad lógica, trae consigo la posibilidad de la existencia de la inferencia controlada y, por consiguiente, la posibilidad de la existencia de principios o postulados lógicos. En efecto, la inferencia, cuando es espontánea, no nos da ningún tipo de garantías respecto de su éxito. Es en la búsqueda de tal tipo de garantías que lo lógico como tal entra en juego, en la forma de postulados o principios que la inferencia ha de cumplir a los efectos de llegar a aserciones garantizadas y que analizaremos a continuación.

\subsection{Los principios lógicos}

Llegamos así a la concepción deweyana de los principios lógicos. Es en esta concepción donde debe quedar recogida la impronta naturalista de la lógica: se trata de ofrecer una manera de comprender las formas lógicas que vuelva plausible la idea de que hay una continuidad entre el comportamiento lógico y el comportamiento biológico. La hipótesis central de Dewey respecto de los principios, leyes o formas lógicas involucra, 
principalmente, dos ideas. En primer lugar, que los principios lógicos no son algo que se imponga a la investigación desde afuera sino que surgen en el proceso mismo de la investigación. En efecto, podríamos decir que los principios lógicos son un subproducto de la investigación. Surgen cuando se formulan explícitamente las maneras en que han sido obtenidas ciertas inferencias que se han mostrado exitosas en relación al cumplimiento del fin de la investigación. Así, un principio lógico es una explicitación de una manera de proceder que en el continuo de la investigación funcionaba de manera implícita. Cuando la reflexión se vuelve sobre la actividad misma y nota, no sólo qué es aquello que se hace sino también cómo se lo hace, comienza un proceso de abstracción que permitirá la formulación explícita de un principio lógico. De este modo, podemos decir, los principios lógicos son el producto de un proceso que, para usar un término más actual, resulta reconstructivo. ${ }^{4}$ Es decir, a partir de las inferencias que hemos realizado de modo exitoso, esto es, de modo que nos permitieron resolver el problema en cuestión, podemos reconstruir los modos de inferencia involucrados, el cómo de la inferencia, explicitando así un principio que se postula hipotéticamente como un legítimo hábito de inferencia.

Ello supone, por supuesto, que la investigación ha trabajado ya durante un tiempo y que se origina, por así decirlo, una investigación de segundo orden. Para explicar esta posibilidad del surgimiento de las formas lógicas, entendidas como explicitaciones de ciertas formas o maneras de establecer inferencias, Dewey recurre explícitamente a la noción de hábito formulada por Peirce, que le permitirá, a su vez, establecer un punto de continuidad entre lo biológico y lo lógico. La inferencia, como hemos dicho, ocurre sin intención. En este sentido, se trata de una forma de conducta que el animal humano ha

\footnotetext{
${ }^{4}$ Este aspecto de explicitación resulta, sin dudas central para el concepto de norma o principio lógico en la obra de Dewey, y ha sido un aspecto abordado por Brandom (2011), quien lo entiende como un aspecto central del pragmatismo.
} 
desarrollado en el proceso de su interacción con el medio. La inferencia permite, como se dijo anteriormente, reaccionar a algo no presente como si estuviera presente y, en este sentido, permite la anticipación y con ello cumple una función destacada en el mantenimiento y el ensanchamiento de la experiencia. Ahora bien, de acuerdo con Peirce, la inferencia, en tanto $\mathrm{y}$ en cuanto presenta ciertos aspectos de generalidad o de recursividad, implica un hábito que funciona, una vez que ha sido formulado, como una herramienta en el control de lo que se hace. En este sentido cabe hablar de hábitos de inferencia, es decir, de maneras más o menos generales y recurrentes en que el organismo humano realiza inferencias. Cuando se analiza el modo en que se extraen inferencias, y se explicita el hábito de inferencia, el principio o guía involucrado, se da un paso significativo hacia el control de lo que se hace, hacia su dirección, y con ello surge un hábito de inferencia que cabe calificar como propiamente lógico.

Otro aspecto relevante de la concepción deweyana de los principios lógicos es que ellos expresan la forma que ciertos materiales que intervienen en la investigación deben asumir si es que se quiere lograr el establecimiento de aserciones garantizadas. Este segundo aspecto indica que las formas lógicas son un caso especial, junto con, por ejemplo, las formas estéticas y las formas jurídicas, en que un cierto material adquiere nuevas propiedades al tomar parte en una actividad en calidad de medio para el logro de alguna consecuencia. Así, los objetos, ideas, datos, sentidos, proposiciones o juicios que revisten un carácter lógico son objetos sobre los que se han ejecutado ciertas operaciones con el fin de transformarlos en objetos que puedan utilizarse como medios para obtener aserciones garantizadas. En este sentido, las propiedades lógicas son propiedades que se añaden a, o se acumulan en, un material simbólico al entrar éste a formar parte de la investigación. Así, un 
conjunto consistente de proposiciones es un conjunto de proposiciones (es decir, un conjunto de formulaciones de relaciones entre sentidos o ideas), en el que se han ejecutado una serie de operaciones de modo tal que puedan ser usadas como base confiable de la inferencia y obtener así aserciones garantizadas. En este proceso de transformación de un material para que pueda servir como medio para obtener un fin buscado reside el carácter racional de los principios lógicos, y en ello reside también su fuerza normativa: una vez formulados los principios lógicos se vuelven obligatorios para ulteriores investigaciones porque se han mostrado como los medios adecuados para cumplir exitosamente con el fin de la investigación. Podemos apreciar que, según Dewey, los principios lógicos, si bien son formales por cuanto estipulan la forma que cierta materia debe asumir para servir como medio en la investigación, no son meras formas puras o a priori, independientes de toda experiencia, sino, como afirma Dewey, formas-de-una-materia, la forma que la inferencia y el discurso deben asumir para que sea posible contar con aserciones garantizadas. Específicamente y en palabras de Dewey, los principios lógicos expresan la idea de que "si sacamos nuestras inferencias de cierto modo [esto es, tal como lo indican los principios lógicos], conseguiremos, en igualdad de circunstancias, conclusiones en que podremos confiar" (Dewey, 1950, p. 25). En otros términos, son principios guías que nos sugieren, sobre la base de lo aprendido en el continuo de la investigación, esto es, en las investigaciones previas, de qué modo debemos extraer nuestras conclusiones, o, en otros términos, qué propiedades deben cumplir o satisfacer nuestras inferencias si es que queremos obtener aserciones garantizadas. Así, los principios lógicos tienen el carácter de postulados que formulan las condiciones ideales que deben ser satisfechas para cumplir con determinados fines, tanto como sea posible. 
Para finalizar este apartado haremos algunos señalamientos. En primer lugar, el carácter de postulado de los principios lógicos señala que no pueden ser ya comprendidos como algoritmos. Es decir, los principios lógicos no imponen una serie finita de pasos que deben cumplirse necesariamente y que, de cumplirse, aseguran un cierto resultado. La razón de ello radica en que, como señala Dewey (1950, p. 30), entre las condiciones que deben cumplirse para llevar a buen puerto la investigación, hay condiciones generales o formales, propiamente lógicas, pero también hay condiciones locales que dependen de la situación, y que por consiguiente sólo pueden ser establecidas en el contexto de la situación concreta de que se trata. En este sentido, la lógica como teoría acerca de los principios que regulan la inferencia no puede ser una teoría completamente formalizada.

Acaso resulte interesante recuperar aquí una distinción que presentamos en el capítulo anterior al exponer la pauta de la investigación. Se trata de la diferencia entre inferencia y razonamiento o discurso racional. Según dijimos, la investigación puede describirse como un proceso de control de la inferencia de modo que obtengamos aserciones garantizadas. Este proceso implica, como se mencionó, de acuerdo con Dewey, no sólo especificar el problema, establecer los datos o hechos del caso y postular ideas entendidas como posibles soluciones, sino también estudiar o analizar las ideas en tanto que ideas, es decir, tomadas en su mera cualidad de signos. Ello implica analizar las ideas en función de los significados implicados por ella y por su relación con otros significados relevantes. Este proceso de cálculo es llamado por Dewey razonamiento o discurso racional. Como vimos en el capítulo anterior, una de las características centrales del razonamiento es su calidad de libre juego de ideas, de exploración de significados, lo que implica, a su turno, que no tiene fuerza probatoria. Un razonamiento en este sentido no 
demuestra su conclusión, sino que sólo explicita consecuencias y relaciones, siendo la inferencia controlada la única que puede establecer la asertabilidad garantizada de su conclusión.

Teniendo en cuenta la posición falibilista y meliorista heredada por Dewey de Peirce, cabe señalar, además, que ninguna inferencia puede darse como establecida de una vez y para siempre, sino que siempre es posible, a la luz de nuevas evidencias, en función de la continuidad de la investigación, que tengamos que revisar las conclusiones a las que hemos llegado. Ello implica, como ha señalado Burke (1992) que la inferencia es, por norma general, en el contexto del pensamiento de Dewey, derrotable. ${ }^{5}$ Tal derrotabilidad es algo que la investigación procura siempre disminuir, pero que no puede eliminarse por completo. Por otro lado, el razonamiento, en tanto que cálculo de proposiciones, sí puede aspirar a la no-derrotabilidad, al menos en algunos campos, por cuanto es sólo una explicitación de las implicaciones de un determinado signo, siempre en el contexto de una red de signos en la que toma parte.

Otro aspecto remarcable en relación con la concepción de los principios lógicos es que pierden su carácter de eternos. En efecto, están sujetos a revisión empírica conforme cambian los métodos de investigación. En palabras de Dewey:

La lógica se apoya en el análisis de los mejores métodos de investigación (siendo considerados "mejores" por sus resultados dentro de la investigación) que existen en un determinado momento. Como los métodos de las ciencias mejoran, se producen cambios correspondientes en la lógica. (...) Los principios lógicos son, por tanto, provisionales: se aceptan hasta que se encuentren razones definitivas para ponerlos en duda (1950, p. 27).

\footnotetext{
${ }^{5}$ La no derrotabilidad expresa la propiedad de la deducción según la cual si una conclusión se sigue de un conjunto de premisas, dicha conclusión se sigue también de ese conjunto de premisas aunque lo ampliemos mediante el agregado de nuevas premisas.
} 
De este modo, vemos que la posición que Dewey defiende en su lógica puede caracterizarse como un naturalismo normativo, siendo tal naturalismo equivalente a la tesis según la cual las normas son un resultado de la investigación o el pensamiento reflexivo, reconstruidas a partir de la reflexión sobre los modos "exitosos" de obtener aserciones garantizadas y cuyo acatamiento resulta "normativo" puesto que se ha mostrado como la manera adecuada de obtener tales aserciones.

Hemos presentado hasta aquí, entonces, la caracterización deweyana de la inferencia, el razonamiento y los principios lógicos. Estamos ya en condiciones de abordar la cuestión acerca de la legitimidad de la caracterización de la lógica de Dewey como una verdadera lógica.

\section{3. ¿Es la lógica de Dewey una verdadera lógica?}

Como hemos afirmado, la reacción más común frente a la lógica de Dewey consiste en interpretar que no es una verdadera lógica o, al menos, que la pretensión de su autor de que lo sea resulta equivocada. El hecho de que tal posición resulte tan extendida, aunque no sea unánime, sugiere que hay algunos puntos problemáticos en la propuesta de Dewey, o al menos oscuros, que apoyan tal lectura.

En nuestra opinión, tres son las razones principales por las cuales los intérpretes tienden a rechazar la pretensión deweyana de haber reconstruido, en su Lógica de 1938, una verdadera lógica. En primer lugar, está el hecho de que las partes más destacables del mismo contienen, no tanto una lógica, sino más bien reflexiones concernientes a lo que hoy llamaríamos filosofía de la lógica. Es decir, contiene, como punto de partida a partir del 
cual se estructura todo lo demás, una discusión acerca de la naturaleza de los principios, propiedades y relaciones lógicas. En segundo lugar, se encuentra el hecho de que el libro de Dewey contiene además reflexiones que escapan al ámbito de la lógica. En efecto, y con el objetivo de ofrecer una concepción de los principios lógicos como normas para el control de la inferencia en el contexto de la investigación, Dewey ofrece una concepción de la misma que contiene, como resulta evidente a la luz de lo discutido en el capítulo anterior, algo más que una lógica. Por último, lo intérpretes pueden verse llevados a negar el calificativo de lógica a la propuesta de Dewey por cuanto la obra en que se expone carece de todo intento de ofrecer un sistema de lógica formalizado. Como su autor advierte, tal carencia no se debe a que su concepción los prohíba. Antes bien, como hemos dicho, Dewey esperaba que como resultado de sus aportes nuevas y mejores formalizaciones fueran realizadas. ${ }^{6}$ El problema con el formalismo en lógica era, en su opinión, que la proliferación de sistemas formales tendía a dejar sin responder algunas cuestiones centrales desde su punto de vista. En particular, la distinción entre materia y forma permitía construir sistemas de lógica formal cuyo carácter formal era interpretado como algo absolutamente independiente de toda materia, de toda referencia al contexto, y era utilizado como base para concluir que la lógica trataba con algún tipo de principio a priori, independiente de toda experiencia cognitiva. De este modo, la principal objeción, aunque no la única, de Dewey al formalismo era que fuera interpretado, generalmente, como una razón en contra de la naturalización de la lógica.

De acuerdo con Esteban (2008, p. 195) el naturalismo normativo de Dewey resulta plausible como una teoría no tanto acerca de las formas lógicas, sino acerca de las normas

\footnotetext{
${ }^{6}$ Hasta donde llega nuestro conocimiento, Burke (1992) ha sido el único en tomar esta esperanza deweyana y tratar de desarrollarla. Un análisis de tal propuesta puede encontrarse en Hebrard, Mercau y Badenes (2009).
} 
metodológicas de la ciencia. En sus palabras, y dada la pretendida autonomía de la lógica actual de la investigación científica, resulta que la lógica de Dewey es "plausible en términos de un naturalismo normativo en general, pero no como una hipótesis referente a la filosofía de la lógica" (2008, p. 195). Más que ofrecer una lógica, sugiere Esteban (2006: 43, n90), la Lógica de 1938 contiene una epistemología o incluso una metodología. Más aún, el hecho de que Dewey recurra a las normas jurídicas para mostrar que en ellas sí ocurre lo que en su opinión ocurre con las formas lógicas, es una señal de que el naturalismo normativo de Dewey es plausible como una teoría general de la normatividad. Resulta curioso que Esteban pretenda excluir a las normas lógicas de la teoría general de la normatividad. Parece que, en su opinión, o la teoría no es tan general o bien las normas lógicas no son verdaderas normas. Cómo sea, la posición de Esteban parece ser un resultado de contrastar las propuestas de Dewey con la lógica formal, y el hecho de que la misma sea una disciplina autónoma respecto de la investigación científica. Frente a tal posición cabe objetar, sin embargo, lo siguiente.

En primer lugar, en el escenario actual de la lógica, y como Esteban mismo reconoce en relación a la lógica cuántica, hay muchas lógicas desarrolladas no de modo completamente autónomo, sino como modelización del razonamiento en diferentes contextos. Por otro lado, hay también propuestas de lógica informal y teorías de la argumentación que cuestionaron diferentes aspectos de la lógica formal, de modo que identificar la lógica con la lógica formal supone asumir ya, de modo inadvertido, un compromiso con una determinada comprensión de la lógica, a saber, el mismo compromiso que los contrincantes de Dewey asumían y que este último pretendía cuestionar. Así, si tenemos en cuenta una concepción de la lógica más amplia, la concepción deweyana no 
resulta ya tan distante de la lógica actual, como intentaremos mostrar en el capítulo 8. Por otro lado, la posición de Esteban parece sustentarse, como dijimos, en la autonomía de la lógica (formal) respecto de la investigación científica. Ahora bien, la identificación de la investigación con la investigación científica no es, en el contexto de Dewey, admisible. En efecto, en el capítulo 4 de la Lógica de 1938, Dewey sostiene la existencia de la investigación de sentido común y su continuidad respecto de la investigación científica. Así, y aunque Dewey se muestre especialmente interesado en el estudio de la investigación científica, lo cierto es que la lógica como investigación de la investigación no tiene por qué limitarse a la investigación científica. En efecto, su libro How we Think, que ha sido muy influyente en el surgimiento del movimiento de lógica informal en Estados Unidos, presenta a la lógica como un estudio del pensamiento reflexivo, comprendido como investigación de sentido común.

Por supuesto, estas páginas no pretenden sostener que la lógica de Dewey debe ser recuperada como un todo cerrado y ya acabado. Antes bien, y como Douglas Browning (2002) y Tom Burke (2009a y 2009b) han mostrado, la lógica de Dewey presenta algunos problemas y ambigüedades importantes. En este sentido, en nuestra opinión, la tesis de Dewey acerca de la relación entre lógica e investigación debe precisarse un poco más: la lógica es investigación de la investigación, aunque no sea toda la investigación sobre la investigación. Su tarea es, como hemos dicho, reconstructiva: debe reconstruir las reglas que permiten llegar, en el contexto de una investigación, a aserciones garantizadas, esto es, las reglas que permiten controlar o dirigir la inferencia. Esta idea de que la lógica de Dewey no debe identificarse con la teoría de la investigación supone ciertamente modificar en algún sentido la caracterización del propio Dewey. Sin embargo, el hecho de que muchos 
comentaristas consideren su lógica como una epistemología o como una filosofía de la ciencia parecería apoyar una lectura contraria a la nuestra. Resulta llamativo en este sentido que Matthew Brown (2012) llegue incluso a afirmar los "estudiosos de la lógica de Dewey [aquellos que, como Burke, sí la consideran una lógica] raramente han enfatizado las conexiones con la filosofía de las ciencias" (p. 259). En nuestra opinión, el hecho de que estudios eruditos acerca de la Lógica de Dewey la reivindiquen alternativamente como una epistemología, como una filosofía de la ciencia o, aunque minoritariamente como una lógica sugiere, efectivamente, que la obra contiene aportes para tales ámbitos.

La discusión entre Browning (2002) y Burke (2009a y 2009b) acerca de ciertos problemas con, y del verdadero alcance de, la definición de investigación presentada por Dewey en la lógica y citada en el capítulo anterior sugiere también un punto de vista como el defendido aquí. En efecto, si como sugieren dichos autores Dewey debería haber distinguido entre investigación, investigación controlada e investigación exitosa, y si, por otro lado, como afirma Dewey, "la teoría lógica es la formulación sistemática de la investigación controlada" (1w.12.29, énfasis añadido), queda sugerida la idea de que la lógica no es toda la teoría de la investigación. Además, si los materiales adquieren propiedades distintivamente lógicas al ser sometidos a control, es decir, si los principios propiamente lógicos remiten exclusivamente al aspecto de control de la investigación, entonces su estudio, es decir, la lógica, puede entenderse como un estudio acerca de las formas en que se controla la investigación, o lo que es lo mismo, un estudio acerca del modo en que se garantiza una inferencia. Como veremos en el capítulo 8 de esta tesis, esta caracterización de la lógica resulta próxima a la caracterización de Stephen Toulmin en su 
clásico The Uses of Argument (1958), considerado como uno de los pilares del resurgimiento de la teoría de la argumentación en el siglo XX.

\section{Conclusiones}

En este capítulo hemos reconstruido algunas tesis de la concepción deweyana de la lógica. Hemos considerado la caracterización de la inferencia y su distinción respecto del razonamiento, así como también la reflexión deweyana acerca de la naturaleza de los principios lógicos. Asimismo, hemos intentado despejar, al menos de modo provisional, algunas de las dudas que han sido planteadas en relación con la consideración de la propuesta de Dewey como una genuina lógica. Al hacerlo, hemos sugerido algunas precisiones en su caracterización de la lógica como teoría de la investigación. Teniendo en cuenta que las propiedades lógicas refieren, para Dewey, al aspecto específico de control de la inferencia en el marco de la investigación y que la investigación no debe reducirse en este contexto a la investigación científica, hemos sugerido que la lógica deweyana puede entenderse como un estudio de las normas o principios que permiten garantizar la inferencia. Un estudio tal supone, como resulta evidente, una caracterización de los elementos y componentes (términos, proposiciones, juicios) que intervienen en dicho proceso. Aunque no nos hemos detenido en ello, Dewey dedica gran parte de su libro de 1938 a ofrecer una interpretación de ellos acorde con su concepción contextualizada y naturalista de la lógica. Este aspecto de la obra de Dewey aparece, acaso, como algo anticuado por cuanto resulta, en líneas generales, una revisión y reconstrucción de la lógica tradicional. Sin embargo, como hemos señalado, ha habido intentos de reconstruir la lógica 
de Dewey con herramientas formales más actualizadas. Independientemente de ello, sin embargo, nos ha interesado recuperar más bien la concepción filosófica de la lógica de Dewey que sus desarrollos concretos, por cuanto creemos, no sólo que tal concepción reviste una cierta actualidad, como habremos de ver, sino que también puede sugerir líneas de trabajo en lógica muy fecundas, fundamentalmente de cara a la enseñanza de la lógica.

Si la lectura que ofrecemos es correcta, entonces se abre la posibilidad de tener en cuenta los aportes de Dewey que analizamos como verdaderos aportes a la filosofía de la lógica. Tales aportes refieren fundamentalmente a su concepción naturalista y empírica y a sus reparos en relación con el formalismo. En este sentido, la tesis que sugerimos y que defenderemos en el capítulo 7, en relación con la lógica de Dewey es que, si ella es juzgada teniendo en cuenta la concepción de la lógica propia de la lógica informal y la teoría de la argumentación, en vez de seguir juzgándola desde el punto de vista de las concepciones de la lógica asociadas a la lógica formal, entonces no sólo su naturalismo normativo se vuelve una tesis plausible acerca de los principios lógicos, sino que también pueden encontrarse allí algunos aportes interesantes. En efecto, según vimos, es fundamentalmente el contraste entre la lógica de Dewey y la lógica formal actual lo que lleva a Esteban a negar el naturalismo normativo de Dewey como una posición aplicable en filosofía de la lógica.

Para finalizar, cabe señalar lo siguiente. Como hemos dicho, las tesis de Dewey tienen como adversario principal a quienes sostienen visiones anti-naturalistas de los principios lógicos, es decir, a quienes sostienen que la validez de los principios lógicos se debe a su carácter de a priori. Es con el objetivo de debilitar tal posición que Dewey cuestiona el formalismo de la lógica. Así, de acuerdo con Dewey, el punto central que la proliferación de sistemas formales tendía a evitar, no tanto porque no diera respuestas a la 
cuestión sino más bien porque tendía a comprometerse con una respuesta sin examinarla lo suficientemente bien, era la cuestión de la posibilidad de una verdadera lógica de los valores. En efecto, el estudio y la explicitación de los modos en que pueden fundamentarse juicios acerca de valores, juicios propiamente valorativos, ha sido para Dewey una preocupación tan central y extendida en el tiempo como lo fue su interés en la lógica. Ello es así hasta tal punto que parece sugerir que el interés en la lógica radicaba más bien en su carácter de instrumento en relación a la teoría de la valoración. A su vez, y como veremos en el capítulo siguiente, esta era una cuestión central para Dewey porque estaba ligada a la posibilidad de realizar una reforma social democratizadora, arrebatando a la tradición y el privilegio de clase la capacidad para fijar los valores y poniéndolo en manos de la inteligencia o la razón humana. En otros términos, si bien es cierto que, como afirmó Hook, la lógica constituyó el interés prioritario de Dewey, tal interés en la lógica se debía a su valor como instrumento de reforma social. 


\section{6}

\section{Investigación científica y valoración}

\section{Introducción: la ciencia y los valores}

En los últimos años, la cuestión de la relación entre conocimiento y valores ha sido ampliamente debatida. ${ }^{1}$ Linda Martin Alcoff (2008) ha señalado, por ejemplo, que aunque durante mucho tiempo se creyó que la epistemología estaba más allá de toda contienda política, de un modo creciente se la ha acusado de cumplir un rol político, y uno más bien opresivo. En este mismo sentido, también Pestre (2005, p. 28) señala que la idea misma de “ciencia pura" en el sentido de ciencia desvinculada de cuestiones éticas y políticas ha tenido una función ideológica. Por otro lado, señala Alcoff, otros filósofos "radicales" como Sandra Harding han sostenido que la epistemología formula sus investigaciones de modo tal que se excluye la posibilidad de identificar al sujeto cognoscente volviendo

\footnotetext{
${ }^{1}$ Cfr. Por ejemplo, Pestre, 2005; Rouse, 1987, Harding, 2006; Alcoff; 2008.
} 
inmune a la crítica sus tendencias políticas. Joseph Rouse, pero también Helen Longino y otros filósofos de la ciencia, han señalado que la epistemología raramente tiene en cuenta el hecho de que el conocimiento científico se realiza en un entramado de instituciones científicas, pero también políticas y económicas, y que estas últimas tienen efectos no sólo en lo que se consideran investigaciones prioritarias sino también en lo que respecta a qué hipótesis son consideradas plausibles. Tal discusión ha estado también particularmente presente en el contexto de la filosofía latinoamericana y española. En tal contexto se han destinado grandes esfuerzos para defender, de una manera precisa y clara, en qué sentidos cabe afirmar que la empresa científica no está libre de valores, ni puede ni debe estarlo. Haciendo uso de ideas propias, pero nutriéndose también de ideas provenientes de tradiciones diversas, se ha defendido la tesis de que la presencia de valores en ciencia no implica negar objetividad ni racionalidad a la ciencia, e incluso que tales valores son un componente necesario para que la ciencia pueda ser racional.

En su reciente libro La dimensión valorativa de las ciencias: hacia una filosofía política (2014), Ricardo J. Gómez ha reconstruido la discusión acerca de la presencia de valores en la ciencia haciendo un recorrido muy preciso por gran parte de la filosofía de las ciencias del siglo XX. Haciendo uso de algunas distinciones relacionadas con ciertas filosofías que se supone han sostenido la tesis de la neutralidad valorativa de la ciencia ${ }^{2}$, Gómez se propone defender la tesis de que "la ciencia está cargada de valores noepistémicos, e incluso de valores éticos, en el contexto de justificación” (20014, p. 14).

\footnotetext{
${ }^{2}$ Nos referimos, claro está, a la filosofía del Círculo de Viena. Sin embargo, como muestra Gómez, Neurath y Carnap han reconocido la presencia ineludible de valores no-epistémicos en la justificación del conocimiento científico (los "motivos auxiliares" y los "factores prácticos" y hasta "subjetivos" de Carnap o las "reglas de aceptación que involucran factores no lógicos”) (Gómez, 2014, cap. 1. pp. 17-48). Así, de acuerdo con Gómez, el verdadero vocero de la neutralidad valorativa de la ciencia ha sido Karl Popper.
} 
Esta manera de formular la tesis de la carga valorativa de la ciencia tiene la virtud de señalar con precisión cuál es el punto de discusión verdaderamente interesante en la controversia acerca de la relación entre conocimiento científico y valores. Resulta obvio que los valores juegan un rol importante en la decisión acerca de los problemas y objetivos que se plantean los investigadores científicos, o en la decisión acerca de los fondos destinados a la investigación, o en la producción de artefactos tecnológicos. Sin embargo, los partidarios de la ciencia libre de valores podrían conceder este punto a la vez que sostener que la justificación de una teoría científica no involucra valores. Otro punto relevante es que la discusión se centra, además, en valores no-epistémicos, o no-cognitivos o externos. En efecto, muchas veces se ha planteado, fundamentalmente a partir de la discusión de ciertas posiciones de Thomas Kuhn, que en los procesos de elección de teorías hay ciertas propiedades como la consistencia, la simplicidad o la adecuación empírica que juegan un rol importante. Ahora bien, el modo no algorítmico, a veces conflictivo, y la jerarquía variable con que funcionan tales propiedades cuando se utilizan para justificar la elección de teorías, permite denominarlos como valores. Sin embargo, tales valores se caracterizan como internos o propios de la ciencia, como cognitivos o epistémicos. Así, el reconocimiento del rol jugado por los valores epistémicos propiamente dichos es compatible con una tesis acerca del carácter de libre de valores no-epistémicos, de valores “impropios", de la ciencia, siendo fundamentalmente tales valores impropios los valores éticos y políticos, económicos, culturales, o sociales en sentido amplio.

La discusión acerca de la relación entre conocimiento y valores tiene un antecedente importante, que no suele tenerse presente en las discusiones actuales antes mencionadas, en la disputa entre la escuela de Frankfurt y el positivismo lógico. En tal contexto, la posición 
discutida era planteada como una discusión acerca de carácter valorativamente neutral o no neutral del la ciencia. ${ }^{3}$ En la actualidad (Gómez, 2014; Kincaid, Dupré y Wylie, 2007) la discusión se centra en el carácter libre o cargado de valores de la ciencia. Aunque las expresiones son tratadas en general como equivalentes ${ }^{4}$ creemos que la segunda apunta en una dirección más específica, a saber, a la presencia o ausencia de valores en el interior de la ciencia. Como hemos dicho, la posición filosóficamente más desafiante en relación con la visión tradicional de la ciencia es que en la justificación del conocimiento científico participan valores extra-epistémicos. Así, el rechazo de la tesis acerca de carácter libre de valores de la ciencia, supone la afirmación de que los valores intervienen también en la ciencia. Nótese que desde un punto de vista positivista, y dada la comprensión de los valores como algo subjetivo y privado, y de los juicios valorativos como la mera expresión de una emoción (Ayer, 1952; Stevenson, 1960), la afirmación de la presencia de valores en la justificación del conocimiento científico parecía negar toda objetividad a la ciencia.

Ahora bien, la expresión neutralidad valorativa o axiológica, contiene en cambio una doble dirección que interesa tener presente aquí. La ciencia puede ser valorativamente neutral, porque está libre de valores en el sentido recién explicitado, o puede ser ella misma neutral respecto de cuestiones propiamente valorativas, tales como cuestiones éticas, políticas, etc. Es decir, la discusión no se reduce al problema de la presencia, influencia o injerencia de valores en la ciencia, sino que debe tenerse presente el problema del peso, la influencia o injerencia de la ciencia, o la investigación empírica en general, en la

\footnotetext{
${ }^{3}$ Así, por ejemplo Herbert Marcuse (1941) reconoce a Dewey, y pese a vincular, como veremos, su posición al positivismo, el haber cuestionado la tesis positivista de la neutralidad valorativa de la ciencia.

${ }^{4}$ Así, leemos en Kincaid, Dupré y Wylie (2007, p. 4) que "el ideal libre de valores ve a la ciencia como neutral".
} 
determinación de los valores. ${ }^{5}$ Esta última cuestión resulta, a su vez, fundamental de cara a la concepción subjetivista de los valores: si la investigación empírica tiene injerencia en la formulación y validación de valores, entonces no sólo los valores no pueden reducirse a meras entidades subjetivas y privadas, sino que, al estar sometidos a investigación, pueden ser inteligente o racionalmente fundados. Si esto es efectivamente así, entonces otra tesis se debe reconsiderar, a saber, la tesis acerca del carácter libre de ciencia, por así decirlo, de la ética y la política. Esta discusión resulta interesante porque en general suele pensarse que, si bien la ciencia puede aportar cierto conocimiento, por ejemplo en el ámbito de la política, la fundamentación de los valores que rigen la práctica política y ética debe tener una fuente distinta: la política y la ética deben apoyarse y constituirse en un ámbito por principio independiente y ajeno a los enunciados científicos que se limitan a describir lo que es.

En el contexto de esta arena de discusión, el objetivo de este capítulo y el siguiente es analizar la relación entre conocimiento y valores que puede reconstruirse a partir de las ideas del filósofo cuyos aportes son objeto de análisis y reconstrucción en esta tesis. Más específicamente, intentaremos argumentar que las ideas de Dewey permiten dar cuenta de de la presencia de valores en el ámbito de la producción y validación del conocimiento científico de un modo preciso y prometedor, que prohíbe además toda exclusión a priori de la participación de valores propiamente éticos y políticos en tal ámbito. En efecto, afirmaremos que la concepción de la investigación como producción y validación de juicios prácticos implica la presencia de valoración incluso en la investigación científica, mientras que el carácter situado y contextual de toda investigación y valoración remite, como veremos, a la posibilidad de la presencia de valores no-epistémicos en ella. Asimismo,

\footnotetext{
${ }^{5}$ Aunque esta dirección de la relación es reconocida por Kincaid, Dupré y Wylie (2007, p. 5), su discusión gira fundamentalmente en torno a la presencia de valores en la ciencia.
} 
insistiremos en la importancia que tiene, en este contexto, la tesis acerca del carácter cargado-de-investigación de los valores, tesis que debe entenderse, en el contexto de las ideas de Dewey, también en un sentido claramente normativo: no sólo puede la valoración apoyarse en la investigación empírica, sino que debe hacerlo, pues de otro modo, se deja librada al peso de la tradición, al privilegio de clase o al mero capricho la determinación de los fines y valores que guían nuestras prácticas y nuestras instituciones. Así, intentaremos sugerir la tesis de que el pensamiento de Dewey tiene un potencial normativo y crítico interesante a la hora de pensar lo que puede llamarse una filosofía política de la ciencia.

Esta tarea será desarrollada en dos tiempos. En primer lugar, es este capítulo, expondremos la tesis deweyana acerca del carácter práctico de la investigación. Mostraremos que ello implica la presencia, en el seno de la ciencia, de verdaderos juicios evaluativos, juicios que, a su vez, constituyen la base para la formulación de juicios valorativos en sentido distintivo, es decir, de juicios acerca de que un cierto fin o un cierto valor es bueno o malo, digno de ser perseguido o susceptible de ser rechazado. La conclusión principal de este capítulo será que los juicios evaluativos, base de todo juicio práctico y de toda valoración, se apoyan en una consideración de la relación medios/fines que se constituye así no sólo en el fundamento de todo juicio práctico, sino también de todo juicio valorativo en sentido distintivo.

En el capítulo siguiente nos detendremos en la consideración instrumental de la racionalidad de Dewey, reconstruyendo no sólo el análisis deweyano en torno a las categorías de medios y fines de la acción, sino también mostrando cuáles son los diferentes factores que intervienen en una tal racionalidad cuando se trata de la fundamentación de valores. Como resulta evidente, esta última posición debe enfrentar una objeción conocida: 
al pretender apoyar la racionalidad en la relación medios-fines, sólo podemos ofrecer una racionalidad meramente instrumental que deja la cuestión de los fines y valores sin ningún tratamiento. Esta objeción, presentada típicamente por los miembros de la Escuela de Frankfurt contra el pragmatismo, será analizada y respondida en el capítulo siguiente. Allí, intentaremos explicitar de qué modo la evaluación de los fines mismos debe analizarse, de acuerdo con Dewey, como evaluación de las cosas en sus relaciones de medios/fines. Asimismo, mostraremos que frente a la pretensión de encontrar valores y fines últimos que operen como legitimadores de todos los demás, Dewey insistirá en el continuo de la investigación/valoración y en el carácter insoslayablemente contextual de toda valoración. A su turno, esta última consideración tendrá como consecuencia la fundamentación de la tesis según la cuál, aún en el ámbito de la investigación científica, las valoraciones en sentido distintivo, es decir, aquellas que tienen que ver con los deseos e intereses de los seres humanos, ocuparán un lugar epistemológicamente relevante. Esta discusión permitirá sostener la interdependencia entre investigación científica y valoración, en las dos direcciones señaladas.

\section{Investigación científica, juicios prácticos y valoración}

Para comenzar con nuestra exposición resulta pertinente señalar de qué modo debe encararse el estudio de la relación entre conocimiento y valores en un contexto como el de Dewey. De acuerdo con el principio de análisis contextual señalado en el capítulo 4, una teoría del conocimiento debe ser un resultado del análisis de la investigación en tanto que proceso de producción de conocimiento. En relación con los valores cabe hacer algo 
semejante. Podemos caracterizar inicial e intuitivamente a los valores como sigue: decir de algo que es un valor significa que ese algo es estimado o apreciado, que se lo considera bueno. Ahora bien, cabe la pregunta acerca de por qué ese algo es un valor. Frente a tal pregunta, podrían ofrecerse, entre otras, estas respuestas: (a) se trata de un valor porque así se desprende de algún tipo de principio a priori, universal y necesario, o de alguna realidad trascendente; (b) se trata de un valor porque simplemente brota o emana de los deseos y los intereses personales y subjetivos de las personas; (c) se trata de un valor porque es algo que la costumbre, el hábito o la tradición impone como tal; o (d) se trata de un valor porque, sobre la base de un proceso que podríamos calificar como deliberativo, hemos llegado a la conclusión de que es digno de ser estimado.

La última respuesta es la única que pone en los seres humanos, en sus manos y sus ideas, la prerrogativa para determinar qué cosa es o debe ser considerada un valor. De acuerdo con la primera respuesta, los valores están ahí dados por la razón y el ser humanos sólo puede, a lo sumo, descubrirlos y acatarlos (o transgredirlos): los valores están ya ahí, determinados y fijos. De acuerdo con la segunda, son meras emociones privadas y subjetivas, que no tienen más fundamento que el capricho humano. Son meros deseos a los que no podemos sino rendirnos. Además, por cuanto se trata de entidades subjetivas y privadas, escapan a toda forma de validación inteligente. De acuerdo con la tercera de las posibilidades antes señaladas, y tal vez sobre la base de los caprichos y emociones, la única autoridad de los valores emana de su lugar en el contexto de una tradición: no son más que estándares sedimentados por el paso del tiempo, y su único fundamento es el peso de la tradición. 
La respuesta que interesa a Dewey es la cuarta: los valores como productos de un proceso de valoración. Desde tal punto de vista, para decir qué es un valor, de acuerdo con el principio del análisis contextual, es preciso analizar el proceso de valoración. Esta tesis, como hemos adelantado ya, tiene un cierto carácter normativo, y no sólo descriptivo: aunque de hecho muchas veces formamos y validamos valores a través de un proceso racional que supone deliberación, lo central es que esta es la mejor manera de hacerlo, ya que de otro modo sólo podemos subordinarnos al peso de la tradición o al mero impulso y capricho. ${ }^{6}$ Así, la tesis que sostendrá Dewey en su Theory of Valuation, como veremos, no es que todo valor sea el producto de la deliberación inteligente, sino que un valor puede ser un resultado de ella, y que es deseable que lo sea.

De acuerdo con lo dicho, entonces, la pregunta por la relación entre conocimiento y valores puede ser traducida, en el contexto del pensamiento de Dewey, a la pregunta por la relación entre el proceso de investigación, esto es, el proceso de producción de conocimiento, y el proceso de valoración, es decir, el proceso de producción de valores. Podemos resumir la posición que desarrollaremos en este capítulo como sigue: (i) Toda investigación, incluso la científica, es un modo de la práctica e involucra la producción y validación de juicios prácticos. (ii) Todo juicio práctico supone juicios evaluativos. (iii) Toda valoración, incluso en el campo de la ética y la política, se apoya en enunciados evaluativos, que versan acerca de medios y fines y sus relaciones, y pueden, por tanto, validarse en procesos de investigación (empírica). Como veremos en el capítulo siguiente,

\footnotetext{
${ }^{6}$ La primera de las posibilidades antes mencionadas, a saber, la determinación de los valores por la autoridad de una razón que manda desde afuera de la experiencia no es para Dewey una opción admisible, no tanto por su mirada acerca de los valores, sino por su anti-naturalismo, posición que, como hemos visto, Dewey ha dejado atrás. Es por ello que, como señalan Faerna y Di Berardino (2008, p. 13 y ss.), Dewey se halla más preocupado por discutir, en su Theory of Valuation, con los positivistas, quienes mantendrían una posición naturalista respecto de la ética pero no-cognitivista, que traza una distinción profunda entre juicios de hecho y juicios de valor, continuando, en este sentido, la posición empirista. Como vimos en el capítulo 4, también respecto del concepto de experiencia su adversario predilecto era, más bien, el naturalista reduccionista.
} 
esta interdependencia de investigación y valoración no es circular sino que remite al continuo de la investigación y la valoración, es decir, a un contexto de investigación/valoración. Esta posición, como habremos de ver, tiene como consecuencia el que no pueda trazarse una distinción previa entre hechos y valores relevantes y no relevantes al problema tratado, razón por la cual no puede excluirse a priori la intervención de valores extra-epistémicos.

2.1. La investigación como producción y validación de juicios prácticos

Comenzaremos entonces a presentar los elementos que nos permitirán, recurriendo a Dewey, sostener el argumento que acabamos de esbozar. El primer paso de ese argumento es establecer que dado que la investigación es un modo de la práctica, quien investiga debe formular lo que Dewey llama juicos prácticos. En el capítulo IX de Logic: The Theory of Inquiry (lw.12.161-182) Dewey aborda tal cuestión. Allí, se retoman ideas que, como señala Jennifer Welchman (2002, p. 27) su autor había estado desarrollando al menos desde 1902, y que utilizaría en 1915 en "The Logic of Judgments of Practice” en su crítica al neorrealismo de Russell.

De acuerdo con Dewey, como hemos visto, la investigación implica "efectuar una transformación y reconstrucción existencial del material con el que trata" (lw.12.161). Por ello, el cambio que introduce la investigación no es un mero cambio de creencias, sino que, más bien, tal cambio no puede ser introducido de manera legítima, a menos que operaciones existenciales modifiquen y recalifiquen el material objetivo con el que trata la 
investigación (ibídem). Así, toda investigación contiene un "factor práctico" (lw.12.162), o lo que es lo mismo, es una práctica tecnológica.

Ahora bien, los cambios que se introducen en la investigación no son cambios ciegos sino cambios introducidos teniendo en cuenta los datos y las hipótesis que se han formulado en proposiciones. En este sentido, los cambios son introducidos en función de un proceso de juzgar práctico que se expresa en un juico de práctica, es decir, un juicio acerca de lo que hay que hacer. Resulta importante señalar que, de acuerdo con esta posición, el investigador, ya sea un científico o una persona cualquiera que emprende una investigación de sentido común, se ocupa fundamentalmente de formular juicios prácticos, puesto que tiene que decidir continuamente qué hacer: qué experimentos hacer, qué observaciones emprender, qué aparatos utilizar, cuándo dar por bien establecido el resultado de un experimento, cómo delimitar el problema, etc. Así, puesto que

la conducción de una investigación científica, ya sea física o matemática, es un modo de práctica [resulta que] ante todo el trabajador científico es un practicante, y está constantemente involucrado en hacer juicios prácticos: decisiones sobre qué hacer y qué medios emplear al hacerlo (lw.12.163).

Esta posición obliga a revisar la concepción tradicional de que los juicios que realmente importan en el contexto de la investigación son juicios declarativos, entendidos como juicios que se limitan a presentar o describir una realidad independiente de ellos mismos $^{7}$. La cuestión resulta relevante porque, si un juicio es meramente declarativo en este sentido, su evaluación debería reducirse a la determinación de su verdad en el sentido

\footnotetext{
7 Al ofrecer una nueva interpretación de las proposiciones declarativas, Dewey está cuestionando una distinción usual de la lógica de su tiempo, a saber, la distinción entre enunciados informativos, interrogativos, directivos y emotivos. Tal distinción era utilizada para justificar la pretensión de que un razonamiento era un conjunto de enunciados declarativos, lo que suponía en última instancia negar toda propiedad lógica a los enunciados de la ética, la política y en general a todo enunciado valorativo. En el capítulo de la lógica que comentamos Dewey aborda los enunciados interrogativos defendiendo su fuerza lógica (cfr. 1w.12.170-172).
} 
tradicional del término: lo único que cabe señalar es si lo que el juicio afirma es lo que de hecho ocurre. En cambio, si la función declarativa no es toda su función, es decir, no es tomada como "completa y final", en los términos de Dewey (lw.12.162), entones cabe evaluar tales juicios en su función de medios para operar las transformaciones necesarias para cumplir con el fin de la investigación. Así, puesto que el investigador formula juicios prácticos, los enunciados que postula en ese proceso de juzgar práctico no tienen por única función representar un estado de cosas, sino que son instrumentos, verdaderos medios para producir la transformación de la situación que es el objetivo o la meta de la investigación. Una cuestión remarcable en este contexto es que, de acuerdo con Dewey, sólo cabe hablar de las propiedades lógicas de los enunciados declarativos en tanto y en cuanto tales enunciados forman parte de un proceso de juicio práctico. Es decir, un enunciado declarativo cualquiera, por ejemplo "me duele mucho la cabeza", no tiene ninguna fuerza inferencial si se toma como final y completo, es decir, independientemente de su uso como instrumento en una situación concreta en la que es utilizado. Fuera de todo contexto, se limita a formular un hecho: no sugiere nada. En otros términos, los enunciados declarativos pueden servir como base de inferencia en tanto y en cuanto son utilizados en un proceso de investigación o deliberación, y fuera de tales situaciones no permiten inferir nada. ${ }^{8}$

Detengámonos, entonces, en los diferentes elementos involucrados en los juicios prácticos. Lo primero que hay que destacar es que Dewey entiende el proceso mediante el cual se formulan y se validan o rechazan juicios prácticos como un proceso de deliberación. En tal proceso hay siempre una situación indeterminada como su origen. Es una situación en la que algo puede o debe hacerse, y que en caso de que no se tome ninguna decisión,

\footnotetext{
${ }^{8}$ La proposición puede, en tanto que mera proposición, en tanto que signo perteneciente a un sistema de signos, implicar a otras proposiciones, pero se trata de implicación, es decir, de lo que Dewey llama razonamiento o discurso racional, y no de inferencia propiamente dicha, cuyo estudio constituye la lógica.
} 
algo de todos modos ocurrirá. De modo que lo que ocurrirá depende en parte de la introducción de nuevos factores que interactuarán con los elementos ya operantes. Tales nuevos factores dependen de lo que se haga, y esto último depende de la intervención de la investigación y las operaciones de observación, inferencia y razonamiento, y de la consideración de cursos de acción alternativos (Dewey, lw.12.164). En pocas palabras, la deliberación se da en una situación en cuyo curso puede incidirse realizando ciertas acciones cuya realización será decidida en función de un proceso deliberativo que involucra inferencia, observación y razonamiento. De este modo, la deliberación supone la formulación y validación o rechazo de proposiciones declarativas que establecen, en primer lugar, cuáles son las condiciones dadas, es decir, los hechos del caso, y, en segundo lugar, proposiciones declarativas acerca de que un curso de acción es el adecuado, o el mejor, para producir las modificaciones que se desean. Este último enunciado se apoya, a su turno, en enunciados acerca de las cosas en su relación de medios y fines o causas y consecuencias. Esto supone, así, la formulación anticipada de cuáles son los resultados, las consecuencias, que se desean obtener, es decir, el fin-a-la-vista. De este modo, sostiene Dewey, al formar parte de un proceso de deliberación, "los enunciados declarativos (siendo ellos mismos resultados de juicios de evaluación [appraisal] provisional), son factores que entran activamente en la constitución real de la materia existencial del juicio final" (lw.12.166). Es decir, tienen un carácter práctico. En otros términos, y para usar el ejemplo de Dewey, si como resultado de un proceso de deliberación decido ir a ver a tal o cual médico, los enunciados declarativos "me siento bastante mal” y "si voy al médico me dará algo que me hará sentir mejor" (enunciados acerca de hechos y acerca de cursos de acción), 
han sido parte activa en la producción de la salud, si es que mi visita al médico conduce a ella.

Un aspecto importante de este proceso de deliberación es, como hemos ya sugerido, que en él se requiere evaluar, sopesar o valorar diferentes materiales, tanto existenciales como conceptuales, en su condición de instrumentos o medios para introducir las modificaciones pretendidas, esto es, para lograr el fin buscado. La relación entre fines y medios resulta de un interés fundamental, pues, como veremos en la sección siguiente, Dewey propone una concepción de ellos que utilizará, a su vez, para dar cuenta de la posibilidad de una verdadera evaluación de los fines y valores, incluso aquellos propiamente morales. El punto a destacar aquí es que, de acuerdo con nuestro autor, todo proceso de investigación, en tanto proceso de formulación de juicios prácticos, supone la realización (e incluso la validación o rechazo) de juicios valorativos. Tales juicios, además, por cuanto son condición de posibilidad de la realización de juicios prácticos, no son externos ni posteriores a la actividad de investigación, sino que forman, incluso en ciencia, parte de la actividad rutinaria de los investigadores.

Dewey afirma también, en el capítulo de la Lógica que analizamos, que las evaluaciones morales son un buen ejemplo (lw. 12.169) de la evaluación de las cosas como medios y como fines, y reconstruye brevemente la posición acerca de los juicios morales que desarrollaremos en la sección siguiente tomando como punto de partida su escrito “Theory of Valuation” (lw.13.189-253), publicado en 1939. Nos contentaremos aquí con señalar que, de acuerdo con Dewey, la deliberación se halla presente tanto en la evaluación moral como en la investigación científica (lw.12.172). Ello es así porque, en última instancia, el juico práctico en que desemboca la deliberación es siempre un juicio 
evaluativo: "todos los juicios de práctica son evaluativos, estando ocupados de juzgar qué hacer sobre la base de las consecuencias estimadas de condiciones que, puesto que son existenciales, van a operar de todos modos" (1w.12.175). Evaluar significa, siempre, valorar las cosas en su calidad de medios y/o fines. Por ello, afirma Dewey,

los juicios evaluativos (...) entran en la formación de todo juicio final. No hay investigación que no involucre juicios de práctica. El trabajador científico tiene que evaluar continuamente la información que recoge a partir de sus propias observaciones y de los hallazgos de otros; tiene que evaluar su relevancia en cuanto a qué problemas abordar y qué actividades de observación, experimentación y cálculo llevar a cabo (lw.12.176).

La conclusión de todo esto es, de acuerdo con nuestro autor, que "las evaluaciones, como juicios de práctica, no son un tipo particular de juicio en el sentido de que pueda contraponerse a otros tipos, sino que son una fase inherente del juzgar mismo" (lw.12.180). ${ }^{9}$ En este sentido, la investigación es siempre un proceso que involucra valoraciones. Esta posición de Dewey constituye, hasta ahora, no sólo un reconocimiento del carácter práctico y valorativo de la ciencia, sino también un rechazo de la dicotomía metodológica entre valoración e investigación, que entiende a esta última como investigación acerca de cuestiones de hecho. Esta continuidad metodológica dada por el carácter práctico o deliberativo, tanto de la producción de valores como de hechos, ha sido tomada por Putnam (2002), como es sabido, para sostener, basándose en Dewey, el colapso de la dicotomía hecho/valor.

\footnotetext{
${ }^{9}$ Así, juicio práctico y juicio evaluativo son casi términos sinónimos. En opinión de Dewey, si es que puede trazarse una diferencia, es más bien una diferencia entre un juicio en el que la que la evaluación de las cosas como medios es directa, de modo que el aspecto evaluativo es dominante (cfr. lw.12.181)
} 
De este modo, podemos decir que, de acuerdo con Dewey, puesto que la investigación involucra producir y validar (o rechazar) juicios prácticos, y puesto que tales juicios prácticos suponen necesariamente juicios valorativos o evaluativos, puede afirmarse que la investigación, incluso la científica, resulta valorativamente cargada o no-neutral. Sin embargo, resulta claro que hasta donde hemos desarrollado las idas de Dewey, las evaluaciones o valoraciones involucradas podrían ser más bien valoraciones puramente epistémicas. En efecto, nos hemos referido fundamentalmente a la valoración de evidencia, a la evaluación de su peso y de su relevancia, respecto de las ideas, soluciones o hipótesis.

En este sentido parece dirigirse la interpretación de Bernstein cuando afirma que, de acuerdo con Dewey, la investigación científica no es moralmente neutral, por cuanto "requiere una sensibilidad a situaciones concretas, una imaginación fértil, la voluntad de probar nuestras hipótesis y de someterlas a procesos públicos de confirmación, así como de rechazar o modificar hipótesis a la luz de nuevas experiencias" (2010, p. 163). De acuerdo con la distinción entre valores epistémicos y no-epistémicos, los ejemplos aducidos por Bernstein parecen apoyar más bien la tesis de que la ciencia no es valorativamente neutral en la medida en que involucra valores epistémicos o acaso, podríamos decir, valores metodológicos, por cuanto aquellos, los valores epistémicos, se asocian con propiedades de las teorías (simplicidad, coherencia, etc.) mientras que los ejemplos de Bernstein parecen aludir más bien a valores acerca del modo en que deben llevarse a cabo las investigaciones. Es decir, de acuerdo con esta lectura, la ciencia no es moralmente neutral, por cuanto la actividad de los científicos está regulada por ciertas normas éticas, de carácter metodológico, que la posibilitan. Esta posición resulta, probablemente, algo ingenua. De hecho, estos valores metodológicos, como los hemos llamado, resultan próximos al ethos 
de la ciencia tal como lo ha postulado Robert Merton y que ha sido muy cuestionado en el ámbito de los estudios sociales de la ciencia. Este ethos de la ciencia, ligado a una idea un tanto idealizada de la comunidad científica, ha sido puesto en cuestión, por ejemplo, mediante el concepto de campo científico de Bourdieu $(1994,2000)$ y el de arenas transepistémicas de investigación (Konrr-Cetina, 1992, 2005).

Como hemos sostenido en la introducción de este capítulo, siguiendo a Gómez, la tesis filosóficamente más interesante acerca de la carga valorativa de la ciencia es la tesis acerca de la incidencia de valores no-epistémicos, y más específicamente valores éticos y políticos, en la producción y validación de conocimiento científico. En este contexto, tal tesis tiene que interpretarse como la tesis de que, en la producción y validación de juicios prácticos, las valoraciones en juego son también valoraciones que pueden ser caracterizadas como éticas o políticas en un sentido propio, y no sólo como valoraciones de las cosas como medios y/o fines. En efecto, resulta claro que en este contexto no toda valoración de las cosas como medios y/o fines constituye una valoración ética o política en sentido distintivo.

Sin embargo, en nuestra opinión, la concepción del conocimiento y la valoración de Dewey permite en efecto afirmar que los valores, incluso los éticos y políticos, pueden jugar un rol importante en la investigación científica, sin que ello signifique, claro está, que se vea mermada su racionalidad. Para ver por qué ello es así, nos detendremos a continuación en la concepción de la valoración de Dewey, para destacar luego el carácter contextual de toda investigación/valoración. 
2.2. Valoración en sentido distintivo: evaluación y apreciación

Como hemos mencionado ya, "Theory of Valuation" (lw.13.189-251) se plantea como objetivo dar cuenta de la posibilidad de formular y validar o rechazar juicios propiamente valorativos. Para comprender en todo su alcance la posición presentada por Dewey es necesario tener en cuenta lo siguiente. En primer lugar, y como menciona Gregory Pappas (2008, p. 111) no debe identificarse la posición allí presentada con la ética de Dewey. En efecto, su ética contiene algo más que una teoría de los valores, posición que en 1930 Dewey explicitó de manera clara en un texto titulado "Three Independent Factors in Morals" (lw.5.279-288) en el que postuló tres variables irreducibles unas a otras, a saber, lo bueno, el deber y la virtud, como fuentes de la experiencia moral. Lo bueno se vincula explícitamente con los deseos, las satisfacciones, la plenitud y las cosas que se estiman. La valoración se vincula expresamente con lo bueno, o más explícitamente, con la deliberación que nos permite afirmar que algo que se estima o se desea, un determinado fin-a-la-vista como dirá Dewey, es digno de ser estimado, es decir que es un verdadero valor. En este contexto, un juicio valorativo es un juicio que afirma que un cierto fin (por ejemplo, el ofrecer un subsidio a un determinado grupo social) es bueno.

Otra cuestión que es importante tener presente antes de abordar la concepción deweyana de los juicios valorativos, tal como la presenta en su "Theory of Valuation", es que dicho texto constituye una discusión con la concepción de los valores del positivismo lógico. En efecto, el escrito constituye uno de los dos aportes de Dewey a la Enciclopedia de la Ciencia Unificada publicada por Otto Neurath. Dewey se había negado a colaborar con el proyecto de Neurath fundamentalmente por las diferencias entre la concepción 
positivista de los valores y la suya propia, aunque finalmente Neurath logró convencerlo, de modo que Dewey preparó, en una de sus contribuciones, una discusión respecto de los valores. Este contexto de discusión supone una concepción naturalista común: tanto para Dewey como para los positivistas, la fuente de los valores eran, en última instancia, los deseos, los sentimientos y las cosas que son de alguna manera disfrutadas. En este sentido, la posición objetivista de los valores, de acuerdo con la cual un valor es algún tipo de entidad racional objetiva que se impone desde algún lugar fuera de la experiencia, es una posición que no es discutida en el texto que mencionamos, sino solamente mencionada como una posición que no puede sostenerse. Puesto que ya hemos explicitado las razones de Dewey para rechazar toda posición anti-naturalista, nos centraremos en su intento de dar cuenta de la posibilidad de validar y rechazar valores sobre la base de razones, desde una posición naturalista que reconoce el vínculo insoslayable entre valores y deseos.

El punto de partida de la exposición de Dewey en el texto que analizamos es mencionar un doble sentido de la palabra inglesa value, tanto tomada como sustantivo (valor) como tomada como verbo (valorar): puede significar un apreciar, estimar, disfrutar algo de modo directo (tomada como sustantivo referiría a un objeto que es directamente apreciado, estimado o disfrutado, y como verbo a la acción de disfrutar directamente algo); o puede significar evaluar, sopesar en el sentido de tratar de establecer qué valor tiene algo, o, tomado como sustantivo, algo que se considera como digno de estima. Nos referiremos al primer sentido como apreciar y al segundo como evaluar. De acuerdo con Dewey, muchas de las discusiones acerca de la valoración tendían a confundir estos sentidos de manera inadvertida, sin explicitar de un modo claro cuál es su relación. 
El primer punto de la discusión de Dewey apunta a sostener que, aun aceptando algunos de los supuestos del positivismo en relación con las expresiones valorativas, los enunciados en los que aparecen son verdaderas proposiciones y pueden, en tanto que tales, ser validadas o rechazadas en virtud de la observación y la experimentación. En el contexto del positivismo se tendía a comprender las expresiones valorativas como expresiones de un sentimiento, equiparándolas por ejemplo a los gestos de agrado o desagrado o al uso de onomatopeyas, que tienen la finalidad de inducir cierta respuesta en otros. La vinculación de los términos valorativos con sentimientos y emociones, entendidos como estados mentales, implicaba en el contexto del positivismo la afirmación de que las oraciones en las que aparecen tales términos no son proposiciones en sentido estricto. Sin embargo, la idea de expresión resulta en este contexto, de acuerdo con Dewey, ambigua. Para defender tal objeción nuestro autor propone un ejemplo: el llanto de un bebé no es, al menos al principio, una expresión de un sentimiento (de malestar o dolor) sino una respuesta orgánica a una determinada condición orgánico/ambiental. Del mismo modo, el grito ante un dolor, un determinado gesto, puede ser sólo una reacción orgánica. Sin embargo, tales manifestaciones pueden también ser usadas como signos: el bebé descubre que su llanto provoca cierta reacción en la persona que lo acompaña. Así, el llanto es usado como signo. En ese sentido no "expresa" un sentimiento, sino que es usado como signo de un cierto estado, y pertenece al dominio del lenguaje (cfr. 2008, p.91/1w.13.197-198). De acuerdo con la concepción de Dewey acerca de las emociones explicitada en el capítulo 4, además, este estado que sugiere no es un mero estado interno inobservable (un mero "sentimiento" en el sentido tradicional del término) sino un estado completo de la transacción 
organismo/medio. Así, de acuerdo con esto, el uso del término expresión resulta ambiguo y el de sentimiento, en el sentido tradicional, superfluo al menos en conexión con los valores.

De este modo, Dewey sostiene que, una vez desambiguado el uso del término expresión y rechazado el uso del término sentimiento en su sentido tradicional, el análisis positivista de los términos valorativos muestra que ellos refieren a una situación en la que, en primer lugar (1) hay una determinada actividad orgánica (por ejemplo, un llanto o la pronunciación de una afirmación como "robar es malo"). En segundo lugar, (2) esa actividad orgánica provoca un cierta reacción en otro, y por último (3) la actividad orgánica puede ser empleada con intención de provocar esas reacciones.

La consecuencia de esto es que, sostiene Dewey, en primer lugar, el fenómeno en cuestión es social, en el sentido de que "existe una forma de comportamiento que tiene la naturaleza de una interacción o transacción entre dos personas" (2008, 93 /lw.13.200). Otra consecuencia es que cuando la actividad orgánica es tomada como un signo (por ejemplo el llanto de un bebé como signo del hambre, o de algún cierto malestar) y cuando tales sonidos se profieren directamente con la intención de provocar una reacción, tales signos “dicen algo y tienen la naturaleza de una proposición” (2008, 93 /lw.13.200). Ello implica que la proposición resulta abierta a una investigación empírica acerca de hechos. Es decir, si alguien dice "me siento mal", su afirmación puede ser sometida a prueba, a partir de hechos observables. El hecho de que sea posible descubrir que alguien está fingiendo un cierto dolor sugiere que podemos concluir, a partir de hechos observables, la presencia o ausencia de un cierto estado del organismo. Ello es así, de acuerdo con Dewey, porque la adscripción de un cierto "estado mental" a un sujeto no es una afirmación acerca de algo 
privado sino una afirmación acerca de la situación total en la que se encuentra el organismo. $^{10}$

De este modo, la posición de Dewey es la siguiente: incluso si fuera cierto que los términos valorativos son signos de un cierto estado del organismo usados para provocar una determinada acción, en una situación tal estarían involucradas proposiciones susceptibles de ser validadas o rechazadas. Así cree Dewey haber refutado la interpretación positivista de los términos valorativos. Pero además, señala que tales proposiciones refieren a una situación presente o existente y a una situación futura que se quiere producir, siendo las proposiciones empleadas un medio para la producción de esa situación futura (Dewey, 2008, p.95 /lw.13.202). En otros términos, si fuera cierto que la valoración remite al uso de términos valorativos para provocar ciertas acciones, se trataría de una situación que se da en un contexto social, que involucra proposiciones declarativas que son utilizadas como medios para transformar una situación. Teniendo en cuenta la concepción de los juicios prácticos analizada en la sección anterior, se trataría precisamente de juicios prácticos.

Pero hay algo más en estas situaciones de valoración: hay proposiciones que atribuyen a la situación presente un valor negativo, proposiciones que atribuyen un valor relativamente positivo a la situación futura y proposiciones que son ellas mismas un medio para producir la transformación y que establecen además una relación entre la situación futura como fin y ciertas cosas y actividades como medios. Así, esta reconstrucción de los contextos en los que se usan proposiciones valorativas para provocar cierta conducta permite plantear dos cuestiones: en primer lugar la cuestión de la aversión/atracción hacia ciertas situaciones, que Dewey llamará disgustar/gustar (2008, 95 /1w.13.202) y su relación

\footnotetext{
${ }^{10}$ Esto es así incluso en el caso de la adscripción de creencias, que son entendidas aquí, siguiendo a Peirce, como hábitos de acción.
} 
con las actividades que transforman uno en otro y, en segundo lugar la cuestión de la relación entre medios y fines.

Respecto de la primera cuestión, lo primero que señala Dewey es que el gustar o disgustar deben ser entendidos como formas de comportamiento y no como estados mentales meramente subjetivos. En la medida en que así se consideren, la afirmación que adscribe un gustar a un sujeto es una proposición cuya aceptabilidad puede ser establecida por medio de la observación. Es decir, la afirmación de que un sujeto valora algo, en el sentido de que le gusta o lo aprecia, es una afirmación cuya aseverabilidad puede garantizarse por medio de la investigación. Sin embargo, una tal proposición no es valorativa en sentido distintivo, sino que más bien se trata de una proposición sobre valoraciones.

Ahora bien, el gustar que resulta relevante de acuerdo con Dewey para la valoración es uno que se vincula más bien con un deseo que impulsa a la acción para satisfacerlo que un mero disfrutar de algo ya hecho. Así, la valoración, en el sentido de la apreciación que se distingue de un mero disfrutar que implica sólo un mínimo de actividad, supone un deseo en tanto que pretensión de mantener algo que se aprecia o de traer a la existencia algo que se valora positivamente. Esta caracterización del deseo como una actividad destinada a conservar o producir un valor, es decir, algo que se aprecia, resulta fundamental para que sea posible la valoración en términos de evaluación. En efecto, afirma nuestro autor,

si 'valoración' se define en términos de deseo, pero entendido como algo final y completo en sí mismo, no hay nada con lo cual discriminar un deseo de otro, ni manera por tanto de medir el mérito de diferentes valoraciones en comparación unas de otras. Los deseos son deseos y no hay nada más que decir" (2008, p. 97/1w.204). 
La tesis de Dewey es, entonces, que la valoración sólo puede ser comprendida como evaluación deliberativa si se considera que su punto de partida es un desear que implique esfuerzo por mantener o crear condiciones que se aprecian. En sus palabras, cuando los deseos se contemplan como algo que surge sólo dentro de determinados contextos existenciales (...) y cuando se considera que su función por referencia a esos contextos es satisfacer la carencia existente, resulta que la relación entre deseo y valoración hace posible y exige, su formulación en proposiciones verificables (2008, p. 98/ lw.13.205).

Entendiendo de este modo al deseo, podemos determinar si un deseo resulta razonable o no razonable, bueno a malo, digno de ser cumplido o no. En otros términos, el fin que supone el deseo, aquello que se quiere lograr (ya sea conservar algo o producir algo), puede ser él mismo evaluado. Así, el enunciado que afirma que el fin de un deseo es digno de ser perseguido constituirá una proposición valorativa en sentido propio, es decir, una proposición que afirma que un fin es bueno y que por tanto el medio que nos permite lograrlo también lo es. La conclusión de esto es que aquello que hace posible validar o rechazar juicios valorativos es que los mismos se basan en juicios acerca de las cosas como medios y como fines.

De este modo, tenemos entonces, en primer lugar, que pueden establecerse proposiciones sobre valoraciones, es decir, proposiciones acerca de los deseos y las cosas apreciadas por las personas por cuanto los deseos y apreciaciones no son cosas que ocurran en un ámbito mental ajeno a toda observación sino estados del organismo que conllevan ciertas formas de acción. Tales proposiciones no constituyen proposiciones valorativas en sentido propio, pero ofrecen un insumo importante en el proceso de formulación y validación de estas últimas, es decir, de proposiciones que establecen que una determinada 
valoración, en el sentido de apreciación o deseo, es buena o mejor que otras. En otros términos, las proposiciones sobre valoraciones son el punto de partida para establecer juicios valorativos, sobre la base de evaluaciones. En palabras de nuestro autor, las proposiciones sobre valoraciones en términos de sus condiciones y consecuencias delimitan el problema de la existencia de proposiciones valorativas en sentido distintivo. ¿Las proposiciones sobre valoraciones ya realizadas son susceptibles de ser ellas mismas evaluadas? Y esa evaluación una vez hecha ¿puede intervenir en la constitución de valoraciones ulteriores? (...) En caso de que (...) se demuestre que ciertos tipos de actos de estima son mejores que otros, los actos de valoración habrán sido ellos mismos evaluados y esa evaluación podrá modificar actos directos de estima ulteriores. Si se cumple esta condición, entonces las proposiciones sobre valoraciones que de hecho se producen se convierten en objeto de valoración en sentido distintivo, es decir, en un sentido que las diferencia de las proposiciones de la física cuanto de proposiciones históricas que se limiten a describir lo que los seres humanos han hecho en la práctica (2008, 100/1w.13.208-209).

Hemos citado en extenso este pasaje por cuanto es un buen resumen de lo que hasta aquí hemos dicho. En primer lugar, hay que distinguir entre (a) proposiciones sobre valoraciones, (b) proposiciones evaluativas y (c) proposiciones valorativas en sentido distintivo. Las primeras son proposiciones acerca de hechos observables, acerca de actos de estima, apreciación o deseo que pueden ser validadas o rechazadas en relación con la observación. Las segundas son proposiciones que evalúan las cosas como condiciones y consecuencias unas de otras, es decir, como medios y fines. Nótese que, en tanto que tales, estas proposiciones son también pasibles de validación o rechazo y que ocurren, no sólo en el ámbito de la valoración ética o política, sino también, como vimos, en el ámbito de la 
investigación científica: son una fase inherente a todo proceso de juzgar práctico. Por último, las proposiciones valorativas en sentido propio son proposiciones que se apoyan en proposiciones evaluativas acerca de actos de estima, apreciación o deseo. Nótese que es este último punto lo que las distingue de proposiciones de física o de proposiciones meramente descriptivas, es decir, el hecho de que ellas sostienen que un determinado acto de estima, apreciación o deseo es bueno.

\subsection{Las proposiciones evaluativas y la relación medios/fines}

Podemos detenernos ahora en las proposiciones evaluativas como tales. A diferencia de una proposición que establezca un determinado estado de cosas, e incluso de una predicción de lo que ocurrirá, una proposición evaluativa, en cualquier contexto, sienta o formula, de acuerdo con nuestro autor, una norma. Tal norma expresa "una condición a la que hay que plegarse en modos de acción futura concretos" (2008, p.102 /lw.13.209). Las normas están presentes en todos los contextos de la actividad humana, y en este sentido afirma Dewey que "toda forma recurrente de actividad, en las artes y en las profesiones, desarrolla reglas que indican la mejor manera de cumplir los fines que se tienen en vista" $(2008$, p.102 /lw.13.209).

La cuestión respecto de las normas es, de acuerdo con Dewey, saber si se limitan a reflejar costumbres, convenciones o tradiciones o si, en cambio, pueden ser ellas mismas justificadas a partir de la consideración de ciertas cosas consideradas como medios o fines. La respuesta afirmativa es obvia, sostiene Dewey, para el caso de las artes y los oficios, (2008, p.102 /lw.13.209) y dada la concepción de la ciencia como un modo de la práctica, 
se sigue que también lo es para la investigación científica. Es decir, en tanto que encargada de la formulación de juicios prácticos garantizados, la ciencia tiene que recurrir a normas bien establecidas por investigaciones anteriores o a normas que deberán ser suficientemente garantizadas en la investigación en curso.

Las normas se justifican, entonces, apelando a la consideración de las cosas tomadas como fines y medios, puesto que ellas son precisamente la formulación de algo que hay que hacer, como medio para obtener un fin. Frente a la pregunta de si es cierto que es eso lo que hay que hacer, entonces, sólo podemos responder sobre la base de la consideración de los medios, los fines y sus relaciones. Llegamos así a una cuestión muy importante en la concepción deweyana de la valoración, por cuanto de ella depende la viabilidad de su proyecto de fundamentar una racionalidad sobre valores en la relación medios/fines, sin renunciar a un punto de vista crítico que dé cuenta de la posibilidad de evaluar no sólo los medios en relación a un fin, sino también los fines. En palabras de Dewey,

lo que está en juego es nada más y nada menos que la posibilidad de proposiciones valorativas en sentido distintivo. No puede negarse que, en el caso de la evaluación de las cosas como medios, son posibles proposiciones que estén garantizadas por la evidencia y puedan someterse a prueba experimental. De ello se sigue que, si esas proposiciones intervienen en la formación de los intereses y deseos que constituyen valoraciones de fines, entonces estos últimos se erigen por ese motivo en objeto también de auténticas afirmaciones y negaciones empíricas” (2008, p. 110/1w.13.217218).

\section{Conclusiones}


En este capítulo hemos establecido algunos elementos para la construcción de una mirada acerca de la relación entre conocimiento científico y valores en el contexto de la obra de Dewey. Como hemos sugerido en la introducción, esta relación puede pensarse en dos direcciones: podemos indagar acerca de la presencia de valores, y específicamente de valores extra-epistémicos, en la validación del conocimiento científico, esto es, en la investigación científica, y podemos preguntarnos acerca de la relevancia de la investigación, incluso la científica, para la producción y justificación de juicios valorativos. Aunque esta última ha sido la dirección que más preocupó a Dewey y que resultará central en el contexto de esta tesis para la elucidación de una dimensión crítica de la reflexión deweyana sobre el conocimiento, hemos intentado sentar las bases para sostener que, también en relación con la primera dirección, Dewey tiene algo interesante que decir.

De este modo, hemos visto que la comprensión de la investigación científica como forma de la práctica supone que la actividad científica consiste mayoritariamente en la formulación de juicios prácticos. Un juicio práctico es un juicio acerca de lo que conviene hacer, y supone entonces evaluar materiales y cursos de acción posibles, en tanto que medios para el cumplimiento de un fin pretendido. Así, los juicios prácticos suponen juicios evaluativos. Ahora bien, hasta aquí no se ha demostrado que tales juicios evaluativos involucren "valoraciones en sentido distintivo" como afirma Dewey, y en un lenguaje más contemporáneo, valores extra-epistémicos y más específicamente valores éticos o políticos. En efecto, tal como hemos visto, un juicio evaluativo es simplemente una valoración de las cosas como medios y fines, y no hay nada aquí que obligue a que tales valoraciones involucren valores éticos o políticos. Por otro lado, hemos visto que los juicios valorativos en sentido distintivo son juicios en los que lo que se evalúa son deseos e intereses. Es decir, 
se evalúan los fines que nos proponemos y tal evaluación puede hacerse sobre la base de proposiciones evaluativas, es decir, sobre la base de proposiciones acerca de las cosas tomadas como medios y fines. Esto último es, a su turno, lo que permite justificar fines y valores, dando cuenta así, y contra las pretensiones positivistas, de una racionalidad valorativa, es decir, de una racionalidad sobre fines y valores. Como hemos mencionado, esta pretensión de fundamentar una racionalidad de valores en la relación medios/fines ha sido objeto de fuertes críticas. Particularmente, Max Horkhiemer y Herbert Marcuse han dirigido importantes críticas contra la posición de Dewey que analizaremos en el capítulo siguiente. Al responder a tales objeciones, habremos de detenernos sobre el carácter continuo y contextual de la investigación y la valoración, lo que nos permitirá, a su vez, profundizar nuestra mirada acerca de la presencia de valores extra-epistémicos en la investigación científica. 


\section{Los medios y los fines en el continuo de la investigación/valoración}

\section{Introducción}

Hemos visto en el capítulo anterior que la posibilidad de fundamentar o rechazar tanto juicios prácticos en el contexto de la investigación, es decir, juicios acerca de lo que hay que hacer, como juicios propiamente valorativos, esto es, juicios acerca de que un determinado objeto de deseo, es decir una valoración en el sentido de apreciación, es buena, depende de la fundamentación, o rechazo, de juicios valorativos en el sentido de evaluativos. Estos últimos son juicios que expresan una norma, y se apoyan, cuando resultan fundados, en la investigación de las relaciones de las cosas como medios/condiciones y fines/consecuencias. Es decir, la fundamentación de juicios, tanto en ciencia como en ética y política, supone, de acuerdo con Dewey, algo así como una 
racionalidad de medios/fines o instrumental: "la racionalidad es un asunto de la relación de medios y consecuencias" (Dewey, lw.12.17).

Ahora bien, contra el modo en que suele entenderse la racionalidad instrumental, sobre todo a partir de la crítica de la Escuela de Frankfurt, no se trata en este contexto de una racionalidad que sólo considere medios en relación a un fin dado, sino de una racionalidad que pretende también evaluar fines. Así, y como dice Dewey, "la objeción permanente a esta visión de la valoración es que se aplica sólo a las cosas como medios" (lw.13.212). La respuesta de Dewey es que una racionalidad que no evalúe ni re-evalúe los fines mismos a la luz de sus condiciones y consecuencias, es decir, desde la relación medios-fines, no tiene nada de racionalidad sino que parece más bien una forma de la obstinación y la estupidez. Para justificar este punto de vista nuestro autor recurre a dos análisis. En primer lugar, recurrirá a una consideración de los conceptos de medio y fin para sostener la dependencia mutua de medios y fines, de modo tal que puede apreciarse que la evaluación de los medios implica o debería implicar una evaluación de los fines y, como consecuencia de ello, tal vez, una reelaboración de los mismos. Por otro lado, Dewey analizará el tipo de situaciones en las que surgen fines y valores para determinar si, en tales situaciones, es posible una verdadera evaluación de los deseos, fines y valores. El resultado de tal análisis será que la evaluación de los deseos, intereses y fines depende de la evaluación de los medios en tanto que obstáculos y recursos, y de las consecuencias totales tanto de los medios como de los fines. Asimismo, señalará Dewey, toda valoración debe apoyarse en valoraciones anteriores, de modo tal que toda valoración se da en el contexto de un continuo de valoración/investigación.

Ahora bien, pese a que Dewey analiza y responde las objeciones respecto del carácter meramente instrumental de toda racionalidad medios /fines, una objeción 
interesante a su propuesta ha sido planteada por Herbert Marcuse. Aunque este último reconoce la pretensión de Dewey de dar cuenta de la evaluación de los fines, sostiene que pese a ello su propuesta es insuficiente y que por ello el pragmatismo, lo mismo que el positivismo, carece de una verdadera dimensión crítica. Esta cuestión resulta relevante en el contexto de esta investigación, toda vez que uno de sus objetivos es sostener que puede reconstruirse, desde la perspectiva de Dewey, una concepción del conocimiento y la ciencia que, al contener una dimensión crítica, permita delinear algo así como una filosofía política del conocimiento. Es por ello que en este capítulo, y luego de considerar la concepción de la valoración de Dewey, analizaremos la crítica de Marcuse. Tal crítica nos permitirá

obtener una mayor claridad respecto de la posición de Dewey, toda vez que nos permitirá sacar a la luz algunos elementos centrales de la posición del pragmatista. Así, deberemos tener presente el carácter contextual de la investigación/valoración así como también su carácter continuo que supone, no sólo una concepción falibilista en relación a los valores, sino la inexistencia de valores últimos. Ello nos permitirá, a su turno, ofrecer una respuesta al problema planteado por Marcuse y, asimismo, dar cuenta de la interdependencia de la investigación/valoración, de modo que sea evidente no sólo el carácter de cargada-devalores de la investigación científica, sino también el carácter cargado-de-investigación de la valoración.

\section{La evaluación de los fines y el continuo de la valoración}

Como hemos dicho en el capítulo anterior, el punto de partida naturalista de la concepción de la valoración de Dewey vincula los valores con deseos e intereses. De acuerdo con 
nuestro autor, como dijimos, la única alternativa a este punto de vista es algún tipo de anti naturalismo que comprende a los valores no como algo que surge y se valida al interior de la experiencia, sino como algo impuesto desde fuera de la misma. Sin embargo, al vincular los valores con deseos e intereses, Dewey rechaza también la concepción de éstos últimos como meros impulsos emocionales, privados o subjetivos, a los que sólo cabría satisfacer (o reprimir) sin introducir en ellos modificación alguna tomándolos, así, como simplemente dados y completos. De este modo, si bien es cierto que los valores se vinculan con los deseos e intereses, de acuerdo con Dewey, en la medida en que elegimos inteligentemente los valores, "el deseo y el interés no se nos dan prefabricados de antemano" (2008, p. 131/ lw.13.239).

En relación con esto, Dewey plantea el problema acerca de si es posible tener deseos fundados, en el sentido de ser validados o garantizados mediante el ejercicio de la inteligencia, o si todo lo que tenemos cuando de valores se trata es el peso de la tradición o del capricho e impulso individual. Si bien es cierto que, en su "Theory of Valuation", Dewey habla de comprobación empírica de los valores e incluso de su demostración científica, hay que tener presente que tales términos remiten, en este contexto, a la investigación tal como ha sido definida en el capítulo 4 de esta tesis, es decir, de un modo que abarca investigaciones tanto científicas como de sentido común. Asimismo, la utilización del término empírico remite a la idea de la experiencia como proceso que permite validar o rechazar hipótesis y en este caso también valores. Para decirlo de otra manera, empírica es toda investigación que tome como punto de partida la experiencia primaria, y que vuelva a ella con los materiales refinados de la experiencia reflexiva para someterlos a control y testeo. Para el caso de la valoración, ello significa que un proceso de valoración inteligente debe tener en cuenta las apreciaciones, los gustos, los deseos e 
intereses que se dan en la experiencia primaria, para someterlos a análisis y evaluación en función de sus condiciones y consecuencias, aspectos todos ello que resultan abiertos a la observación e investigación empírica.

Es importante tener presente, como ya hemos señalado, que Dewey no niega que los impulsos caprichosos o la mera costumbre puedan determinar los fines y valores. Efectivamente, muchas veces los valores que guían las prácticas e instituciones humanas están subordinados a tales factores. En sus palabras, "los valores han sido determinados en el pasado por las costumbres, ensalzadas debido a que favorecían algún interés especial -y ello podía hacerse por medios coercitivos o exhortativos o por una mezcla de ambos" (2008, p. 135 /lw.13.243). La cuestión que discute es más bien "la posibilidad de proposiciones genuinas y fundamentadas en torno a los propósitos, planes, medidas y políticas que influyen sobre la actividad humana siempre que ésta no es puramente impulsiva o rutinaria" (2008, p. 134/ 1w.13.243, cursivas nuestras). La pregunta es entonces si es posible fundamentar los fines que influyen sobre las prácticas humanas. Nótese que la pregunta pone en pie de igualdad tanto a las prácticas que podríamos llamar propiamente científicas como a las prácticas vinculadas a valores que podríamos llamar éticos y/o políticos. Que ello es efectivamente así, es decir, que pueden fundamentarse propósitos, pareciera ser, en el ámbito de la ciencia, las artes y los oficios, más claro. Por ello, el abordaje de Dewey en el texto que discutimos va más bien dirigido a la cuestión de las valoraciones en sentido distintivo, es decir, a la investigación acerca de si un determinado deseo, interés o fin es bueno o no es bueno, es correcto o es incorrecto.

Antes de analizar el proceso mismo de evaluación de los deseos e intereses conviene detenerse en la forma en que el pragmatista comprende a los mismos. Lo primero que hay 
que tener en cuenta es que deseos e intereses surgen siempre en relación a un determinado contexto o situación, en cuyo seno no sólo adquieren un cierto contenido sino que también funcionan como medios. Así, afirma nuestro autor que "no existen deseos ni intereses al margen de algún campo de actividades que los haga aparecer y funcionar como medios" (2008, p. 132/ lw.13.240). La primera condición para su ocurrencia es que el contexto o situación en la que aparecen implica alguna carencia, alguna falta que genera conflictos entre aspectos de la situación que sí están presentes. El concepto de situación que ya hemos analizado encuentra así su lugar en el contexto de la teoría de la valoración. El deseo surge en el contexto de una situación indeterminada o problemática, e implica un esfuerzo por modificar la situación de modo que, o bien se traiga a la existencia aquello cuya carencia ha originado la respuesta orgánica consistente en el deseo, o bien se mantenga algo cuya existencia resulta amenazada. En este sentido, el deseo implica siempre una cierta anticipación: se anticipa contrafácticamente, por así decirlo, una situación futura en la que la carencia o el peligro han sido hechos a un lado. El deseo supone, así, lo que nuestro autor llama fin-a-la-vista, en el sentido de un resultado, una meta o un objetivo anticipado.

Resulta conveniente tener presente aquí otro aspecto de la situación que ya hemos comentado en el capítulo 4. Toda situación tiene un aspecto de inmediatez cualitativa que no sólo da unidad a la situación, sino que también hace que la situación sea experimentada como una experiencia, es decir, que sea tenida más que conocida. En el contexto de la valoración, cuando el deseo está involucrado, la situación que origina la tensión o el problema es sentida como algo negativo, como algo de lo que se desea salir, sea por alguna carencia o sea porque algo que era experimentado como bueno resulta amenazado. En contraposición a ello, hay una situación futura anticipada a la que se le asigna, en carácter hipotético, una cualidad positiva. 
Asimismo, hay un aspecto del desear vinculado con el término interés que Dewey señala especialmente en contraposición con la idea de un mero anhelo o una fantasía. El deseo implica siempre, y como parte suya, no sólo un fin a la vista, sino también una cierta idea respecto de los medios o condiciones que harán posible la obtención del resultado. Así, un fin no es nunca independiente de los medios, sino que la consideración del modo y los medios en que el fin puede obtenerse forman parte constitutiva del mismo. En eso se distingue el desear de un mero anhelar, es decir, de una apreciación hipotética de un cierto fin a cuyo logro no se destina más esfuerzo que su mera formulación. Nuevamente, no se niega que existan anhelos en este sentido ni fines pretendidamente queridos más allá de toda forma y posibilidad de alcanzarlos y sin esfuerzo alguno en esa dirección. La cuestión es más bien lo que ocurre cuando nos formamos fines que sí intentamos alcanzar.

De este modo, el deseo que constituye la base sobre la que se apoyará el proceso de valoración implica (a) un componente afectivo (cualitativo), al depender de la asignación de un valor negativo a una situación presente y uno relativamente positivo a la situación anticipada; (b) un componente motor o activo que supone un cierto esfuerzo por parte del organismo por producir los cambios necesarios; y por último (c) un componente que Dewey llama intelectual o ideacional, por cuanto implica hipótesis e ideas acerca de un fina-la-vista e ideas acerca de la manera de traer a la existencia la situación anticipada. De este modo, los deseos que constituyen el material sobre el que opera la valoración implican una “unión de las condiciones afectivo-motoras de la acción con lo intelectual o ideacional. (...) allí donde hay un fin-a-la-vista del género que sea, hay actividad afectivo-ideacionalmotora" (2008, p.110-111/lw.13.218). 
Los valores serán entendidos así, por Dewey, como fines-a-la-vista generalizados, es decir, como intereses y deseos que la experiencia nos ha mostrado que resulta deseable o bueno perseguir en diferentes situaciones. Nótese que la idea de valor o valoración garantizada, como la llama Dewey (lw.13.213), resulta paralela a la idea de asertabilidad o aseverabilidad garantizada como subproducto de una investigación concreta. Toda investigación concreta es la transformación de una situación problemática en una que ya no lo sea. Sin embargo, para poder operar tal transformación de un modo controlado es preciso arribar a aserciones que resulten garantizadas en virtud del proceso de inferencia controlado que las origina. Al resultar garantizadas esas afirmaciones resultan garantizadamente aseverables en el contexto de otras investigaciones: se convierten en un recurso que puede ser usado en otras situaciones, siendo siempre su aseverabilidad, pese a resultar garantizada, de carácter hipotético. Del mismo modo, un fin-a-la-vista que en un determinado contexto se ha mostrado como correcto, es decir, como deseable o digno de ser perseguido, puede resultar generalizado como algo a ser perseguido en otras situaciones, es decir, se constituye en un valor, sin perder por ello nunca su carácter hipotético, es decir, su carácter de abierto a ulteriores críticas y re-evaluaciones. En palabras de Dewey:

Las ideas generalizadas de fines y valores sin duda existen (...). Se repiten situaciones similares; los mismos deseos e intereses se transportan de unas a otras y van progresivamente consolidándose. El resultado es un inventario de fines generales (...). Al igual que sucede en la práctica de cualquier ciencia natural esas ideas generales se usan como instrumentos intelectuales en el juicio de casos particulares cuando tales casos se plantean; son, en efecto, herramientas que dirigen y facilitan el examen de las cosas en su concreción, a la vez que ellas mismas se desarrollan también y se ponen a prueba a la vista de los resultados de aplicarlas a esos casos (2008, p. 122-123 /1w.13.230). 


\subsection{La evaluación de los fines}

Podemos detenernos ahora en la cuestión de la evaluación de fines-a-la-vista para analizar los elementos que están, de acuerdo con nuestro autor, involucrados en ella. En primer lugar, resulta comúnmente señalado que hay cosas que se evalúan en relación con su capacidad de medios para la producción de un cierto fin. En ese sentido, se dice que tales cosas son buenas en la medida en que permiten cumplir un determinado fin. Es importante tener presente, de acuerdo con Dewey, que si bien tales cosas tiene un valor instrumental, ello no las priva de tener algo así como un valor intrínseco, inmediato, es decir, no las priva de poder ser apreciadas o estimadas por sí mismas. Este señalamiento tiene por objetivo hacer a un lado la idea de que la distinción entre medios y fines pueda ser pensada como la distinción entre algo que es querido o estimado por sí mismo, el fin, y algo que tiene sólo un valor instrumental, es decir que es querido como medio para algo más. De acuerdo con nuestro autor, tanto las cosas, procesos o situaciones que funcionan como fines como las que funcionan como medios, en tanto que existencias de alguna clase, tienen su propio aspecto de inmediatez cualitativa de modo que pueden ser directamente apreciadas o estimadas. Así, la distinción entre medios y fines es siempre funcional: en situaciones concretas en las que se trata de traer algo a la experiencia o de conservarlo, hay cosas que ocupan el lugar de medios y otras que ocupan el lugar de fines. Así, en sus palabras,

la distinción entre medios y fines es temporal y relacional. Cualquier condición que deba traerse a la existencia para servir como medio es, dentro de esa relación, un objeto de deseo y un fin-a-la-vista, mientras que el fin de hecho alcanzado es un medio para futuros fines a la vez que un test de las valoraciones previamente realizadas (2008, p. 121/ lw.13.229). 
Así, las cosas que llamamos medios o fines no lo son en virtud de una propiedad intrínseca, sino solamente en el contexto de una actividad concreta en la que sirven de medios o de fines. Ello implica que la idea misma de fin en sí mismo carece para Dewey de todo sentido. Un fin es siempre un fin-a-la-vista, en el sentido de que es una anticipación de un cierto estado de cosas que se quiere producir. Pero una vez producido, una vez cumplido el fin a la vista, se ha introducido un cambio en el mundo que, al interactuar con otros procesos, o al intervenir en otros cursos de acción, es decir, en la medida de que ese fin-a-la-vista se convirtió en una consecuencia, en un final, es condición de nuevas consecuencias, y medio para nuevos fines-a-la-vista. Este doble sentido de la palabra fin, como fin-a-la-vista y como terminación, consecuencia o final resulta para Dewey muy importante por cuando contiene en sí mismo la explicación del proceso de evaluación de los deseos e intereses, es decir, de los fines mismos y de los valores.

Ahora bien, de acuerdo con Dewey, "los fines se evalúan dentro de las mismas valoraciones en las que se sopesan las cosas en tanto que medios" (2008, p. 104 /lw.13.2012). Para comprender por qué ello es así, hay que tener presente, en primer lugar, que las categorías de medio y fin son interdependientes de modo tal que siempre un medio es un medio para un fin, a la vez que la consideración de los medios que permiten alcanzar un fin forma parte del contenido mismo del fin. Es decir, en la medida en que los deseos e intereses, esto es, los fines-a-la-vista, son sometidos a un proceso de evaluación reflexiva o inteligente, adquieren un contenido específico en función de la reflexión acerca de los medios para obtenerlos y de las consecuencias efectivas de lograrlo. Esta es, efectivamente, la posición que puede leerse en el texto que comentamos:

Cualquier estudio de las experiencias por las que se forman fines-a-la-vista, y en las que las tendencias impulsivas iniciales se decantan mediante la 
deliberación en un deseo elegido, revela que el objeto valorado en último término como fin por alcanzar está determinado en su configuración concreta por la evaluación de las condiciones existentes como medios (2008, p. 106/ lw.13.213).

Hemos presentado ya todos los elementos que, de acuerdo con Dewey, intervienen en la evaluación de los fines. En primer lugar, interviene una consideración de los medios, es decir, de los materiales y operaciones que permitirán cumplir el fin. Así, los medios necesarios para cumplir con un determinado fin pueden resultar demasiado costosos, en el sentido de que, por ejemplo, suponen sacrificar el cumplimiento de otros fines o amenazan con poner en peligro algo que es un valor consolidado. Incluso puede resultar que los medios en cuestión conllevan un esfuerzo desproporcionado en relación al fin o tales medios pueden ser objeto de una apreciación profundamente negativa. En todos esos casos, se tiene una primera herramienta para evaluar el fin mismo: como consecuencia de consideraciones tales, el fin puede ser considerado un fin inadecuado o malo e incluso irracional. Así, la valoración de los medios para un fin, tanto en el sentido de su evaluación como de su apreciación, constituye un factor en la valoración misma del fin. El otro aspecto importante que interviene en la evaluación de un fin, en el sentido de un propósito o un resultado esperado, es decir, de un fin-a-la-vista, es su comparación con los resultados de hecho obtenidos, es decir, con el fin en el sentido de consecuencia o resultado final. Ello es posible en la medida en que un fin es también un medio y una condición. En tanto que fina-la-vista es un medio para dirigir la acción que pretende incidir en el curso de una situación o una experiencia: puesto que el fin se configura en el proceso de deliberación acerca de los medios, que repercute a su vez en la evaluación de sí mismo, se constituye en un factor mediador sin cuya intervención la situación no se transformaría de ese modo. Así, 
porque el fin es un medio de dirigir la acción puede ser él mismo evaluado en función de la relación medios/consecuencias. Pero, además, una vez obtenido un fin, es decir, una vez que el fin es una consecuencia efectiva de la acción, su final o su consumación, por ejemplo, una vez que hemos transformado una cierta práctica o institución de modo tal de convertirlas en democráticas, el resultado obtenido es una realidad, una existencia como dice Dewey, como cualquier otra que en interacción con otros aspectos de la situación producirá nuevas consecuencias. Tales consecuencias, pueden, por ejemplo, afectar otros fines y valores que habían sido obtenidos u otras cosas que eran apreciadas en un determinado contexto, en cuyo caso el fin podría revelarse como un mal fin, siendo así objeto de un proceso de testeo, comprobación o, para usar un término más neutro, justificación o rechazo. Es decir, dado que el fin es también una consecuencia, puede ser evaluado en función de la relación medios/fines: "puesto que el fin logrado es condición para la ocurrencia de nuevos sucesos, debe ser evaluado por su potencial como obstáculo y como recurso" (2008, p.121/1w.13.229).

\subsection{El continuo de la valoración y el contexto del pensamiento}

Hay otro aspecto que resulta central en la concepción deweyana de la valoración, que ha sido ya sugerido pero no ha sido suficientemente explicitado. En efecto, hemos dicho que al considerar los medios de un fin, tanto como al considerar las consecuencias del cumplimiento del fin mismo, hay que tener en cuenta qué otros fines y valores pueden verse afectados o reforzados. Así, por ejemplo, cuando se considera un fin como consecuencia, como resultado realmente obtenido, es importante tener presentes todas las consecuencias y analizar de qué modo tales consecuencias han afectado a otros fines. 
Ello puede apreciarse más claramente si tenemos presente el análisis deweyano de la conocida máxima "el fin justifica los medios”. En su opinión tal máxima suele interpretarse en el sentido de que el valor del fin que ha sido obtenido es tal que justifica los medios, independientemente de las consecuencias "negativas" o no queridas. Esta idea se corresponde, de acuerdo con Dewey, con la idea de que hay algo como un fin-en-sí-mismo, es decir, un fin que es valorado independientemente de las consecuencias que pueda tener. La máxima no niega que los medios y el fin alcanzado tengan otras consecuencias, sino que más bien decide ignorarlas, seleccionando arbitrariamente una parte de las consecuencias generadas como el fin y aislando el fin que se perseguía de los restantes fines que funcionan como valores en una situación dada. Es decir, no se tiene en cuenta que la valoración ocurre siempre en el contexto de un continuo de valoración.

Así, dado que toda valoración de fines, en el sentido de evaluación, se apoya en otras valoraciones que son tanto evaluaciones anteriores cuanto apreciaciones o actos de estima, es decir, deseos e intereses vigentes, el punto inicial de toda valoración debe ser la investigación acerca de los valores vigentes, entendidos no como entidades a priori ni como meros estados mentales, sino como las reglas que de hecho modelan nuestras prácticas y nuestras instituciones. La valoración en sentido distintivo es una evaluación de los valores así entendidos, que deben en primer lugar ser estudiados. El conocimiento de tales valoraciones "tiene la naturaleza de los saberes históricos y antropológico-culturales" (Dewey, 2008, p.135/ lw.13.243) y es un punto de partida, una "condición sine qua non para poder formular proposiciones valorativas" (ibídem). Así, de acuerdo con Dewey, sin ese conocimiento de las valoraciones humanas como acontecimientos ya ocurridos (2008, p. 136/ lw.13.244), no pueden formularse valoraciones válidas. Es importante señalar que 
ello no implica que las valoraciones pasadas deban ser tomadas tal como están, sino que ellas mismas deben ser sometidas a evaluación por medio de un proceso de deliberación acerca de medios y de fines que tendrá como resultado su refuerzo, su modificación o su abandono. Así, afirma nuestro autor,

Dada la continuidad de las actividades humanas, personales y en sociedad, el signo de las valoraciones presentes no se puede establecer de forma válida en tanto no se vean sobre el trasfondo de los casos pasados de valoración con los que son continuos (ibídem).

Es importante tener presente que el fundamento de la continuidad de la valoración es la continuidad misma de las actividades humanas, tanto desde un punto de vista individual como social. Podemos referirnos a tales actividades humanas como la experiencia sin más. Es decir, puesto que la experiencia, esto es, la transacción organismo/medio, resulta continua, los fines y valores que nos proponemos tienen siempre una dependencia respecto de valoraciones anteriores: la experiencia en general, y la experiencia de valoración en particular, no comienza nunca desde la nada, sino que carga siempre con el peso de la experiencia pasada.

Otra forma de mencionar este aspecto de continuidad es señalar, como ya lo hemos hecho, que toda valoración se da en un cierto contexto. Ese contexto no debe ser pensado, como meramente temporal, es decir, por referencia a las valoraciones pasadas, sino también como un contexto espacial. En un interesante artículo de 1931 titulado "Context and Thought" (Dewey, lw.6.3-21) nuestro autor explicita la insoslayable dependencia de todo pensamiento, y a fortiori, de toda investigación y de toda valoración, de un contexto.

En dicho artículo, Dewey comenta un ensayo de Malinowski en que este último señala la importancia del contexto para la determinación del significado de los términos en 
el lenguaje vivo de ciertas comunidades "salvajes". Dewey expande el análisis de Malinowski y señala que "sería un gran error imaginar que ese principio limita su aplicación a tales personas" (lw.6.4). Así, sostiene: "nosotros comprendemos el significado de lo que es dicho en nuestro propio lenguaje no porque la apreciación del contexto sea innecesaria, sino porque el contexto está muy inevitablemente presente. Se da por sentado; es un asunto de hecho, y así, no se especifica explícitamente" (ibídem). Además de expandir el principio de Malinowski a todo lenguaje, Dewey señala que lo mismo puede decirse de todo pensamiento. En efecto, si mediante el término lenguaje, arguye Dewey, nos referimos a todo tipo de signo y símbolo, y no solo al hablado, no hay pensamiento sin lenguaje, y dado que todo signo depende del contexto, todo pensamiento depende del contexto. El resultado de negar el contexto tiene, de acuerdo con Dewey, una consecuencia muy perjudicial en filosofía, e induce a cometer lo que él entiende como las falacias filosóficas por antonomasia, a saber, la falacia analítica, que consiste en tomar distinciones analíticas que funcionan en un determinado contexto como si refirieran a entidades autosuficientes, y la falacia de la universalización, consistente en pretender que un principio que resulta aplicable a un contexto específico deba valer para todo contexto. Así, afirma nuestro autor: "la negación del contexto es el más grande desastre en el que el pensamiento filosófico puede incurrir" (lw.6.11).

Lo que nos interesa aquí es destacar lo que, de acuerdo con Dewey, se halla involucrado en la afirmación acerca de la dependencia del pensamiento respecto del contexto, a saber, un trasfondo y un interés selectivo (ibídem). Este último aspecto refiere a que en toda reflexión y en todo pensamiento hay una cierta "selectividad (y rechazo)" (lw.6.14) que es una función del contexto. Mediante la expresión trasfondo, que es en la 
que nos detendremos, nuestro autor refiere al "ambiente completo que la filosofía debe tomar en cuenta" (lw.6.11). El trasfondo resulta implícito en todo pensamiento, hasta cierto punto, aunque no puede ser explicitado completamente: “envolviendo, bañando, saturando las cosas de las que somos explícitamente consientes hay alguna situación inclusiva que no entra en el material directo de la reflexión" (lw.6.11). Sólo partes de tal trasfondo pueden ser traídas a la conciencia, y ello ocurre, señala Dewey, cuando sospechamos que ejercen algún efecto sobre lo que pensamos conscientemente o porque parecen generar algún problema.

Tal trasfondo es, de acuerdo con Dewey, tanto espacial como temporal. En el sentido temporal, la idea de trasfondo señala que toda reflexión surge del algún estado de cosas precedente (lw.6.12) y es tanto intelectual como existencial, es decir, no sólo involucra un estado anterior de la interacción organismo/medio, sino también un trasfondo de tradición, en un sentido que se distingue de una mera costumbre. Las tradiciones, que refieren tanto a culturas como a teorías específicas en ciertos contextos, dice Dewey, "son formas de interpretación y de observación, de valoración, de todo aquello sobre lo que se piensa explícitamente" (ibídem). Anticipando algunos aspectos de la noción kuhniana de paradigma, Dewey refiere a la física aristotélica y la astronomía ptolemaica, a la física newtoniana, al fijismo y al darwinismo en biología como ejemplos de tales trasfondos que en una cierta época se dan por descontados. Se trata de "tradiciones regulativas, órganos de apercepción o hábitos mentales” (lw.6.13), como quiera que se los llame, que contribuyen a entender lo que en una determinada época se piensa, y sin los cuales no hay pensamiento.

Por otro lado, el trasfondo es espacial en el sentido de que cubre todo el escenario contemporáneo en el cual emerge un curso de pensamiento. Cuando estudiamos algo en particular, aquello que estudiamos se da en un contexto total en el que no hay rupturas 
Federico E. López / Una reconstrucción de la lógica de la investigación de John Dewey

totales ni asilamientos absolutos: "demarcaciones tan tajantes que equivalgan a aislamientos no ocurren en la naturaleza" (lw.6.13). Dewey ejemplifica este sentido espacial de trasfondo mediante la imagen de una ruta que corre sobre un cierto terreno: "el contexto espacial es el suelo a través del cual el camino corre y en razón del cual el camino existe" (lw.6.14). Recordemos que la reflexión es vista por Dewey como un proceso de transacción en el que intervienen tanto el organismo como el medio, es decir, que se trata de lo que Dewey llama una situación. El punto que Dewey remarca aquí es que toda situación reflexiva se da en un determinado contexto, es decir, que es continua con otros procesos naturales y sociales que constituyen su trasfondo. Esto resulta central, puesto que dada tal continuidad, no puede evitarse a priori que las actividades que se realizan en un determinado contexto espacial tengan consecuencias que afecten diferentes aspectos del trasfondo. Un claro ejemplo de ello lo constituyen los laboratorios científicos: lo que ocurre en su interior, toda actividad cognitiva, cualquier investigación realizada allí, puede tener y de hecho tiene consecuencias que afectan su trasfondo o contexto, tanto en un sentido temporal, es decir, en relación a la teoría científica, como espacial, es decir, en relación al mundo en el que la investigación toma lugar.

Así, resulta claro que la valoración, en tanto que forma de la conducta reflexiva, supone un contexto o de trasfondo: en un sentido temporal y existencial, el proceso de valoración es una respuesta a una situación caracterizada por algo que se experimenta como una carencia o un peligro; en un sentido temporal intelectual, sostiene Dewey, toda valoración se hace en el contexto de una tradición de valoraciones, se decir, se apoya, como vimos, en las valoraciones pasadas que operan como formas de interpretar y valorar que ya han sido establecidas. Nótese que, en la medida en que las valoraciones se apoyan en 
valoraciones anteriores, y puesto que toda valoración involucra, para Dewey, como hemos visto, juicios acerca de la relación de las cosas como medios y fines, es decir, juicios empíricos, la tradición sobre la que se apoya la valoración no remite sólo a un continuo de la valoración, sino a un continuo de valoración/investigación, que involucra creencias y hábitos de inferencia acerca de hechos y valores.

Por otro lado, dado que (a) la valoración ocurre en un contexto que es también espacial (signado por la continuidad de la naturaleza), y (b) la valoración supone investigación y esta última una actividad de "hacer y rehacer" que es de naturaleza práctica (cfr. cap. 4 de esta tesis), resulta esperable que (c) las actividades desarrolladas en los contextos de investigación/valoración tengan consecuencias que se propaguen más allá de la situación específica en la que ocurren dichas actividades, provocando tal vez nuevos problemas y generando carencias y peligros no previstos, y hasta nuevas formas de disfrute, que proporcionen la ocasión para nuevos procesos de valoración/investigación.

Así, de acuerdo con Dewey, la evaluación de los fines involucra un proceso de deliberación acerca de medios y fines que usa como recurso valoraciones e investigaciones anteriores, es decir, que supone siempre un cierto trasfondo. Como resulta evidente Dewey no está proponiendo una serie de criterios que permitan al filósofo en tanto que tal validar o rechazar fines-valores. La posición señala, más bien, que es posible, para la inteligencia humana, fundamentar y rechazar valores y fines del modo recién señalado.

Por otro lado, cabe señalar que el hecho de que Dewey refiera a las proposiciones verificables en las que se apoya la valoración como proposiciones científicas no debe llevarnos a pensar que estamos frente a una reducción de la racionalidad práctica a una racionalidad teórica que pretende zanjar toda cuestión ética y política a partir de hechos científicamente comprobables, anulando así la verdadera deliberación práctica. Ello no es 
así, en primer lugar porque la investigación científica misma es una forma de la deliberación en la que todo lo que puede obtenerse, además de transformaciones de la realidad, es asertabilidad con garantías, pero con garantías nunca definitivas sino siempre falibles e hipotéticas. Por otro lado, la deliberación sobre fines y valores toma como punto de partida, pero no como un punto de partida ya dado y terminado, sino como un material a ser modificado, los deseos e intereses que operan en el contexto real en que se desarrolla la valoración en sentido distintivo, es decir, la deliberación acerca de deseos, intereses, fines y valores.

Así, nuevamente, Dewey no está diciendo qué fines deben descartarse o seguirse sino afirmando que consideraciones acerca de los medios necesarios para un fin, y acerca del fin mismo en su calidad de medio, pueden servir como razones y muchas veces así lo hacen, para evaluar un fin, y así descartarlo o reconfigurarlo. La cuestión de cuáles son los fines que aceptaremos y cuáles los que rechazaremos no es algo que pueda hacerse en abstracto, sino como resultado de la evaluación en contexto; y no es, en todo caso, la tarea de una teoría de la valoración. Así, "una teoría de la valoración, en tanto que teoría sólo puede plantear las condiciones a que debe atenerse en las situaciones concretas un método para formar deseos e intereses" (2008, p. 134/ lw.13.242), y un poco más adelante afirma también nuestro autor que su discusión

no pretende en y por sí misma resolver los problemas de valoración; aspira a establecer condiciones que la investigación debe satisfacer si es que dichos problemas van a resolverse y servir de esa manera como principio rector a la hora de dirigir dichas investigaciones (2008, p. 135/ 1w.13.242-243, cursivas nuestras). 
Vemos, de este modo, que la teoría de la valoración de Dewey ${ }^{1}$, si bien no es normativa en el sentido de proponer ciertos fines particulares, sí tiene una dimensión normativa, por cuanto pretende establecer de qué modo deben establecerse los fines y los valores. Como hemos dicho ya reiteradas veces, la única opción a su propuesta era, dado el rechazo a fines y valores entendidos como entidades impuestas desde afuera de la experiencia, seguir permitiendo que los fines y valores sean determinados por el peso de la tradición o el mero impulso caprichoso. Pero, podemos preguntar, ¿es ello suficiente? ¿Nos permite realmente esta teoría de la valoración someter a crítica los valores vigentes en un contexto histórico y cultural en el que, por ejemplo, los recursos y los obstáculos estén configurados de modo tal que toda crítica a los valores vigentes parezca condenada al fracaso? Este es el tipo de crítica que los partidarios de la escuela de Frankfurt dirigieron al pragmatismo en general y a Dewey en particular y que analizaremos en la sección siguiente.

\section{El pragmatismo y la teoría crítica: racionalidad y valores}

En este capítulo y en el anterior hemos abordado la cuestión de la relación entre investigación científica y valores, con el objetivo de recuperar las ideas de Dewey al respecto y de cara a los debates contemporáneos. Sin embargo, la recuperación de las ideas de Dewey en el marco de tal discusión debe responder, en nuestra opinión, a la objeción antes sugerida. En efecto, mientras el debate actual sobre la relación entre conocimiento y valores tiene una clara pretensión crítica, en el sentido de cuestionar el papel social y político que han tenido la ciencia y la epistemología en el siglo $\mathrm{XX}$, en más de una

\footnotetext{
${ }^{1}$ Nótese que nos referimos a la teoría de la valoración y no a la filosofía de Dewey o a su pensamiento. En efecto, él sí propuso a la democracia como un valor (cfr. Pappas, 2008).
} 
oportunidad se ha sostenido que el pragmatismo clásico carece precisamente de esa fuerza crítica. Esta manera de comprender al pragmatismo, y a la filosofía de Dewey en particular, ha estado presente en lo que se suele denominar la tradición de la Teoría Crítica. Por ello, nos detendremos en esta sección en el análisis de la recepción que las ideas de Dewey han tenido en el contexto de dicha tradición. Desde el feroz ataque de Horkheimer, la aguda crítica de Marcuse y la acusación de Apel, ${ }^{2}$ hasta el tímido reconocimiento de Habermas y la clara reivindicación de Honneth, las reacciones son múltiples y variadas y, sin embargo, todas ellas parecen centrarse en la relación establecida por Dewey entre la ciencia y el conocimiento en general, de un lado, y los otros ámbitos de la experiencia humana, del otro. Sin embargo, y aunque la presencia de ideas de cuño pragmatista es por demás clara en Apel, Habermas y Honneth, la cuestión de la relación entre las ideas de Dewey con la así llamada Escuela de Frankfurt permanece aún poco explorada. ${ }^{3}$ Por ello, lo más importante aquí, y lo que reclamará el centro de atención, es la reacción de Horkheimer y Marcuse frente a la filosofía de Dewey, tanto más cuanto que tal reacción contiene la objeción antes señalada; objeción que, de ser adecuada, minaría las pretensiones y posibilidades críticas del pensamiento de Dewey y, con ello, la pretendida recuperación de sus ideas sobre las relaciones entre ciencia y valores.

\footnotetext{
${ }^{2}$ Para un análisis de la acusación de Apel a Dewey cfr. López, Federico E. (2006) "Filosofía Conocimiento y acción: Dewey y Apel" en Actas de las VI Jornadas de Investigación en Filosofía para profesores, graduados y alumnos, T. II, La Plata, al Margen, pp. 123-129

${ }_{3}^{3}$ Para un análisis general de las relaciones entre el pragmatismo y la Escuela de Frankfurt cfr. Joas, Hans (1998: 92-108). En este trabajo, Joas sostiene que fueron ciertos "prejuicios" marxistas los que impidieron que los pensadores frankfurtianos emigrados a Estados Unidos pudieran comprender al pragmatismo.
} 


\subsection{Las críticas de Horkheimer}

Para un lector de Dewey, las críticas de Horkheimer adquieren, desde el comienzo, un carácter claramente extralimitado. En efecto, muchas de las críticas de Horkheimer parten de la atribución a Dewey de ideas con las que el filósofo pragmatista no se hallaba comprometido. Sobre la base de tal atribución, Horkheimer formula su objeción principal: el pragmatismo de Dewey no puede constituirse en una filosofía crítica, sino que, por el contrario, sólo logra constituirse en apología de una razón meramente instrumental. Es en su Crítica de la razón instrumental que Horkheimer formula contra Dewey tales objeciones. En efecto, allí puede leerse que:

el pragmatismo, al intentar la conversión de la física experimental en el prototipo de toda ciencia y el modelamiento de todas las esferas de la vida espiritual según las técnicas de laboratorio, forma pareja con el industrialismo moderno, para el que la fábrica es el prototipo del existir humano, y que modela todos los ámbitos culturales según el ejemplo de la producción en cadena sobre una cinta sin fin o según una organización oficinesca racionalizada $(2007$, p. 57$)$.

Esta cita contiene, en primer lugar, la visión del pragmatismo americano y de la filosofía de Dewey (a la que Horkheimer considera como la forma más radical y consecuente del pragmatismo) como un tipo extremo de cientificismo que celebra la racionalidad puramente instrumental y propone trasladar los métodos de las ciencias naturales, "las técnicas de laboratorio", a todos los ámbitos de la cultura. En segundo lugar, contiene la idea según la cual el pragmatismo, precisamente en virtud de ese cientificismo, esto es, dado que exaltaría esa ciencia, que por otro lado esta puesta al servicio de la alienación y la explotación, no es más que una apología del capitalismo. En efecto, un poco más adelante 
Horkheimer sugiere que el filósofo pragmatista, aunque pueda oponerse a las consecuencias que tiene el uso de la ciencia en la sociedad, al reducir razón a experimento carece de principios críticos desde los cuales sustentar su oposición, ya que se "ha dedicado a justificar los criterios fácticos, sosteniéndolos como superiores” (2007, p. 58). Esto, por otra parte, se debería al hecho de que el pragmatismo sostiene como criterio de racionalidad del pensamiento su utilidad respecto de un fin, midiendo así al pensar con algo que no es el pensar (2007, p. 57). De este modo, si se considera válido, simplemente, a aquello que permite cumplir con un determinado fin, todo aquello que, por ejemplo, permita mejorar la producción, aún cuando implique la deshumanización, e incluso el exterminio, del hombre, deberá ser considerado válido. De ello se desprendería, para Horkheimer, la tendencia de los pragmatistas a presentarse como "liberales, tolerantes, optimistas y enteramente incapaces de ocuparse del desastre cultural de nuestros días" (2007, p. 58) dado que su filosofía ha destruido cualquier principio al que apelar para sustentar una oposición a tal desastre.

De este modo, la filosofía pragmatista quedaría reducida a una concepción epistemológica cientificista y a una posición política conservadora del status quo y declaradamente inútil a la hora de intervenir en la "crisis cultural". El fundamento último de estas posiciones parece radicar, a los ojos de Horkheimer, en otras dos ideas, a saber, una concepción antropológica que reduce toda forma interesante de experiencia al experimento y, en consecuencia, un realismo científico que declara que "todas las cosas de la naturaleza llegan a identificarse con los fenómenos que representan cuando se las somete a las prácticas de nuestros laboratorios" (2007, p. 56). Así, prosigue Horkheimer, el pragmatismo parece representar la ideología de la sociedad burguesa volcada al consumo, 
una sociedad en la que el avance de los medios técnicos coincide con un proceso de deshumanización que tiende a aniquilar la idea misma de hombre. En palabras de Horkheimer: "el pragmatismo refleja una sociedad que no tiene tiempo de recordar ni reflexionar" (2007, p. 51) y que deja inerme a la crítica filosófica: “el filósofo pragmatista ideal sería, según lo define el proverbio latino, el que callara”. (2007, p. 56).

Ahora bien, si esta breve reconstrucción es correcta, entonces Horkheimer atribuye a Dewey algunas ideas que el pragmatista no ha defendido. Por lo demás, resulta curioso que en la actualidad un pensador vinculado a la tradición de la teoría crítica recurra a algunas ideas de Dewey que van precisamente contra esta interpretación de su filosofía. En efecto, Axel Honneth recurre a Dewey para sustentar la idea de que la relación entre el hombre y su entorno no puede pensarse ni como puramente ni como fundamentalmente cognitiva, idea que como hemos visto en el capítulo 3 Dewey ha sostenido con mucha insistencia, y que constituía a sus ojos el punto de partida para ofrecer un concepción correcta del conocimiento. En este sentido, afirma Honneth que de acuerdo con Dewey "en nuestro accionar nos relacionamos con el mundo previamente no en la postura del conocimiento, neutralizada en el plano afectivo, sino en la actitud de la aflicción, del apoyo, teñida existencialmente" (2007, p. 55). De este modo, Honneth se aparta de aquellas interpretaciones que hacen del pragmatismo una filosofía que, en palabras de Horkheimer, reduce la experiencia humana al experimento científico. Por el contrario, recupera la concepción deweyana de la experiencia como interacción cualitativa entre organismo y medio y su crítica a la idea de que la relación entre el hombre y su entorno sea primariamente cognitiva.

Respecto de esa suerte de realismo científico que Horkheimer atribuye a Dewey cabe señalar que es precisamente ese tipo de realismo el que Dewey señala como uno de los 
fallos más perjudiciales de la filosofía moderna. Más bien, Dewey defendió una concepción instrumentalista de la ciencia, tal como lo hemos visto en los capítulos 3 y 4 de esta tesis. Efectivamente, de acuerdo con Dewey, la idea de que la ciencia es la encargada de decirnos cómo son realmente las cosas, junto con el hecho de la transformación de la ciencia misma en ciencia experimental que hace abstracción de los aspectos cualitativos del mundo, han llevado a la filosofía a un callejón sin salida, en el que se eliminan teóricamente del mundo muchos de los aspectos humanamente más importantes, los fines y valores, recluidos así en algún tipo de mundo inteligible y sustraídos del alcance de la inteligencia humana.

Por otro lado, es importante señalar que la propuesta de Dewey, en el sentido de su programa de una filosofía experimental, no significaba un mero traslado de los métodos de la ciencia, de sus prácticas de laboratorio, a la filosofía y a las humanidades. Antes bien, por ejemplo en Experiencia y naturaleza, la propuesta de Dewey parece ir en el sentido de recordar a la filosofía que, en la medida en que es una forma de conocimiento, no debe olvidar que en tanto que tal es una forma de experiencia, esto es, una forma de interacción del organismo humano con su medio, cuya investigación debe partir de algún problema real que se ha suscitado en una situación concreta, y que debe finalizar, para ser válida, en un cambio de la situación hacia una nueva en la que el problema haya sido resulto. En este sentido, el experimentalismo filosófico tiene el sentido de recordar que la filosofía no es un saber que se vincule con algún tipo de realidad fija y ubicada más allá de la experiencia, sino con situaciones de hecho, con problemas de hecho, y que se constituye, por consiguiente, en un programa de acción. Si esto es correcto, entonces no puede entenderse a la propuesta de Dewey como un intento de reducir razón a experimento. 
De este modo, las premisas de las que Horkheimer pretende derivar sus objeciones no pueden atribuirse a Dewey. Surge entonces la siguiente pregunta: ¿hay que descartar también la idea según la cual su filosofía no es más que una apología del capitalismo y de la democracia liberal? Aun cuando sea cierto, como señala Ramón del Castillo ${ }^{4}$, que la posición política de Dewey no ha sido del todo clara, con todo, puede afirmarse con seguridad que sí ha mantenido una posición fuertemente crítica respecto de la forma que estaba tomando la democracia de su tiempo. A este respecto, algunas citas de Dewey servirán para mostrarlo.

En 1935 Dewey escribe Liberalismo y acción social, en el que somete a crítica al liberalismo y, respecto de la escena social contemporánea, afirma lo siguiente:

En la actualidad este sistema competitivo no es más que un estado de guerra apenas encubierta (...). Donde quizá haya que insistir es en el control de los medios de producción por parte de una minoría que los posee legalmente y que los emplea como un potente instrumento para reprimir a la mayoría (1935, p. 98).

También en 1934 Dewey afirma, en un estilo que incluso recuerda a algunos pasajes de $E l$ hombre unidimensional, que el desorden de la vida actual se disfraza, a menudo, por el hecho de que toma la forma de una división estática en clases, y esta separación es aceptada como la esencia misma del orden, en la medida en que se fija y se acepta de modo que no pueda engendrar un conflicto abierto (2008, p. 23).

\footnotetext{
${ }^{4}$ Sobre la posición y la actividad política de Dewey cfr. Del Castillo, Ramón (2004) “Érase una vez en América. John Dewey y la crisis de la democracia” Estudio preliminar de Dewey, J., (2004) La opinión pública y sus problemas, Madrid, Morata y del mismo autor (2003) “El Amigo americano" Introducción a Dewey, J., (2003) Viejo y nuevo individualismo, Barcelona, Paidós.
} 
Estas citas, al igual que otras innumerables que pueden encontrase en la obra de Dewey, dan clara muestra de su posición crítica frente a lo que en palabras de Horkheimer podemos llamar el "desastre cultural".

Por otro lado, y de acuerdo con lo que hemos dicho en la sección anterior, resulta erróneo atribuir a Dewey una posición según la cual la racionalidad instrumental ${ }^{5}$ se limita a evaluar los medios en función de un fin dado. Para Dewey, como hemos explicitado, una racionalidad que toma a los fines como simplemente dados y que no los revisa a la luz de sus condiciones y consecuencias, más que racionalidad se parece mucho a la obstinación y estupidez. Sin embargo, podemos preguntarnos, nuevamente ¿es suficiente esta pretendida evaluación de los fines para fundamentar una dimensión crítica de la filosofía? El análisis de la crítica de Marcuse que emprenderemos en la sección siguiente nos permitirá abordar de modo directo tal cuestión.

\subsection{Las críticas de Marcuse}

Herbert Marcuse $\left(2011^{6}\right.$ y 1941) publicó en el Zeitschrift für Sozialforschung, la conocida revista del Instituto de Investigación social, dos reseñas de dos de las obras de Dewey en las que más nos hemos detenido en esta tesis, a saber Logic: The Theory of Inquiry y “Theory of Valuation”. En la segunda de estas reseñas, que analizaremos a continuación", Marcuse formula una crítica a la concepción de los valores de Dewey que, a diferencia de

\footnotetext{
${ }^{5}$ Este punto ha sido desarrollado por Esteban (2008) en el capítulo 8 acerca de "Racionalidad Instrumental y racionalidad pragmatista"

${ }^{6}$ Publicada originalmente en 1939-1940.

${ }^{7}$ Para un análisis crítico de la reseña de Marcuse de la lógica de Dewey véase Deen (2011)
} 
las críticas de Horkheimer, reconoce de modo explícito algunos avances de la propuesta de Dewey en relación con el positivismo.

La reseña inicia llamando la atención acerca del uso, en la tradición que identifica como positivista, de un concepto de razón con contenido crítico. La razón era vista en los comienzos del positivismo, de acuerdo con Marcuse, como "una fuerza de oposición al estado de cosas como dado. Pensar y actuar de acuerdo con la razón era casi idéntico a pensar y actuar en oposición a las normas y opiniones aceptadas" (1941, p. 144). De este modo, la razón tenía fuerza crítica, si y sólo si su relación con los hechos no era una relación de ajuste a, sino de cambio de esos hechos, en la medida en que los mismos fueran considerados problemáticos. Así, "si los hechos estaban en desacuerdo con los dictados de la razón, los primeros estaban 'mal' y tenían que ser cambiados en conformidad con las demandas de la última" (ibídem). Sin embargo, sostiene Marcuse, el positivismo, a partir del siglo XVIII, comenzó a desistir de ese aspecto crítico, al que reemplazó por una función “conformista y apologética" (ibídem). Así, "el principio de verificación a través de los hechos, en lugar de servir para iluminar una verdad que debe ser y aun no es, refuerza la verdad de lo que es" (ibidem).

En este contexto, Marcuse discute una idea debatida en su tiempo acerca de la relación entre el fascismo y el autoritarismo y el positivismo. En su opinión, si bien es cierto que el positivismo, al defender la libertad de investigación, no puede ser acusado de promover el fascismo y el autoritarismo, lo cierto es que no ofrece ningún resorte crítico para enfrentar y cambiar una sociedad en la que el autoritarismo y el fascismo han sido establecidos. Así, pregunta Marcuse, puesto que el positivismo hace de la sujeción a los hechos el principio fundamental de la razón, 
Si el experimento fascista fuera completado, si el fascismo tuviera éxito en la organización del mundo, ¿tiene el positivismo algún derecho a negarle aprobación y aceptación? ¿No se vería el positivismo compelido a acatar ese orden del mundo y a trabajar con él y no contra él? (1941, p. 146)

La respuesta de Marcuse a tales preguntas es, efectivamente, que el positivismo carece de toda fuerza crítica para oponerse a lo dado, aún si lo dado fuera un orden social fascista. Tal es el modo en que Marcuse introduce su análisis del tratamiento deweyano del valor.

Si bien Marcuse reconoce a Dewey el haber llamado la atención acerca de la necesidad de rechazar la idea de una "ciencia social carente de juicios de valor" (1941, p. 146), cuestiona la pretensión de Dewey de apoyar tales juicios en proposiciones verificables, acerca de medios y fines. Aquí, Dewey se toparía con los mismos límites del positivismo, toda vez que resultaría imposible decir "algo 'científico' acerca de la deseabilidad de los fines mismos" (ibídem). Por ello, aunque Dewey reconoce que la cuestión principal es si los deseos son razonables o no lo son, "su análisis acaba pronto frente a los deseos e intereses prevalecientes de los hombres" (ibídem). En efecto, prosigue Marcuse, en el contexto de los positivistas, y de Dewey, los estándares con los que los deseos e intereses son clasificados como razonables e irrazonables residen en el contexto existencial mismo, refieren a los recursos y obstáculos que la situación presenta. Nuevamente, el ajuste a una realidad dada constituye, de igual modo que para los positivistas, en opinión de Marcuse, el criterio de racionalidad de Dewey. En un orden fascista establecido, los fines que consolidarían tal estado de cosas serían juzgados como racionales desde la perspectiva del pragmatista, en tanto y en cuanto estuvieran de acuerdo con los recursos disponibles, los obstáculos que se presenten y el continuo de los fines, deseos e intereses establecidos. 
Si bien Marcuse reconoce que Dewey sostiene que los fines mismos son reevaluados, y que dado el continuo de la valoración, es decir, el hecho de que toda evaluación de fines se hace sobre la base de otros fines ya establecidos, considera que tal posición constituye un optimismo infundado que niega la existencia de contextos tales como el aludido en el párrafo anterior, esto es, contextos fuertemente opresivos en que la lucha por la libertad, es decir, el fin de obtener libertad, parece ser imposible a la luz de los obstáculos y recursos disponibles, e incluso a la luz de los fines, deseos e intereses imperantes. Así, por ejemplo, de acuerdo con Marcuse, los órdenes sociales que se articulan en torno a la defensa de un pequeño grupo o una clase especial, "responden a deseos humanos profundamente arraigados, deseos que se esparcen bastante más allá del estrato gobernante” (1941, p. 147). Tales serían, por ejemplo, “el deseo de una protección fuerte, el anhelo de crueldad, el disfrute del poder sobre un enemigo impotente y de liberación del peso de la autonomía” (ibídem) junto con "otros numerosos deseos que configuran al individuo en la pre-historia del fascismo" (ibídem). En resumidas cuentas, la crítica de Marcuse es que la teoría de la valoración de Dewey, en tanto y en cuanto hace depender la valoración de los obstáculos y recursos disponibles, es decir, de una consideración de medios y consecuencias, y del continuo de los fines, carece de fuerza crítica para fundar valores que sean verdaderos instrumentos de cambio en contextos en los que los recursos, los obstáculos y los deseos e intereses prevalecientes atenten contra toda posibilidad de cambio.

En este punto podemos preguntar por la alternativa a la que apunta Marcuse. Es decir, su argumento es que la concepción de la valoración de Dewey es insuficiente puesto que pretende que los fines y valores deben ser fundamentados en base a contextos existenciales definidos, y sobre la base de los obstáculos, los recursos y los deseos e 
intereses que conforman el continuo de la valoración. Sin embargo, en opinión de Marcuse,

si la distinción entre deseos razonables y no-razonables ha de tener algún sentido en absoluto, no puede ser derivada del contexto existencial real [given] que provoca la distinción. Los estándares de la razón deben, de algún modo, ir más allá de ese contexto -más aún, incluso deben cuestionar a ese contexto en su totalidad (1941, p. 146).

De este modo, Marcuse parece optar por una respuesta anti-naturalista al problema, respuesta que como, hemos visto, Dewey rechaza de plano. Aunque analizar en detalle la propuesta de Marcuse escapa a los límites y posibilidades de esta investigación, resulta conveniente detenernos en algunos comentarios finales de la reseña analizada. Allí sostiene Marcuse, en referencia a la situación por la que atravesaba el mundo (recordemos que la reseña es de 1941), que en tal situación el problema de los valores es el problema de la libertad. Tal valor, afirma Marcuse,

cubre todo lo que es bueno, correcto y admirable en el mundo. Y todo esfuerzo por ubicar el valor de la libertad en el mismo nivel científico que otras valoraciones actuales es una afronta a la libertad. Pues la ciencia es en sí misma libertad, y no se puede verificar la libertad mediante otra cosa que la libertad. La libertad, y este es el resultado profundo del análisis de Kant, es el único 'hecho' que 'es' sólo en su creación; no puede ser verificado salvo al ser ejercitado [except by being exercised] (1941, p. 148).

Así, eso que parece estar más allá de cualquier situación dada, aquello que tiene la posibilidad de cuestionar y sacudir incluso los deseos e intereses en una sociedad totalitaria, es la libertad. Resulta llamativo que si cambiáramos la palabra libertad por la palabra democracia, término al que no alude Marcuse, obtendríamos, salvo en un aspecto que 
señalaremos en seguida, una posición próxima a la de Dewey. Algo así parece reconocer el propio Marcuse, por cuanto inmediatamente después de la cita anterior, reconoce que es esa convicción la que impulsa a Dewey a "salvar la validez científica de los valores". Sin embargo, en opinión de Marcuse, Dewey contradice la base de su "método positivista" (ibídem) por cuanto "su fe en el poder de la 're-evaluación' presupone una preferencia anterior a todo examen y verificación, a saber, que la libertad y la 'liberación de las potencialidades individuales' son mejores que sus opuestos" (ibídem). Esta última cita sugiere, en nuestra opinión, que, en última instancia, la respuesta de Marcuse al problema planteado, es decir, la posibilidad de una ciencia social crítica, que pueda servir para justificar la lucha por la libertad aun cuando tal lucha sea percibida como un salto suicida hacia la nada, depende en última instancia de una preferencia anterior a toda ciencia y que no puede ser fundamentada porque su fundamentación científica, en tanto que la ciencia implica libertad de opinión y examen, ya la supone. Pareciera así tratarse de una suerte de decisionismo. Esta lectura encuentra apoyo, además, en la introducción a El Hombre unidimensional. Ensayo sobre la ideología de la sociedad Industrial avanzada (1993). Allí, afirma Marcuse que los juicios de valor tienen un rol en la teoría crítica. Uno de los juicios de valor implicados por una teoría crítica de la sociedad afirma que

la vida humana merece vivirse, o más bien que puede ser y debe ser hecha digna de vivirse. Este juicio subyace a todo esfuerzo intelectual; es el a priori de la teoría social, y su rechazo (que es perfectamente lógico) niega la teoría misma (1993, pp. 20-21).

Así, parece ser que en última instancia la diferencia, en relación a la cuestión de los valores, entre Dewey y Marcuse es, para este último, que su propia teoría reconoce un a priori que no puede ser ya fundamentado. El rechazo de ese a priori es perfectamente lógico, es decir, 
es posible, pero al costo de negar la posibilidad de una teoría crítica, esto es, de una teoría que nos permita cuestionar los contextos dados, el orden establecido. Y ese poder crítico, de cuestionamiento y oposición, debe poder ser esgrimido aún cuando a la luz de los deseos e intereses imperantes y de los recursos y obstáculos presentes, la totalidad parezca "tener el aspecto mismo de la Razón” (Marcuse, 1993, p. 19).

Podemos resumir, entonces, la crítica de Marcuse señalando que, en su opinión, el concepto de razón de Dewey, al proponer la verificación como criterio central, pierde fuerza crítica porque ve a la razón como algo que debe ajustarse a la realidad dada. Tal concepto de razón, en verdad, sólo es viable en el contexto de una sociedad que haya aceptado ya la libertad como un valor. En una sociedad en la que los deseos e intereses dominantes sean contrarios a la libertad, el proceso de deliberación racional sobre valores que propone Dewey, o bien no es aplicable o bien sólo puede reforzar los valores vigentes. De esta manera, la propuesta de Dewey sería viable sólo en tanto y en cuanto suponga una preferencia, anterior y no fundamentable en los términos de la valoración deweyana, a favor de la libertad.

Lo primero que cabe mencionar, a modo de respuesta a Marcuse, es que éste último parece no tener en cuenta suficientemente uno de los aspectos centrales del pensamiento de Dewey que hemos ya señalado en esta tesis: la relación del conocimiento, la inteligencia o la racionalidad con el (resto del) mundo o, en otros términos, la función que la conducta racional tiene en la experiencia, es una función trasformadora, de cambio del mundo y no de un mero ajuste a él. La idea de que la racionalidad y el conocimiento deben ser verificados estableciendo su ajuste a la realidad, propia de la teoría del conocimiento del espectador, fue uno de los blancos de crítica permanentes de Dewey. La determinación de 
los datos, de los hechos del caso, es tan sólo un momento en la producción práctica o tecnológica del conocimiento, que sólo puede ser validado en y por las trasformaciones que opera.

Usualmente, cuando desde algunas posiciones se critica la importancia otorgada por el pragmatismo a la ciencia, no se tiene en cuenta este aspecto transformacional de la investigación científica. La idea de que la pretensión de defender la relevancia de la ciencia para la ética y la política implica un intento de cancelar la discusión, mediante la apelación a una supuesta verdad entendida como un ajuste a lo que es, y por tanto como una defensa del stau quo, no puede ser adjudicada a Dewey: el conocimiento es para él una práctica de transformación del mundo, práctica guiada por un razón que como hemos sugerido involucra ya una dimensión valorativa ${ }^{8}$. Esta insistencia en el poder transformador de la realidad ha sido señalado por Robert Brandom (2011, pp. 35 y ss.) quien, acaso tomando una sugerencia del propio Dewey (lw.2.21), ha señalado algunos vínculos entre el pragmatismo y la Ilustración. En opinión de Brandom (ibídem), el pragmatismo puede ser visto como una segunda ilustración. Así, en nuestra opinión, este aspecto crítico y transformador de la razón, presente, en opinión de Marcuse, en el positivismo en sus orígenes, pero ausente en el positivismo del siglo $\mathrm{XX}$, es un aspecto que lejos de resultar ausente en el pragmatismo ha sido uno de los rasgos distintivos del pensamiento de Dewey.

Otro aspecto importante en el contexto de esta discusión es que al referirse a los deseos e intereses que configuran a los individuos en la "pre-historia" del fascismo, Marcuse parece incurrir en una de las confusiones que Dewey rechaza en "Theory of Valuation". En efecto, allí afirma Dewey que los deseos e intereses no son datos originarios o premisas de una teoría de la valoración (lw.13.239). Un deseo, en la medida en que se

\footnotetext{
${ }^{8}$ Este es un punto que ha sido reconocido por Habermas (2002, p. 138).
} 
diferencia de un mero anhelo, es una respuesta a una determinada situación que es problemática. Ello implica que el deseo no es algo final y dado sino que cumple una función mediadora: en tanto que instituye un fin-a-la-vista, es un medio para la transformación de la situación. El deseo de protección, por ejemplo, sólo puede ser mantenido mediante la presencia de algún tipo de amenaza. Así, el proceso de valoración no comienza con el deseo ya configurado, sino que debe analizar tal deseo como medio para traer a la existencia algo que se percibe como una carencia o conservar algo que se ve amenazado. Así, el comienzo de la re-evaluación de los fines se halla en el análisis del contexto en que tales fines se proponen. Es cierto que Marcuse reconoce la importancia conferida por Dewey a esta re-evaluación de los fines, pero la considera simplemente como un optimismo ingenuo.

El tratamiento de esta cuestión excede las posibilidades de la presente investigación, ya que requeriría analizar algunos aportes de la psicología social. Con todo, el punto es, en nuestra opinión, irrelevante respecto de la teoría de la valoración de Dewey. En efecto, su único objetivo es establecer la posibilidad de evaluar los fines, deseos e intereses, apelando a una consideración de la relación medios/fines y al continuo de la valoración. Es en principio posible que haya determinados contextos en los que tal re-evaluación de los fines sea completamente imposible. De hecho, como señala Dewey, la mayoría de las veces los fines y valores resultan determinados por el peso de una tradición que muchas veces se limita a reproducir los intereses de una pequeña clase. En este sentido, Marcuse no logra visualizar que, como hemos mencionado ya, la teoría de la valoración de Dewey no se propone recomendar algún valor en especial, sino solamente mostrar que es posible validar fines del modo en que se describe y que, puesto que las alternativas a ello sustraen los fines 
del alcance de la razón, es deseable que así se haga. De hecho, la alternativa sugerida por Marcuse parece consistir en una mera postulación del valor de la libertad, excluyendo la posibilidad de ofrecer razones para sostener que la libertad es mejor que su opuesto.

En todo caso, desde la perspectiva de Dewey no sería recomendable tomar una situación como la que describe Marcuse como modelo para la teoría de la investigación. En efecto, los deseos e intereses que, de acuerdo con el frankfurtiano, configuran a los individuos en la pre-historia del fascismo, serían casos de "hábitos que se han establecido sin un examen crítico de la relación de medios a fines" (2008, p. 122/ 1w.13.230) ${ }^{9}$. Y por ello, señala Dewey, "no suministran un modelo que la teoría de la valoración pueda seguir". (ibídem). Ello no implica, en nuestra opinión, negar la posibilidad de situaciones como las que describe Marcuse, sino señalar que incluso en tales situaciones la posibilidad de fundar valores que sean verdaderos instrumentos de cambio depende de la consideración de los medios y los fines de la situación. Pero por “consideración de los fines de la situación” no refiere Dewey a su mera aceptación, sino a su evaluación crítica toda vez que fuera necesario. La postulación de un a priori de la valoración no cambia las cosas: en una sociedad totalmente controlada y totalitaria, la lucha por la libertad seguiría siendo vista como un salto suicida hacia la nada, independientemente de si la libertad es un a priori valorativo o si es un valor fundado en la consideración de los medios para obtenerla y en las consecuencias que cabe esperar de ella una vez que fuera alcanzada. Por otro lado, un proceso de valoración como el descripto por Dewey podría mostrar que los deseos imperantes en una situación tal no son medios para transformar la situación sino para

\footnotetext{
${ }^{9}$ Ello sería así porque, recordemos, los deseos que ofrecen el material para una valoración crítica no son puntos de partida sino respuestas que deben ser evaluadas como instrumentos en la producción de una nueva situación en la que la amenaza haya sido eliminada.
} 
perpetuarla, y que el único medio posible para el cambio es, por ejemplo, la lucha por la libertad o por la democracia considerados como fines-a-la-vista.

\section{Conclusiones: conocimiento y valores}

En este capítulo y en el anterior hemos analizado la concepción de la valoración de Dewey y su relación con la investigación científica o empírica. Lo primero que hemos establecido es que, en tal contexto, la valoración y la investigación deben ser vistas como procesos de deliberación racional que exhiben una misma estructura. De acuerdo con Dewey la valoración supone una evaluación de medios y fines, expresable en proposiciones evaluativas, que debe ser vista como un proceso crítico: como un "proceso de investigación para la determinación de un bien precisamente similar al que es emprendido en la ciencia para la determinación de la naturaleza de un evento" (mw.8.25). Tal continuidad está dada, así, fundamentalmente porque ambos tipos de juicios son formas de juico práctico:

Un juicio práctico ha sido definido como un juicio acerca de qué hacer, o de lo que debe hacerse: un juicio respecto de una futura terminación de una situación incompleta y hasta cierto punto indeterminada. Decir que los juicios de valor caen en este campo, es decir dos cosas: una, que el juico de valor nunca es completo en sí mismo, sino siempre como parte de la determinación de lo que debe hacerse; la otra, que los juicos de valor (como distintos de la experiencia directa de algo como bueno) implican que el valor no es algo previamente dado, sino algo que debe darse por una acción futura, determinada en sí misma por (dependiente de) el juicio (Dewey, mw.8.30.31).

Esta comunidad de estructura entre valoración e investigación, esta continuidad metodológica, contiene algunos puntos que resulta importante recapitular aquí. En primer 
lugar, toda evaluación de fines y valores, al igual que toda investigación científica, es un modo de respuesta a una situación problemática, y sus productos deben ser evaluados en función de su calidad de medios para transformar la situación. Un subproducto de tal proceso es la generación de asertabilidad garantizada, en el ámbito de la investigación científica, y de valores en el campo de la valoración. Una proposición valorativa, cuando resulta fundada, es en realidad un tipo de enunciado que puede ser aseverado de modo garantizado. En ambos casos, la importancia de tales productos, de los valores y de las proposiciones científicas garantizadas, es que se constituyen en recursos, en medios para ulteriores investigaciones y valoraciones. Sin embargo, su utilización en nuevos contextos está siempre sometida a revisión crítica, en la medida en que su carácter de garantizados es siempre hipotético: así como no hay creencias científicas aseguradas de una vez y para siempre, no hay valores eternos y universales. Todo valor, lo mismo que toda proposición científica, está por principio sujeto a la revisión que nuevas investigaciones y valoraciones pudieran exigir.

Hay otro aspecto señalado por esta suerte de isomorfismo investigación/valoración que resulta importante. En relación con la investigación científica hace tiempo que se ha hecho a un lado el modelo axiomático propio del fundacionalismo. Es decir, la idea de que el conocimiento deber poder ser obtenido deductivamente a partir de unos primeros principios intuitivos ha sido duramente cuestionada por Peirce, como hemos visto en el capítulo 1, cuestionamiento que Dewey ha hecho suyo. De acuerdo con éste último, en toda investigación se recurre a datos, o a hechos del caso, pero tales datos o hechos del caso no son ni dados ni absolutamente primeros, sino construidos y siempre provisionales.

Para el caso de los valores, ese modelo axiomático que toma como punto de partida la distinción aristotélica entre bueno en sí y bueno para otra cosa sigue sin embargo vigente 
en buena medida. Parece presupuesto, por ejemplo, en la pretensión de Marcuse de que una teoría crítica debe apoyarse en un a priori valorativo, o de que hemos de suponer una preferencia, que no puede fundamentarse ya, a favor de la libertad. Dewey rechazaría todo a priori valorativo. Ello no quiere decir que haya valores que no son sometidos a evaluación sino simplemente aceptados. Pero en tales casos, dichos valores o son el resultado de una evaluación crítica anterior o se limitan a reproducir una costumbre y carecen así de una fundamentación inteligente y no pueden ser tomados como modelo de una teoría de la valoración. Cualquier valor puede ser sometido a revisión y reevaluación, siendo la ocasión para tal revisión una cierta situación problemática y, si bien es cierto que hay valores que las personas no están dispuestas a revisar, ello no muestra que sean valores a priori sino más bien valores dogmáticos, que no tienen más respaldo que la tradición. Así como no hay en la ciencia verdades incuestionables ni primeros principios, no hay valores racionales incuestionables ni primeros.

No debe pensarse que esta posición constituye algún tipo de relativismo moral en el que todo vale: no es cierto que todo vale, pero lo que vale debe ser determinado en cada caso mediante investigación sin que tengamos ninguna garantía de que aquello que hoy constituye un valor no vaya a ser revisado en el futuro. Esta posición constituye, más que un relativismo acerca de los valores, una concepción anti-fundacionalista, anti-escéptica y falibilista, no sólo del conocimiento, sino también de los valores.

Otro aspecto que resulta remarcable acerca de la concepción deweyana de la valoración y la investigación es la cuestión de la relación entre cocimiento científico y valores que puede establecerse en dicho contexto. Como marco general, cabe señalar, en primer lugar, que la valoración en sentido distintivo, es decir, el proceso de evaluación de 
los fines, deseos e intereses que guían las prácticas e instituciones humanas, debería ser, de acuerdo con Dewey, un tipo de investigación particular. Tal investigación se apoyaría, no sólo en valores que han sido críticamente evaluados en otras valoraciones, sino también en juicios sobre valoraciones, es decir, juicios acerca de las cosas que son estimadas o apreciadas por los seres humanos, y también en juicios garantizables acerca de las cosas en sus relaciones mutuas de medios y fines. Este último aspecto señala que la ciencia, o mejor dicho, los aportes de la ciencia pueden y deben ser tenidos en cuenta al evaluar fines y valores.

Es importante tener en cuenta que no se trata aquí de una confianza ingenua que no tiene en cuenta la complejidad de los procesos de formación de deseos, intereses y valores, ni acrítica en el sentido de que desconozca los usos y los resultados de la ciencia, por ejemplo, en el contexto de una sociedad capitalista. Baste como muestra de ello la siguiente cita extraída de un escrito de 1939 (Freedom and Culure, lw.13.64-189):

Ya no es posible sostener la simple fe de la Ilustración en que el avance seguro de la ciencia producirá instituciones libres al disipar la ignorancia y la superstición:- fuentes de la esclavitud humana y pilares de los gobiernos opresivos. El progreso de la ciencia natural ha sido incluso más rápido y expansivo de lo que se podría haber anticipado. Pero su aplicación tecnológica en la producción a gran escala y en la distribución de bienes ha requerido concentración de capital; ha resultado en corporaciones de negocios que poseen derechos legales e inmunidades; y -ya es un lugar común decirloha creado un conjunto vasto e intrincado de nuevos problemas. Ha puesto a disposición de dictadores medios de controlar la opinión y el sentimiento de una potencia que reduce a una mera sombra todas las fuerzas previas al alcance de los dirigentes despóticos (lw.13.156). 
Ahora bien, como hemos sugerido ya, el remedio contra esto no es, para Dewey, defender un ideal de ciencia libre de valores, de ciencia no contaminada por la aplicación que pueda hacerse de ella, sino, más bien, tener presente en primer lugar que todo conocimiento es aplicado a la vez que discutir críticamente los deseos e intereses en cuyo favor tal ciencia debería ser puesta. De este modo, Dewey plantea con toda radicalidad la necesidad de ejercer una reflexión ética y política acerca de la ciencia. En efecto, en el libro recién mencionado reconstruye, sin suscribir a ella, la siguiente posición: los principios de liberalismo económico, es decir, los principios del individualismo del laissez-faire, han gobernado la investigación científica de modo que se ha permitido que los gustos y preferencias de los científicos regulen su actividad; en tal contexto, se ha producido "una connivencia tácita de la ciencia con la actividad individualista y descontrolada en la industria" (lw.13.157). Aunque Dewey considera un poco extrema esta posición, sostiene que no debe ser pasada por alto como si fuera simplemente una aberración. Más bien, en su opinión, plantea un problema genuino:

¿cuáles son exactamente las consecuencias sociales de la ciencia? (...) puede el tipo de control social de la industria ansiado por los socialistas llevarse a cabo sin algún tipo de regulación pública de las investigaciones científicas que son la fuente de las invenciones que determinan el curso de la industria? ¿Y no podría tal regulación ahogar la libertad de la ciencia? Aquellos que dicen que el efecto social de los inventos (que existen sólo a causa de los hallazgos de la investigación científica) es tan inquietante que lo menos que puede hacerse es establecer una moratoria sobre la ciencia expresan el mismo problema con más moderación (lw.13.157).

Así, como queda sugerido, la posición de Dewey se mueve hacia una reflexión política acerca de la ciencia. El primer punto en ese recorrido es reconocer que la ciencia misma, 
con sus resultados, tiene una importante influencia en la determinación de los fines y valores que guían a las personas, y que a menos que tal influencia sea tenida en cuenta y usada críticamente para evaluar los fines y los valores, la única alternativa es dejar que "fuerzas no-racionales y anti-racionales" (lw.13.162) los conformen. Si los fines no son ni fijos ni innatos, arguye Dewey, son el producto de la cultura. Si esto último es el caso, entonces la cuestión es si es posible o deseable que "la actitud científica" se vuelva un constituyente tan importante de la cultura como para que permita formar valores y propósitos. Como hemos visto, ello es posible porque la valoración descansa en juicios evaluativos que son validados o rechazados mediante una investigación.

De acuerdo con nuestro autor, en última instancia, la pretensión de que la ciencia sea neutral, en el sentido de que no tenga nada que decirnos acerca de los fines, se apoya en una pretendida separación y aislamiento de los diferentes ámbitos de la experiencia humana: el arte de un lado, la moral del otro, y aún en otro más, la ciencia. Como hemos visto, es esta disección de la experiencia aquello que la teoría deweyana de la experiencia buscaba evitar. Por otro lado, una vez que hemos comprendido a la ciencia como una forma de la experiencia, que se desarrolla siempre en un contexto o seno que es natural y cultural (como hemos visto en el capítulo 4), y que tiene tanto una dimensión temporal (contexto de tradición) como espacial (en una cierta extensión del mundo), resulta que al consistir la investigación en un hacer y rehacer, nada nos permite sostener que los medios y los fines de los que se vale la ciencia, y aquellos que genera, deban limitar su alcance al laboratorio como sitio destacado de la experiencia científica. En otros términos, si la ciencia es experiencia científica, es decir, una forma inteligente de transformar el mundo, no sólo sus resultados afectarán el mundo más allá de la ciencia, afectando por ejemplo los fines y 
valores de los hombres, sino que éstos últimos no podrán sino ser tenidos en cuenta en el contexto mismo de la investigación científica.

En resumidas cuentas, entonces, no sólo los valores y los deseos están cargados de ciencia (piénsese por ejemplo en el deseo de ser madre después de cumplir 40 años, o en el deseo de recorrer el mundo, o en el deseo de relaciones a distancia), sino que también la ciencia puede y debe estar cargada de valores, puesto que sus alcances de ningún modo se limitan a sí misma. Por supuesto, esto no prueba que de hecho se hallen involucrados valores éticos y políticos en la investigación, sino simplemente que la pretensión de excluirlos por principio no puede sostenerse de acuerdo a una comprensión del conocimiento como investigación y de los valores como valoración. Es decir, y para usar la distinción de Dewey presentada en el capítulo 5, nuestro razonamiento nos sugiere la presencia de valores éticos y políticos en la ciencia, pero el razonamiento no prueba sus conclusiones, puesto que es sólo un cálculo de significados: sólo la inferencia, cuando es controlada, permite garantizar una conclusión, pero ello supone una investigación completa: el razonamiento solo no puede probar tal conclusión sino que es necesario, además, realizar observaciones y experimentaciones. Es decir, tenemos un enunciado general, una hipótesis, que afirma que es esperable que valores extra-epistémicos intervengan en la producción de conocimiento científico (sin que ello suponga una merma de racionalidad). Esta afirmación puede ser utilizada como guía para una investigación que permita afirmar de modo garantizado que, en el contexto de una investigación particular, han intervenido como elementos en la validación del conocimiento tales o cuales valores éticos, políticos, económicos, culturales o estéticos. 
La ciencia puede y debe ser guiada por valores, pero por valores que hayan sido críticamente analizados: tales valores no son ni los valores de los individuos en connivencia con la industria, ni los fines de un estado totalitario o que sólo representa los intereses de una clase especial: deben ser los fines abierta y democráticamente analizados, criticados y validados o rechazados por el público ${ }^{10}$. Llegamos, así, a un punto que apenas podemos esbozar en esta tesis, pero que resulta central en el programa de una filosofía política de la ciencia. En opinión de Dewey, un público está constituido por un grupo de personas que son afectadas por las consecuencias indirectas de una determinada transacción (lw.2.245246). Así, si aquello que ocurre, por ejemplo, en un laboratorio en el que se experimenta con un determinado material, tiene consecuencias sobre personas que no están directamente involucradas en la transacción que ocurre en el laboratorio, tales personas constituyen un público, y la transacción misma tiene, entonces, un carácter público. Puesto que la constitución de un público depende de que tales consecuencias sean advertidas, el conocimiento de aquello que ocurre en el laboratorio, y por tanto, la comunicación de la ciencia, resultan centrales. Así, en una sociedad democrática, la comunicación de la ciencia y la discusión pública acerca de los valores que la guían, constituyen para nuestro autor verdaderos valores que los hombres y las mujeres de ciencia, lo mismo que el público en general, deberían perseguir. Nos encontramos, así, con un potencial crítico del pensamiento de Dewey que, en nuestra opinión, no ha sido suficientemente reconocido por los miembros de la escuela de Frankfurt cuyas críticas hemos analizado en este capítulo, y que en la actualidad tiene mucho que ofrecer en el contexto de una filosofía política de la ciencia.

\footnotetext{
${ }^{10}$ El concepto de público es un concepto interesante que ha sido discutido recientemente por ejemplo en Di Gregori y Duran (2009) y en el contexto de los abordajes pragmatistas de la sociología francesa reciente. Al respecto, puede consultarse el número 15 de Tracés. Revue de Sciences humanines, dedicado al pragmatismo, y especialmente la introducción de Cécile Lavergne y Thomas Mondémé (2008).
} 


\title{
III. Tercera parte
}

La teoría de la investigación de Dewey a la luz de algunos

\author{
desarrollos recientes
}




\section{Recapitulación de los resultados de la segunda parte y}

\section{presentación de la tercera}

La segunda parte de esta tesis se ha ocupado de estudiar la concepción de la investigación de John Dewey. Tal estudio nos ha permitido reconstruir, principalmente, los aportes de Dewey en relación con tres áreas: (a) la filosofía del conocimiento y la ciencia, (b) la filosofía de la lógica y (c) la filosofía de los valores. En relación con (a) el aporte más significativo de Dewey ha sido, en nuestra opinión y como hemos argumentado, la construcción de una concepción del conocimiento como práctica tecnológica de transformación del mundo. Según hemos argumentado, tal concepción toma como punto de partida un concepto de experiencia que Dewey elabora teniendo en cuenta los aportes de la biología, la psicología y la antropología. Tal concepto, junto algunos cambios metodológicos en la forma en que la filosofía elabora su concepto de conocimiento, ha permitido a Dewey comprender al conocimiento como una forma de la experiencia, es decir, de transacción entre el organismo humano y su ambiente, en la que el ser humano realiza ciertas operaciones que modifican los materiales con los que trabaja, siendo la validación de creencias idéntico con tal proceso. En ese sentido, entonces, el conocimiento es una práctica que, mediante la utilización de herramientas conceptuales y materiales, opera una serie de transformaciones en el mundo que conoce.

En segundo lugar (b), hemos analizado la concepción de la lógica de Dewey y hemos tratado de mostrar que la misma debe entenderse como conteniendo, principalmente, 
dos tesis que podemos caracterizar aquí como una tesis sustantiva y otra metodológica. Esta última tesis es la que afirma que para ofrecer una caracterización correcta de la naturaleza de las propiedades y relaciones lógicas, es preciso estudiar la forma en que es posible establecer aserciones garantizadas, mediante un proceso de control de la inferencia al que cabe llamar investigación. En segundo lugar, la tesis sustantiva es la que sostiene lo que, siguiendo a Esteban, hemos llamado un naturalismo normativo, es decir la posición según la cual las normas y principios lógicos son resultados reflexivos o subproductos de la investigación, que resultan normativos porque se han mostrado como formas adecuadas o mejores de cumplir con los fines de la investigación, es decir, de lograr aserciones garantizadas.

Por último (c), hemos visto que Dewey ofrece una concepción de los valores que señala la posibilidad y deseabilidad de que los valores que configuran las prácticas e instituciones humanos sean formados y validados en función de su consideración como medios para la transformación de una situación, que se hace y debe hacerse en el contexto de un continuo de valores y estimaciones, que deben ser ellas mismas sometidas a crítica y evaluación siempre que sea necesario. El proceso de fundamentación de los valores es, así, visto como un proceso semejante al proceso de fundamentación de normas en la ciencia, es decir, de proposiciones generales acerca de lo que debe hacerse, que se apoya a su vez en normas y enunciados ya establecidos que pueden y deben ser sometidos a crítica siempre que la situación lo requiera. Esta concepción de los valores, junto con la concepción de la investigación científica como forma de la práctica, nos ha permitido, a su turno, ofrecer una mirada deweyana sobre una cuestión ampliamente discutida en la filosofía del conocimiento actual, a saber, la relación entre conocimiento científico y valores. Ello nos 
ha habilitado a argumentar que, desde la perspectiva de Dewey, cabe sostener el carácter cargado de valores de la ciencia, a la vez que el carácter cargado de investigación de los valores. En este contexto, hemos sugerido, luego de evaluar y rechazar algunas críticas a la concepción deweyana de la valoración, que, en opinión de Dewey, la ciencia está influida por valores, pero que debe ser guiada, en el contexto mismo de su producción, por valores que hayan sido pública y críticamente evaluados. Nos hemos encontrado, así, con un aspecto crítico y normativo de la concepción de la investigación de Dewey, que permite delinear el programa de una filosofía política del conocimiento.

El objetivo de esta tercera parte es mostrar algunas líneas de continuidad entre las posiciones de Dewey que acabamos de reseñar y algunos desarrollos recientes vinculados con el estudio de la lógica y del conocimiento científico. En primer lugar, en el capítulo 8 de esta tesis, trataremos de argumentar que, pese a que autores como Peirce o como el propio Esteban han minimizado los aportes de Dewey a la lógica, sus estudios han tenido una influencia importante aunque no siempre reconocida en ciertas posiciones posteriores sobre el modo en que debe desarrollarse la lógica y halla además ciertas líneas de continuidad en algunos desarrollos actuales, particularmente en la teoría de la argumentación de Toulmin. En segundo lugar, veremos cómo la concepción de la investigación de Dewey encuentra importantes líneas de continuidad con algunos estudios empíricos posteriores en el ámbito de la sociología de la ciencia, y, especialmente, en el así denominado giro hacia las prácticas de los estudios de la ciencia. En particular nos detendremos en algunos resultados y aportes de Bruno Latour y de Karin Knorr Cetina, que reactualizan y complementan bien, en nuestra opinión, los aportes de Dewey. Por último, y para cerrar esta tesis, nos detendremos en un problema actual en el campo de los estudios de la ciencia, a saber, el problema de la reflexividad, lo que nos permitirá mostrar que la 
perspectiva de Dewey tiene, aún hoy, algo interesante que ofrecer para pensar el campo de la filosofía y la sociología de la ciencia. Tal aporte lo constituye, en nuestra opinión, la concepción práctica y transformacional de la filosofía misma, que guió gran parte de los aportes de Dewey a dicho campo. 


\section{La lógica de Dewey y la teoría de la argumentación}

\section{contemporánea}

\section{Introducción: Dewey, Toulmin y el giro práctico de la lógica}

Como señalan John Woods y Dov Gabbay (2005), la historia de la lógica en el último siglo y medio ha estado caracterizada por un giro matemático. Este giro implicó una reorientación respecto de las preocupaciones históricas de la disciplina. La preocupación tradicional por la argumentación y el razonamiento, reflejada no solo en la lógica o analítica de Aristóteles sino también en su dialéctica y en su retórica, fue reemplazada por una preocupación por las matemáticas. Esta reorientación hizo posibles importantes desarrollos, tanto en el ámbito de la fundamentación como en el de la metodología de la matemática. Sin embargo, es pertinente recordar que junto con el rechazo de la hegemonía del enfoque silogístico tradicional, esta modificación radical de la lógica implicó una reducción considerable de su ámbito de incumbencias previo. Es digno de mención el hecho de que, a pesar del giro efectuado, los lógicos matemáticos no rompieron completamente con la pretensión tradicional de que la lógica trata del razonar y el 
argumentar. Así, se siguió sosteniendo, en la literatura, que la lógica matemática es la teoría fundamental o más general del razonamiento. Otros, con más cautela, sostendrían que la nueva lógica simbólica es la teoría de base del razonamiento matemático. Sin embargo, los propios lógicos matemáticos pronto vieron los obstáculos que amenazaban la realizabilidad incluso de la más débil de tales pretensiones. Una de las primeras dificultades a enfrentar provenía del hecho de que la moderna lógica matemática conduce sus investigaciones en el marco de un lenguaje artificial que nadie habla ni podría hablar. Pero el razonamiento y la argumentación, si no hemos de restringir el alcance de estos términos a un subdominio particular, por caso la prueba matemática, ocurren en el ámbito de nuestros lenguajes naturales. Luego, no parece que la lógica matemática pueda ser una teoría del razonamiento y la argumentación, en este sentido amplio.

Esta concepción de la lógica matemática ha recibido críticas desde los ámbitos, más bien independientes, de la inteligencia artificial y de la lógica informal y la teoría de la argumentación. Lo que estos desarrollos críticos más recientes comparten, como su denominador común, es un interés por las contingencias del razonamiento y la argumentación humanos en contextos vitales reales. Woods y Gabbay proponen considerar estas tendencias, que se orientan en la dirección de un interés por la lógica del razonamiento práctico y de los sistemas cognitivos, bajo la rúbrica común de un giro práctico en la lógica. Según estos autores, este giro práctico ha de considerarse, sin embargo, en el marco de una transformación más general de la lógica que consiste en poner como objeto de consideración ineludible la relación existente entre los medios cognitivos a disposición de un agente y sus objetivos cognitivos: "desde este punto de vista, un razonamiento es válido sólo en relación a la tarea cognitiva que el razonador se ha fijado y 
a los recursos cognitivos disponibles para su ejecución" (Gabbay y Woods, 2005, p. 18). Parece razonable, pues, sostener que, si la lógica quiere ser una teoría del razonamiento, debe tomar en cuenta las condiciones variables en las cuales el razonamiento ocurre de hecho. Como es sabido, Stephen Toulmin es uno de los autores que, en el siglo XX, son considerados como pioneros en empujar a la lógica a adoptar este giro práctico. Por otro lado, tal como ha quedado de manifiesto en el capítulo 5 de esta tesis, la lógica de Dewey puede ser vista como un antecedente claro, aunque no muy tenido en cuenta, de este giro práctico. En este capítulo, nos detendremos a analizar la relación entre dichos autores.

El libro publicado por Stephen Toulmin en 1958, que lleva por título Los usos de la argumentación (en adelante LUA) ha sido considerado, en efecto, como uno de los pilares del resurgimiento del interés por la reflexión teórica sobre la argumentación en el siglo XX. Si bien los estudios sobre dicho libro y, en general, sobre la posición de su autor, son numerosos (p. ej. Hitchcock, y Verheij, 2006 y Marafioti, y Santibáñez Yáñez, 2010), hay un aspecto de su obra que permanece aún poco analizado y que será objeto de análisis en este capítulo. Se trata de su vínculo con las ideas de Dewey. Este vínculo resulta problemático habida cuenta de que, si bien las referencias a Dewey en el conjunto de la obra de Toulmin son numerosas y a menudo elogiosas, en particular las referencias al filósofo pragmatista en LUA son escasas y de tono crítico pese a que, como se mostrará más adelante, puede sostenerse que la teoría de la argumentación de Toulmin no sólo incorpora, como suele reconocerse, una perspectiva pragmática, sino también una pragmatista. En efecto, si bien se reconoce que la obra de Toulmin incorpora una perspectiva pragmática (Bermejo Luque, 2007), tal señalamiento desatiende la perspectiva pragmatista allí incorporada e incluso ha venido acompañada por la negación explícita de la presencia de esta última (Santibáñez, 2010). 
Este intento de analizar, por decirlo de un modo más general, el vínculo entre la argumentación y su estudio de un lado, y el pragmatismo del otro, resulta relevante por dos razones. En primer lugar, se trata de un asunto poco estudiado, pese a que el resurgimiento mismo de la teoría de la argumentación ha estado ligado de algún modo a la figura de Dewey e incluso al pragmatismo en general. En efecto, tal ligazón se advierte claramente en los dos intereses, uno práctico y uno teórico, que van Eemeren, Grootendorst y Snoeck Henkemans (1996, p. 51) señalan como impulsores de dicho resurgimiento. En lo que hace al interés práctico, más bien de carácter pedagógico, el surgimiento de cursos y estudios sobre lo que suele llamarse "pensamiento crítico" encuentra un fuerte impulso en la idea deweyana, desarrollada en How We Think ${ }^{1}$, de pensamiento reflexivo, aun cuando la reintroducción de cursos de retórica y oratoria tiene, también en Estados Unidos, una historia previa. En efecto, y como mencionan Simon y Walsh, editoras de las obras completas de Dewey, "la publicación inicial de How we Think ha revolucionado la teoría educativa americana al presentar un enfoque práctico de los procesos de pensamiento para los estudiantes en los cursos elementales de lógica" (lw.8.387). Incluso, prosiguen Simon y Walsh, en How We Think Dewey se aleja del "tratamiento teórico formalista de la lógica" (lw.8.387). Por otro lado, el resurgimiento de un interés teórico por la argumentación ha estado signado por una pretensión semejante a la que impulsó a Dewey y a los pragmatistas clásicos: el intento de construir una concepción de la racionalidad que supere los estrechos márgenes a los que la exigencia fundacionista de certeza y necesidad la había confinado. Como hemos mencionado ya, Brandom sostiene que (2011, pp. 35 y ss.) puede pensarse al pragmatismo clásico americano como una segunda ilustración, que confía en la razón como herramienta de transformación, pero en una razón pensada no ya desde el paradigma

\footnotetext{
${ }^{1}$ El texto fue publicado originalmente en 1910 y reimpreso con considerables modificaciones en 1933.
} 
newtoniano de leyes necesarias y universales sino desde el modelo de las explicaciones darwinianas y estadísticas cuya modalidad no es ya la de la certeza y la necesidad, sino la de lo posible y lo contingente. Este alejamiento de la modalidad de lo necesario hacia la modalidad de lo plausible, lo probable y lo contingente está también presente en los dos textos que suelen considerarse como fundacionales de la teoría de la argumentación en el siglo XX, a saber, La nueva Retórica de Chaïm Perelman y Lucie Olbrechts-Tyteca y Los usos de la argumentación de Toulmin. ${ }^{2}$

La segunda razón que motiva este análisis es la siguiente. El pragmatismo, ya desde sus orígenes en Peirce, según hemos visto en la primera parte de esta tesis, se ha esforzado por llevar adelante una reconstrucción de las ideas de conocimiento y racionalidad que dejara atrás definitivamente el fundacionismo. La estrategia principal adoptada por los pragmatistas para llevar a buen puerto tal tarea ha sido la de reconstruir los conceptos clásicos de la filosofía sobre la base de una nueva concepción de la experiencia entendida como una forma de transacción entre el organismo humano y su medio. Se trata, como señala Brandom (2011, pp. 5-9), de una nueva forma de naturalismo. ${ }^{3}$ Especialmente en la obra de Dewey esta estrategia resulta, como vimos, omnipresente, y lo llevó a intentar reconstruir, sobre la base de tal concepto de experiencia, todas las disciplinas filosóficas. Dewey ha escrito obras sobre ética, estética, metafísica, teoría del conocimiento e incluso política en las que el concepto de experiencia y la pretensión de reconstrucción ocupan un lugar fundamental. Sin embargo, y al menos a primera vista, no encontramos en la obra de Dewey un intento por estudiar el fenómeno de la argumentación tomando esta estrategia

\footnotetext{
${ }^{2}$ Además de estos autores, puede mencionarse a Rupert Crawshay-Williams y a Arne Naess como impulsores de este resurgimiento. Para una presentación sucinta de sus ideas véase van Eemeren, Grootendorst y Snoeck Henkemans (1996, cap. 3).

${ }^{3}$ Para una caracterización del naturalismo y de su centralidad para el pragmatismo clásico véase, además del escrito de Brandom mencionado, Bernstein, 1971, cap. 2 y Bernstein, 2010, especialmente p. 20 y ss y la Introducción de Nagel a la Lógica de Dewey (lw.12. ix-xxvii).
} 
como guía, esto es, no encontramos una teoría pragmatista de la argumentación. Lo que sí se encuentra en la obra de Dewey es una lógica entendida como teoría de la investigación que parecería, al menos en una mirada superficial, descuidar la cuestión de la argumentación y de los cánones y criterios a los que la misma se debería ajustar, al menos si entendemos por argumentación el intento de dar razones que justifiquen nuestras opiniones y creencias. La lógica de Dewey, tal como encuentra su expresión más acabada en la Logica de 1938, parece consistir, y así fue mayoritariamente interpretada, en un estudio del método científico. Ahora bien, si, como hemos argumentado, la lógica de Dewey sí puede pensarse como una verdadera lógica, queda abierta entonces la posibilidad de preguntarse por su valor en el campo de la lógica actual, entendiendo además que la lógica no refiere en la actualidad solamente a la creación y estudio de sistemas formales sino también a la teoría de la argumentación y a la lógica informal.

En este contexto, este capítulo se propone echar luz sobre las relaciones entre el pragmatismo, como corriente o escuela filosófica, y el fenómeno y el estudio de la argumentación. Para ello, en primer lugar, será necesario aclarar la relación entre lo que llamaremos una perspectiva filosófica pragmática y el pragmatismo, habida cuenta de cierta confusión al respecto que tiende a ocultar las conexiones entre la teoría de la argumentación y el pragmatismo. En particular, el análisis se centrará en las obras de Dewey, como representante del pragmatismo clásico, de un lado y de Stephen Toulmin, del otro, con el objetivo de mostrar hasta qué punto la propuesta de este último puede considerarse como una continuación del programa filosófico del primero. Para lograr tal objetivo, en primer lugar analizaremos y compararemos los programas de reforma de la lógica propuestos por los mencionados autores para examinar, luego, las referencias del propio Toulmin a Dewey. 
Tales referencias nos permitirán, a su turno, precisar en qué sentido el programa de Toulmin incorpora elementos de la versión deweyana del pragmatismo.

\section{Toulmin y Dewey, entre pragmática y pragmatismo}

El vínculo entre el pragmatismo y la teoría de la argumentación, como mencionamos, ha sido poco estudiado. ${ }^{4}$ Sin embargo, tal vínculo resulta, en alguna medida, reconocido por algunos autores cuyos aportes para la reflexión sobre la argumentación han sido muy importantes. Por una parte, Perelman ha mencionado su admiración por Peirce, el padre del pragmatismo. ${ }^{5}$ Más aun, la idea de auditorio universal contenida en La nueva Retórica y la idea de comunidad indefinida de investigación desarrollada por Peirce resultan, como lo ha señalado K. O. Apel, muy próximas. Por otro lado, las referencias a Dewey en el resto de la obra de Toulmin, es decir, excluyendo LUA, son numerosas e incluso Toulmin ha escrito, en 1984, una introducción muy elogiosa a una de las principales obras de Dewey, a saber, The Quest for Certainty. Por su parte, y para citar un ejemplo más actual, Johnson (2000) ha reconocido la influencia que sobre su enfoque ha ejercido Dewey.

Esta relación parece ser tenida en cuenta por Bitonte y Matienzo (2010), quienes dan por descontado que "el proyecto de Toulmin se inscribe en la línea trazada por dos referentes del pragmatismo de gran influencia en Estados Unidos, Charles. S. Peirce y Ludwig Wittgenstein” (p. 61). Ahora bien, dejando a un lado la cuestión acerca de si puede considerarse que Wittgenstein es un pragmatista, lo cierto es que Toulmin se refiere muy

\footnotetext{
${ }^{4}$ Una de las pocas excepciones es un artículo de Ratner (1992). En este artículo, Ratner argumenta que la posición naturalista o pragmatista respecto de las matemáticas y de la lógica desarrollada por Dewey ha tenido, en autores como Lakatos, Putnam, Kitcher y Toulmin, una notable continuidad.

${ }^{5}$ Véase van Eemeren, Grootendorst y Snoeck Henkemans (1996, p. 95n8)
} 
poco a Peirce ${ }^{6}$ y que cuando habla del pragmatismo suele mencionar a Dewey. Aquella afirmación parece más bien un juicio retrospectivo, que depende de la asimilación de las consideraciones pragmáticas de Wittgenstein con las ideas del padre del pragmatismo y que asocia el proyecto toulminiano más con la pragmática que con el pragmatismo americano propiamente dicho. En ese sentido, por ejemplo, Bermejo Luque afirma que la pragmática es la seña distintiva de la teoría de la argumentación. Desde su punto de vista, "el origen de la disciplina que hoy denominamos teoría de la argumentación está estrechamente vinculado al desarrollo de una perspectiva pragmática sobre un fenómeno, la argumentación (...).” (2007, p. 42). Por su parte, Santibáñez acepta la posición de Bermejo Luque y agrega, luego de recordar atinadamente que cuando Toulmin cita a Dewey, en LUA, lo hace para distanciarse de la posición del pragmatista, que "en un sentido extendido Toulmin es un pragmático, porque es parte de un movimiento centrado en lo práctico, pero en un sentido acotado, y más importante, no lo es porque no considera que la verdad esté determinada por lo útil y lo exitoso" (2010, p. 196). Así, prosigue Santibáñez, "si divorciamos, definitivamente, lo que es el pragmatismo (americano) con lo que es la pragmática, entonces Toulmin en Los usos de la argumentación sería un pragmático" (196197). Nos encontramos, en estas referencias, con sentidos diversos de los términos pragmático y pragmatismo que crean una cierta confusión sobre la que intentaremos, a continuación, echar luz.

Siguiendo a Naishtat (2004, p. 75), podemos establecer una primera distinción entre dimensión y perspectiva pragmáticas. Por dimensión pragmática se entiende uno de los aspectos del lenguaje que pueden ser investigados, y que hace referencia al hablante o usuario de ese lenguaje. Así entendida, la dimensión pragmática puede pensarse como

\footnotetext{
${ }^{6}$ De hecho, en LUA no hay referencias a Peirce.
} 
aquel aspecto del lenguaje, o como aquella parte de su estudio, que se vincula con el contexto de uso. Por otro lado, la idea de perspectiva hace referencia a un punto de vista filosófico sobre el lenguaje. Este punto de vista filosófico que, de acuerdo con Naishtat, habría sido inaugurado fundamentalmente por el segundo Wittgenstein y desarrollado por Austin y Searle, contendría como una de sus ideas principales aquella que sostiene que todo intento de reconstrucción formal (reducida a las dimensiones semántica y/o sintáctica) del lenguaje resulta limitado, y constituye en verdad sólo una aproximación insuficiente a las prácticas lingüísticas. Una perspectiva pragmática en filosofía es, entonces, aquella de acuerdo con la cual todo análisis del lenguaje debe ser un análisis de las prácticas lingüísticas, esto es, un estudio del lenguaje en su contexto de uso. Así, asumir una perspectiva pragmática implica asumir como una idea filosóficamente relevante la idea de que el lenguaje es también una forma de acción, una práctica. Con el lenguaje, o tal vez sea mejor decir en el lenguaje, hacemos cosas, e incluso eso que hacemos es bastante más amplio que el mero constatar o describir.

Ahora bien, esta perspectiva pragmática de ningún modo es ajena a la perspectiva de Dewey. Acaso la muestra más cabal de la incorporación de una perspectiva pragmática en su pensamiento se encuentre en el capítulo V de Experience and Nature, texto publicado por primera vez en 1925 y que es considerado como una de sus obras fundamentales. Allí, Dewey sostiene una serie de ideas acerca del lenguaje que anticipa muchas de las tesis que serán luego desarrolladas por los pioneros de la perspectiva pragmática antes mencionados. ${ }^{7}$ Así, por ejemplo, en la segunda edición del libro, hecha en 1929, Dewey

\footnotetext{
${ }^{7}$ Por ejemplo, como vimos en el capítulo 4, Dewey (lw.8.162) rechaza la idea de que todas las proposiciones que toman parte en la investigación sean meramente declarativas de lo que "existe o subsiste con anterioridad a ellas" e insiste en la idea de que toda investigación involucra juicios prácticos que no se limitan a enunciar lo que sucede sino que constituyen verdaderas herramientas en su modificación. Asimismo, Dewey (lw.1.132-162) afirma la prioridad de la conversación con los demás por sobre el soliloquio privado, afirmando con ello ideas muy próximas a la conocida tesis wittgensteiniana
} 
cierra el capítulo sobre "Naturaleza, comunicación y significación" con una cita de Malinowski que, desde su punto de vista, afirma con mucha fuerza y mucha claridad las siguientes ideas que Dewey hace suyas: (a) el lenguaje es un modo de acción; (b) para entender el lenguaje hay que restablecer el contexto social completo, puesto que es lo único que puede dotar al lenguaje de significado; (c) el uso descriptivo o constatativo del lenguaje es una función derivada y no la que expresa su naturaleza (lw.1.160-161). Esta clara incorporación de una perspectiva pragmática sobre el lenguaje al interior de la perspectiva de Dewey, lejos de ser sorpresiva, resulta profundamente coherente con, e incluso parece ser una aplicación de, algunas de las ideas y presupuestos metodológicos que impregnan la totalidad de la obra de Dewey. Como se mencionó anteriormente, Dewey es un naturalista. Tal naturalismo encuentra su máxima expresión en lo que Dewey mismo llama el principio de continuidad, que postula que hay una continuidad entre las actividades biológicas y aquellas involucradas en la investigación y el pensamiento reflexivo. Esta continuidad, en palabras de Dewey, “excluye, por un lado, la ruptura completa y, por otro, la mera repetición de identidades; excluye la reducción de lo superior a lo inferior no menos que la existencia de hiatos completos" (1w.12.30). ${ }^{8}$ Esto implica, como hemos dicho ya, que toda facultad o capacidad humana es un modo de conducta forjado por el animal humano en su continua interacción con el ambiente. Así, el lenguaje es un producto de la comunicación, entendida como una forma de interacción entre los seres humanos en y con su entorno. Este principio de continuidad implica también, como señala Nagel (lw.12.xi), un principio de análisis contextual de acuerdo con el cual la distinción entre proceso y producto es tal que ninguno puede ser entendido con independencia del otro. En este sentido, el significado y el

sobre la imposibilidad del lenguaje privado. Para una comparación entre Dewey y Wittgenstein veáse el prólogo de Hilary Putnam a Goodman (1983).

${ }^{8}$ Traducción de José Gaos. Dewey (1952, p. 37) 
lenguaje mismos no pueden ser entendidos sin tener presente el proceso mediante el cual cobran existencia. En términos generales, el lenguaje debe analizarse teniendo en cuenta el contexto comunicativo, la comunidad en la que encuentra lugar. De este modo, resulta claro que la perspectiva pragmática antes explicitada no sólo está presente en la obra de Dewey sino que incluso resulta profundamente coherente con los aspectos centrales de la filosofía del pragmatista antes mencionados.

Que la obra de Toulmin incorpora una perspectiva pragmática es algo que, como vimos, está fuera de discusión. El título mismo de su primer libro sobre argumentación es ya una clara señal de ello, así como también su insistencia en la importancia de la evaluación práctica de los argumentos y la noción misma de campo. Más aun, la idea de Toulmin de que las ambiciones formalistas de la lógica tuvieron como contrapartida el abandono del problema práctico acerca de la evaluación de argumentos, y su consiguiente intento por recuperar tal problema, pueden entenderse como un llamado a (re)introducir consideraciones pragmáticas en el estudio de la argumentación. Ahora bien, es claro que la mera presencia en dicha obra de una perspectiva pragmática en el sentido antes explicitado no convierte a su autor en un pragmatista, aunque acaso constituya un indicio de ello. No obstante, y como se argumentará en la sección siguiente, los programas de reforma de la lógica propuestos por Dewey y por Toulmin exhiben algunos significativos puntos de encuentro.

Antes de realizar esta comparación resulta oportuno decir algo más acerca del sentido del término pragmatismo. Como se mencionó anteriormente, Santibáñez afirma que Toulmin no es un pragmatista, en el sentido acotado del término. Tal caracterización es 
tomada por Santibáñez de Brandom (2005). ${ }^{9}$ Es importante señalar, sin embargo, que la caracterización de la perspectiva pragmatista con una concepción de la verdad como utilidad resulta demasiado estrecha aun cuando pueda hallar cierto apoyo en los escritos de los pragmatistas clásicos. Por nuestra parte, no seguiremos a Brandom en ello. La razón radica en que, por un lado, como lo explicita Putnam (2005) en su crítica a Brandom (2005), hay muchos elementos para cuestionar que los pragmatistas hayan sostenido una tal teoría de la verdad. ${ }^{10}$ Por otro lado, el concepto amplio de pragmatismo, tal como es presentado por Brandom (2005), queda ligado más bien a la pragmática y refiere a una posición en filosofía contemporánea que incluye a autores como Heidegger y Wittgenstein, entre otros, y no a un punto de vista propio de los pragmatistas clásicos americanos, entre los que contamos a Dewey, cuya proximidad con la propuesta Toulmin es objeto de análisis en este capítulo. Brandom (2011, Introducción y cap. 1) ofrece también una visión del pragmatismo clásico americano más amplia, de acuerdo con la cual la teoría de la verdad como utilidad sería sólo una estrategia de los pragmatistas para cumplir con un programa más amplio, que incluye la ya mencionada versión pragmatista del naturalismo junto con la nueva concepción de la razón ilustrada antes referida. En la sección siguiente se explicitarán, entonces, algunos puntos de contacto entre el programa de Toulmin y la versión deweyana del pragmatismo americano clásico.

\footnotetext{
${ }^{9}$ Reimpreso también en Brandom (2011, cap. 2).

${ }^{10}$ Para una crítica de la interpretación habitual de la concepción pragmatista de la verdad véase, además del texto recién mencionado de Putnam (2005), Faerna (1996, pp. 134- 151).
} 


\section{Toulmin y Dewey, una comparación programática}

Resulta oportuno recordar que en el momento de la publicación de LUA Toulmin no creía estar sentando las bases para el desarrollo de una nueva disciplina llamada teoría de la argumentación. Antes bien, el libro de Toulmin se presenta como un intento por reformar la lógica misma, motivado por el abandono, por parte de la lógica formal, de una de sus legítimas pretensiones. Según señala nuestro autor, la lógica, desde el momento mismo de su fundación en los trabajos de Aristóteles, llevaba consigo una doble pretensión, a saber, la de ser una ciencia y la de decir algo acerca del modo en que los hombres establecen sus conclusiones. De acuerdo con Toulmin, la lógica se volvió una disciplina formal para satisfacer su pretensión de constituirse en ciencia, abandonando con ello la pretensión de decirnos algo acerca del modo en que los seres humanos, en sus vidas y sus prácticas, establecen sus conclusiones. ${ }^{11}$ Frente a esto, Toulmin propone un programa filosófico que permita reorganizar la lógica para satisfacer ambas pretensiones. En este contexto, de acuerdo con Toulmin, resulta fundamental considerar la cuestión de la "evaluación práctica de los argumentos" (2007, p. 18) o "la evaluación critica de argumentos reales" (2007, p. 19). En otros términos, se trata de reformular la pregunta acerca de la relación entre la lógica como disciplina y aquello que está por fuera de ella pero que, se supone, forma de algún modo su objeto de estudio, esto es, la argumentación. En palabras de Toulmin, se trata de reformular la pregunta acerca de "cómo se aplican éstos [los descubrimientos de la lógica] en la práctica, y qué relaciones tienen con los cánones y los métodos que se usan

\footnotetext{
${ }^{11}$ Esta afirmación de Toulmin se vuelve cuestionable a la luz de los desarrollos de las lógicas derrotables y condicionales, que pretenden modelar algunos aspectos del razonamiento de sentido común. Al respecto véase Palau (2003)
} 
cuando, en la vida diaria, evaluamos la validez, la fuerza y el carácter concluyente de los argumentos" (2007, pp. 17 y 18).

En la conclusión de su libro, Toulmin explicita tres principios que, en caso de que su crítica a la lógica resulte adecuada, deberían adoptarse como ejes para su reorganización. En primer lugar sostiene la necesidad de generar un acercamiento entre la lógica y la epistemología. Esta necesidad se explica como sigue: si la epistemología se aleja de las cuestiones más propiamente psicológicas que se había planteado en la modernidad y si, por otro lado, la lógica deja de tener a la matemática pura como su modelo y como canon del razonar, resulta claro que, en palabras de Toulmin, “el objeto apropiado de ambas es el estudio de las estructuras de nuestra argumentación en campos diferentes y la explicación clara de la naturaleza de los valores y defectos típicos de cada clase de argumento" (2007, p. 321). El segundo de los principios es el que resalta la importancia del método comparativo, esto es, la importancia de comparar los argumentos de los distintos campos, de modo tal que pueda advertirse cuáles son los aspectos que varían de un campo a otro y cuáles son los que no. Lo fundamental respecto de este segundo principio es que nos recuerda que los criterios que permiten determinar la validez de los argumentos son dependientes de los campos, y con ello nos alerta frente a la extrapolación ilegítima de criterios de validez de un campo a otro. El tercer principio sostiene la necesidad de reintroducir consideraciones históricas, empíricas y antropológicas en el estudio de la argumentación. Si pretendemos que la lógica nos diga algo acerca de las formas reales de argumentación, deberá asumir un punto de partida declaradamente empírico. También habrá que incorporar una dimensión histórica, que nos permita ver de qué modo las 
maneras de argumentar y los estándares mismos de relevancia y prueba han cambiado a lo largo de la historia de los diferentes campos.

Estos aspectos de la propuesta de Toulmin resultan sorprendentemente próximos a los lineamientos que Dewey había trazado en sus investigaciones lógicas, que toman su forma más acabada en la Lógica de 1938. El título mismo de la obra es una señal clara del vínculo entre lógica y epistemología. De acuerdo con Dewey, conocimiento es el nombre con que nos referimos al producto de la investigación. Por otro lado, la lógica, en tanto estudio de los principios y normas de la inferencia y del razonamiento, debe proceder analizando precisamente las formas lógicas, para decirlo en términos de Dewey, tal como se originan y se usan en la investigación. El término investigación tiene en el uso de Dewey, cabe recordar, un gran alcance, y cubre no sólo los casos propios de la investigación científica, sino también todo caso de conducta inteligente y de pensamiento reflexivo. Así, si bien Dewey señala las importantes diferencias entre la investigación científica y, por así decirlo, la investigación de sentido común o pensamiento reflexivo, argumenta que ellas exhiben una pauta, patrón o estructura común, cuyo estudio compete al lógico. Por otro lado, desarrolla una concepción de los principios o formas lógicas, como vimos en el capítulo 5, de acuerdo con la cual tales principios son resultados de la investigación; son un subproducto suyo que, debido a las consecuencias que conllevan para la investigación misma, adquieren un carácter normativo. Como resulta evidente, esta concepción de los principios lógicos -de las formas de inferir y razonar que ocurren en la investigación- los coloca claramente bajo la lupa del estudio empírico y en la historia, en tanto y en cuanto abre la necesidad de estudiar las formas en que de hecho infieren y razonan quienes investigan, y la posibilidad de estudiar sus cambios a lo largo del tiempo. Nótese que se trata de un llamamiento, similar al de Toulmin, a reformular la pregunta por 
la relación entre la lógica y aquello que está por fuera suyo pero que constituye su objeto de análisis, a saber, la investigación entendida como forma de la acción que, en tanto que tal, resulta accesible al estudio empírico. Se trata de que los lógicos formulen sus hipótesis y principios viendo de qué modo se desarrolla de hecho la práctica de la investigación.

Este carácter empírico es central en la versión deweyana del pragmatismo. Resulta sugerente que este aspecto del pragmatismo deweyano sea precisamente el que Johnson (2000) reivindica como una forma de dar respuesta al problema de la brecha entre la lógica como teoría de la argumentación y la práctica. Como señala Johnson, para Dewey, un método de filosofar empírico, aquel por el que el pragmatista abogó, tiene que ser capaz de usar aquello que produce, esto es, sus teorías y conceptos, como un camino que lleve de vuelta a algo en la experiencia primaria, a las cosas de la experiencia ordinaria. Esto constituye un verdadero test para determinar el valor de una teoría cualquiera. Así, una buena filosofía, de acuerdo con Dewey (lw.1.40), es aquella que, al volver sobre las cosas de la vida ordinaria, las ilumina, las hace más comprensibles y significativas e incluso aquella que sirve como una herramienta en su mejoramiento. De acuerdo con Dewey, "el asunto importante es que los filósofos han negado que la experiencia común es capaz de desarrollar desde dentro métodos que aseguren su dirección y creen estándares inherentes de juicio y valoración” (lw 1.41).

Así, y como señala Johnson, "Dewey parece sugerir que podríamos generar, desde nuestra experiencia de argumentación y desde la reflexión sobre ella, los necesarios estándares y valores para su evaluación” (2000, p. 367). En este sentido, prosigue Johnson, la lógica informal puede ser vista como un intento por seguir la dirección señalada por tal “enfoque empírico". En sus palabras: 
Una manera de entender la significación de la lógica informal es verla como un intento de satisfacer el test de Dewey, desarrollando una teoría más aplicable a la experiencia de la vida ordinaria y que busca iluminar más que despreciar tal esfera (2000, p. 367).

Así, como queda de manifiesto, los lineamientos primero y tercero de la propuesta de Toulmin encuentran una clara expresión en la lógica de Dewey. En lo que hace al segundo de dichos lineamientos, la cuestión resulta más problemática. Mientras la posición de Toulmin parece francamente coherente con una posición pluralista en lógica, de acuerdo con la cual en diversos contextos pueden valer diversos principios lógicos, en el caso de Dewey las cosas no resultan tan sencillas. Para poner un ejemplo, mientras que desde el punto de vista del pluralismo lógico puede sostenerse que hay ciertos contextos en que el principio clásico de no contradicción no se satisface, Dewey afirma explícitamente que tal principio formula un postulado ideal de la investigación, esto es, de toda investigación. No obstante ello, es importante recuperar aquí el concepto de situación, en el que nos hemos detenido ya. Resulta pertinente mencionar que, para Dewey, la situación es siempre una situación única y que la investigación o el pensamiento reflexivo es un modo de conducta que reacciona, por así decirlo, frente a una situación que se presenta como indeterminada o problemática. Además, el tipo de respuesta que resulte adecuado dependerá de cómo sea la situación misma y de cómo estén relacionados sus diversos componentes. En otros términos, la investigación es dependiente del contexto. Nos encontramos así con que, por un lado, hay principios lógicos que rigen para toda investigación mientras que, por otro lado, la investigación es contexto-dependiente. Acaso no resulte errado afirmar que nos encontramos aquí con un señalamiento similar al de Toulmin respecto de la existencia de aspectos de la argumentación o la investigación que son dependientes de los campos y de 
otros invariables. Por otro lado, cabe mencionar que, en tanto que esos principios de los que habla Dewey tienen un carácter ideal, no resulta exigible para toda investigación en todo contexto que se adecue efectivamente a ellos. Si lo que hemos argumentado es correcto, resulta que las posiciones de Toulmin y Dewey respecto de esta cuestión son convergentes aun cuando puedan divergir en cuanto a cuáles son los elementos invariables respecto al campo.

Podemos afirmar, para concluir esta sección, que el programa de reorganización de la lógica de Toulmin resulta claramente compatible con el programa deweyano de reforma de la lógica. Incluso podríamos afirmar que aquel resulta una nueva versión de éste. No obstante ello, y como mencionamos antes, Toulmin mismo, al menos en LUA, no parecía pensar lo mismo, e incluso toma una clara distancia respecto de la propuesta de Dewey. Habida cuenta de esto, pasaremos en la próxima sección a analizar la recepción de la lógica de Dewey en la obra de Toulmin.

\section{Toulmin lector de Dewey}

Que Toulmin conoce la obra de Dewey, e incluso que esta ha tenido un gran impacto en él, es algo que queda fuera de discusión. Pueden encontrarse referencias a Dewey a lo largo de toda la obra de Toulmin, e incluso, aunque escasas, en su The Place of Reason in Ethics de 1950. Por el contrario, en el libro de Toulmin de 1990, Cosmópolis, pueden encontrarse varias referencias al filósofo pragmatista e incluso puede verse a la obra misma, al menos en parte, como una discusión con la interpretación deweyana de la filosofía moderna. Dado el asunto que nos ocupa en esta investigación es importante señalar que Toulmin se ha 
referido explícitamente también a la obra lógica de Dewey, e incluso en términos claramente elogiosos. Así, por ejemplo, en uno de sus escritos, Toulmin (2006) comienza con unas palabras de gratitud hacia Dewey. Afirma que el libro de Dewey Essays in Experimental Logic, a pesar del desdén con que fue tomado por sus colegas británicos, tiene muchos méritos:

Mucho antes que la mayoría de nosotros, [Dewey] vio la necesidad de considerar cómo el razonamiento entra, no sólo en la vida técnica, sino también en la cotidiana, de tal modo que las maneras en que nos expresamos y -más importante- las actividades en que nos expresamos, preparan el escenario sin el cual los juicios de solidez y aceptabilidad nunca podrían ser formulados o puestos a trabajar (2006, p. 25).

De esta manera, vemos que Toulmin parece reconocer en Dewey, al menos en parte, los lineamientos programáticos para el estudio de la argumentación antes explicitados. En efecto, encontramos ese mismo reconocimiento y de un modo mucho más elaborado en la introducción al libro de Dewey The Quest for Certainty que Toulmin escribió en 1984. En este escrito, que constituye una clara reivindicación de Dewey como uno de los grandes filósofos del silgo XX, a la par de Heidegger y Wittgenstein, Toulmin señala lo que a su juicio son las dos grandes movidas o avances contenidos en la obra de Dewey, vista esta desde el punto de vista de la historia de la filosofía. Se trata de una "movida" (o tal vez podríamos decir un giro), escéptica ${ }^{12}$ y una "movida" o giro hacia el estudio del

\footnotetext{
${ }^{12}$ Hemos mencionado ya que parece haber cierta discrepancia en cuanto a la consideración del pragmatismo como escéptico o anti-escéptico. Mientras Putnam, como hemos mencionado, considera al pragmatismo como anti-escéptico, Toulmin lo considera escéptico. Claramente, aunque parezca extraño, las caracterizaciones son compatibles: para Putnam, el pragmatismo es anti-escéptico porque afirma la posibilidad del conocimiento, mientras que para Toulmin el componente escéptico tiene que ver con el rechazo al ideal platónico de conocimiento, es decir, más bien con un anti-fundacionalismo. Es esta combinación, la de antifundacionalismo y anti-escepticismo, lo que resultaba, para Putnam, el mayor aporte del pragmatismo en relación a la teoría del conocimiento.
} 
razonamiento práctico. Al hablar de escepticismo, Toulmin se refiere a pensadores como Pirrón y Sexto Empírico, cuyas críticas estaban dirigidas al ideal platónico de conocimiento (episteme) y cuyos seguidores en la historia de la filosofía se habrían centrado, una vez rechazado aquel ideal, en la diferencia entre opiniones bien fundadas y opiniones sin sustento (y no ya entre doxa y episteme). Así, de acuerdo con Toulmin, este escepticismo avanza hacia el estudio de la retórica o del razonamiento práctico.

Nótese que estos dos pasos o movidas que describe Toulmin son precisamente aquellos que él mismo había bosquejado en LUA. Más aun, son estos dos movimientos, primero hacia el escepticismo, y luego, como consecuencia suya, hacia el estudio del razonamiento práctico, los que atribuye a las obras de Dewey, La búsqueda de la certeza y Ensayos en Lógica Experimental, respectivamente. Esta última obra, afirma Toulmin, complementa, con su teoría sobre el razonamiento (reasoning), el estudio sobre el pensamiento (thinking) llevado a cabo en la primera. Así, "el escéptico en Dewey rechaza todo modelo a priori sobre el conocimiento, (...); mientras el pragmatista en él encuentra la materia primera para la teoría del conocimiento en las prácticas reales de razonamiento de los pensadores humanos" (1984, p. 8). Es interesante señalar que, de acuerdo con Toulmin, esta mitad pragmatista de Dewey lo lleva a ubicarse en la tradición de los sucesores de los Tópicos de Aristóteles. Como es sabido, en más de una oportunidad se ha señalado que LUA pertenecen a esa misma tradición, aun cuando, y en palabras del propio Toulmin, sea ese un vínculo que él mismo no haya vislumbrado sino hasta algunos años después de publicar su libro (2006, p. 26). Nótese que Toulmin considera como el aspecto específicamente pragmatista de Dewey aquel que lo lleva a estudiar las prácticas reales de 
razonamiento como material de análisis para la teoría del conocimiento, en la misma dirección señalada, según vimos, por Johnson (2000).

Hasta aquí resulta muy claro, entonces, que el programa de investigación sobre el conocimiento y el razonamiento que Toulmin atribuye a Dewey es el mismo, o al menos uno muy similar, al que él mismo había bosquejado en 1958. No obstante ello, en LUA, encontramos que Toulmin reconstruye una serie de maneras de entender la lógica, una de las cuales atribuye a Dewey, y se distancia luego de todas ellas proponiendo la idea de hacer de la lógica jurisprudencia generalizada. Así, de acuerdo con Toulmin, la lógica deweyana sería algo así como una sociología que estudia "los hábitos y prácticas desarrollados en el curso de la evolución social” (2007, p. 20). Estos hábitos de inferencia, prosigue Toulmin, comenzarían siendo mera costumbre, pero con su desarrollo se convertirían en "obligatorios". La tarea de este sociólogo-lógico sería estudiar, así, no todos los hábitos de inferencia, sino sólo aquellos que resultan apropiados o racionales. Un poco más adelante, señala que la posición de Dewey tiene un mérito: recuerda que si, por ejemplo, queremos estudiar la lógica de la física, debemos tener en cuenta la estructura de los argumentos empleados por aquellos que hacen física. De acuerdo con Toulmin, ello da plausibilidad a la idea de Dewey acerca del modo en que las inferencias habituales llegan a ser forzosas. Pero, prosigue, "no puede ser sólo la costumbre lo que dé validez y respaldo a la forma de un argumento, o el lógico habría de aguardar para realizar su tarea a los resultados de la investigación de los antropólogos” (2007, p. 22).

Cabe recordar que, como hemos dicho en el capítulo 5, desde el punto de vista de Dewey no es la mera costumbre lo que da carácter normativo a un hábito de inferencia, sino más bien los rendimientos, las consecuencias que acarrea para la investigación. En otros términos, hay razones por las cuales un hábito de inferencia adquiere carácter normativo, 
razones que van más allá de la mera costumbre. Así, por ejemplo, en How We Think afirma que algunas maneras de pensar "son mejores que otras y se pueden enunciar las razones por las cuales son mejores" (1w.8.113). Un hábito de inferencia adquiere un carácter normativo si resiste el peso de ulteriores investigaciones y se abandona, no simplemente cuando produce conclusiones que luego se muestran erróneas, sino cuando se advierte que hemos llegado a conclusiones erróneas en virtud de ese hábito. Así, en el transcurso de la investigación, "se hallaron métodos de investigación de tal condición que la persistencia en ellos no sólo aportaba conclusiones que resistían el peso de investigaciones ulteriores sino que tendían a ser auto-correctivos. Se trataba de métodos que mejoraban en y por el uso" (lw.12.14). ${ }^{13}$ De acuerdo con Dewey, así como los procedimientos y métodos de la industria son creados y/o mejorados en el curso mismo de su desarrollo, así también los hábitos de inferencia son generados y corregidos en el curso de la investigación, y en esta capacidad de resistencia y de auto-corrección radica la razón en virtud de la cual adquieren carácter normativo.

Por otro lado, resulta sorprendente que Toulmin señale como uno de los problemas de esta propuesta que el lógico deba esperar a los resultados de la investigación de los antropólogos, habida cuenta de que la inclusión de consideraciones históricas y antropológicas es uno de los principios para la reorganización de la lógica formulados por él mismo en la conclusión de su libro. Esta tensión acaso obligue a repensar esos pasajes en los que Toulmin reconstruye y critica la posición de Dewey. En dichos pasajes, Toulmin reconstruye de modo secuencial cuatro posiciones acerca del tipo de ciencia que se supone que es la lógica, y a partir de las limitaciones de cada una construye la siguiente. Así, podría pensarse que las críticas a Dewey no son realizadas desde el punto de vista de

\footnotetext{
${ }^{13}$ Traducción de Imaz, en Dewey (1950, p. 18).
} 
Toulmin sino de la visión matemática o incluso técnica de la lógica, que a su turno Toulmin rechaza oponiéndole su modelo jurisprudencial. Sin embargo, aunque no podamos tomar de un modo literal las críticas a Dewey contenidas en la introducción a LUA, con todo resulta inobjetable que, lejos de reivindicar la propuesta de Dewey, Toulmin ofrece una propia que se opone también a aquella.

A pesar de esta distancia, como vimos, con posterioridad a la publicación de LUA Toulmin parece reconocer que el programa que él mismo se había propuesto se dirigía en la misma dirección que el de Dewey. Incluso es posible encontrar en la obra de éste último pasajes que contienen distinciones muy próximas a algunas de las contenidas en LUA. Por ejemplo, en la sección 2 del primer capítulo de How We Think Dewey distingue tres componentes básicos de lo que llama pensamiento reflexivo. El pensamiento reflexivo es aquel en que una cosa es sugerida o inferida a partir de otra, pero de modo tal que el pensamiento se detiene en analizar hasta qué punto aquello a partir de lo cual inferimos resulta una garantía de aquello que es inferido. Así, nos encontramos con aquello que es inferido, con aquello a partir de lo cual inferimos (fundamentos, hechos, grounds) y con la conexión entre ellos. Sin que se establezca una verdadera conexión entre el fundamento y lo inferido no estamos en presencia del pensamiento reflexivo sino de una mera sugerencia. El pensamiento reflexivo comienza, de hecho, cuando se indaga qué es lo que hace que una cosa sea el fundamento de otra, esto es, cuando se trata de ver "qué garantías hay de que los datos existentes señalen realmente la idea sugerida, de modo tal que justifique la aceptación de esta última" (lw.8.119). Aun cuando esta descripción del pensamiento reflexivo tenga algunas diferencias relevantes con la idea de argumento analizada por Toulmin, que explicitaremos en la sección siguiente, la proximidad con la distinción entre fundamentos o 
datos y garantía o ley de pasaje, elementos del así llamado modelo de Toulmin, resulta clara. Incluso los términos grounds y warrants son usados en dicho capítulo.

\section{Investigación y argumentación}

Como se mencionó antes, no se encuentra en la obra de Dewey algo indiscutiblemente equiparable a una teoría de la argumentación en un sentido actual. A pesar de ello, hemos sostenido que la teoría de la argumentación de Toulmin recupera y desarrolla diferentes aspectos de la propuesta de reforma de la lógica de Dewey. Como hemos visto, Toulmin reconoce en la necesidad de estudiar la práctica real de la argumentación o, para decirlo en términos de Dewey, los hábitos de inferencia o el pensamiento reflexivo, el componente específicamente pragmatista en Dewey. Además, el rechazo a la idea de que un enfoque exclusivamente formal pueda dar cuenta del fenómeno de la argumentación o del pensamiento reflexivo está presente en ambos autores. De este modo, resulta que la teoría de la argumentación de Toulmin podría entenderse como un modo renovado de llevar a cabo el programa deweyano de reforma de la lógica, es decir, como una teoría pragmatista de la argumentación. Sin embargo, aquí puede surgir la siguiente objeción: el concepto de argumentación, tal como se entiende en Toulmin, y en gran parte de la teoría de la argumentación contemporánea, supone un medio lingüístico y tiene además un sentido retrospectivo, de acuerdo con el cual la argumentación es el intento de justificar o dar razones que avalen nuestras afirmaciones. A diferencia de ello, la idea deweyana de pensamiento reflexivo, en tanto que idea relevante para la lógica, parece asociarse más bien a una posición psicologista previa, por así decirlo, al giro lingüístico de la filosofía del siglo 
XX. Por otro lado, el concepto de investigación parece tener un alcance mucho mayor al de argumentación. Investigación suele referir a esa actividad o proceso mediante el cual obtenemos o producimos conocimiento. Para usar una vieja distinción, mientras la idea de argumentación parece circunscribirse al así llamado contexto de justificación, la idea de investigación, e incluso de la de pensamiento reflexivo, parece estar más bien vinculada con el contexto de descubrimiento. Si estas objeciones son correctas, la teoría de la argumentación de Toulmin constituiría una severa corrección, antes que una continuación, de la lógica de Dewey.

Para responder a estas objeciones es preciso tener en cuenta, en primer lugar, que lo que Dewey llama pensamiento reflexivo o investigación es una forma de acción. Es decir, el pensamiento reflexivo, al igual que la investigación, no es algo que ocurre simplemente en las mentes de los seres humanos, sino que es una forma de interacción entre el animal humano y su ambiente, generada y modificada en el curso de la vida misma. Mientras que pensamiento reflexivo es el nombre que Dewey usa para referirse a esa forma de conducta tal como se da en la vida cotidiana, el término investigación se asocia comúnmente con la actividad científica. En otros términos, pensamiento reflexivo es el nombre mediante el cual nos referimos a la investigación de sentido común. La investigación y el pensamiento reflexivo, en tanto que formas humanas de interacción, suponen el lenguaje. A su vez, el lenguaje no se limita a ser el vehículo de expresión de un significado, sino que lo crea. En palabras de Dewey:

Una vez que tienen un nombre llevan los acontecimientos una vida independiente y doble. Además de su existencia original quedan sujetos a una experimentación ideal: sus significaciones pueden someterse a infinitas combinaciones y nuevas disposiciones en la imaginación, y el resultado de 
esta experimentación interna -que es el pensamiento- puede proseguir en interacción con los acontecimientos nudos o crudos (lw.1.132).

Esta cita da clara muestra de que, desde el punto de vista de Dewey, el pensamiento supone al lenguaje, y de que esa experimentación interna no sólo es lingüística, sino que puede proseguirse como forma de interacción con los acontecimientos mismos. Más aun, el pensamiento reflexivo, en tanto diferente de la mera fantasía, y la investigación, en tanto diferente de la mera especulación, suponen esa prosecución de la interacción. La investigación y el pensamiento reflexivo son procesos que suponen el lenguaje y que no pueden reducirse a meros procesos mentales subjetivos, sino que son formas de interacción orgánicas que suponen por ello mismo un sujeto y un medio en interacción. Son formas de la conducta inteligente, tipos de respuesta que los seres humanos hemos desarrollados para habérnoslas con las situaciones problemáticas que se nos presentan.

La segunda de las objeciones anticipadas resulta, en cambio, más significativa. Los términos argumentación e investigación no sólo tienen alcances diferentes, sino que incluso el primero, en el uso de Toulmin, adquiere un sentido bien delimitado. El estudio de Toulmin se auto-limita a lo que llama argumentos justificatorios (2007, p. 30), entendiendo que, si bien hay otros usos o funciones de los argumentos, la justificación o defensa de afirmaciones sólidas es su función primaria, siendo las restantes derivadas. De acuerdo con esta idea de argumento justificatorio, la situación básica que el teórico de la argumentación debe tener presente es una en que un sujeto intenta dar razones para sostener una afirmación que ya ha sido formulada, al menos implícitamente. En efecto, algo así parece desprenderse de la siguiente cita de Toulmin: 
Imaginemos, por tanto, que alguien ha realizado una aseveración y que el respaldo que ha expuesto en su apoyo ha sido puesto en entredicho. La pregunta entonces es: ¿cómo puede elaborar un argumento en defensa de la aseveración original?, ¿cuáles son los modos o la crítica y la evaluación apropiados para considerar los méritos del argumento que está presentando? (2007, p. 30).

A diferencia de esto, tanto el pensamiento reflexivo como la investigación son entendidos como procesos mediante los cuales llegamos a una conclusión y no como el proceso mediante el cual damos razones que justifiquen la conclusión a la que ya hemos arribado. En términos de Dewey, la investigación comienza con la duda, es decir, comienza al presentársenos una situación problemática, y finaliza con el establecimiento de la creencia, o mejor de una aserción garantizada. Esto es, la conclusión no tiene por qué estar disponible desde el comienzo mismo del proceso, y si bien muchas veces lo está, constituye una hipótesis que será rechazada, validada o modificada y no una creencia. La investigación no es el proceso de justificación de una creencia de la que ya disponemos, sino el proceso de elaboración de aseveraciones garantizadas. Cabe mencionar, además, que desde el punto de vista de Dewey la distinción entre justificación y descubrimiento, aquí supuesta y que tiende a separar el conocimiento o la creencia del proceso de investigación, no sólo resulta cuestionable sino que es una de las causas de la confusión que, desde su punto de vista, reinaba en la lógica. En palabras de Dewey:

la idea de que se puede establecer cualquier conocimiento particular con independencia de que sea la consumación de una investigación y que el conocimiento en general se puede definir aparte de esta conexión, constituye una de las fuentes de la confusión que reina en la teoría lógica (lw.12.16). 
Cabe mencionar que, en este punto, la posición de Dewey resulta, al menos desde el punto de vista de la teoría del conocimiento, más actual que la expresada por Toulmin en LUA, habida cuenta de que la distinción entre contexto de descubrimiento y justificación ha sido, en gran medida, abandonada (Marcos, 2000).

Nos encontramos aquí con una diferencia que no puede ser reducida, y que incluso marca una divergencia entre las ideas lógicas de Dewey, de un lado, y las de Toulmin y otros teóricos de la argumentación contemporáneos, del otro. Acaso un modo de apuntar tal diferencia sea señalar que el objeto de estudio que reclama para sí la teoría de la argumentación contemporánea es otro que el que Dewey proponía para su lógica. El objeto de estudio construido por la teoría de la argumentación es, más bien, la situación en que un sujeto posee ya una tesis o conclusión pre-fabricada y busca la manera mejor, correcta o adecuada para lograr que otros la acepten. Esa idea está presente, también, en la definición de Perelman y Olbrechts-Tyteca de la argumentación como el intento de influir en el grado de adhesión a una tesis por parte de un auditorio. Lo mismo ocurre en el modelo pragmadialéctico. Para intentar resolver una diferencia de opinión, lo primero que hay que establecer es que hay de hecho una diferencia de opinión, para lo cual resulta necesario establecer cuál es o cuáles son los puntos de vista en juego. Por su parte, la analogía jurídica de Toulmin refuerza este mismo supuesto: quien se presenta a litigar tiene ya una determinada pretensión que intentará justificar frente al jurado. En palabras de Toulmin, efectivamente, la lógica trata no de la manera en que inferimos ni sobre cuestiones de técnica: su objetivo principal es retrospectivo y justificatorio, pues trata de los argumentos que pueden esgrimirse a posteriori con el fin de apoyar nuestra pretensión de que las conclusiones a las que hemos llegado son conclusiones aceptables porque pueden justificarse (Toulmin, 2007, p. 23). 
En este sentido, tal vez el factor determinante del resurgimiento de la teoría de la argumentación en el siglo $\mathrm{XX}$, y de su constitución como disciplina más o menos autónoma, sea el de haber recortado o recuperado el fenómeno de la argumentación así entendido como objeto de análisis para la lógica y la filosofía. Así, el trabajo de Dewey parece resultar previo, en un sentido que va más allá de la cuestión meramente cronológica, al resurgimiento de la teoría de la argumentación en el siglo XX.

\section{Conclusiones}

De acuerdo con lo que hemos desarrollado en este capítulo, resulta que, aun cuando cabe trazar una distinción entre una perspectiva pragmática y una pragmatista, la distinción no debe implicar que la atribución de una de ellas a un autor sea una razón para la exclusión de la otra. Antes bien, la perspectiva pragmatista de Dewey parece incluir como uno de sus componentes una perspectiva pragmática acerca del lenguaje. Así, habiendo reconocido la presencia de una perspectiva pragmática en la teoría de la argumentación de Toulmin, quedó abierta la pregunta acerca de su compromiso con una perspectiva pragmatista. En esta dirección, hemos argumentado que en lo que hace a los lineamientos programáticos para la transformación de la lógica hay una proximidad muy significativa en las propuestas de Dewey y Toulmin. Más aún, como hemos visto, en su introducción al libro de Dewey, Toulmin le atribuye un programa muy similar al suyo, pese a que cuando escribe y publica LUA no reconozca su filiación pragmatista y deweyana. Incluso, como argumentamos, cuando busca diferenciarse de Dewey, lo hace al costo de ofrecer una interpretación, al menos, cuestionable de las ideas lógicas de Dewey. Las semejanzas van incluso un poco 
más allá de los lineamientos programáticos, dado que, como vimos, la propia diferencia entre datos y garantía, desarrollada por Toulmin, encuentra antecedentes relevantes en la obra de Dewey. Esta filiación resulta en alguna medida reconocida tardíamente por el propio Toulmin. Acaso no sea errado suponer que al momento de la publicación de LUA su autor haya caído presa de los mismos prejuicios y el mismo desdén que, en sus palabras, sus colegas británicos habían mostrado hacia la obra de Dewey. Después de todo, tuvieron que pasar todavía algunos años para que, de la mano de pensadores como Apel, Habermas y Rorty, el pragmatismo clásico vuelva a leerse de un modo más amigable. Por supuesto, lo que hemos sostenido no implica que las propuestas de los autores sean idénticas, y tampoco que la propuesta de Toulmin se reduzca a repetir la de Dewey. Persisten diferencias destacadas, e incluso la propuesta de Toulmin contiene aportes que, como es sabido, han tenido una gran influencia en el desarrollo de la teoría de la argumentación. Como hemos visto, existen diferencias importantes entre la investigación, que es el objeto de estudio de la lógica tal como es entendida por Dewey, y los argumentos justificatorios tal como son entendidos por Toulmin.

Frente a esto, tal vez alguien podría señalar lo siguiente: dado que los programas de Dewey y Toulmin versan acerca de cosas distintas, de actividades y prácticas diversas, son programas distintos y el intento de compararlos resulta un tanto ocioso. Criticar a uno por no adecuarse al otro sería, y para usar una expresión de Toulmin, como criticar a un simio por no ser un hombre o a un cerdo por no ser un puercoespín. Sin embargo, Dewey y Toulmin tenían la misma pretensión: realizar una reforma de la lógica. Pero además, hay otra cuestión importante que debe ser tenida en cuenta. Como se mencionó, la preocupación por la enseñanza de la lógica y la argumentación ha sido uno de los factores que han 
impulsado el desarrollo de la teoría de la argumentación contemporánea. Asimismo, la preocupación por la educación, y por una educación para la democracia, ha sido una preocupación que Dewey llevó consigo durante toda su vida. Incluso, su obra How We Think contiene un resumen de sus ideas lógicas elaborado a los efectos de discutir el modo en que puede y debe enseñarse el pensamiento reflexivo. Desde su punto de vista, sería un error, y un resabio de la vieja distinción entre forma y contenido, pretender enseñar a argumentar a partir de unas cuantas recetas, en el sentido de consejos para buscar las razones que permitan convencer a otros de una tesis cualquiera. En lugar de ello, la enseñanza del pensamiento reflexivo debería promover las habilidades y actividades que permitan formar creencias adecuadas de un modo adecuado. En otros términos, la cuestión pedagógicamente importante sería la de enseñar no a justificar una creencia cualquiera, sino a formarnos las creencias adecuadas, es decir, aquellas que son resultado de procesos responsables de investigación. Con esto último no se pretende reeditar la discusión entre Sócrates y lo sofistas en torno a los dilemas epistémicos y éticos implicados en la enseñanza de la retórica, sino más bien recordar las críticas de Descartes al uso escolástico de la silogística, habida cuenta del riesgo del empleo de "argumentos de cajón”, ineficaces a la hora de aumentar y mejorar nuestras creencias. ${ }^{14}$

Pero tal vez la divergencia no tiene por qué ser llevada tan lejos. Después de todo, para Toulmin la función justificatoria de los argumentos es una de sus funciones, y por otro lado, para Dewey el proceso retrospectivo de búsqueda y formulación de razones para justificar creencias juega un rol positivo por cuanto permite revisar, aclarar, rever, o ejercer el control sobre los pasos que han sido dados en la marcha de la investigación. Así

\footnotetext{
${ }^{14}$ Esta expresión, así como la interpretación de las críticas de Descartes a la escolástica han sido tomadas de Cottingham, (1995, pp. 19-20).
} 
planteada, la diferencia parece ser más bien de énfasis. Los aportes de Toulmin y de Dewey constituirían dos enfoques lógicos que toman como punto de partida aspectos diferentes de un mismo fenómeno, es decir, el modo en que pueden establecerse conclusiones fundadas. Sin embargo, casi como un reflejo pragmatista, podemos sospechar que tal diferencia, como cualquier distinción que intentemos trazar, ha de tener consecuencias prácticas si se trata de una verdadera diferencia. Y acaso estos dos enfoques tengan consecuencias divergentes en lo que respecta a la enseñanza de la lógica. Tal vez, en la diferencia entre enseñar a justificar creencias y enseñar a investigar problemas radique la diferencia de méritos entre ambos enfoques. 
9

\section{La teoría de la investigación de Dewey y los estudios de laboratorio}

\section{Introducción}

El propósito de este capítulo y el siguiente es explorar los vínculos entre la concepción de la investigación de Dewey y algunos desarrollos y resultados de los estudios sociales de la ciencia. Como hemos argumentado en la introducción de esta tesis, desde nuestro punto de vista, la teoría de la investigación de Dewey no sólo es compatible con algunos desarrollos del giro práctico de los estudios sociales de la ciencia, y en especial de las etnografías de laboratorio, sino que, al contener una dimensión crítica, propia de su comprensión de la filosofía, la perspectiva de Dewey se constituye en una filosofía política de la ciencia que plantea la necesidad de una discusión pública acerca de los fines del conocimiento científico. Como hemos sostenido en esta tesis, este resultado se logra, en primer lugar, al construir una concepción performativa del conocimiento científico, y del conocimiento en

general, y al ofrecer una dimensión normativa y crítica, que señala la posibilidad y legitimidad de una discusión racional sobre fines. 
A efectos de sustentar esta tesis acerca de la compatibilidad y complementariedad del enfoque de Dewey en relación con algunas de las líneas más destacadas y vigentes de los estudios sociales de la ciencia, en este capítulo y en el siguiente nos detendremos en el análisis crítico de algunos aportes tomados de tal contexto. Nos referimos, en primer lugar, a algunos aportes de Bruno Latour, quien, a partir de sus estudios etnográficos o antropológicos de los laboratorios, ha ofrecido una interesante concepción de la ciencia. En particular, nos detendremos en la tesis acerca de la continuidad entre ciencia y política sostenida por Latour (sub-sección 2.1); en su cuestionamiento de la distinción interno/externo (sub-secc. 2.2); y en su cuestionamiento de la dicotomía natural/social (subsecc. 2.3). En segundo lugar, en la sección 3, nos detendremos en el análisis del concepto de arenas transepistémicas de investigación propuesto por Knorr Cetina para dar cuenta del modo en que se produce la ciencia. Dicho concepto permite explicitar las continuidades entre el ámbito de la ciencia y ciertos agentes no-científicos, superando, como arguye Knorr Cetina, algunas concepciones de la ciencia que, como la de Bourdieu, se encuentran comprometidas, a pesar suyo, con cierta forma internalista de concebir la ciencia. En este capítulo nos detendremos, entonces, en el análisis de los aportes de dichos autores, mientras que en el siguiente nos detendremos, en el problema de la reflexividad de los estudios de la ciencia $\mathrm{y}$ en especial en el modo en que Bourdieu ha tratado el asunto. Una vez reconstruidos estos aportes, y retomando las conclusiones a las que hemos arribado en nuestro estudio de la teoría de la investigación de Dewey, trataremos de explicitar en qué sentidos dicha teoría resulta compatible con, y en buena medida empíricamente respaldada por, tales estudios de la ciencia, a la vez que señalaremos qué es lo que de interesante tiene para ofrecer la perspectiva filosófica de Dewey. 


\section{Los aportes de Bruno Latour}

\subsection{La retórica científica y la política}

En un texto acerca de la retórica científica (1986), Bruno Latour toma como objeto de análisis la argumentación científica, esto es, el juego de pruebas y argumentos en virtud del cual una proposición es transformada hasta constituirse en la expresión de un "hecho" científico. El objetivo de este análisis es mostrar que la distinción, o más bien la dicotomía entre retórica política, de un lado, y argumentación, razón o prueba científica, del otro, entorpece los estudios de la ciencia por cuanto tiende a ocultar lo que, por otro lado, los estudios empíricos demuestran, a saber, "la continuidad entre el universo de la política y el de la ciencia” (1986, p. 6).

El proceso de producción de un hecho científico es visto por Latour como un proceso de modalización o, como dirá en otros escritos, de estabilización de un enunciado. Supongamos que una persona, digamos un científico, afirma de una fábrica de pasta de celulosa $\mathrm{X}$ que no es contaminante. Pues bien, un oyente puede entonces afirmar que el científico A ha demostrado que la fábrica X no es contaminante. Con ello, ha agregado al enunciado original una modalización: el enunciado original, la fábrica no es contaminante se ha transformado en se ha demostrado que la fábrica no es contaminante. Con ello, el enunciado original es tomado como un hecho bien establecido. Por otro lado, otro oyente podría decir: el científico $A$, que trabaja para la fábrica $X$, pretende que $X$ no es contaminante. Con ello el enunciado, en vez de ser tomado como la expresión de un hecho, es transformado, mediante una nueva modalización (el empleado de X pretende que) de manera tal que sus condiciones de producción, el modo o el contexto en que el enunciado fue producido sale a la luz. Así, el enunciado es tomado, en palabras de Latour, como un 
artefacto, como algo fabricado o producido y no como un hecho. Este segundo ejemplo, por supuesto, remite directamente a lo político, puesto que parece sugerir que la posición del científico está influida por su carácter de empleado de la fábrica. No obstante ello, el mismo enunciado puede ser transformado en artefacto mediante otras modalizaciones. Por ejemplo, otro oyente podría decir: el científico $A$ ha afirmado que la fábrica $X$ es contaminante pero no ha especificado el método utilizado para analizar las muestras. En este caso, que resulta menos político, por así decirlo, lo mismo que en el anterior, el enunciado es remitido a sus condiciones de producción, es decir, es tratado no como un hecho, sino como un artefacto

De este modo, Latour describe la producción de la ciencia, la construcción de hechos científicos, como un proceso de sucesivas modalizaciones de los enunciados que supone tramas de traducciones, negociaciones e inscripciones que comienzan con enunciados controversiales y finalizan con la estabilización del enunciado $y$, eventualmente, con la producción del hecho científico. ${ }^{1}$ Pero este proceso va más allá de este aspecto lingüístico. En efecto, el proceso de sucesivas modalizaciones se apoya, de acuerdo con Latour, en una práctica de movilización de aliados. El científico, lo mismo que el político, es un vocero que moviliza o recluta aliados para fortalecer o imponer su posición. Entre esos aliados se encuentran las instituciones que financian la investigación, los comités de especialistas de las revistas en que publica sus resultados, los comités que deciden acerca de los subsidios, etc. Pero, además, es importante señalar -para hacer a un lado la idea de que Latour está describiendo la producción de conocimiento científico sólo

\footnotetext{
${ }^{1}$ Hasta aquí, se podría objetar, lo único que se ha establecido, en lo que respecta a la continuidad entre ciencia y política, radica en que los enunciados científicos pueden ocupar un lugar en las disputas políticas. Sin embargo, resulta claro que el ejemplo anterior sobre los intereses del científico podría desencadenar procesos de investigación científica que apunten, por ejemplo, a demostrar la debilidad de la posición del científico A. En este sentido, la continuidad resultaría reversible, por así decirlo.
} 
en el nivel del texto científico- que entre los actores y recursos movilizados se encuentran, también, esas cosas que no hablan, las ratas, los microbios, las enzimas que los investigadores movilizan en su laboratorio. El científico es un vocero de esas cosas que no hablan, y que son movilizadas por el investigador para decirles a sus colegas y al público en general lo que él dice que aquellas dicen. Así, el científico cuenta con una herramienta fundamental, su laboratorio, con sus pruebas y ensayos, que multiplica enormemente su capacidad de reclutar aliados, invirtiendo las relaciones de fuerza en que se encontraba y dejándolo en una posición privilegiada para imponer sus propias modalizaciones. Esta función del laboratorio y, en términos generales, de las posibilidades de experimentación con que cuenta el científico, es sostenida por Latour sobre la base de sus estudios empíricos. En el texto "Dadme un Laboratorio y moveré el mundo" (2008) Latour muestra de qué modo Pasteur logra producir una vacuna contra el ántrax invirtiendo las relaciones de fuerza que se dan entre él y el microbio, precisamente al lograr cultivarlo en su laboratorio de modo que, estando en control de la situación, puede experimentar hasta vencer al microbio.

De este modo, la diferencia entre la ciencia y la política radica, de acuerdo con Latour, en las posibilidades de experimentación de la primera, cada vez más importantes a medida que fue avanzando su desarrollo. Pero tal diferencia no es "de principio": en ambos casos se trata de un proceso de movilización de recursos y actores, es decir, de aliados. En palabras de Latour:

Cuando se honra la ciencia de ser más fuerte que la retórica, lo que se hace es reconocerle medios superiores de movilización (...). No se pasa de la retórica a la razón cuando se va de la política al laboratorio: se pasa de una retórica débil, amable, donde hay una igualdad con pequeños elementos que pueden inclinar la balanza hacia un lado u otro, a una retórica fuerte, en la que son 
movilizados -a gran costo, a altísimos precios- un número de actores mucho más considerable (2008, p. 6).

En resumidas cuentas, Latour está describiendo la actividad de producir ciencia como un proceso que, partiendo de meros artefactos de opinión, controversiales en tanto que tales, pretende estabilizar enunciados, es decir producir hechos científicos, clausurando, al menos momentáneamente, la controversia. Por otro lado, insiste que este proceso es el mismo que muestra la actividad política con la diferencia de que el científico cuenta con una herramienta mucho más fuerte para reclutar aliados. La aceptación de esta tesis de la continuidad entre ciencia y política tiene consecuencias importantes para los estudios de la ciencia, e incluso, podríamos decir, para una filosofía política de la ciencia. En efecto, una vez que aceptamos tal continuidad, debemos cambiar algunas de las categorías con que suele pensarse la relación entre ciencia y política. Si hay continuidad, entonces la idea de la influencia de lo político sobre lo científico ya no puede pensarse como la influencia de algo externo a la ciencia misma, sino que más bien habría que pensar en la construcción de hechos científicos y políticos como uno y el mismo proceso. Así, la idea de la supuesta autonomía de la ciencia, tanto en el plano de lo que se supone que sucede como en el de lo que debería suceder, queda puesta en cuestión.

\subsection{La ciencia y la sociedad: dentro y fuera del laboratorio}

En sus estudios sobre Pasteur, Latour se propone corregir lo que él mismo entiende como un defecto de los estudios de laboratorio, tal como ellos fueron desarrollados en sus comienzos. El defecto, que no se trata en su opinión de un error sino de un cierto carácter 
de incompletud, radica en la escasa atención prestada a las cuestiones externas al laboratorio, es decir, a la relación entre el adentro y el afuera del laboratorio. El objetivo de Latour no es mostrar de qué modo el medio social influye en la actividad científica, o el modo en que los factores políticos tienen consecuencias en ella, sino más bien mostrar de qué manera la actividad científica misma, la vida del laboratorio, desestabiliza, deshace y rehace lo social, esto es, pretende sacar a la luz el modo en que la ciencia transforma la sociedad. En efecto, uno de los objetivos centrales en esos estudios es mostrar que los así llamados intereses sociales no son algo simplemente dado que afecte a la ciencia desde el exterior, sino que son resultado de las prácticas del laboratorio. El punto es ilustrado en el estudio sobre Pasteur que muestra de qué modo Pasteur logró traducir a su propio lenguaje, y con ello transformar, los intereses de distintos grupos sociales, granjeros, veterinarios, higienistas, de modo tal que depositaran sus expectativas en lo que ocurría dentro de su laboratorio. En palabras de Latour, "sus intereses [los de esos grupos] son una consecuencia y no una causa de los esfuerzos de Pasteur por traducir lo que quieren o lo que él hace que quieran” (2008, p. 11). Al hacer eso, argumenta Latour, Pasteur logró, con su laboratorio, transformar el mundo. En esta dirección, según Latour, los estudios de la ciencia deben "rastrear cómo las ciencias suelen transformar la sociedad y redefinir de qué está hecha y cuáles son sus objetivos" (ibídem).

En el estudio sobre Pasteur al que nos referimos, Latour identifica tres movimientos que muestran la permeabilidad de la distinción dentro/fuera del laboratorio. El primero de ellos consiste en el esfuerzo de Pasteur por captar los intereses de ciertos grupos, para lo cual se traslada a sí mismo y a su laboratorio a la granja para llamar la atención y transformar el interés de los granjeros cuyos animales morían sin que se supiera por qué ni se pudiera hacer nada al respecto. El segundo movimiento consiste en una vuelta al 
laboratorio que implica un cambio de escala que invierte la relación de fuerza entre Pasteur y el microbio causante de la enfermedad. Fuera del laboratorio los bacilos del ántrax se mezclan con otros microorganismos, lo que les otorga un alto grado de invisibilidad, pero dentro del laboratorio se vuelven visibles puesto que frente a la ausencia de microorganismos su número crece exponencialmente volviéndose observables y manipulables. Al lograr cultivar al bacilo del ántrax, Pasteur arrastra a las sociedades agrícolas que ahora se interesan por lo que hace. Este cambio de escala da al laboratorio de Pasteur un papel desestabilizador: "las complejas relaciones entre los microbios y el ganado, los granjeros y su ganado, los veterinarios y las ciencias biológicas se van a transformar gracias a las prácticas del laboratorio" (2008, p. 24). En efecto, el tercer movimiento de vuelta al campo implica un cambio en el campo que permite reproducir en éste las condiciones que en el laboratorio permitieron que los animales inoculados con el microbio atenuado no contrajeran la enfermedad frente a nuevos contagios.

Este resultado de los estudios de laboratorio resulta interesante, además, porque introduce algo que en el campo de la sociología de la ciencia resulta novedoso. Tal como lo sugiere Andrew Pickering, el proyecto del programa fuerte de la sociología de la ciencia de la escuela de Edimburgo era poner al conocimiento en relación con las variables sociológicas clásicas, como el interés, la ideología o la clase social. Ello venía inspirado, además, por la idea de que el conocimiento es algo así como una red conceptual que los científicos tienen que ir completando o extendiendo hasta lograr el consenso o clausura. Sin embargo, como la filosofía de la ciencia había mostrando a partir de Kuhn, la producción del consenso, la clausura, no podía explicarse apelando tan sólo a la observación y el método. De allí los sociólogos de la ciencia parecen inferir que hay otros factores, a saber, 
variables sociales como la clase y el interés, que operan como factores de clausura, es decir que explican, en última instancia, que un científico, o una comunidad de científicos, acepten o rechacen una determinada teoría. Se trata, por así decirlo, de una visión "por defecto" de la injerencia de lo social en la ciencia, por cuanto el argumento parece ser que, dado que es imposible explicar la producción de consenso en ciencia apelando a la observación y el método, entonces algo más debe producir la clausura, a saber, los factores sociales entendidos como algo no-epistémico o extra-científico. Sin embargo, en la propuesta de Latour el carácter social del conocimiento científico es pensado de una manera distinta. El puntapié inicial de esta visión ha sido el estudiar la práctica misma de la producción de conocimiento científico tal como esta se desarrolla en los laboratorios. Este estudio de la práctica muestra que la ciencia es social en un sentido más profundo: no se trata de que intereses foráneos la afecten o incluso que sean determinantes respecto del cambio científico, sino que la ciencia misma es un factor de producción de tales intereses y de la sociedad misma y ello de un modo tanto más marcado en las sociedades contemporáneas. En palabras de Latour: "la debilidad congénita de la sociología de la ciencia es su propensión a buscar motivos políticos e intereses obvios en uno de los únicos lugares, los laboratorios, en los que emergen nuevas fuentes de política todavía no reconocidas como tales" (2008, p. 43).

De este modo, esta nueva concepción acerca del carácter social del conocimiento y la ciencia cuestiona la distinción entre los aspectos "epistémicos" y "extra-epistémicos" de la ciencia, entre aspectos "internos" y "externos". Una vez más, no se trata de ver de qué modos dos cosas distintas, a saber, la ciencia y la sociedad, se relacionan e influyen mutuamente, sino de comprender a la primera como una práctica cultural, que, al igual que toda práctica humana, se produce en un determinado tiempo y en un determinado lugar, que 
se relaciona de maneras determinadas con otras prácticas humanas y que conlleva múltiples y variadas consecuencias respecto de la conservación y la transformación de las sociedades.

\subsection{Una crítica metodológica a Latour}

La propuesta de Latour ha sido objeto de una crítica importante por parte de los sociólogos de la ciencia. Como mencionamos antes, en su explicación sobre la producción del conocimiento científico Latour hace jugar como un elemento importante a los actantes nohumanos. En efecto, en sus estudios sobre Pasteur, Latour remarca la importancia que tuvo el hecho de que aquel fuera capaz de cultivar el microbio causante del ántrax. Fue esta práctica de cultivo lo que le permitió invertir las relaciones de fuerza entre él y el microbio: fuera del laboratorio, el microbio, al interactuar con otros organismos, resultaba invisible; dentro del laboratorio, al hacerse visible gracias al cultivo, Pasteur puede manipularlo, atenuarlo y luego inocularlo en el ganado que resulta inmunizado frente a nuevas infecciones. Ahora bien, Collins y Yaerley (1992) sostienen que esto implica una vuelta atrás respecto de los logros de la sociología de la ciencia puesto que reintroduce, en la explicación sobre el conocimiento científico, la visión de los propios científicos acerca de lo que creen que observan y hacen. Mientras la sociología de la ciencia habría tenido el objetivo de desmitificar la autoridad y la actividad de la ciencia cuestionando la idea de que los científicos se limitan a mostrarnos lo que está ahí fuera, a sacar a la luz la verdad, Latour estaría tomando como verdadero aquello que los científicos dicen que ocurre. El problema no es tanto que creamos o no lo que los científicos dicen que ocurre, sino más bien que la sociología de la ciencia, como producto del sociólogo, se volvería imposible si 
se limitara a reproducir la versión de los científicos sobre sus propios resultados. En este sentido, la crítica de Collins y Yaerly es metodológica: el sociólogo, en tanto que tal, no puede simplemente aceptar la visión de los científicos si pretende ofrecer una explicación social del conocimiento: no puede explicar el conocimiento apelando a la naturaleza, como lo hace el científico, no al menos si considera, en tanto que sociólogo, al conocimiento como un hecho social.

La respuesta de Latour es por demás interesante. Desde su punto de vista, esta crítica supone una inaceptable dicotomía entre lo natural y lo social, entre lo no-humano y lo humano, dicotomía que resulta inaceptable por dos razones. En primer lugar resulta ontológicamente cuestionable por cuanto, de acuerdo con Latour, una de las cosas que caracterizan a la sociedades modernas es la existencia creciente de híbridos de naturaleza y cultura, como los son, por ejemplo, los ratones usados en las pruebas oncológicas, las vacas de los tambos, o los miles de vegetales modificados por los seres humanos a lo largo de la historia. En segundo lugar, Latour cuestiona metodológicamente la distinción por cuanto la considera un resultado, más bien que un punto de partida, de la producción de conocimiento. En efecto, sostiene Latour, cuando se plantea una pretensión científica, cuando se enuncia la pretensión de que un cierto hecho es un hecho científico, resulta controversial, lo que significa que no hay acuerdo acerca de su estatus ni, por tanto, de su carácter natural o social. En palabras de Latour, "la sociedad (o sujeto, mente, cerebro) no puede utilizarse para explicar la práctica de la ciencia, y por supuesto tampoco la naturaleza, puesto que ambas son el resultado de la práctica de hacer ciencia y tecnología” (1992, p. 253). Es por ello que Latour intenta buscar un lenguaje simétrico, es decir, que sea neutral respecto del carácter humano o no humano del agente cuya trayectoria se está estudiando, que le permita explicar la producción de las naturalezas/sociedades sin 
prejuzgar acerca del carácter social o natural de los agentes o actantes estudiados. En esta dirección, el objetivo de los estudios de la ciencia no es mostrar de qué modo lo social determina, causa o meramente influye en la ciencia, sino más bien estudiar el modo en que un enunciado científico resulta estabilizado, esto es, aceptado como un hecho, en virtud de la participación de múltiples actantes, tanto humanos como no-humanos. Para decirlo otra vez en palabras de Latour, "los objetos y los sujetos son consecuencias tardías de una actividad experimental e histórica que no distingue claramente si una entidad está ahí fuera en la naturaleza o ahi arriba en la sociedad. Lo cual significa que cada entidad debe clasificarse según su grado de estabilización" (1992, p. 255).

De acuerdo con la reconstrucción de la propuesta de Latour que hemos realizado podemos resumir de la siguiente manera su posición. En primer lugar, hay que señalar que la manera en que pensamos la ciencia y el conocimiento tiene que estar apoyada en el estudio empírico de la práctica científica tal como se lleva a cabo, por ejemplo, en los laboratorios. En segundo lugar, vimos que el proceso de producción del conocimiento es visto como un proceso de estabilización de enunciados, estabilización respecto de los modalizadores de los enunciados que supone una práctica de traducción de intereses y de reclutamiento y movilización de actores y recursos, que, tal como se ve en el caso de Pasteur, exceden con mucho a los actores y recursos meramente "científicos" en el sentido tradicional del término. En virtud de ello se destaca el papel de la ciencia como transformadora de las naturalezas/sociedades. En este sentido, la ciencia no es tanto una descripción de la realidad cuanto una transformación de la misma. Por otro lado, este carácter práctico de la ciencia revela su continuidad respecto de otras prácticas de transformación como la práctica política. Por último, hemos visto que de acuerdo con 
Latour este carácter práctico y transformador de la ciencia sólo puede ser adecuadamente explicitado si, lejos de presuponer una dicotomía entre la naturaleza y la sociedad, estudiamos de qué modo la práctica científica es una práctica de construcción de la realidad.

\section{Las arenas transepistémicas de investigación}

Como es sabido, el de Knorr Cetina es uno de los primeros estudios de laboratorio que, de forma más o menos simultánea, se desarrollaron en la década del 70. Como uno de los resultados de sus investigaciones Knorr Cetina desarrolla el concepto de arena transepistémica de investigación para caracterizar el lugar en que se lleva a cabo el trabajo científico. En su opinión, el laboratorio, como lugar concreto en el que se produce el trabajo científico, está atravesado por relaciones de diversa índole que, si bien se localizan en el laboratorio, tienden a trascenderlo, configurando un espacio de relaciones que es caracterizado como una arena transepistémica de investigación.

Antes de detenernos en tal concepto resulta conveniente explicitar algunos de los resultados más destacados de los estudios de laboratorio de Knorr Cetina. El primero de ellos, coincidente con los resultados de Latour, es que la investigación científica tiene un carácter constructivo más que descriptivo. Lo que el estudio de laboratorio muestra es que el conocimiento se hace a través de un proceso no tanto de descripción de una realidad dada previamente cuanto de construcción, cuyo resultado es la "fabricación" del hecho científico. Así, en opinión de Knorr Cetina, la observación real de la producción de conocimiento muestra lo inadecuado que resulta el lenguaje "descriptivista" para dar cuenta de tal producción. 
En efecto, dicho lenguaje cobra sentido sólo si pensamos que hay un mundo que está ahí y que es independiente de la ciencia misma, y que la tarea de conocer ese mundo puede comprenderse como la tarea de formular oraciones verdaderas en el sentido de que describen o representan lo que de hecho ocurre. Sin embargo, al entrar al laboratorio, lo primero que se destaca es que no hay allí adentro nada parecido a una realidad independiente que será conocida, sino más bien una serie de instrumentos, de materiales, de sustancias e incluso de animales que han sido producidos en el mismo laboratorio o comprados a otros. Así, afirma Knorr Cetina que "parecería, entonces, que a la naturaleza no se la va a hallar en el laboratorio, a menos que se la defina desde un principio como un producto de un trabajo científico" (2005, p. 58).

Por otro lado, si bien es cierto que en la jerga de los científicos, en el modo en que describen sus acciones, aparecen muchas veces referencias a lo que es verdadero y lo que no lo es, a lo que ocurre realmente, de acuerdo con nuestra autora su uso de tales expresiones no difiere del uso retórico que suelen tener en el habla cotidiana y en cambio se evidencia una preocupación y un esfuerzo grande porque las cosas "funcionen", lo que apunta, más bien, a criterios de éxito de la actividad científica que a criterios de verdad como elementos constitutivos de la práctica científica.

Así, afirma Knorr Cetina que "más que considerar los productos científicos como algo que de alguna manera captura lo que es, los consideraremos como selectivamente extraídos, transformados y construíos a partir de lo que es" (2005, p. 56). De este modo, el proceso de producción de conocimiento se muestra como un proceso en el que el científico tiene que realizar elecciones y selecciones, entablando también un proceso de negociación. La actividad principal del científico es, entonces, tomar decisiones respecto de cómo hacer 
que las cosas funciones, es decir, hacer selecciones. Tales selecciones se hacen siempre sobre la base de selecciones anteriores y condicionarán las selecciones futuras, al constituirse en un recurso o en un tema para nuevas investigaciones.

Otro resultado interesante del estudio que comentamos es la idea de que no puede separarse la validación de los hechos científicos del proceso de su producción. En otros términos, la validación de las selecciones realizadas por los científicos se encuentra en el proceso mismo de su producción, de su realización, y radica en que esa selección sea incorporada como recurso en nuevas selecciones. Esto implica que la validación del conocimiento no es tanto un proceso de formación de opinión o consenso en una comunidad de investigadores sino un proceso de solidificación de resultados mediante su incorporación permanente en el curso de la investigación (2005, p. 68).

Un último resultado que destacaremos antes de abordar el concepto de arena transepistémica de investigación es que las selecciones no son producto de criterios y reglas pre-existentes, de algo así como un método científico, sino que son el resultado de la “co-ocurrencia e interacción de factores cuyo impacto y relevancia se constituyen en un tiempo y lugar dados, es decir, de las circunstancias en las cuales el científico actúa" (2005, p. 70). El proceso de validación se remite al proceso de selecciones y estas últimas sólo pueden explicarse en función del contexto específico en que se toman, como resultado de diversos factores que se combinan en el laboratorio.

Así, entonces, la investigación puede ser descripta como un proceso social de producción de hechos científicos consistente en una red de selecciones que se explican teniendo en cuenta aspectos contextuales contingentes que concurren en el laboratorio. Ahora bien, esta descripción corre el riesgo de ser interpretada como un nuevo tipo de posición internalista para abordar el conocimiento científico. $\mathrm{Si}$, como dijimos, el proyecto 
del giro cognitivista en la sociología de la ciencia desde el programa fuerte era poner en relación al conocimiento científico mismo con ciertas variables o aspectos sociales del contexto social más amplio en el que toma lugar la actividad científica, los estudios de laboratorio corren el riesgo de incurrir en una nueva forma de internalismo, en el sentido de que sólo recurrirían a los factores internos al laboratorio para dar cuenta de la producción de conocimiento. Sin embargo, el concepto de arenas transepistémicas de investigación tiende precisamente a señalar los vínculos de las selecciones hechas en el laboratorio con factores ajenos al mismo. En palabras de Knorr Cetina:

Las elecciones de un laboratorio, situadas en un espacio localmente
circunscripto, parecen estar simultáneamente ubicadas en un campo de
relaciones sociales. Las contingencias situacionales observadas en el
laboratorio están atravesadas y sostenidas por relaciones que constantemente
trascienden el sitio de la investigación (1996, p. 132).

El concepto de arenas transepistémicas de investigación pretende así dar cuenta de una manera más adecuada de la práctica real de la investigación superando, a la vez, algunos de los inconvenientes de los principales conceptos que se han usado para describir el espacio relevante para la producción de conocimiento científico. En primer lugar, el concepto permitiría superar algunas de las limitaciones de las analogías económicas con las que suele describirse el trabajo científico. Así, en algunos modelos, se dice que los científicos buscan acumular prestigio o reconocimiento, que obtienen a cambio de sus aportes al desarrollo de su disciplina. Ese reconocimiento, otorgado por los parescompetidores que conforman la comunidad de especialistas, funciona a nivel individual como una motivación que asegura, por otro lado, el crecimiento del conocimiento. En modelos de la actividad científica más complejos como los de Bourdieu o Latour no es un 
mero reconocimiento lo que se busca, sino un cierto capital simbólico o un cierto crédito, que es reinvertido por los científicos a efectos de reproducir, no tanto el conocimiento mismo, cuanto el capital o crédito. Así, los científicos son vistos como una suerte de empresarios que invierten su capital a efectos de multiplicarlo. En el caso de Bourdieu, además, el disponer de mayores niveles de capital permitiría, como veremos en la sección siguiente, a sus poseedores, determinar las normas y reglas que rigen la producción de conocimiento al interior del campo, lo que implica, a su vez, que el campo científico es también un campo de lucha por el control mismo del campo. Como Knorr Cetina señala, esta idea de un campo de lucha, al introducir el factor de conflicto, permite superar ciertas limitaciones del concepto más tradicional de comunidad científica pero, sin embargo, parece seguir sosteniendo que el espacio en el que se sitúa la producción de conocimiento es el espacio de la especialidad. Knorr Cetina sostiene, en cambio, que la comunidad de especialistas, pese a ser un concepto privilegiado de los estudios de la ciencia, no resulta pertinente para explicar la producción de conocimiento. En efecto, en su opinión, resulta necesario "cambiar la imagen del científico capitalista en una comunidad de especialistas por una que reconozca las dependencias básicas del trabajo científico que nos llevan más allá de estas comunidades" (1996, p. 146).

Así, en su opinión, "el trabajo científico se muestra en el laboratorio como atravesado y sostenido por relaciones y actividades que trascienden continuamente el sitio de indagación" (1996, p. 150). Ello es así porque los científicos hacen inteligible su labor remitiendo sus elecciones a compromisos y negociaciones que apuntan, no sólo afuera del laboratorio, sino también afuera de la especialidad e incluso afuera del ámbito propiamente científico. Así, por ejemplo, los científicos no sólo negocian con pares y especialistas, sino también con científicos de otras especialidades y con no científicos, típicamente a través de 
los cambios operados en los proyectos de investigación con el fin de obtener financiación. Cabe destacar que uno de los principales problemas con los modelos económicos es, para nuestra autora, la ausencia casi total como un participante relevante de aquellos que ponen los recursos reales para la investigación, es decir, de las diferentes agencias de financiación. Así, nos encontramos con arenas de acción que son transepistémicas en el sentido de que "involucran una mezcla de personas y argumentos que no se dividen naturalmente en una categoría de relaciones pertenecientes a la ciencia o la especialidad y una categoría de otros asuntos" (1996, pp. 150-151). Este último punto resulta muy relevante puesto que señala que no hay una diferencia de naturaleza entre criterios técnicos o científicos de un lado, y sociales del otro, a la hora de tomar decisiones en el laboratorio. Todos los criterios se definen, revisan y negocian en el contexto de estas arenas, que deben ser vistas, de acuerdo con Knorr Cetina, como caracterizadas por lo que entiende como relaciones de recursos. En sus palabras, los intercambios en las arenas, involucran lo que conviene llamar relaciones de recursos -esto es, relaciones a las cuales se recurre, o de las cuales se depende, para obtener insumos o apoyos. Las arenas transepistémicas de acción simbólica se muestran como el sitio en el cual se negocian el establecimiento, la definición, la renovación o la expansión de relaciones de recursos (1996, p. 153).

Uno de los aspectos más interesantes de este concepto de arenas transepistémicas es que permite cuestionar las distinciones entre social y cognitivo y entre interno y externo que han dominado ciertas visiones filosóficas sobre la ciencia y aún aquellas que pretendían dar cuenta de la relevancia de los así llamados "factores sociales" en ciencia, en un sentido coincidente con los resultados de Latour. Al hacer esto, la idea de la autonomía de la 
ciencia es desplazada por el señalamiento de la necesaria dependencia del trabajo científico respecto de lo que está más allá del laboratorio.

\section{Conclusiones}

Estos resultados de los estudios de laboratorio resultan coincidentes con la caracterización deweyana de la investigación que hemos reconstruido en el segunda parte de esta tesis. Según hemos sostenido, la investigación es, para el pragmatista, una práctica tecnológica de transformación del mundo que permite obtener, en virtud de las transformaciones que opera, y como sub-producto, aserciones garantizadas, o mejor dicho, asertabilidad garantizada, es decir, conclusiones y resultados que se caracterizan por su utilizabilidad potencial, como recursos para ulteriores investigaciones. Hemos visto, además, que la comprensión de la investigación como forma de experiencia reflexiva, y su vínculo insoslayable con lo que Dewey denomina experiencia primaria, indica un señalamiento fuerte en relación a la dependencia de la actividad científica de recursos y procesos que ocurren por fuera de lo estrictamente científico.

Esta última cuestión, junto con el análisis de la valoración y su relación con la investigación, permite señalar, con Bourdieu y Knorr Cetina, las continuidades entre la actividad científica y el ámbito de la política: hechos y valores resultantes de investigaciones/valoraciones concretas se constituyen en recursos que pueden ser reinvertidos en otras investigaciones. Así, la idea de Latour acerca de la proximidad de la retórica científica y la retórica política resulta una nueva versión acerca de la tesis del “isomorfismo" investigación/valoración que, en nuestra opinión, puede atribuirse a Dewey. Este modo de ver al conocimiento revela, en primer lugar, que el investigador es un 
razonador práctico que, al igual que el político, ocupa la mayoría de su tiempo en tomar decisiones acerca de qué es lo que debe hacer para lograr el objetivo que se plantea. En este sentido, y como lo muestra el análisis sobre la valoración propuesto por Dewey, hay una clara continuidad entre ciencia y política, por cuanto en ambos casos se trata de una misma manera de proceder, se llame retórica o investigación. Aún cuando ciencia y política diverjan en ciertos sentidos, su distinción no puede trazarse en términos de métodos, o en términos de una supuesta distinción entre la teoría y la práctica, la razón y la retórica, o el mundo de los hechos y el mundo de los fines. En ambos casos se trata de la producción de objetos y sujetos, que, como afirma Latour, son consecuencias tardías de una actividad experimental e histórica, producción que no se auto limita a una escisión previa entre lo natural y lo social, del mismo modo que las situaciones de las que habla Dewey son a la vez naturales y sociales. Esta actividad experimental que produce objetos y sujetos es llamada por Dewey investigación, y es entendida por ambos autores como una forma de la acción de producir naturalezas/sociedades o de la transformación de situaciones naturales y sociales.

Este último punto parece señalar una divergencia entre Latour y Dewey. En efecto, según el primero, el filósofo pragmatista habría sostenido más bien un naturalismo que no alcanza a romper del todo con la dicotomía natural/social (1992, p. 248 y ss.). En opinión de Latour, Dewey se limitaría a reconocer a la vez la intervención de factores naturales y sociales en el conocimiento, mientras que él produciría un giro más al sostener que lo social y lo natural son consecuencias de la investigación y no meramente aspectos ya presentes en la situación que la desencadena. Sin embargo, en muchas oportunidades Dewey ha insistido, como vimos, en la idea de que el conocimiento no puede entenderse como la aprehensión de una realidad antecedente, o ya existente, sino como la transformación de la 
situación. En ese sentido, la realidad que conoce la ciencia es la que produce y no la que la antecede. Por otro lado, ese proceso se da en un seno que es a la vez natural y social. Es decir, no es que para Dewey intervengan tanto factores "sociales" como "naturales", como si fueran cosas separadas, sino que los problemas y los recursos que intervienen en la producción de conocimiento son a la vez naturales y sociales, por cuanto son componentes de una situación que es a la vez natural y social. No debe olvidarse, en este punto, que tanto el organismo como el medio son resultados de la transacción, de modo tal que aquello que cuenta como medio es, en parte, dependiente de les estructuras y condiciones del organismo.

Otro aspecto que cabe destacar en estas conclusiones es que la idea de Dewey acerca de la dependencia insoslayable de toda investigación y toda valoración respecto del contexto resulta compatible y bien reflejada por el concepto de arena transepistémica de investigación. Como hemos dicho, la tesis acerca del carácter contextual de la ciencia es un resultado de los estudios de Knorr Cetina, e incluso la trascendencia respecto de la especialidad es algo que queda sugerido si tenemos en cuenta que el contexto es, para Dewey, siempre, a la vez temporal y espacial: es decir, toda investigación se da en un contexto de tradición, en el sentido de formas de respuesta habituales y unificadas y de teoría. Pero el contexto es también espacial: toda investigación se da en un lugar específico, razón por la cual debe hacer uso de recursos disponibles para transformar la situación que le dio origen, sin que pueda establecerse una separación a priori entre un contexto específicamente científico y uno social. De hecho, las condiciones que permitan aislar lo que ocurre en el laboratorio, por ejemplo, cuando se manipulan microorganismos, sólo pueden ser eficazmente establecidas luego de una serie de operaciones rigurosas. Los resultados de la investigación científica son también realidades, procesos, hechos e 
instrumentos, que interactuarán con otros procesos, hechos e instrumentos produciendo a su vez nuevas consecuencias. El hecho de que tales consecuencias puedan afectar, incluso, a personas no involucradas en la transacción científica que creó tales hechos y procesos es el fundamento, como vimos, para sostener el carácter irreductiblemente público de la ciencia. Dado ese carácter público de la ciencia, que las selecciones del laboratorio se elijan y negocien en arenas transepistémicas de investigación que involucran agentes científicos y no científicos es algo completamente esperable. La ciencia ocurre en un contexto y es un hecho social como cualquier actividad en la que se hallen involucrados seres humanos, que hace uso de recursos materiales, económicos y humanos que sólo pueden ser provistos por, o producidos a partir de, el contexto en el que ocurre. 


\section{0}

\section{El problema de la reflexividad de los estudios de la ciencia}

\section{Introducción}

En este capítulo abordaremos el problema de la reflexividad de los estudios de la ciencia. Como es sabido, la reflexividad es uno de los cuatro principios del programa fuerte de la sociología del conocimiento científico, tal como fuera propuesto por David Bloor. Este principio, que proponía que las formas de explicación de la sociología de la ciencia debían en principio ser aplicables a sí misma, dio lugar a una importante controversia. En efecto, se discutió tanto acerca de los modos en que puede o debe llevarse a cabo el proyecto de una sociología de la sociología de la ciencia, como acerca de las implicancias que tal proyecto tiene respecto del estatus epistemológico de la sociología de la ciencia. El propósito de este capítulo es reconstruir una perspectiva sobre este problema tomando algunas ideas de Dewey. Tal perspectiva, en nuestra opinión, permitirá superar dos observaciones críticas sobre el campo de los estudios sociales de la ciencia que han sido planteadas por sendos autores contemporáneos, a saber, Andrew Pickering (1992) y Steve Fuller (1992). 
De acuerdo con Pickering (1992) el proyecto del programa fuerte de la sociología de la ciencia de la escuela de Edimburgo, y de gran parte de los estudios sociales de la ciencia, era poner al conocimiento en relación con ciertas variables sociológicas clásicas, como el interés, la ideología o la clase social. En tal contexto, el conocimiento era visto como una red conceptual que los científicos tienen que ir completando o extendiendo hasta lograr el consenso o clausura. Sin embargo, como la filosofía de la ciencia había mostrando a partir de Kuhn, la producción del consenso, la clausura, no podía explicarse apelando a una supuesta observación neutral y a un supuesto método racional. De esta imposibilidad, los sociólogos de la ciencia parecen inferir que tienen que operar otros factores, a saber, variables sociales como la clase y el interés, que funcionan como determinantes de la clausura, es decir que explican, puesto que la apelación a la observación y al método no lo hace, por qué un científico, o una comunidad de científicos, aceptan o rechazan una determinada teoría. De esta manera queda sugerida una distinción entre aspectos sociales que van más allá de lo propiamente epistémico -extra-epistémicos-, y los aspectos nosociales o propiamente epistémicos de la ciencia. Bajo esta interpretación, lo social es visto como algo exterior a la ciencia pero que ciertamente influye en ella. Esta manera de pensar los estudios de la ciencia supone, de acuerdo con Pickering, una visión del conocimiento según la cual el mismo es básicamente una forma de representación conceptual, más específicamente, una red conceptual, y la tarea del científico consiste en extender, ampliar o modificar tal red. Frente a esta manera de pensar el conocimiento y la ciencia, Pickering propone la elaboración de lo que llama un lenguaje performativo para abordar el estudio de la ciencia, asumiendo así la idea de que la ciencia es fundamentalmente una forma de acción que involucra ciertamente representaciones pero que no puede reducirse a ellas. 
Por otro lado, de acuerdo con Fuller (1992), la marca distintiva de lo que él llama epistemología social es el desarrollo de una perspectiva normativa en los estudios de la ciencia. En su opinión, los estudios sociales de la ciencia, con la consolidación de su abordaje descriptivo, han perdido -o más bien ocultado- la dimensión normativa presente en la tradición epistemológica. Esta pérdida quedaría evidenciada, de acuerdo con Fuller, en la renuencia de los estudiosos de la ciencia a formular la pregunta acerca de si el conocimiento que de hecho produce la ciencia es el que sería deseable obtener. Esta renuencia, a su vez, sería producto del consenso tácito respecto del “éxito" de la empresa científica. Contra este acuerdo más o menos extendido, que al consagrar a la ciencia como una empresa exitosa parece cancelar la discusión acerca de la evaluación de la ciencia misma, Fuller afirma la necesidad y legitimidad de discutir o re-discutir los fines de la misma, recuperando así para la reflexión epistemológica una clara dimensión normativa.

Teniendo en cuenta estas observaciones, entonces, en este capítulo intentaremos ofrecer una perspectiva deweyana sobre el tema de la reflexividad que asuma una mirada performativa sobre el conocimiento científico e incorpore también una perspectiva normativa o crítica. En relación a esto último, cabe recordar que, tal como lo hemos explicitado en el capítulo 7, de acuerdo con el espíritu deweyano, no se trata de ofrecer una serie de principios desde los que se puedan derivar, de una vez y para siempre, prescripciones respecto de lo que debe hacer o dejar de hacer un científico, sino más bien de ofrecer una concepción sobre la investigación científica que ofrezca herramientas de análisis crítico frente a diferentes realizaciones científicas y pueda constituirse así en una herramienta para la transformación de las prácticas de investigación.

Para alcanzar nuestro objetivo, reconstruiremos, en primer lugar, el problema de la reflexividad tal como ha sido formulado y abordado por Bloor. Tal reconstrucción nos 
permitirá, a su vez, sacar a la luz algunos supuestos que han jugado un rol importante en el debate sobre la reflexividad y explicitar uno de los modos, acaso el más influyente, en que se ha comprendido la tarea de los estudios sociales de la ciencia. Una vez hecho esto, reconstruiremos la visión que Pierre Bourdieu $(2000,2003)$ ha propuesto sobre la cuestión de la reflexividad, señalando asimismo lo que desde nuestro punto de vista constituyen problemas en su concepción del campo científico. Por último, reconstruiremos algunos aspectos de la concepción deweyana del conocimiento a efectos de ofrecer una mirada sobre el problema de la reflexividad que, si bien resulta convergente en algunos sentidos con la propuesta de Bourdieu, resulta, en otros, superadora.

\section{Dos miradas sobre el problema de la reflexividad: Bloor y Bourdieu}

Como es sabido, los estudios sociales de la ciencia (o más específicamente la sociología del conocimiento científico) cobraron un fuerte impulso a partir de la formulación, debida a David Bloor, del "programa fuerte de la sociología del conocimiento". Dicho programa se proponía promover un abordaje sociológico del conocimiento científico sin auto-limitarse a los así llamados factores externos de la ciencia, centrándose, en cambio, en el contenido mismo del conocimiento y su naturaleza, lo que tradicionalmente estaba reservado para una rama de la filosofía. Este programa de investigación fue articulado por el propio Bloor en torno a cuatro principios, a saber, causalidad, imparcialidad, simetría y reflexividad (Bloor, 1994, p. 98).

El principio de causalidad estipula que el sociólogo de la ciencia debe dar cuenta de las condiciones que dan lugar a la creencia o a estados de conocimiento, es decir, debe 
ofrecer explicaciones causales del conocimiento. El principio de imparcialidad (que implica una primera ruptura con la sociología mertoniana de la ciencia y, por tanto, un alejamiento de la así llamada sociología del error) estipula que el sociólogo debe dar cuenta tanto de creencias que se consideran verdaderas como de creencias consideradas falsas siendo así imparcial respecto del éxito o fracaso de la creencia que estudia. Por su parte, el principio de simetría establece que el mismo tipo de causas explicarán tanto creencias consideradas verdaderas como aquellas consideradas falsas. Así, este principio viene a rechazar el intento de ofrecer explicaciones que distingan entre el error y la verdad, adjudicando al primero determinantes sociales como su causa y al segundo factores pretendidamente racionales como el método científico. Por último, el principio de reflexividad, que nos ocupa en este capítulo, estipula que los patrones de explicación de la sociología del conocimiento tendrán que ser aplicables a sí misma. En palabras de Bloor,

en principio sus patrones de explicación tendrían que ser aplicables a la sociología misma. Como el requerimiento de simetría, esto es una respuesta a la necesidad de buscar explicaciones generales. Se trata de un requerimiento obvio de principio porque, de otro modo, la sociología sería una refutación viva de sus propias teorías (Bloor, 1994, p. 98).

Así, tal como es presentado por Bloor, el principio de reflexividad viene exigido por dos consideraciones. En primer lugar, por la necesidad de encontrar explicaciones generales, habida cuenta de que su generalidad resultaría limitada si se excluyera a la sociología del conocimiento de la lista de disciplinas científicas susceptibles de explicación sociológica. En segundo lugar, este principio viene exigido por la necesidad de consistencia: si la sociología del conocimiento afirma que el conocimiento puede ser estudiado sociológicamente, entonces debe aceptar, bajo pena de incurrir en una (auto) 
contradicción, que la sociología del conocimiento misma, en tanto forma de conocimiento, puede ser estudiada sociológicamente. En caso de no aceptarse esto, se debería asumir o bien que la sociología del conocimiento no es una forma de conocimiento o bien que no es cierto que el conocimiento sin más pueda ser explicado sociológicamente sino tan sólo algunas formas de conocimiento y, en particular, no el conocimiento proporcionado por la sociología del conocimiento. Esto último, que resultaría un tanto arbitrario, abriría las puertas a una recaída en formas anteriores de la sociología del conocimiento que afirmaban que sólo algunas ciencias eran pasibles de estudios sociales, por ejemplo, las ciencias sociales y no así las exactas o las naturales.

Ahora bien, aun cuando Bloor formula el principio de reflexividad como una manera casi obligada de evitar la auto-refutación, tal principio ha sido tratado como si implicara algún tipo de contradicción interna de la sociología del conocimiento. En efecto, si traducimos tal principio a la afirmación de que toda creencia, incluida ésta que se está formulando, está socialmente determinada, y entendemos esto último en el sentido de que no refleja un mundo objetivo e independiente del sujeto que la formula, parecería que tal creencia resultaría refutada al negarse a sí misma la posibilidad de objetividad y verdad que, por otro lado, debería reconocer si pretende ser conocimiento. La respuesta de Bloor ante este argumento es tajante. En su opinión, el argumento descansa en una premisa oculta, a saber, la premisa de que el condicionamiento social de una creencia implica que es falsa o, al menos, que carece de los atributos mínimos que la convertirían en conocimiento. Sin este supuesto, que Bloor rechaza, el argumento pierde su premisa fundamental y, con ello, su conclusión no puede considerarse como establecida. 
Ahora bien, no obstante este argumento de Bloor, el problema de la reflexividad de los estudios de la ciencia ha sido visto más de una vez como un problema que comprometía, si no la verdad, sí al menos la credibilidad de los estudios de la ciencia. Así, por ejemplo, como señala Kreimer (1999), Woolgar entiende el problema de la reflexividad como el problema de la falibilidad: el problema de si el discurso del sociólogo de la ciencia resulta invalidado al aplicársele las mismas reglas que al discurso de los científicos estudiados (Kreimer, 1999, p. 157). Por su parte, Hamlin plantea el problema en términos similares, como un problema acerca de la (posible) auto-desacreditación que podría implicar el intento de desacreditación de la ciencia operado por el sociólogo de la ciencia. En sus palabras, la “desacreditación de los desacreditadores podría ser vista como un esfuerzo reaccionario, el cual (...) restauraría, en última instancia la autoridad de los científicos naturales quienes habrán conseguido [así] mantener la confianza de gran parte del crédulo público" (Hamlin, 1992, p. 515).

Esta manera de plantear el problema de la reflexividad supone un compromiso con la idea de que el objetivo de los estudios de la ciencia, o al menos de la sociología del conocimiento científico, consiste en desacreditar o cuestionar de algún modo la autoridad de la ciencia o de los científicos al sacar a la luz su insoslayable complicidad con determinantes sociales tales como intereses, grupos de poder, etc. Así, si los estudios sociales de la ciencia son vistos como un intento de invalidar, de algún modo, los resultados de la ciencia, la auto-aplicación parece convertirse en auto-invalidación. Es esta visión de los estudios de la ciencia la que subyace, por ejemplo, a las acusaciones de Collins y Yearley (1992) a Latour y Callon (1992) acerca del carácter reaccionario de las propuestas de estos últimos o, en otros términos, acerca de quiénes son los que confieren una mayor autoridad a las producciones de los científicos (naturales). 
Ahora bien, no es esta la única manera en que se ha pensado la tarea del sociólogo de la ciencia. Por su parte, y oponiéndose explícitamente a esta manera de plantear el problema, Pierre Bourdieu ha abordado la cuestión de la reflexividad pero desde un punto de vista diferente. En sus palabras,

[Resulta] necesario someter a la ciencia a un análisis histórico y sociológico que no tiende, en absoluto, a relativizar el conocimiento científico refiriéndolo y reduciéndolo a sus condiciones históricas, y, por tanto, a unas circunstancias situadas espacial y temporalmente, sino que pretende, muy al contrario, permitir a los practicantes de la ciencia entender mejor los mecanismos sociales que orientan la práctica científica y convertirse de ese modo en «dueños y señores» no sólo de la «naturaleza», (...) sino también (...) del mundo social en el que se produce el conocimiento de la naturaleza (Bourdieu, 2003, pp. 9-10).

De este modo, Bourdieu ofrece una visión diferente de la tarea del sociólogo de la ciencia y con ello también una forma distinta de pensar el problema de la reflexividad. En su opinión, el objetivo de la sociología de la ciencia no es ya el de cuestionar la autoridad de la ciencia, negándole objetividad y adscribiéndole compromisos con intereses sociales o grupos de poder, sino más bien el de ofrecer un saber que pueda ser útil a los científicos. De este modo, el sentido de la tarea del sociólogo resulta invertido: no se trata ya de desautorizar a los científicos sino de dotarlos de herramientas para ejercer su autoridad con mayores márgenes de libertad; de convertirlos en amos y señores de la naturaleza y del mundo social. Coincidentemente, el "problema" de la reflexividad se convierte así en el mandato de reflexionar, también, acerca de las propias formas de producción de conocimiento, acerca de las reglas que rigen el funcionamiento del campo de la sociología de la ciencia, a efectos de mejorarse a sí misma. En palabras de Bourdieu, 
al dirigir sobre el mundo social una mirada irónica que desvela, desenmascara e ilumina lo oculto, [la sociología de la ciencia] no puede dejar de mirarse a sí misma, pero no con la intención de destruirse, sino, por el contrario, de servirse y de utilizar la sociología de la sociología para convertirla en una sociología mejor (Bourdieu, 2003, p. 18).

En este sentido, la propuesta de Bourdieu de desarrollar una sociología de la ciencia y una sociología de la sociología de la ciencia que sirvan como instrumentos para mejorar y modificar el tipo de conocimiento que se produce y la forma en que se lo hace, puede ser vista como una reintroducción de una perspectiva normativa, en línea con el planteo de Fuller mencionado antes. En efecto, la pretensión de mejora de la producción de conocimiento lleva consigo la necesidad de plantear la pregunta por el valor del conocimiento producido, y acaso también por sus fines, sus logros y sus consecuencias.

\section{Algunas dificultades en torno a la propuesta de Bourdieu}

Ahora bien, la propuesta de Bourdieu tiene, desde nuestro punto de vista, algunas dificultades. Como es sabido, uno de los aspectos centrales de la noción de campo científico propuesta por Bourdieu es la insistencia en la idea de que la actividad científica tiene una lógica propia, caracterizada también por sus propias formas de capital. La noción de campo científico (Bourdieu, 2000) refiere a ese universo, relativamente autónomo, que incluye a los agentes y las instituciones que producen, reproducen o difunden la ciencia. En palabras de Bourdieu: "la noción de campo pretende designar ese espacio relativamente autónomo, ese microcosmos provisto de sus propias leyes” (2000, pp. 74-75). Además, si bien el campo "nunca escapa del todo a las coacciones del macrocosmos, dispone de una 
autonomía parcial, más o menos marcada, con respecto a él” (Bourdieu, 2000, p. 74). Como queda de manifiesto en esta cita, la relación entre la ciencia y el contexto en el que se halla inmersa es vista como una relación entre dos universos distintos que se encuentran, de algún modo, entrelazados en una lucha. Lo que el macrocosmos social tiene para ofrecer a la ciencia parece ser coacción, y la ciencia, por su parte, debe o puede escapar de las injerencias del macrocosmos. Tal como queda planteado el asunto, de acuerdo con Bourdieu, surgen dos problemas. En primer lugar, el problema de determinar la naturaleza de las coacciones externas $\mathrm{y}$, en segundo, el problema de determinar "cuáles son los mecanismos que introduce el microcosmos para liberarse de esas coacciones externas y estar en condiciones de reconocer únicamente sus propias determinaciones internas" (Bourdieu, 2000, p. 75). De este modo, Bourdieu parece suponer una clara separación entre los factores propios de la ciencia -lo interno, el microcosmos- y lo externo, y piensa su relación como una en que lo interno busca liberarse de los condicionamientos sociales externos para regirse de acuerdo con sus propias leyes. Así, lo extra-científico, lo social en sentido amplio, es visto como algo que molesta, que interfiere, que coacciona al campo científico que queda, así, definido como un universo autónomo, o a lo sumo, como un universo en una constante lucha por la autonomía. Así, un alto grado de autonomía es visto como algo positivo. De acuerdo con Bourdieu,

cuanto más heterónomo es un campo, más imperfecta es la competencia y más legítimo resulta que los agentes hagan intervenir fuerzas no científicas en las luchas científicas. Al contrario, cuanto más autónomo es un campo y más cerca está de una competencia pura y perfecta, más puramente científica es la censura, que excluye la intervención de fuerzas meramente sociales (Bourdieu, 2000, p. 85). 
Por otro lado, la estructura interna de un campo en un determinado momento queda caracterizada por el modo en que está distribuido el capital propio de ese campo. En el caso de la ciencia, el capital científico es un tipo de capital simbólico que consiste básicamente en el "reconocimiento (o el crédito) otorgado por el conjunto de los pares-competidores" (Bourdieu, 2000, p. 79). Así, las luchas en el interior del campo científico, las luchas libradas por los capitalistas cientificos, son vistas como luchas entre agentes que ocupan distintas posiciones que se enfrentan, por así decirlo, en una verdadera dialéctica del amo y el esclavo, en una lucha a muerte por el reconocimiento. Cabe recordar que esta concepción de Bourdieu no sólo tiene alcances descriptivos sino que sobre ella pretende basar una verdadera política para la ciencia, tal como puede apreciarse en la siguiente cita:

para que progrese la cientificidad, hay que hacer progresar la autonomía y, más concretamente, sus condiciones prácticas, mediante la elevación de las barreras de entrada, la exclusión de la introducción y utilización de armas no específicas y la promoción de formas reguladas de competencias, únicamente sometidas a las restricciones de la coherencia lógica y la verificación experimental (Bourdieu, 2000, pp. 95-96).

Así, si bien Bourdieu reconoce que lo no científico puede tener injerencias en campos heterónomos, lo cierto es que la heteronomía no es, desde su punto de vista, algo deseable. La ciencia puede progresar sólo si refuerza su autonomía. Resulta llamativo que esta insistencia de Bourdieu en la autonomía, y en la necesidad de evitar que se introduzcan factores no-científicos no implica, como podría pensarse, que Bourdieu niegue toda utilidad social a la ciencia. Muy por el contrario, en su opinión, se trata de que el científico sea más autónomo a los efectos de ganar el prestigio y el poder necesarios para intervenir luego en la solución de problemas y en el mejoramiento de las condiciones sociales. En palabras de 
Bourdieu: "el principio de toda la Realpolitik de la razón por la que abogo consiste en acumular la mayor cantidad posible de autoridad para hacer de ella, llegado el caso, una fuerza política, sin convertirse por ello, desde luego, en un político" (2000, pp. 129-130). Y un poco más adelante agrega que: "mi gran anhelo es que lo que se denomina comunidad científica (...) se constituya poco a poco como una instancia colectiva para intervenir como una fuerza política y dar su opinión sobre los problemas que son de su incumbencia” (2000, p. 130). De este modo, parece que la búsqueda de autonomía queda justificada por la necesidad de obtener poder para luego intervenir como científico, desde el lugar del sabio, y no como político. Nos encontramos aquí con una suerte de enmascaramiento del aspecto político de la ciencia: la ciencia debe funcionar como una fuerza política, pero no como tal, sino desde el lugar de un saber autónomo e independiente. Así la ciencia se arrogaría una cierta neutralidad ética y política, puesto que se regiría sólo mediante leyes y reglas puramente científicas, para intervenir con mayor eficacia como fuerza política: niega su carácter político para operar, con mayor eficacia, como fuerza política.

En este contexto se plantea al científico, y parece ser que sólo al científico, el problema de lograr que las conquistas que obtuvo en su búsqueda por el reconocimiento y por la autonomía de su campo, en su lucha por el poder dentro del mismo, se conviertan en saberes aptos para resolver problemas públicos: "uno de los problemas que se plantea a todos los científicos en grados diversos (...) es el de restituir las conquistas de la ciencia a los ámbitos en que podrían contribuir de manera decisiva a resolver problemas que han alcanzado la conciencia pública" (Bourdieu, 2000, p. 134). De este modo, y así como Descartes tuvo que pensar el problema de cómo la mente mueve al cuerpo luego de haber separado dicotómicamente la res extensa y la res cogitans, la separación entre lo científico 
y lo social por la que aboga Bourdieu parece crear el problema de buscar la manera de unir lo que previamente se separó, esto es, de volver socialmente útil el conocimiento producido por una casta científica autónoma del entorno en el que trabaja. En este sentido la mirada de Bourdieu es una mirada no-democrática de lo que él mismo llama uso social de la ciencia: los científicos, qua científicos, como especialistas autónomos, deben ocuparse de volver aptos los logros de la ciencia para resolver problemas públicos. Se trata de una mirada tecnocrática de la participación de la ciencia en los problemas sociales, que no problematiza, por ejemplo, la participación del público en la definición de los problemas a ser abordados por la ciencia, ni en la definición e identificación por parte de la ciencia de algo como un problema social (cfr. Gusfield, 1981), o la posibilidad de un cuestionamiento por parte del público del tipo de saber producido por la ciencia.

Esta manera de pensar la ciencia como algo opuesto y distinto a la sociedad, más o menos cerrado sobre sí mismo, como algo con una propia constitución que sale luego al encuentro de lo otro, de lo social, o, si se quiere, como una suerte de nave que debe atravesar el macrocosmos social luchando por su propia integridad, ha sido criticada por Knorr Cetina. Como hemos visto en la sección anterior, Knorr Cetina ha cuestionado la idea misma de capital tal como pretende ser aplicada en los estudios de la ciencia, y específicamente el reduccionismo que supone aseverar que los objetivos de los científicos se reduzcan a acumular prestigio, negando las diferentes lógicas que intervienen en la fabricación del conocimiento. Asimismo, esta autora insiste, apoyada en sus propios estudios de laboratorio, en que la actividad científica, lejos de desarrollarse en una suerte de microcosmos aislado constituido por el campo de una disciplina, se desarrolla en arenas transepistémicas en las que intervienen científicos de distintas disciplinas pero también una gran multiplicidad de agentes no-científicos. Así, la visión de Bourdieu incurriría en una 
nueva forma de internalismo que concentra su mirada en el mundo institucional de la ciencia, las comunidades o los campos, buscando lógicas internas, y que no tiene suficientemente en cuenta su vínculo con lo que está por fuera. Como señala Knorr-Cetina, las comunidades científicas se han transformado en mercados en los cuales los productores y los clientes son de igual forma colegas en una especialidad, o en áreas de investigación vinculadas. (...) Los científicos se han vuelto capitalistas, pero aún son tratados como si estuvieran aislados en un sistema auto-contenido y cuasi-independiente (1996, pp. 140-141).

Otro aspecto de la posición de Bourdieu que cabe resaltar es su compromiso con una mirada representativista sobre el conocimiento científico, esto es, su aceptación de que el conocimiento es básicamente una forma de representar el mundo. Así, en su visión, los científicos acumularían capital básicamente mediante la construcción de explicaciones y representaciones acerca de lo real. Aunque Bourdieu tiene en cuenta que no hay observaciones y métodos pretendidamente neutrales, sino que señala que tales métodos son ellos mismos objetos de disputa por cuanto la facción dominante en un campo impone sus propias reglas, lo cierto es que sigue viendo al conocimiento científico como una forma de representación lingüística de lo que se supone real. Ello queda de manifiesto en la siguiente cita:

En el campo se enfrentan construcciones sociales antagónicas, representaciones, (...) pero representaciones realistas, que se pretenden fundadas en una "realidad" dotada de todos los medios para imponer su veredicto a través del arsenal de métodos, instrumentos y técnicas de experimentación colectivamente acumulados y colectivamente puestos en acción, bajo la coacción de las disciplinas y las censuras del campo (Bourdieu, 2000, p. 86). 
Así, y para resumir, nos encontramos con tres aspectos del pensamiento de Bourdieu que resultan cuestionables a la luz de la posición de Dewey que hemos reconstruido en esta tesis y de algunos resultados de los estudios de la ciencia que hemos analizado. Se trata, en primer lugar, de una visión internalista de la actividad científica, de una visión no-democrática o tecnocrática del uso social de la ciencia y, por último, de una mirada representativista del conocimiento científico.

Para finalizar, recordaremos algunos aspectos de la concepción deweyana del conocimiento que nos permiten sostener que, desde el punto de vista de Dewey, el problema de la reflexividad de los estudios de la ciencia debe ser pensado como un asunto de control, dirección y mejora de mismos. Aunque hay en este aspecto una proximidad con el enfoque de Bourdieu -al plantear abiertamente la cuestión de los fines de la ciencia y por tanto incorporar la perspectiva normativa o crítica reclamada por Fuller- su visión no resulta comprometida con los aspectos cuestionables de la propuesta de Bourdieu antes mencionados. Tal perspectiva crítica es lograda en la propuesta deweyana al asumir una visión performativa del conocimiento que lo conduce a reconocer fuertemente las continuidades entre la investigación científica propiamente dicha y el conjunto de la vida biológica y cultural del ser humano, o, lo que es lo mismo, la experiencia, lo que lleva, en última instancia a tener presente la relación entre el público y la ciencia. Recordemos que, para Dewey, la investigación es transformación de la realidad y no mera descripción de la misma. En ese sentido el conocimiento, en tanto práctica tecnológica de transformación del mundo, es siempre aplicado o instrumental. Desde este punto de vista, arguye Dewey, el problema con la aplicación del conocimiento reside en la limitación de los fines en función de los cuales se realiza. En la siguiente cita, a la que ya hemos recurrido, Dewey expresa tal punto de vista con mucha claridad: 
la ciencia se convierte en conocimiento en su sentido honorable y categórico sólo en la aplicación. En caso contrario permanece truncada, ciega, distorsionada. Y cuando se aplica, se hace de una forma que explica el sentido desfavorable que tan a menudo se da a la 'aplicación' y lo 'utilitario', a saber: se la usa con fines pecuniarios y en beneficio de unos pocos (2004, p. 151).

Ahora bien, esta concepción del conocimiento puede y debe ser aplicada a la teoría de la investigación misma: si el estudio de la ciencia es conocimiento deberá ser, en este contexto, pensable como forma de investigación y, en esa medida, como intento de resolver una situación problemática, es decir, como intento de transformación de la realidad de la que se ocupa y no como su mera descripción. Esto nos obliga, en primer lugar, a identificar el problema que tales estudios se proponen abordar. La última parte de la cita anterior sugiere ya el problema: una de las mayores preocupaciones de Dewey era precisamente que los resultados de la ciencia, en vez de ser puestos a disposición del público, en vez de constituir verdaderas herramientas de las que el público se pudiera apropiar a efectos de enriquecer y ensanchar su propia experiencia, resultaban apropiados por intereses particulares que los ponían así al servicio del beneficio privado y el privilegio de clase. Resulta llamativa la proximidad entre este punto de vista de Dewey y la crítica de la escuela de Frankfurt acerca del rol del desarrollo científico-tecnológico en las sociedades capitalistas. De acuerdo con Dewey, este era el problema más acuciante respecto de la investigación científica y su causa era, en parte, que científicos, políticos, filósofos y el público en general sostenían una visión del conocimiento como contemplación ociosa de verdades eternas que resultaba pre-experimental y pre-científica. Desde su punto de vista, esa concepción del conocimiento como algo radicalmente separado y separable de la experiencia humana en su conjunto, como algo más o menos autosuficiente que encuentra 
su fin en sí mismo, resultaba altamente perjudicial. En sus palabras, "la idea de la separación completa de la ciencia respecto al ambiente social es una falacia que fomenta la irresponsabilidad en los científicos por lo que respecta a las consecuencias sociales de su trabajo" (1950, p. 536).

Este aspecto de investigación transformadora de la reflexión sobre el conocimiento es de hecho, para Dewey, un elemento central en su concepción de la filosofía. En efecto, el método empírico de filosofar que proponía debía ser capaz de usar aquello que produce, a saber, sus teorías y conceptos, como un camino que lleve de vuelta a la experiencia ordinaria. Más aún, esto constituye un verdadero test para determinar el valor de una teoría cualquiera. Así, una buena filosofía, de acuerdo con Dewey (1981, p. 40), es aquella que, al volver sobre las cosas de la vida ordinaria, las ilumina, las hace más comprensibles y significativas e incluso aquella que sirve como una herramienta en su mejoramiento.

En este contexto, para Dewey, era una tarea de vital importancia -de cara al objetivo de transformar la práctica científica- elaborar una concepción de la ciencia que sacara a la luz sus continuidades con los otros aspectos del mundo natural y social y llamara la atención sobre sus efectos respecto de tal mundo y sobre el potencial enriquecimiento de la experiencia que tiene para ofrecer.

Resulta claro que desde esta perspectiva el problema de la reflexividad de los estudios de la ciencia debe ser visto como el problema de generar las condiciones que permitan a quienes los realizan perfeccionar y enriquecer sus propias prácticas de modo que sirvan mejor como medios para alcanzar el fin que se proponen, esto es, la mejora de la ciencia. Tal mejora significa, para Dewey, la democratización de la ciencia, tanto en su propia producción como en sus resultados. En efecto, como sostiene Dewey, "la concordancia entre las actividades científicas y las consecuencias que provocan en el 
público (...) constituye una parte integrante del testeo completo de las conclusiones físicas, siempre que su pertinencia pública resulte relevante" (1950, pp. 537-538).

Esta constante referencia al público, incluso como parte del testeo, esto es, de la validación de las conclusiones de la ciencia, es decir, esta inserción de lo social y lo público en el corazón mismo de la ciencia, resulta claramente incompatible con cualquier forma de internalismo en el estudio de la ciencia. Con ello, cae también la idea de una actividad científica autónoma que debe resguardarse frente a las injerencias de lo externo. Tal resguardo sería de hecho, para Dewey, una forma de irresponsabilidad social por parte de los científicos. La ciencia no es autónoma porque es una forma social de intervención, de transformación del mundo en que habitan los seres humanos. La visión contraria, la idea de una ciencia separada del mundo, no es más que una forma de ocultar la real injerencia de la ciencia en nuestras vidas. Esta reflexión de Dewey acerca del rol ideológico, por así decirlo, de la imagen internalista de la ciencia, parece confirmada en gran medida por Dominique Pestre, quien señala que tal visión

contribuyó a legitimar a los 'sabios' e 'intelectuales', haciendo de ellos personajes más allá del bien y del mal, personajes dedicados sólo al conocimiento y al bien público, personajes 'desinteresados', y eso en el momento mismo en el que su inserción en el mundo de los negocios y de las industrias basadas en el conocimiento cobraba nuevo vuelo y nueva forma (2005, p. 28).

\section{Conclusiones}

En este capítulo hemos opuesto dos maneras de pensar el problema de la reflexividad de los estudios de la ciencia. Mientras según algunos autores el problema que plantea la 
reflexividad es un problema acerca de la posible auto-desacreditación de la sociología de la ciencia, hemos llamado la atención, apoyándonos en Bourdieu y también en Dewey, acerca de un modo distinto de pensar el problema. Desde tal punto de vista, el problema de la reflexividad es el problema acerca de cómo hacer que los métodos empleados por los estudios sociales de la ciencia sirvan para mejorar la práctica misma de los estudios de la ciencia. Asimismo, hemos llamado la atención sobre lo que consideramos problemas en el enfoque de Bourdieu y, recurriendo a Dewey, hemos explicitado una manera de comprender el conocimiento que rechaza la visión internalista de la actividad científica, la visión no democrática de la utilidad social de la ciencia y la visión representativista del conocimiento científico.

Merece destacarse que, en la visión de Dewey, todo ello se logra rechazando a la vez la idea de la ciencia como algo distinto de lo social, o tal vez sea mejor decir, como una actividad humana que se distingue de otras por su vínculo con o referencia a algo así como la verdad y la objetividad y sólo con ello. En la ciencia, tanto como en (casi) cualquier otra actividad humana, intervienen tanto aspectos tradicionalmente considerados racionales como aspectos ligados a las emociones, los deseos y especialmente los valores. Así, cuando un interés social interviene en la ciencia, no lo hace como algo extraño a la ciencia misma sino como algo inherente a la actividad científica. El problema no es, para la ciencia, la búsqueda de una autonomía creciente, en el sentido de regirse sólo por las reglas que la ciencia se da a sí misma, sino, en todo caso, la búsqueda de una mayor y más explícita vinculación con ciertos fines, con ciertos valores, a saber, con los fines que los ciudadanos, incluidos los científicos, consideren, luego de una examen público y razonado, dignos de ser perseguidos. Nuevamente, el problema no es la intromisión de lo social sobre lo científico sino, en todo caso, la colonización del ámbito científico por parte de ciertos 
intereses, y especialmente de aquellos vinculados con el beneficio privado y el privilegio de clase. De este modo, según esta concepción ya no cabe hablar de valores epistémicos y extra-epistémicos: los valores éticos y políticos son también epistémicos en tanto que forman parte indisociable del quehacer científico. La diferencia importante será, más bien, la que hay entre aquellos valores que persiguen y posibilitan el enriquecimiento de la experiencia de todos, es decir, los democráticos, y aquellos que no lo hacen. Democratización de la ciencia quiere decir, en este contexto, discusión pública de sus fines y apropiación colectiva de sus logros. 


\section{Conclusiones generales: recapitulación de los resultados}

\section{alcanzados}

En esta tesis hemos abordado la teoría de la investigación de Dewey teniendo en cuenta sus antecedentes en los escritos de Peirce y algunas de sus derivaciones en la teoría de la argumentación contemporánea y en los estudios de laboratorio. A continuación recordaremos y resumiremos las conclusiones alcanzadas en cada uno de los capítulos.

\section{De Peirce a Dewey}

En el comienzo de esta tesis hemos presentado la caracterización del programa pragmatista propuesta por Putnam. En su opinión, el pragmatismo puede caracterizarse como un falibilismo antiescéptico, que otorga un carácter central a la práctica y que propone superar la dicotomía entre hechos y valores. Como hemos visto, Peirce desarrolló, en efecto, una concepción del conocimiento falibilista y antiescéptica que rechaza la pretensión de certeza absoluta pero sin renunciar a la posibilidad de un conocimiento legítimo. Hemos visto, también, que Peirce realiza una crítica a lo que entiende como la concepción moderna del conocimiento en general y del conocimiento filosófico en particular. Esta crítica supone, como hemos mostrado, un cambio hacia una concepción del conocimiento que podemos caracterizar, además, como antifundacionalista por su rechazo de la intuición como fundamento del conocimiento, y como intersubjetiva o social por su idea de que aquello 
que se considera verdadero, e incluso real, es siempre una función de una comunidad indefinida de investigación.

El resultado principal de dicho capítulo ha sido llamar la atención respecto de los profundos cambios que Peirce estaba promoviendo en relación a la forma en que debe hacerse filosofía y al tipo de problemas que esta debería abordar: el filósofo es más parecido a un pensador empírico que busca pruebas e indicios, que recoge las fibras que le permitirán ofrecer una soga firme aunque no absolutamente irrompible, que a un razonador algorítmico que encadena paso a paso, y siempre deductivamente, sus argumentos. En un contexto como éste, las tesis filosóficas son siempre hipótesis que, como cualquier hipótesis, tienen que ser validadas siguiendo sus consecuencias y que no pierden nunca su carácter provisorio.

Es importante reconocer que la lectura de Peirce que hemos ofrecido es una lectura ciertamente parcial aunque posible y es, en todo caso, la lectura del propio Dewey: se trata de las ideas que este último creyó encontrar en los escritos de Peirce. Acaso el punto más controversial sea el referido a la concepción de la lógica. En efecto, como hemos visto, la crítica de Peirce a Dewey parece desautorizar cualquier intento de establecer cierta continuidad entre las posiciones de nuestros pragmatistas. Sin embargo, como hemos intentado mostrar, hay aspectos de la concepción peirceana de la lógica que resultan próximos a la concepción deweyana. En todo caso, resulta evidente que así fue a los ojos del propio Dewey.

Independientemente de esa discusión, tal vez el aspecto más destacable de la reapropiación deweyana de las ideas de Peirce sea la asimilación, en cierto sentido, de la filosofía con las ciencias experimentales. Si la filosofía es una forma de conocimiento, 
entonces debe exhibir las características que resultan inherentes a todo conocimiento: no puede basarse en intuiciones últimas (anti-fundacionalismo), ni arribar a certezas incuestionables (falibilismo) y sus afirmaciones, en tanto que hipótesis, al igual que cualquier hipótesis científica, reciben su confirmación a partir del análisis de sus consecuencias (anti-escepticismo). Así, la filosofía misma no es más que una forma de investigación. Además, la filosofía, como forma de investigación, no comienza con la ignorancia absoluta sino que toma como punto de partida creencias que, a los efectos de esa investigación, pueden darse como descontadas. La filosofía debe comenzar, necesariamente, con todos los prejuicios reales que constituyen la base a partir de la cual podemos formular las razones de nuestras dudas.

\section{La teoría de la investigación de Dewey}

En la segunda parte de esta tesis nos hemos detenido en el análisis de la teoría de la investigación de Dewey. Hemos analizado la teoría deweyana de la experiencia, a la que consideramos como un punto de partida de la filosofía de Dewey, y hemos visto de qué manera esta concepción de la experiencia prefigura la concepción de la investigación. Asimismo, nos hemos detenido en algunos aspectos importantes de tal concepción, a saber, en el carácter transformacional de la misma, en sus consecuencias respecto de la concepción de la lógica y de los principios que regulan las prácticas cognitivas y en los vínculos entre conocimiento y valores que permite establecer.

En el capítulo destinado a la concepción deweyana de la experiencia hemos explicitado los alcances de su concepción de la misma como transacción, lo que ha permitido apreciar en qué sentidos pretende Dewey apartarse de la concepción tradicional 
de la experiencia. Asimismo, hemos visto que el reconocimiento del carácter de inmediatez cualitativa de toda experiencia constituye un punto de partida importante para vincular distintos tipos de experiencia. En efecto, fue una preocupación constante de Dewey superar la compartimentación de la experiencia que tendía a mantener separados los diferentes modos y campos de la experiencia humana. Una vez que pueden verse las continuidades entre los distintos tipos de experiencia, puede apreciarse mejor el carácter mediador de la experiencia cognitiva en relación a la experiencia primaria y su doble dependencia respecto de esta última: como punto inicial en el planteamiento de los problemas y los recursos de la investigación, y como punto de llegada de las transformaciones que opera. Esto nos ha llevado, a su vez, a explicitar algunos aspectos de su concepción instrumental del objeto de la ciencia y de la actividad científica misma.

Por otra parte, hemos cuestionado la pretendida tensión afirmada por Rorty entre el giro lingüístico de la filosofía del siglo XX y el recurso al concepto de experiencia a la vez que hemos argumentado, contra Rorty, que la renuncia tardía de Dewey a los términos experiencia y metafísica es más bien una renuncia a las palabras que no modifica, al menos no sustancialmente, el programa que intentó desarrollar en Experience and Nature. Ello nos permitió ver que, más allá de estas cuestiones, Dewey no creía estar desarrollando una metafisica de la experiencia. Más bien, la utilización como un punto de partida del concepto de experiencia, en casi todas sus obras, era una consecuencia insoslayable de tomarse en serio a Darwin. Este recurso a Darwin se apoyaba, a su turno, en una cierta concepción de la filosofía que seguía de cerca las consideraciones de Peirce. Si la filosofía ha de producir conocimiento, debe entenderse, entonces, como una forma de investigación. Y ninguna investigación empieza de la nada: siempre lo primero es establecer cuáles son 
los puntos de partida que en la investigación que se desarrolla pueden darse por sentados, y ello no porque sean verdades incuestionables sino porque han sido bien establecidas en otras investigaciones, a saber, las investigaciones en el campo de la psicología, la biología y la antropología social. De este modo, y tal como lo hemos explicitado en el capítulo 4, la posición de Dewey se encuentra comprometida, desde el principio, con una posición naturalista, que pretende oponerse tanto a las posiciones anti-naturalistas como a los naturalismos reduccionistas, al tener en cuenta tanto el seno biológico como el cultural en el que la investigación ocurre.

Hemos visto, también, que su concepción del conocimiento supone dos movimientos metodológicos. El primero de ellos es la adopción del principio de análisis contextual que supone rechazar una distinción dicotómica entre proceso y producto como forma de delimitar el espacio de la reflexión filosófica acerca del conocimiento. Así, la concepción del conocimiento debe considerarse como una generalización de las características que se encuentran como pertenecientes a los resultados de un proceso de investigación. Como consecuencia de ello, se sustituye la verdad por la asertabilidad garantizada como resultado de la investigación, cuya característica principal es que constituye un recurso para otras investigaciones. Por otro lado, este principio de análisis contextual, al dirigir la mirada al proceso de investigación, supone una aproximación empírica a la problemática del conocimiento, aproximación que evitaría a la filosofía volver a caer en la vieja trampa de imponer sobre los hechos una pretendida descripción que no es más que una deducción a partir de supuestos filosóficos tradicionales heredados y no sometidos a revisión. 
El segundo movimiento consiste en una inversión de la prioridad conceptual del así llamado conocimiento aplicado por sobre el conocimiento básico. El análisis de esta cuestión nos ha llevado a especificar tres sentidos o dimensiones de la comprensión instrumental del conocimiento de Dewey: (a) el conocimiento es instrumental porque su objeto es instrumental: se trata de las relaciones de condiciones-consecuencias, los procesos que acaecen en la naturaleza; (b) el conocimiento es en sí mismo un instrumento porque constituye un verdadero medio, una herramienta para la transformación del mundo y (c) el conocimiento es instrumental porque su propia producción es una práctica tecnológica de utilización y modificación de los materiales existenciales y conceptuales que intervienen en la investigación.

Una vez explicitada esta concepción de la investigación, hemos analizado las consecuencias de tal visión en relación con la comprensión de la lógica de Dewey, y específicamente su comprensión de la inferencia como diferente del razonamiento y su consideración acerca de la naturaleza de los principios lógicos. Asimismo, hemos intentado despejar algunas de las dudas que han sido planteadas en relación con la consideración de la propuesta de Dewey como una genuina lógica. Para que tal lectura sea plausible, hemos defendido la idea de que si bien la lógica de Dewey es teoría de la investigación, no es toda la teoría de la investigación. En este sentido, argumentamos que la lógica deweyana puede entenderse como un estudio de las normas y principios que permiten garantizar la inferencia, que tiene, aun en el contexto de los debates actuales, algo que ofrecer. Tales aportes refieren fundamentalmente a su concepción naturalista y empírica y a sus críticas al formalismo. En este sentido, la tesis que sugerimos es que si la lógica de Dewey es juzgada teniendo en cuenta la concepción de la lógica propia de la lógica informal y la teoría de la 
argumentación, en vez de seguir juzgándola desde el punto de vista de las concepciones de la lógica asociadas a la lógica formal, entonces no sólo su naturalismo normativo se vuelve una tesis plausible acerca de los principios lógicos, sino que también pueden encontrarse allí algunos aportes interesantes.

Una vez reconstruida la teoría deweyana de la investigación, hemos analizado su teoría de la valoración a efectos de ofrecer una mirada acerca de la relación entre conocimiento científico y valores en el contexto de la obra de Dewey. Hemos visto que la comprensión de la investigación científica como forma de la práctica supone que la actividad científica consiste mayoritariamente en la formulación de juicios prácticos. Un juicio práctico es un juicio acerca de lo que conviene hacer, y supone entonces evaluar materiales y cursos de acción posibles, en tanto que medios para el cumplimiento de un fin pretendido. Así, los juicios prácticos suponen juicios evaluativos. Ahora bien, hasta aquí no se ha demostrado que tales juicios evaluativos involucren valores extra-epistémicos y más específicamente valores éticos o políticos. Un juicio evaluativo es simplemente una valoración de las cosas como medios y fines, y no hay nada hasta aquí que obligue a que tales valoraciones involucren valores éticos o políticos.

Por otro lado, se ha llamado la atención sobre la idea de Dewey según la cual los juicios valorativos en sentido distintivo son juicios en los que lo que se evalúa son deseos e intereses. Es decir, se evalúan los fines que nos proponemos y tal evaluación puede hacerse sobre la base de proposiciones evaluativas, es decir, sobre la base de proposiciones acerca de las cosas tomadas como medios y fines. Otro aspecto importante en el que nos hemos detenido es que toda evaluación, ya sea científica, ética o política supone un contexto que puede caracterizarse como un continuo de investigación/valoración. Puesto que ese contexto refiere a la vez a las tradiciones y teorías en que se apoyan los actos singulares de 
investigación/valoración y al espacio, los materiales y los problemas específicos que impulsan la investigación y la valoración, no puede trazarse una distinción a priori entre investigación y valoración, sino que más bien es esperable que en toda investigación se recurra a valores como recursos, y en toda valoración, en la medida en que resulte fundada, a aserciones garantizadas. Aunque hemos afirmado que, en este contexto, la pretensión de que una teoría científica particular ha recurrido a un cierto valor en el proceso de su validación es algo que debe ser decidido localmente, es decir, como consecuencia de estudios empíricos de la investigación, es posible afirmar que, desde el punto de vista de Dewey, toda investigación está cargada de valores, lo mismo que toda valoración está cargada de investigación.

Así, la valoración y la investigación deben ser vistas como procesos de deliberación racional que exhiben una misma estructura. Esta comunidad en su estructura permite extraer algunas conclusiones: en primer lugar, toda evaluación de fines y valores, al igual que toda investigación científica, es un modo de respuesta a una situación problemática, y sus productos deben ser evaluados en función de su calidad de medios para transformar la situación. Un subproducto de tal proceso es la generación de asertabilidad garantizada en el ámbito de la investigación científica, y de valores en el campo de la valoración. En ambos casos, la importancia de tales productos es que se constituyen en recursos, en medios para ulteriores investigaciones y valoraciones, aunque su utilización en nuevos contextos está siempre sometida a revisión crítica. En segundo lugar, este isomorfismo investigación/valoración tiene una consecuencia importante para la cuestión de los valores: hace tiempo que en relación al conocimiento se ha superado el modelo axiomático propio del fundacionalismo, y lo mismo debe ocurrir, como consecuencia de la posición de 
Dewey, respecto de los valores. En otros términos, así como no hay verdades primeras ni últimas, no hay valores primeros ni últimos: todos los valores pueden y deben ser sometidos a crítica, siempre que sea necesario. Así, Dewey ha sostenido una concepción anti-fundacionalista, anti-escéptica y falibilista, no sólo del conocimiento, sino también de los valores. Recordemos que, desde la perspectiva naturalista de Dewey, o bien los valores hallan su fundamentación en algún tipo de experiencia inteligente, o carecen de toda fundamentación.

La consideración de tal concepción de los valores nos ha permitido dar una respuesta a las objeciones de Horkheimer y Marcuse, reafirmando así el potencial crítico de la filosofía de Dewey. En efecto, nuestro autor ha planteado con toda radicalidad la necesidad de ejercer una reflexión ética y política acerca de la ciencia. En su opinión, los principios de liberalismo económico, es decir, los principios del individualismo del laissezfaire, han gobernado la investigación científica de modo que se ha permitido que los gustos y preferencias de los científicos regulen su actividad. Puede afirmarse, siguiendo a Dewey, que la ciencia puede y debe ser guiada por valores, pero por valores que hayan sido críticamente analizados: tales valores no son ni los valores de los individuos en connivencia con la industria, ni los fines de un estado totalitario o valores que sólo representan los intereses de una clase especial: deben ser los fines abierta y democráticamente analizados, criticados y validados o rechazados por el público. 


\section{Dewey y el giro práctico de la lógica y de los estudios de la ciencia}

En la tercera parte de esta tesis nos hemos detenido en analizar los vínculos entre la teoría de la investigación de Dewey y lo que puede caracterizarse como un giro hacia las prácticas de la lógica y de los estudios de la ciencia.

En relación con la lógica, lo primero que cabe señalar es que el carácter de genuina lógica de la propuesta de Dewey no puede seguir siendo juzgado desde la perspectiva de la comprensión formalista y deductivista de la lógica, que se consolidó en las últimas décadas del siglo XIX y las primeras del XX. Hemos señalado, con Woods y Gabbay, que la lógica misma, desde mediados del siglo XX, ha dado un giro práctico. Dicho giro ha tomado, en la obra de Toulmin, uno de los impulsores del resurgimiento de la teoría de la argumentación, una forma muy próxima a la transformación de la lógica pretendida por Dewey. Hemos visto incluso que Dewey ha anticipado algunos de los aportes de Toulmin y que ha tenido una influencia importante no sólo en dicho autor, sino también en el movimiento de lógica informal en Estados Unidos, tal como ha sido reconocido, por ejemplo, por Johnson.

Un aspecto importante que hemos señalado, y que caracteriza en alguna medida los aportes de Dewey y los distingue de la visión dominante sobre la argumentación, refiere a las diferencias importantes entre la investigación y la argumentación, al menos tal como esta última ha sido comprendida en el ámbito de la teoría de la argumentación contemporánea. La argumentación es en general comprendida como el intento de justificar o fundamentar una tesis o conclusión frente a otros. En un contexto tal, la conclusión es algo de lo que se dispone desde el comienzo. En el caso de la investigación, la conclusión o hipótesis no es algo de lo que necesariamente se disponga desde el comienzo: el punto de partida es la 
determinación del problema, la especificación de cuál es, precisamente, el problema. En tal especificación se determina cuáles son los hechos del caso, que sugieren la hipótesis, que sólo tendrá el carácter de conclusión al finalizar el proceso de control o evaluación de la sugerencia o inferencia. La diferencia entre la investigación y la argumentación es una diferencia relevante de cara a la cuestión de la enseñanza de la lógica, que, vale la pena recordar, fue una cuestión importante en el desarrollo de la lógica informal y la teoría de la argumentación.

Otra área en la que los aportes de Dewey muestran una notable actualidad es el campo de los estudios sociales de la ciencia. Hemos visto que hay una serie de ideas presentes en la obra de Dewey que parecen ser revalidadas en el contexto de algunos de los estudios de laboratorio. Ello resulta, en primer lugar, consistente con la pretensión deweyana de que su concepción del conocimiento resultaba de una observación del modo en que de hecho se produce el conocimiento, esto es, de la investigación. Creemos, en este sentido, con Latour, que los estudios del laboratorio pueden considerarse como un desarrollo del programa epistemológico de Dewey. Esta idea parece ser reforzada por el hecho de que muchas de las tesis e ideas del pragmatista en torno a la investigación resultan muy próximas a los resultados de tales estudios.

En primer lugar, resalta el carácter productivo o constructivo de la investigación. Los hechos científicos, afirma Latour, son artefactos, cuyos procesos de producción pueden ser seguidos por el antropólogo en el laboratorio. La realidad, ha sostenido según vimos Knorr Cetina, no se encuentra en el laboratorio, a menos que se la defina como el producto del trabajo del laboratorio. Ello es así, podemos argumentar con Dewey, porque toda investigación supone una activad de hacer y rehacer, o más bien de transformar, materiales, procesos y conceptos. La realidad conocida es un producto de la investigación y no un 
mundo antecedente al que simplemente describamos. Consistentemente con ello, la tarea del científico es, en palabras de Dewey, realizar juicios prácticos, esto es, juicios acerca de lo que conviene hacer. En términos de los estudios de laboratorio, la construcción o producción de hechos científicos se da en un proceso que supone elecciones, selecciones, inscripciones, en un proceso de negociación.

Este carácter productivo o constructivo de la investigación señala, a su vez, su carácter local o contextual. Ello significa, para Knorr Cetina, que los criterios y las razones que utilizan los científicos para justificar sus selecciones remiten más bien al contexto concreto en el que desarrollan la investigación que a los estándares o patrones puramente disciplinares. Ello no significa que estos últimos no jueguen un rol importante, sino más bien que las selecciones de laboratorio no pueden explicarse recurriendo sólo a ellos. Las selecciones de laboratorio se justifican mediante razones que trascienden el sitio de la investigación, e incluso el perímetro disciplinar y el científico: las selecciones del laboratorio se realizan, no en el contexto de una comunidad de especialistas, sino en el seno de una arena transepistémica de investigación. Ello resulta consistente con la idea de Dewey de la dependencia de la investigación respecto de la situación (problemática), como aquello que ejerce el control de la investigación: aquello que resulta relevante en relación con la investigación está determinado, no pura y exclusivamente por los condicionantes disciplinares, que son sin embargo un aspecto importante, sino por esa situación que es parte del contexto de la investigación.

Otro aspecto importante es que, en línea con el isomorfismo investigación/valoración afirmado por Dewey, Latour ha llamado la atención acerca de la continuidad entre la ciencia y la política, señalando a la primera como uno de los espacios 
privilegiados en los que se crean y se refuerzan intereses políticos. En este sentido, podemos decir que para Latour, lo mismo que para Dewey, la política, la valoración, está cargada de investigación científica.

Un último aspecto que cabe recordar es que la asertabilidad garantizada, como uno de los resultados de la investigación, debe ser entendida como un recurso: su valor radica en que puede ser reutilizado en ulteriores investigaciones, es decir, y para usar un término propio de los estudios de laboratorio, es un crédito que puede ser reinvertido.

Así, creemos que la teoría de la investigación de Dewey condensa algunos de los resultados más interesantes de los estudios de laboratorio y en esa línea permite superar algunas limitaciones de los enfoques tradicionales sobre el carácter social de la ciencia. En alguna medida limitados por su concepción descriptivista o representativista de la ciencia, las posiciones próximas al programa fuerte han ofrecido algo así como una concepción por defecto del carácter social de la ciencia: puesto que no puede explicarse la clausura o el consenso sólo mediante lógica y observación, debe operar algún otro factor, social o extraepistémico. Ello llevó a los sociólogos, en términos de Latour, a buscar intereses ocultos y determinantes políticos no confesados para explicar el consenso. En cambio, si se pone el acento en la investigación como forma de acción localizada o situada, pueden observarse los diferentes factores que intervienen en la formulación de juicios prácticos que responden, no a un supuesto método universal sino a las características propias de la situación y al contexto de tradición, y al contexto natural y cultural en el que se da la investigación.

A su vez, esta visión de la investigación permite cuestionar y hacer a un lado la imagen autonomista de la actividad científica, defendida por ejemplo por Bourdieu, al cuestionar la distinción entre aspectos epistémicos y extra-epistémicos: si en la toma de decisiones de los científicos intervienen legítima y regularmente valores y consideraciones 
acerca del costo y la oportunidad de hacer ciertos experimentos, acerca de la utilidad social o individual de la investigación, acerca del riesgo que cabe o no cabe correr en relación a ciertos experimentos, no parece que haya razón para referirse a ellos como extraepistémicos, puesto que parecen ser elementos propios de la investigación.

Todo esto permite, además, como vimos, pensar el problema de la reflexividad de los estudios de la ciencia en el contexto de una política científica democrática, que busca intervenir en la actividad científica y en su dirección a partir de la discusión pública de los fines y valores que resultan utilizados, reforzados, creados o perseguidos dentro de la ciencia y a través de ella. En este sentido, la comprensión de la filosofía de Dewey es consistente con su propia visión acerca del conocimiento: si la investigación es transformación de una situación problemática, la filosofía de la ciencia es, así, una reflexión acerca del conocimiento que busca incidir en las prácticas científicas al promover la discusión pública de los fines de la ciencia, y en ese sentido se trata de una filosofía política de la ciencia. 


\section{Bibliografía}

> Alcoff, L. M. (2008) How is Epistemology Political? En Bailey, A., Cuomo, Ch., The Feminist Philosophy Reader. New York: McGraw-Hill. pp. 705-718.

> Ali Jafella, S. (2006). Travesías filosóficas y sociales de la "escuela nueva" en Europa y en Estados Unidos. La Plata: Al margen.

Aliseda, A. (2003). Adbucción y pragmati(ci)smo en C. S. Peirce. En Cabanchik, Penelas y Tozzi (comps) (2003). El giro pragmático en la filosofía. Barcelona: Gedisa.

Allen, B. (2010). Pragmatism and Gay Science: Comparing Dewey and Nietzsche. En Fairfield, P. (2010). Ed. John Dewey and Continental Philosophy. Carbondale and Edwardsville IL: Southern Illinois University Press.

Anderson, E. (2014). Dewey's Moral Philosophy. The Stanford Encyclopedia of Philosophy(Spring 2014 Edition), Edward N. Zalta(ed.), URL = $<$ http://plato.stanford.edu/archives/spr2014/entries/dewey-moral/>.

Apel, K. O. (1975). El problema de la fundamentación última filosófica a la luz de una pragmática trascendental del lenguaje (Ensayo de una metacrítica del 'racionalismo crítico'). Diánoia. Nro XXI, Vol, 21. pp. 140-173.

Apel, K. O. (1985). La transformación de la filosofía. Vols. 1-2. Madrid: Taurus.

Apel, K. O. (1991). Teoría de la verdad y ética del discurso. Barcelona: Paidós.

Apel, K. O. (1997). El camino del pensamiento de Charles S. Peirce. Madrid: Visor. Ayer, A. (1952). Language, Truth and Logic. New York: Dover.

Bengoa Ruiz de Azúa, J. (1997). De Heidegger a Habermas. Hermenéutica y fundamentación última en la filosofía contemporánea. Barcelona: Herder.

$>$ Bermejo Luque, L. (2007). La concepción retórica del valor de la Argumentación. En Santibáñez, C. y Riffo, B. (comps.) (2007). Estudios de argumentación y 
retórica. Teorias contemporáneas y aplicaciones. (pp. 39-56). Concepción: Editorial Universidad de Concepción.

> Bermejo Luque, L. (2010). El programa de Los usos de la Argumentación de Stephen Toulmin. En Marafioti, R. y Santibáñez Yáñez, C. (coords.) (2010). Teoría de la argumentación. A 50 años de Perelman y Toulmin. (pp. 17-38). Buenos Aires: Biblos.

Bernstein, R. (1971). Praxis and Action: Contemporary Philosophies of Human Activity. Philadelphia: University of Pennsylvania Press.

Bernstein, R. (2010). Filosofía y democracia: John Dewey. Barcelona: Herder.

Bernstein, R. (2010). The Pragmatic Turn. Cambridge: Polity.

Bernstein, R. (2010). The pragmatic turn. Malden: Polity Press.

Bird, O. (1961). The re-discovery of the topics. Mind 70 (280): 534-539

Bitonte, M. E.; Matienzo, T. (2010). La razonabilidad como garantía en la teoría de Stephen Toulmin. En Marafioti, Roberto y Santibáñez Yáñez, Cristián. (coords.) (2010). Teoría de la argumentación. A 50 años de Perelman y Toulmin. pp. 59 79. Buenos Aires: Biblos.

Bloor, D. (1994). El programa fuerte de la sociología del conocimiento. En Olivé, L. La explicación social del conocimiento (págs. 93-117). México D.F.: UNAM.

$>$ Bourdieu, P. (1994). El campo científico. REDES N² 2, vol. 1

Bourdieu, P. (2000). Los usos sociales de la ciencia. Buenos Aires: Nueva Visión.

Bourdieu, P. (2003). El oficio del Científico. Ciencia de la ciencia y reflexividad. Barcelona: Anagrama.

> Boydston, J. A. (ed.) (1969). The Collected Works of John Dewey, 1882-1953 (37 Volumes). Southern Illinois Up.

Brandom, R. (2005). Pragmatics and Pragmatisms. En Conant, J. y Zeglen, U. (Eds.). (2005). Hilary Putnam: Pragmatism and Realism. London: Routledge. pp. $40-58$. 
Brandom, R. (2011). Perspectives on pragmatism: classical, recent, and contemporary. Cambridge-Massachusetts, Londres: Harvard University Press.

> Broncano, F.; Pérez Ransanz, A. R. (2009). La ciencia y sus sujetos. México: UNAM- Siglo XXI.

Brown, M. J. (2012). John Dewey's Logic of Science. En HOPOS: The Journal of the International Society for the History of Philosophy of Science, vol. 2 (Fall 2012). pp. 258-303.

Brown, M. J. (2013). Dewey's Situational Theory of Science. En http://www.matthewjbrown.net/professional/papers/situation-science.pdf

Burke T. (2008). (Anti)Realist Implications of a Pragmatist Dual-Process ActiveExternalist Theory of Experience. Philosophia Scientice, 12 (1), 2008, 187-211.

Burke, T. (1992). Dewey on Defeasibility. En Tiles, J. E. (ed.) (1992) John Dewey, Critical Assessments. London y New York: Routledge.

Burke, T. (1994). Dewey's New Logic: A Reply to Russell. Chicago: University of Chicago Press.

$>$ Burke, T. (2000). What is a Situation? History and Philosophy of Logic, 21 (2). pp. 95-113.

Burke, T. (2002). Prospects for Mathematizing Dewey’s Logical Theory. En Burke, F. Thomas ; Hester, D. Micah \& Talisse, Robert B. (eds.) (2002). Dewey's Logical Theory: New Studies and Interpretations. Vanderbilt University Press. pp. 121159.

Burke, T. (2007). Introduction. En Dewey, J. (2007) Essays in Experimental Logic. Carbondale: Southern Illinois University Press.

$>$ Burke, T. (2009a). Browning on Inquiry into Inquiry, Part 1. En Transactions of the Charles S. Peirce Society. Vol. 45, nº 1 .

$>$ Burke, T. (2009b). Browning on Inquiry into Inquiry, Part 2. En Transactions of the Charles S. Peirce Society. Vol. 45, nº 2. 
Burke, T. (2014). Dewey's Transformation of Peirce Method of Science. SAAP at APA Pacific, 16 de Abril de 2014.

> Burke, T.; Hester, D. M. y Talisse, R. B. (eds.) (2002). Dewey's Logical Theory: New Studies and Interpretations. Vanderbilt University Press.

Cabrera, I. (comp). (1999). Argumentos trascendentales. México: FCE- UNAM.

$>$ Carnicer, D. (2003). Comunidad y Cooperación en C.S.Peirce. Lectura ética del Sentido Común Crítico. Valencia: Universidad de Valencia. http//www.unav.es/gep/TesisDoctorales/TesisDCarnicer.pdf

$>$ Colapietro, V. (2002). Experimental logic: Normative Theory or Natural History? en Burke, T., Hester, D. y Talisse, R. (eds.) (2002). Dewey's Logical Theory: New Studies and Interpretations, Nashville, Tennessee: Vanderbilt University Press. pp. 43-66.

> Collins, H. M.; Yearley, S. (1992a). Epistemological Chicken. En Pickering (Ed.) (1992). Science as practice and culture. Chicago: The University of Chicago press. pp. 301-326.

$>$ Collins, H. M.; Yearley, S. (1992b). Journey into Space. En Pickering (Ed.) (1992). Science as practice and culture. Chicago: The University of Chicago press. pp. 369-389.

> Cottingham, J. (1995). Descartes. México D. F: UNAM.

$>$ Crelier, A. (2010). De los Argumentos Trascendentales a la Hermenéutica Trascendental. La Plata: EDULP.

$>$ Deen, P. (2011). Dialectical vs. Experimental Method: Marcuse's Review of Dewey's Logic: The Theory of Inquiry. En Transactions Of The Charles S. Peirce Society. Vol. 46, No. 2 pp. 258-265.

Delaney, C. F. (1973). Peirce's Critique of Foundationalism. The Monist Pragmatism Reconsidered. Volume 57, Issue 2, April 1973.

$>$ Deledalle, G. (1996). Leer a Peirce hoy. Barcelona: Gedisa.

Descartes, R. (2011). Reglas para la dirección del espíritu. Madrid: Gredos. 
Dewey, J. (1929). The Quest for Certainty: A Study of the Relation of Knowledge And Action. New York: Putnam.

Dewey, J. (1948). La Experiencia y la Naturaleza. México: FCE.

Dewey, J. (1950). Lógica: Teoría de la Investigación. México D. F.: FCE.

Dewey, J. (1981). Experience and Nature. En The Later Works of John Dewey, vol. 1. Carbondale: Southern Illinois University Press.

$>$ Dewey, J. (1984). The later Works of John Dewey, 1925-1953, 15 vols. Carbondale and Edwardsville, Southern Illinois University Press.

$>$ Dewey, J. (1989a). La reconstrucción de la Filosofía. Barcelona: Planeta-Agostini.

Dewey, J. (1989b). Cómo pensamos. Nueva exposición de la relación entre pensamiento y proceso educativo. Barcelona: Paidós. (Trad. de Marco Aurelio Galmarini).

$>$ Dewey, J. (2004). La opinión pública y sus problemas. Madrid: Ediciones Morata.

> Dewey, J. (2004). La opinión pública y sus problemas. Madrid: Morata.

Dewey, J. (2008). Teoría de la Valoración, un debate con el positivismo sobre la dicotomía de hechos y valores. Madrid: Biblioteca Nueva.

Dewey, J.; Schilpp, P. A. \& Hahn, L. E. (eds.) (1939). The Philosophy of John Dewey. Open Court.

Di Berardino, M. A. (2010). Crítica a la interpretación jamesiana de las tesis realistas en Ferdiand Schiller y John Dewey (Tesis de posgrado). Presentada en Universidad Nacional de La Plata. Facultad de Humanidades y Ciencias de la Educación para optar al grado de Doctora en Filosofía. Disponible en: http://www.memoria.fahce.unlp.edu.ar/tesis/te.352/te.352.pdf

Di Gregori, M. C. (1995). La fundamentación racional del conocimiento: programas fundamentistas. Enciclopedia Iberoamericana de Filosofía, Vol. 9 Racionalidad epistémica. Madrid: Trotta. pp. 41 - 59. 
Di Gregori, M. C.; Duran, C. (2002). Lewis y las tensiones en torno a su noción de "realismo" [En línea]. IV ${ }^{\mathrm{o}}$ Jornadas de Investigación en Filosofía, 7-9 de noviembre de 2002, La Plata. En: Revista de Filosofía y Teoría Política, Anexo 2004.

Disponible

en: http://www.fuentesmemoria.fahce.unlp.edu.ar/trab_eventos/ev.165/ev.165.pdf

Di Gregori, M. C.; Duran, C. (2003). Metafísica especulativa vs. Metafísica pragmatista en C. I. Lewis. Epistemología e Historia de la Ciencia. Vol.9.Nro.9. pp. $133-139$.

Di Gregori, M. C.; Duran, C. (2008). Acerca del arte, la ciencia y la acción inteligente. En Actas de las VII Jornadas de Investigación en Filosofía para profesores, graduados y alumnos.

Di Gregori, M. C.; Duran, C. (2008). El valor epistémico y político de la opinión pública. Una versión deweyana. En Borsani, M. E., Gende C. E. y Padilla, E. (editores). (2008). La diversidad signo del presente. Ensayos sobre filosofia, crítica y cultura. Buenos Aires: Ediciones del Signo.

Di Gregori, M. C.; Duran, C. (2009). John Dewey: acerca de medios, fines y aventuras biotecnológicas. En Di Gregori, M. C. y Hebrard, A. (2009). Peirce, Schiller, Dewey y Rorty. Usos y revisiones del pragmatismo clásico. Buenos Aires: Ediciones del Signo. pp. 173 - 195.

D Di Gregori, M. C.; Duran, C. (2011). Confiabilidad, intuición estratégica y emociones. Michael Polanyi en clave pragmatista. En Actas VIII Jornadas de Filosofia. Fahce UNLP. La Plata; 2011.

Di Gregori, M. C.; Duran, C. (2011). William James. Esbozos de una teoría de la racionalidad en Perez Ransanz, A. R., Velasco, A. (eds.) (2011). Nuevos Enfoques Sobre La Racionalidad. México DF. pp. 91 - 100.

Di Gregori, M. C.; Pérez Ransanz, A. R. (2010). Las emociones en la ciencia y el arte. En Marcos, A. y Castro, S. (2010). Ciencia y Arte: mundos convergentes. Madrid: Ed. Plaza y Valdés. pp. 273 - 307. 
Di Gregori, M. C.; Pérez Ransanz, A. R. (2011). Experience and Creativity. En Castro, S. y Marcos, A. (eds.). (2011). The Paths of Creation. Creativity in Science and Art, Berna: Peter Lang.

Esteban Cloquell, J. M. (1999). La ciencia como tecnología en John Dewey. En Diánoia, anuario de filosofía. Año WLV. Núm. 45 pp. 133-155.

> Esteban Cloquell, J. M. (2006). Variaciones del Pragmatismo en la filosofía contemporánea. Cuernavaca: Ediciones Mínimas.

Esteban Cloquell, J. M. (2008). Dewey y la historia natural de las normas. En Esteban, J. M. y Martínez, S. F. (2008) Normas y prácticas en la ciencia. México: UNAM, Instituto de Investigaciones Filosóficas.

Faerna, A. M. (1996). Introducción a la teoría pragmatista del conocimiento. Madrid: Siglo Veintiuno de España Editores.

$>$ Faerna, A. M. (2003). Creer en Darwin: sobre las relaciones entre marco científico e interpretación filosófica. Quaderns de filosofia i ciència, 32-33, 2003, pp. 21-27.

Fairfield, P. (2010). Dewey, Nietzsche, and the Self-Image of Philosophy. En Fairfield, P. (Ed). (2010). John Dewey and Continental Philosophy. Carbondale and Edwardsville IL: Southern Illinois University Press.

Fisch, M. H. (1986). Peirce, Semeiotic and Pragmatism: Essays. Editado por K. L. Ketner y C. Kloesel. Bloomington: Indiana University Press.

Fossier, A. (2006). Entretien avec Bruno Latour, Tracés, 2006/1 n 10, p. 113-129.

Fuller, S. (1992). Social Epistemology and the Research Agenda of Science Studiesen Pickering, A. (1992a). Science as practice and culture. Chicago: The University of Chicago press.

- Godfrey-Smith, P. (2002). Dewey on Naturalism, Realism and Science. Philosophy of Science 69 (2002): S1-S11 (Proceedings of PSA 2000).

$>$ Godfrey-Smith, P. (2013). Dewey and the Question of Realism. Noûs, online first, November 2013 <DOI: 10.1111/nous.12059> 
Gómez, R. J. (2014). La dimensión valorativa de las ciencias: hacia una filosofía política. Bernal: Universidad Nacional de Quilmes.

> Gusfield, J. (1981). The culture of public problems. Drinking-driving and the symbolic order. Chicago: The University of Chicago Press.

Haack, S. (2001). Viejo y nuevo pragmatismo. En DIÁNOIA, Vol. XLVI, Núm. 47 (noviembre 2001). pp 21-59.

Haack, S. (2006). Pragmatism old and New. Amherst, Nueva York: Prometheus Books.

Habermas, J. (2002). Ciencia y Técnica como ideología. Madrid: Tecnos.

Hacking, I. (1983). Representing and Intervening: Introductory Topics in the Philosophy of Natural Science. Cambridge: Cambridge University Press. En español: Hacking, I. (1997). Representar e intervener. Trad. de Sergio Martinez. Mexico: UNAM-Paidós.

Hamlin, C. (1992). Reflexivity in Technology Studies: Toward a Technology of Technology (And Science)? Social Studies of Science, Vol 22, № 3, pp. 511-544.

$>$ Hammer, E. (2007). Peirce's Logic. En Zalta, E. (ed.). The Stanford Encyclopedia of Philosophy. Disponible en http://plato.stanford.edu/archives/fall2007/entries/peirce-logic/

$>$ Harding, S. (2006). Science and Social Inequality. Feminist and Postcolonial Issues. Urbana y Chicago: University of Illinois Press.

Hebrard, A.: Mercau, H. y Badenes, A., (2009). Notas sobre la relación entre la teoría lógica de Dewey y la lógica formal a través de su desarrollo histórico. En Di Gregori, M. C.; Hebrard, A. (2009) Peirce, Schiller, Dewey y Rorty. Usos y revisiones del pragmatismo clásico. Buenos Aires: Ediciones del signo. pp. 137151.

> Hickman, L. (1986). Why Peirce Didn't Like Dewey’s Logic, Southwest Philosophy Review, vol. 3, pp. 178-189. 
Hickman, L. (1992). John Dewey's Pragmatic Technology (the Indiana Series in the Philosophy of Technology). Bloomington: Indiana University Press.

Hickman, L. (2001). Philosophical tools for technological culture: putting pragmatism to work. Bloomington: Indiana University Press.

Hickman, L. (2012). Technological Pragmatism. En Jan Kyrre Berg Olsen Friis, Stig Andur Pedersen \& Vincent F. Hendricks (Eds.). (2012). A Companion to the Philosophy of Technology. Wiley-Blackwell.

Hickman, L. (Ed.). (2001). The Correspondence of John Dewey, vol. 1: (18711918), CD-rom, InteLex-Past Masters, Charlottesville.

Hildebrand, D. L. (2003). Beyond Realism and Antirealism: John Dewey and the Neopragmatists. Vanderbilt University Press.

Hitchcock, D.; Verheij, B. (eds.) (2006). Arguing on the Toulmin Model: New Essays in Argument Analysis and Evaluation. Dordrecht: Springer.

Hobbs, C. A. (2013). Reconsidering John Dewey's Relationship with Ancient Philosophy. International Philosophical Quarterly Vol. 53, no. 2, issue 210 (June 2013) pp. 325-336.

$>$ Honneth, A. (2007). Reificación. Un estudio en la teoría del reconocimiento. Traducción de Graciela Calderón. Buenos Aires: Katz.

> Hook, S. (2000). John Dewey. Semblanza intellectual. Barcelona: Paidos.

Hook, S.; Nagel, E. (1945). Are naturalists materialists? Journal of Philosophy, 42, pp. 515-530.

$>$ Hookway, C. (1985). Peirce. Londres: Routledge \& Kegan Paul.

Hookway, C. (2000). Truth, Rationality and Pragmatism: Themes from Peirce. Oxford: Clarendon Press.

Houser, N. (2006). Peirce en el siglo XXI. Anthropos 212, 2006.

$>$ James, W. (1898). Philosophical Conceptions and Practical Results. En The University Chronicle, Vol. I N 4, Berkeley, California. 
Joas, H. (1998). El pragmatismo y la teoría de la sociedad. Madrid: Centro de Investigaciones Sociológicas.

Joas, H. (1995). The Creativity of Action. Cambridge, MA: Polity Press.

Johnson, R. H. (2000). Manifest Rationality: A Pragmatic Theory of Argument. Mahwah, NJ: Lawrence Erlbaum Associates.

Kahn, S. J. (1948). Experience and Existence in Dewey's Naturalistic Metaphysics, in Philosophy and Phenomenological Research 9. December 1948. pp. 316-321.

Kellner, D. (2009). Review of Thomas P. Wheatland. The Frankfurt School in America: A Transatlantic Odyssey from Exile to Acclaim. Minneapolis, Minnesota: University of Minnesota Press.

Kirby, C. (ed) (2014). Dewey and the Ancients: Essays on Hellenic and Hellenistic Themes in the Philosophy of John Dewey. Bloomsbury.

> Kloppenberg, J. T. (1996). Pragmatism: An Old Name for Some New Ways of Thinking? The Journal of American History, Vol. 83, No. 1 (Jun., 1996). pp. 100138.

$>$ Knorr Cetina, K. (1992). ¿Comunidades científicas o arenas transepistémicas de investigación? Una crítica de los modelos cuasieconómicos de la ciencia. Redes. Revista de estudios sociales de la ciencia $\mathrm{N}^{0}$ 7, Volumen 3, UNQUI, Septiembre de 1996. pp. 129-160.

Knorr Cetina, K. (2005). La fabricación del conocimiento. Un ensayo sobre el carácter constructivista y contextual de la ciencia. Bernal: Universidad Nacional de Quilmes.

$>$ Kreimer, P. (2005). Estudio preliminar. El conocimiento se fabrica ¿cuándo? ¿dónde? ¿cómo? En Knorr Cetina, K. (2005). La fabricación del conocimiento. Un ensayo sobre el carácter constructivista y contextual de la ciencia. Bernal: Universidad Nacional de Quilmes.

Kreimer, P.; Thomas, H. (2005). Production des Connaissances Dans la Science Périphérique: L’hypothèse CANA (Connaissance Applicable Non Appliquée). En 
J.B. Meyer and M. Carton (Eds.). Development through Knowledge? A New Look at the Global Knowledge-based Economy and Society. Ginebra: IUED.

Kreimer, P.; Zabala, J. (2006). ¿Qué Conocimiento y Para Quién? Problemas Sociales y Producción de Conocimientos Científicos: Persistencia Del Mal de Chagas Como "Enfermedad de Pobres" en Argentina, REDES, 13(23), pp. 32-64.

$>$ Kreimer, P. (1999). De probetas, computadoras y ratones. La construcción de una mirada sociológica sobre la ciencia. Buenos Aires: Ed. U.N. Quilmes.

Latour, B. (1991). ¿Qué es la fuerza de un argumento? (versión original en Sens et Place des connaissances dans la société, CNRS, Paris, 1986).

Latour, B. (1992). La ciencia en acción. Barcelona: Labor.

Latour, B. (2007). Nunca fuimos modernos. Ensayo de antropología simétrica. Buenos Aires: Siglo XXI.

Latour, B. (2008). Dadme un laboratorio y conquistaré al mundo. Versión Castellana, Ciencia, Tecnología y Sociedad, CTS, OEI. Versión original "Give me a laboratory and I will raise the world", en Knorr-Cetina, K.y Mulkay, M. (eds.) (1983). Science observed: perspective on the social study of science. Londres: Sage. pp. 141-170.

Latour, B.; Callon, M., (1992). Don't throw the Baby Out with the Bath School! En Pickering (ed.) (1992a). pp. 343-368.

Latour, B.; Woolgar, S. (1986). Laboratory Life: The Construction of Scientific Facts. Princeton, NJ: Princeton University Press.

Latour, B.; Woolgar, S. (1995). La Vida en el Laboratorio: la Construcción de Los Hechos Científicos. Madrid. Alianza Editorial.

Levi, I. (2010). Dewey's logic of inquiry. En Cochran, M. (ed.) The Cambridge Companion to Dewey. Cambridge University Press.

> Marafioti, R.; Santibáñez Yáñez, C. (coords.) (2010). Teoría de la argumentación. A 50 años de Perelman y Toulmin. Buenos Aires: Biblos.

Marcos, A. (2000). Hacia una Filosofía de la Ciencia amplia. Madrid: Tecnos. 
Marcuse, H. (1940). Review of John Dewey's Logic: The Theory of Inquiry in Zeitschrift für Sozialforschung 8 (1939-40), pp. 221-28.

$>$ Marcuse, H. (1941). Review: Dewey, John, Theory of Valuation. Zeitschrift für Sozialforschung 9, No. 1, pp. 144-148.

Marcuse, H. (1993). El Hombre unidimensional. Ensayo sobre la ideología de la sociedad Industrial avanzada. Barcelona: Planeta De Agostini.

Marcuse, H. (2011). Review of John Dewey's Logic: The Theory of Inquiry. Transactions of The Charles S. Peirce Society. Vol. 46, No. 2. Publicada originalmente en Zeitschrift für Sozialforschung 8 (1939-40) pp. 221-28.

Margolis J. (2002). Reinventing Pragmatism. Nueva York: Cornell University Press.

Mates, B. (1979). Lógica Matemática elemental. Madrid: Tecnos.

Menand, L. (2002). El club de los metafisicos. Historia de las ideas en América. Madrid: Destino.

> Menand, L. (2002). The Metaphysical Club: A Story of Ideas in America. New York: Farrar, Starus and Giroux.

- Mercau, H. H. (2012). La filosofia de la experiencia de John Dewey: Implicaciones para las nociones de conocimiento, sociedad y racionalidad (Tesis de posgrado). Presentada en Universidad Nacional de La Plata. Facultad de Humanidades y Ciencias de la Educación para optar al grado de Doctor en Filosofía.

Merton, R, K. (1984). Ciencia, tecnología y sociedad en la Inglaterra del siglo XVII. Madrid: Alianza.

Merton, R. (1964). Teoría y estructura sociales. México: Fondo de Cultura Económica.

$>$ Misak, C. (ed.). (2004). The Cambridge Companion to Peirce. Cambridge: Cambridge University Press.

Murphey, M. G. (1961). The Development of Peirce's Philosophy. Cambridge, MA: Harvard University Press. 2a. edición, 1993, Indianapolis: Hackett. 
Nagel, E. (1984). Introduction. En John Dewey, Logic: The Theory of Inquiry. En Dewey, John. The later Works of John Dewey. Vol. 12. Carbondale and Edwardsville: Southern Illinois University Press.

Naishtat, F. (2005). Problemas filosóficos en la acción individual y colectiva: una perspectiva pragmática. Buenos Aires: Prometeo.

$>$ Pagan, N. O. (2008). Configuring the Moral Self: Aristotle and Dewey. Foundations of Science, Vol. 13, Issue 3-4. pp. 239-250.

Palau, G. y colaboradores (2004). Lógicas Condicionales y razonamiento de sentido común. Buenos Aires: Gedisa.

> Perelman, C.; Obrechts-Tyteca, L. (1958). La nouvelle réthorique. Traité de l'argumentation. Paris: Presses Universitaries de France. Traducción española Perelman, C.; Obrechts-Tyteca, L. (2006). Tratado de la Argumentación. La nueva Retórica. Madrid: Gredos.

$>$ Pestre, D. (2005). Ciencia, Dinero y política. Buenos Aires: Nueva Visión.

$>$ Philstrom, S. (2005). Peirce Place in the Pragmatist Tradition. En The Cambridge Companion to Peirce. Cambridge University Press, Cambridge 2004.

$>$ Pickering, A. (1992b). From Science as Knowledge to Science as Practice. En Pickering (1992a). Science as practice and culture. Chicago: The University of Chicago press.

$>$ Pickering, A. (1995). The mangle of practice. Time, Agency and Science. Chicago: The University of Chicago Press.

$>$ Pickering, A. (ed.) (1992a). Science as practice and culture. Chicago: The University of Chicago press.

Pinto, R. (2006). Evaluating Inferences: the Nature and Role of Warrants. Informal Logic Vol. 26, No. 3 (2006): pp. 287-317.

$>$ Posada Kubissa, L. (2012). "Sobre Kant, Putnam y el realismo interno" En Anales del Seminario de Historia de la Filosofía. Vol. 29 Núm. 1 (2012): 173-187. 
Pronko, N. H; Herman, D. T. (1982). From Dewey's Reflex Arc Concept to Transactionalism and Beyond. Behaviorism, Vol. 10, No. 2 (Fall, 1982), pp. 229254.

Putnam, H. (1983). Preface. En Goodman (1983). Fact, Fiction, and Forecast. Cambridge: Harvard University Press. pp. viii-ix.

> Putnam, H. (2002). The Collapse of The Fact-Value Dichotomy and Others Essays. Cambridge y Londres: Harvard University Press.

> Putnam, H. (2005). Comment on Robert Brandom's paper. En J. Conant and U. Zeglen (eds.). (2005) Hilary Putnam: Pragmatism and Realism (pp. 59-65) London: Routledge.

$>$ Putnam, H. (2006). El pragmatismo: un debate abierto. Barcelona: Gedisa.

$>$ Ratner, S. (1992). John Dewey, Empiricism, and Experimentalism in the Recent Philosophy of Mathematics. Journal of the History of Ideas, Vol. 53, No. 3 (Jul. Sep., 1992). pp. 467-479.

Rescher, N. (1977). Methodological Pragmatism. A Systems-Theoretic Approach to the Theory of Knowledge. Oxford: Blackwell.

Richardson, A. (2003). Logical Empiricism, American Pragmatism, and the Fate of Scientific Philosophy in North America. En Logical Empiricism in North America, ed. Alan W. Richardson and Gary L. Hardcastle, 3-23. Minneapolis: University of Minnesota Press.

Richardson, A. W. (2002). Engineering Philosophy of Science: American Pragmatism and Logical Empiricism in the 1930s. Philosophy of Science 69. Pp. 36-47.

Rorty, R. (1982). Consequences of Pragmatism. Minneapolis: University of Minnesota Press.

$>$ Rorty, R. (1982). Dewey's Metaphysics. En Rorty, R. (1982). Consequences of Pragmatism. Minneapolis: University of Minnesota Press.

Rorty, R. (1998). El giro lingüístico. Barcelona: Paidós. 
> Rorty, R. (2000). Verdad y Progreso. Estudios filosóficos 3. Paidós: Barcelona.

> Rosenthal, S. B. (1976). The Pragmatic A Priori, A study on the Epistemology of C.I. Lewis, St. Louis, Missouri: Warren H. Green, Inc.

Rosenthal, S. B. (1994). Charles Peirce's Pragmatic Pluralism. Albany: State University of New York Press.

$>$ Rouse, J. (1987). Knowledge and Power: Toward a Political Philosophy of Science. Cornell University Press

Russell, B. (1919). Professor Dewey's "Essays in Experimental Logic". The Journal of Philosophy, Psychology and Scientific Methods, Vol. 16, No. 1 (Jan. 2, 1919). pp. 5- 26.

Russell, B. (1939). Dewey's New Logic. En Schilpp, P. R; Hahn, L. E. (1989). The Philosophy of John Dewey. Carbondale: Southern Illinois University.

> Santibáñez Yáñez, C. (2010). Los usos de la argumentación: ¿retórica, dialéctica o pragmática? En Marafioti, R.; Santibáñez Yáñez, C. (coords.) (2010). Teoría de la argumentación. A 50 años de Perelman y Toulmin. Buenos Aires: Biblos. pp. 181204.

> Schatzki, T. R. (2001). Practice mind-ed orders. En Schatzki, T. R; Knorr-Cetina, K. y von Savigny, E. (Eds.). (2001). The Practice Turn in Contemporary Theory. Routledge. Pp. 42-55.

$>$ Schatzki, T. R.; Knorr-Cetina, K. y von Savigny, E. (eds.). (2001). The Practice Turn in Contemporary Theory. Routledge.

$>$ Schmitt, F. (ed). (1994). Socializing Epistemology. The Social Dimensions of Knowledge. Lanham, MD: Rowman and Littlefield.

$>$ Seigfried, H. (2002). Dewey's Logical Forms. En Dewey's Logical Theory: New Studies and Interpretations, ed. F. Thomas Burke, D. Micah Hester, and Robert B. Talisse. pp. 180-201. Nashville: Vanderbilt University Press. 
Simon, H. F.; Walsh, B. A. (1984). Textual Commentary. En Dewey, J. (1984). The later Works of John Dewey, Vol. 8 (1w.8.381-393), Carbondale and Edwardsville: Southern Illinois University Press.

Sleeper, R. W. (2001). The Necessity of Pragmatism: John Dewey's Conception of Philosophy. New Haven: Yale University Press.

Solas, S. (2008). Arte y Experiencia: la recepción de Dewey por Hans-Robert Jauss. En Actas de las VII Jornadas de Investigación en Filosofía para profesores $\begin{array}{llll}\text { graduados alumnos. } y \text { La } & \text { Plata: }\end{array}$ http://sedici.unlp.edu.ar/bitstream/handle/10915/16142/Documento completo.pdf? $\underline{\text { sequence }=1}$

Stevenson, C. (1960). Ethics and Language. New Haven, CT: Yale University Press.

$>$ Toulmin, S. (1950). An examination of the Place of Reason in Ethics. Cambridge: Cambridge University Press.

Toulmin, S. (1958). The Uses of Argument. Cambridge: Cambridge University Press. Traducción española Toulmin, S. (2007). Los usos de la argumentación. Trads. María Morrás y Victoria Pineda. Barcelona: Península.

Toulmin, S. (1984). Introduction to 1929: The Quest for Certainty, en Dewey, J. (1984). The Later works of John Dewey Vol. 4, 1925-1953, Carbondale and Edwardsville: Southern Illinois University Press.

$>$ Toulmin, S. (2001). Cosmópolis. El trasfondo de la modernidad. Barcelona: Península.

$>$ Toulmin, S. (2006). Reasoning in theory and practice. En D. Hitchcock y B. Verheij (eds.), Arguing on the Toulmin Model: New Essays in Argument Analysis and Evaluation, (pp. 25-29), Dordrecht: Springer, 2006.

$>$ Turner, S. (1994). The Social Theory of Practices: Tradition, Tacit Knowledge, and Presuppositions. Chicago: University of Chicago Press. 
van Eemeren, F. H.; Grootendorst, R. y Snoeck Henkemans, F. (1996).

Fundamentals of Argumentation Theory. Mahwah, New Jersey: Lawrence Erlbaum Associates.

$>$ Vessuri, H. (comp.). (1983). La ciencia periférica. Caracas: Monte Avila.

$>$ Welchman, J. (2002). Logic and Judgments of Practice. In Dewey's Logical Theory: New Studies and Interpretations, ed. F. Thomas Burke, D. Micah Hester, and Robert B. Talisse. Nashville: Vanderbilt University Press. pp. 27-42.

> White, M. (1949). Social Thought in America: The Revolt Against Formalism. Nueva York: Viking Press.

$>$ Wright Mills, C. (1940). Methodological consequences of the sociology of knowledge. En American Journal of Sociology, 1940/1, pp. 316-322. 